\begin{abstract}
SUMPTER, MATTHEW. Behavior of High Performance Steel as Shear Reinforcement for Concrete Beams. (Under the direction of Dr. Sami Rizkalla.)

The objective of this research is to study the feasibility of using high performance steel as shear reinforcement for concrete beams. High performance steel is characterized by enhanced corrosion resistance and higher strength in comparison to conventional Grade 60 steel reinforcement. Advantages of using higher strength steel include the ability to design for longer span lengths and/or reducing the amount of material needed for design. This could greatly reduce the overall costs of construction for future structures.

Nine reinforced concrete beams were constructed using No. 9 longitudinal bars and No. 3 bars for the stirrups. The main variables considered in the study are the stirrup spacing and the type of reinforcing steel material. Testing was performed using a single concentrated load positioned closer to one end of the beam, which allowed for two tests per beam.

Research findings indicate that using MMFX stirrups increases the overall shear strength and enhances serviceability by distributing cracks and reducing crack width. Pairing high performance longitudinal and transverse reinforcement shows an optimum design in terms of strength gain and reduction in crack width. Enhanced serviceability behavior can be attributed to the better bond characteristics of MMFX steel in comparison to conventional Grade 60 steel. Test results suggest that combining high performance steel with high strength concrete could lead to a better utilization of the materials. Analysis shows that the ACI 318-05, CSA, and AASHTO LRFD design codes can conservatively be used for the design of high performance steel up to a yield strength of $80 \mathrm{ksi}$. Detailed analysis using the Modified Compression Field Theory can be used to accurately predict the behavior of the beams.
\end{abstract}




\section{BEHAVIOR OF HIGH PERFORMANCE STEEL AS SHEAR REINFORCEMENT FOR CONCRETE BEAMS}

By

\section{Matthew S. Sumpter}

A thesis submitted to the Graduate Faculty of North Carolina State University in partial fulfillment of the requirements for the degree of Master of Science

\section{Civil Engineering}

Raleigh, NC

2007

Approved By:
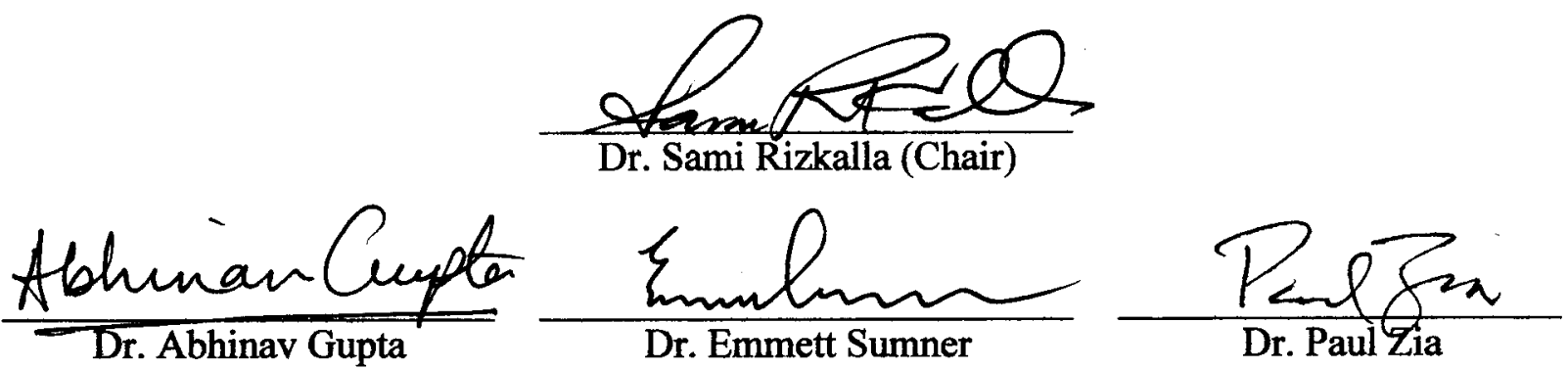


\section{BIOGRAPHY}

Matthew Sumpter started his engineering education in August, 2001 as an undergraduate in the Construction Engineering and Management program at North Carolina State University. While an undergraduate, Matthew gained experience interning for a construction company over the course of two summers and one winter. He graduated in May, 2005 with the honors of being Summa Cum Laude and Valedictorian of his class. Matthew then enrolled in the graduate program at North Carolina State University to pursue his Master of Science degree in Civil Engineering, with a concentration in Structures and Mechanics. Upon completion of his Master's, he will begin working for an engineering company in the Raleigh, NC area. 


\section{ACKNOWLEDGEMENTS}

First and foremost, I would like to thank all of my family and friends for their continued love, support, and encouragement during my studies. Without them, I would truly not be the person I am today.

I would also like to thank the MMFX Technologies Corporation for supplying the MMFX and conventional steels used in this project, as well as their generous financial support for the research.

My sincere gratitude is offered to the members of my research committee including Dr. Sami Rizkalla, Dr. Emmett Sumner, and Dr. Abhinav Gupta. Their tireless work for the Department of Civil Engineering is greatly respected and it has been an honor to work beside them. I would also like to impart thanks to Dr. Paul Zia who offered his suggestions and assistance throughout my research, and was on my research committee. I feel lucky to have received such wonderful guidance during my graduate studies, and have learned a great deal from each professor.

I am deeply indebted to the entire staff at the Constructed Facilities Laboratory including Jerry Atkinson, Bill Dunleavy, Greg Lucier, and Lee Nelson. Their help was invaluable in dealing with the details of beam fabrication and testing. In addition, special thanks are owed to Amy Yonai and Renee Howard, who truly "steer the ship" when it comes to the intricacies of administrative requirements.

Finally, my earnest thanks are given to all my fellow graduate students at the CFL. In particular, I would like to thank Aruna Munikrishna for her hard work and aid during the construction and testing program. Also, special thanks are extended to Hatem Seliem, Mina Dawood, and Amr Hosny for their extensive knowledge and guidance during my research. 


\section{TABLE OF CONTENTS}

LIST OF TABLES .......................................................................................................... vii

LIST OF FIGURES ...................................................................................................................... viii

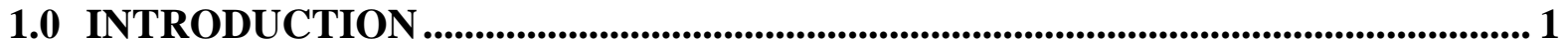

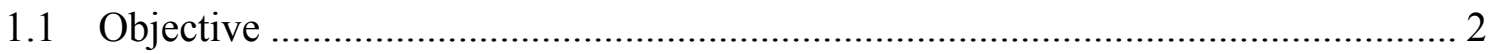

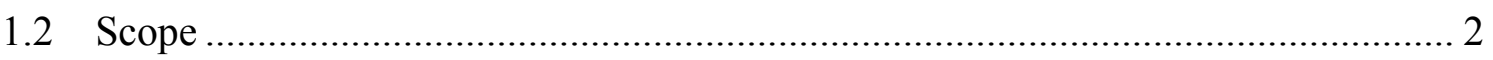

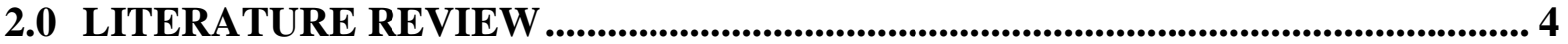

2.1 High Performance Steel............................................................................. 4

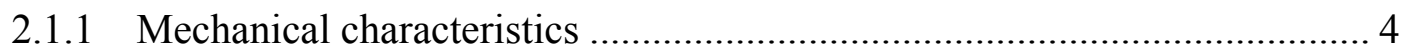

2.2 Shear Resistance of Reinforced Concrete Beams …………………....................... 6

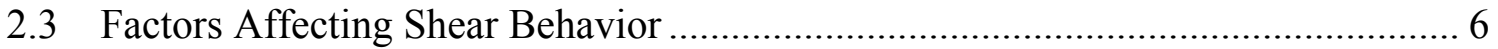

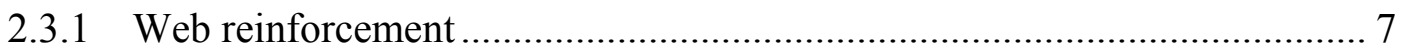

2.4 Mechanisms of Shear Resistance .......................................................................... 9

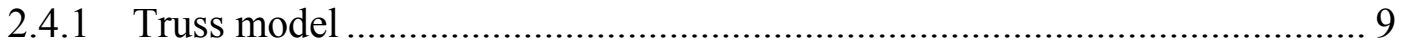

2.4.2 Modified Compression Field Theory ........................................................ 11

2.4.3 Simplified Modified Compression Field Theory ……….............................. 16

2.4.4 Strut and Tie Model............................................................................. 16

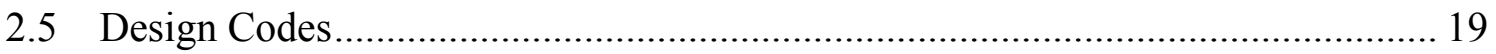

2.5.1 American Concrete Institute, ACI 318-05 ................................................ 19

2.5.2 AASHTO LRFD Bridge Design Specifications (2004) ………................. 20

2.5.3 Canadian Standards Association, CSA A23.3-04 ...................................... 26

3.0 EXPERIMENTAL PROGRAM ……............................................................................. 27

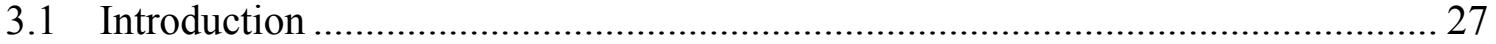

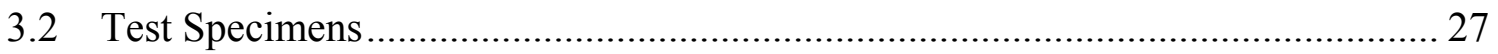

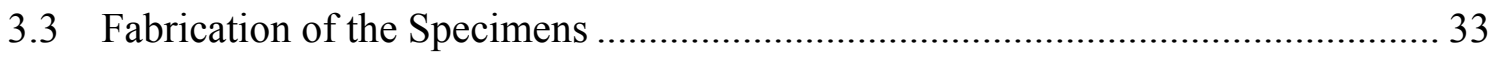

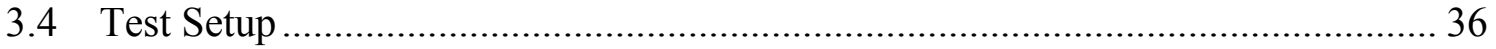

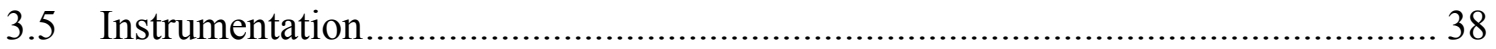

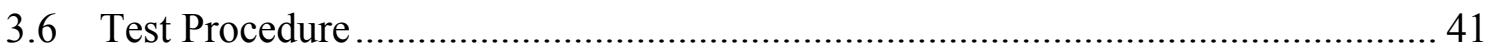

3.7 Material Property Testing................................................................................. 42

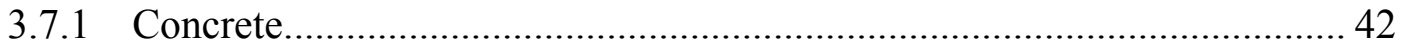




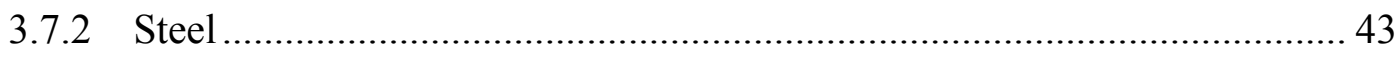

4.0 TEST RESULTS AND DISCUSSION …....................................................................... 45

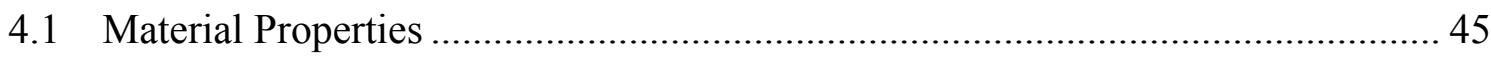

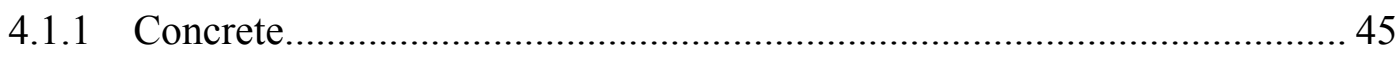

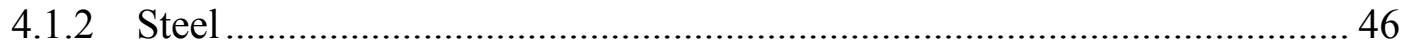

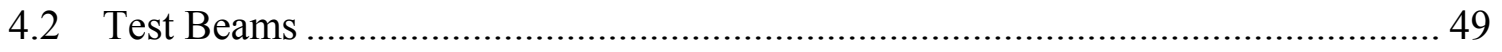

4.3 Shear Load-Deflection Behavior ......................................................................... 49

4.4 Shear Load-Transverse Strain Behavior.............................................................. 52

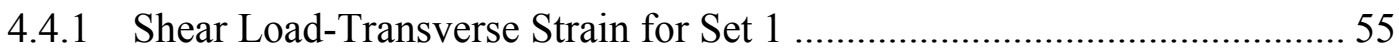

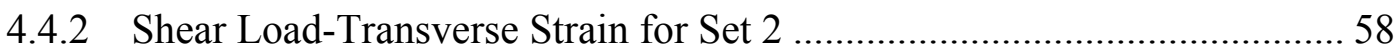

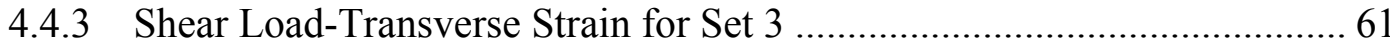

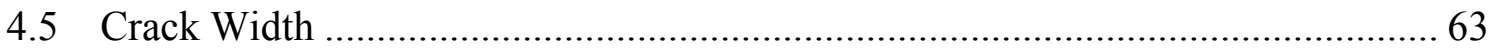

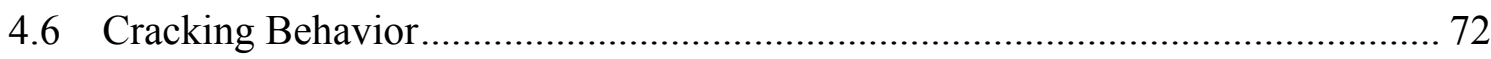

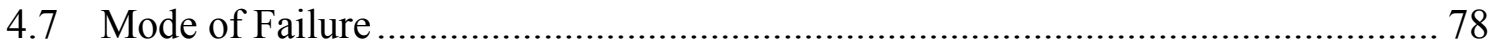

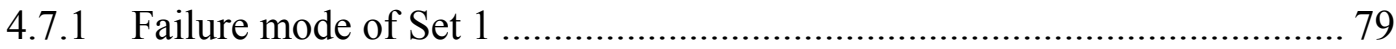

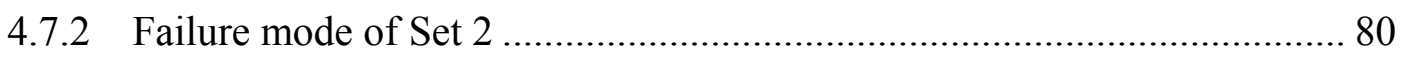

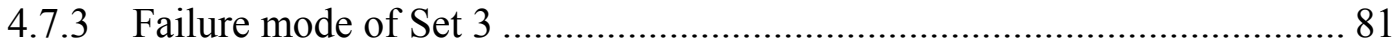

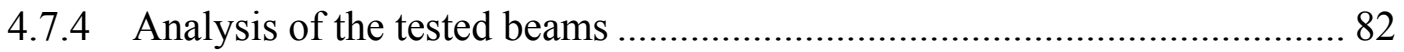

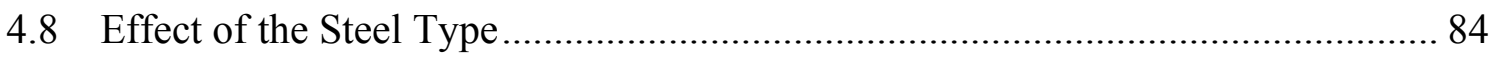

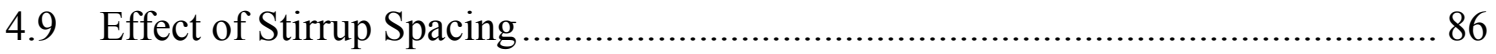

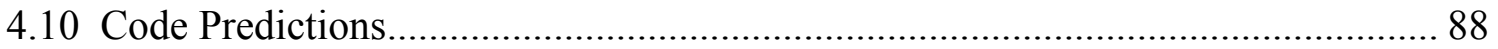

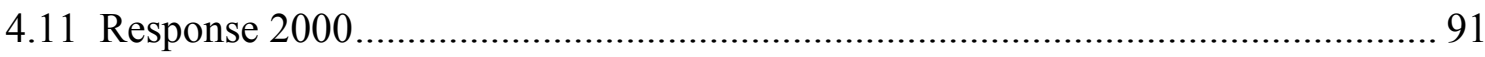

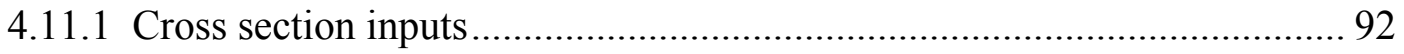

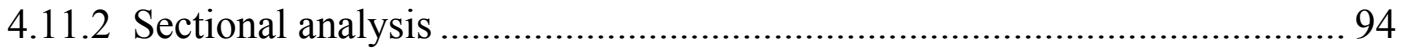

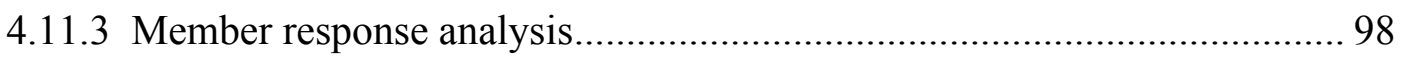

4.11.4 Results of the analysis ......................................................................... 100

5.0 CONCLUSIONS AND RECOMMENDATIONS ...................................................... 104

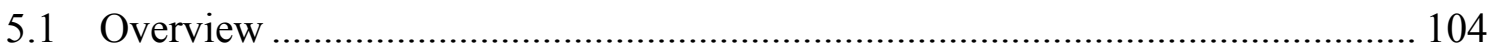

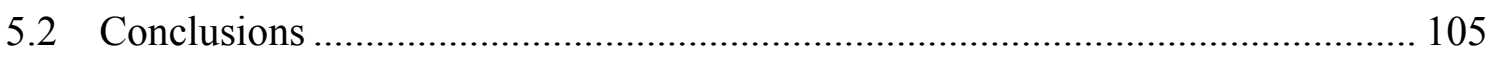

5.3 Recommendations for Future Research .......................................................... 106

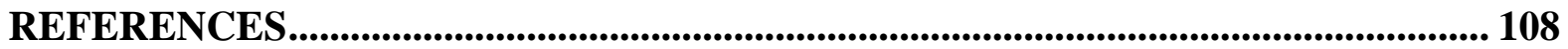




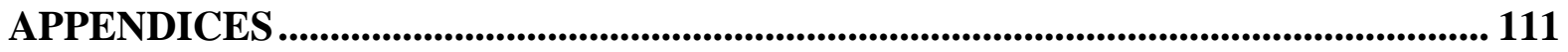

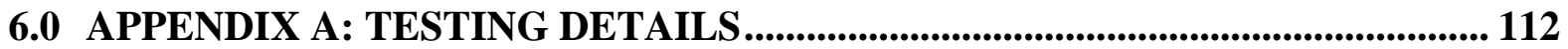

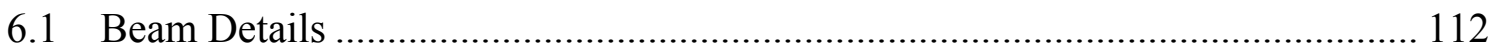

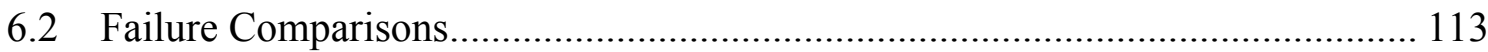

7.0 APPENDIX B: DATA AND ANALYSIS ....................................................................... 116

7.1 Concrete Compressive Cylinder Strengths........................................................ 116

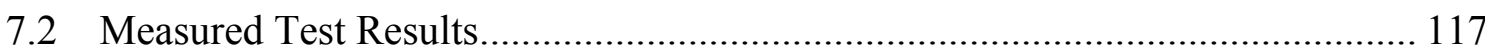

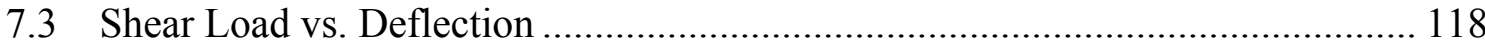

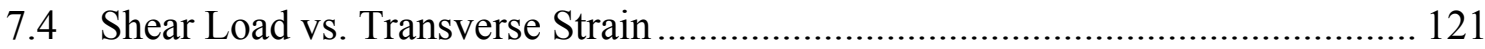

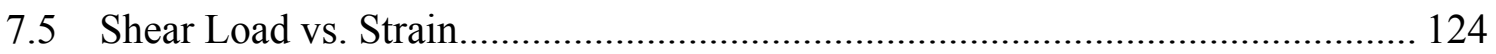

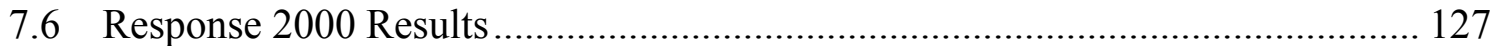

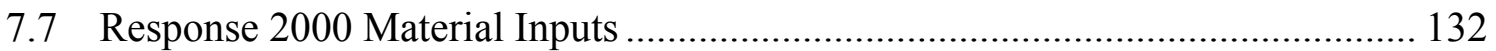




\section{LIST OF TABLES}

Table 2.1 Members with at least minimum shear reinforcement (NCHRP, 2005).............. 23

Table 2.2: Members with less than minimum shear reinforcement (NCHRP, 2005)............ 24

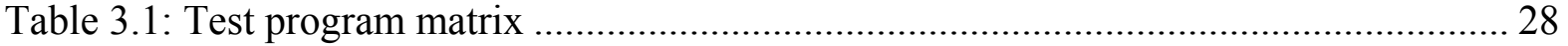

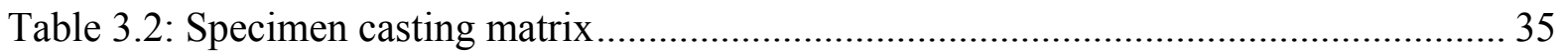

Table 4.1: Compressive strength of concrete (psi) ....................................................... 46

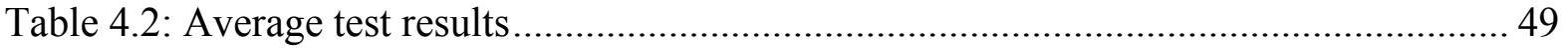

Table 4.3: Service loads using a service stress of $36 \mathrm{ksi}$................................................. 66

Table 4.4: Service loads using a service stress of $48 \mathrm{ksi}$.............................................. 70

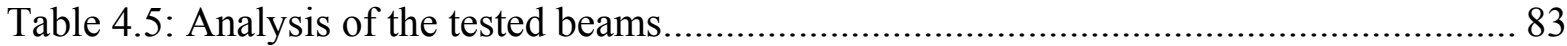

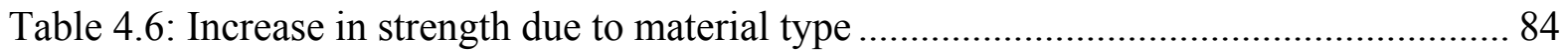

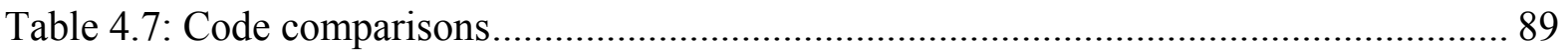

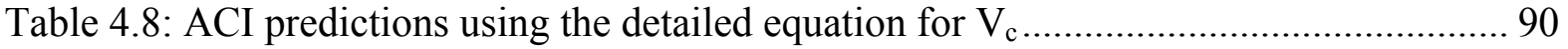

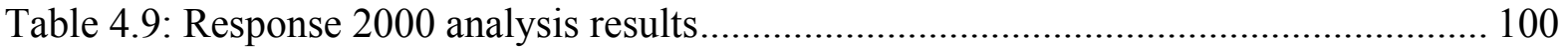

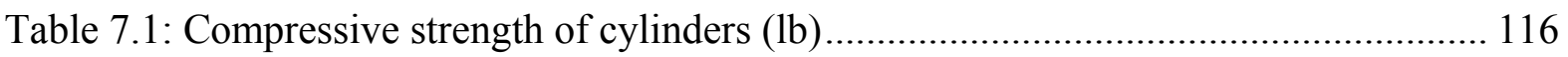

Table 7.2: Measured ultimate load for each test ............................................................. 117 


\section{LIST OF FIGURES}

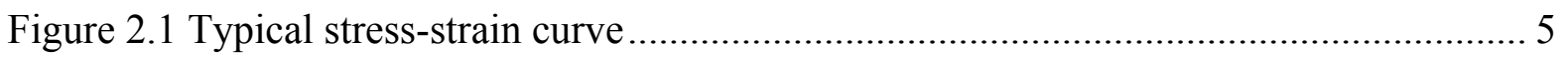

Figure 2.2: Forces at a crack (Nilson et al., 2004) ........................................................... 8

Figure 2.3: Simple truss model (MacGregor \& Wight, 2005) ........................................... 9

Figure 2.4: Variable angle truss model (Nilson et al., 2004) ........................................... 10

Figure 2.5 Average strains in a cracked element (Collins \& Vecchio, 1986) ...................... 12

Figure 2.6 Average stresses in a cracked element (Collins \& Vecchio, 1986)..................... 13

Figure 2.7: Strut and tie model (Nilson et al., 2004) ......................................................... 17

Figure 2.8: Nodal zones (Nilson et al., 2004) ............................................................ 18

Figure 2.9 Flowchart for AASHTO design for shear reinforcement (NCHRP, 2005) .......... 25

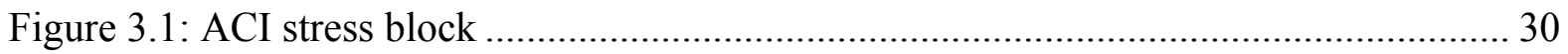

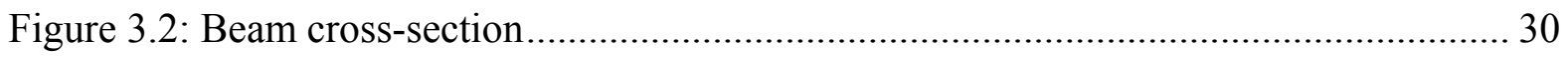

Figure 3.3: Typical reinforcement dimensions ........................................................ 32

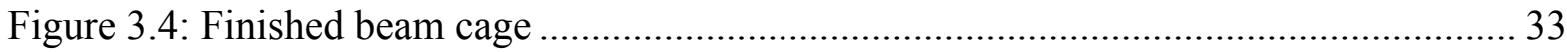

Figure 3.5: Casting bed with prepared formwork ....................................................... 34

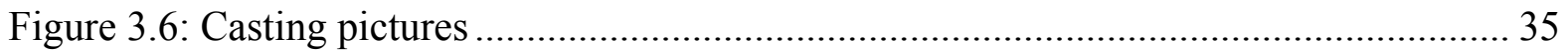

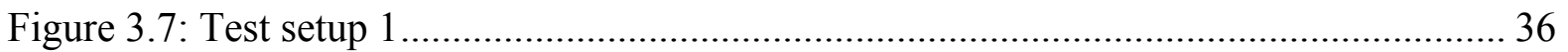

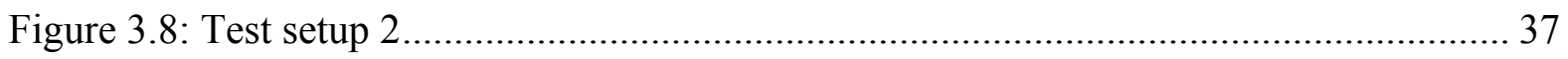

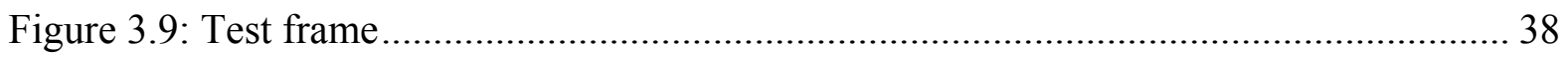

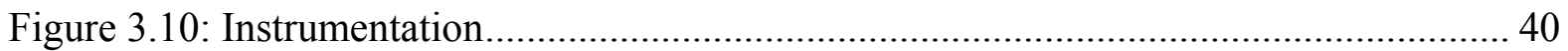

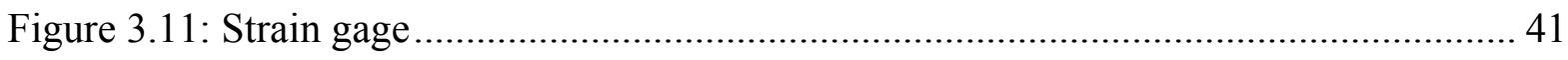

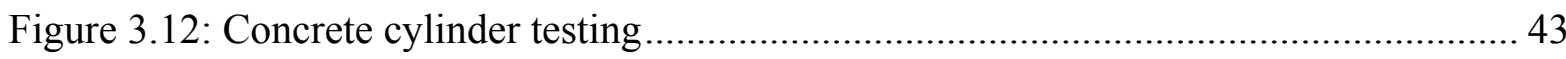

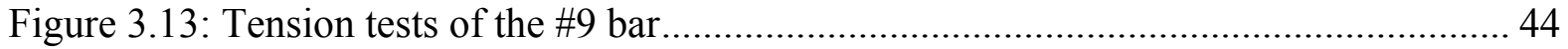

Figure 4.1: Conventional Grade 60 stress-strain relationship......................................... 47

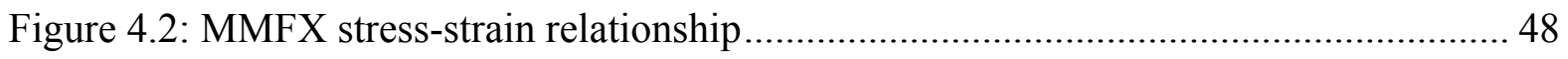

Figure 4.3: MMFX vs. G60 steel reinforcement......................................................... 48

Figure 4.4: Typical Shear Load-Deflection behavior of Set 1, stirrup spacing $=6 "$ "........... 50

Figure 4.5: Typical Shear Load-Deflection behavior of Set 2, stirrup spacing $=4$ " ............ 51

Figure 4.6: Typical Shear Load-Deflection behavior of Set 3, stirrup spacing = 3" $\ldots \ldots \ldots \ldots . . .51$

Figure 4.7: Typical Shear Load vs. Transverse Strain curve ............................................ 53 


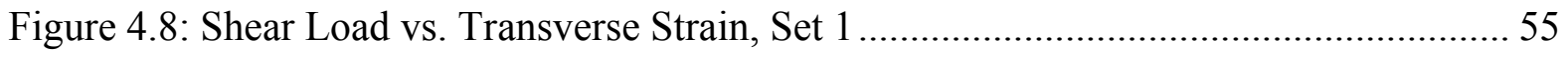

Figure 4.9: Shear Load vs. Strain, C-C-6................................................................... 56

Figure 4.10: Shear Load vs. Transverse Strain, Set 2 .................................................... 58

Figure 4.11: Shear Load vs. Strain, C-C-4 .................................................................. 59

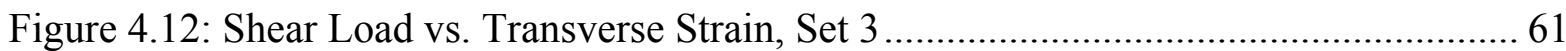

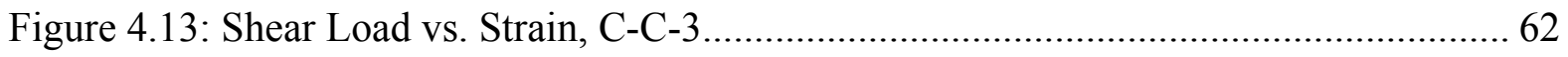

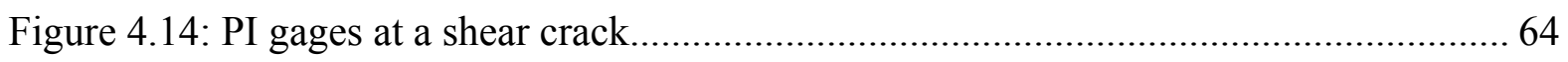

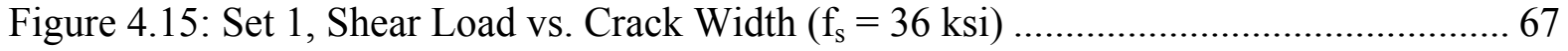

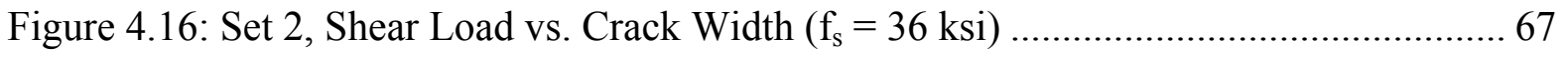

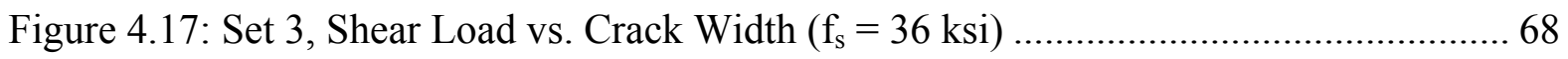

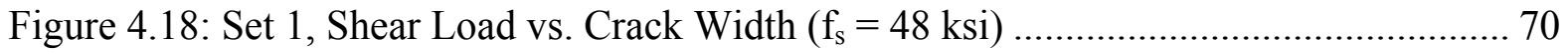

Figure 4.19: Set 2, Shear Load vs. Crack Width $\left(\mathrm{f}_{\mathrm{s}}=48 \mathrm{ksi}\right)$........................................ 71

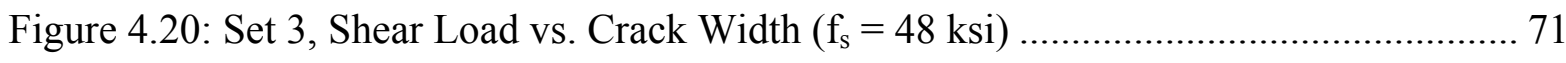

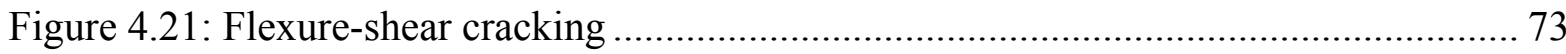

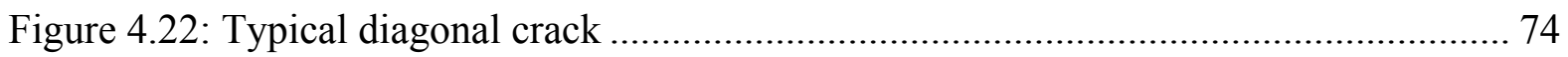

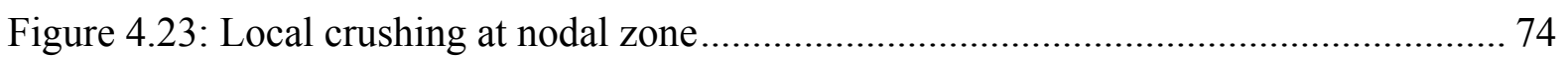

Figure 4.24: Localized failure zone of beam M-M-3 ................................................ 75

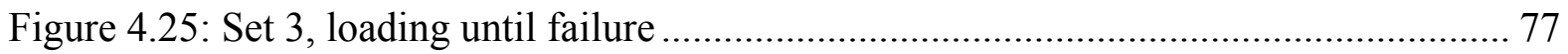

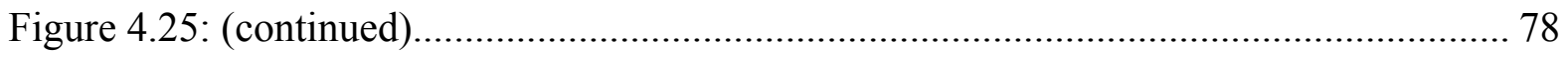

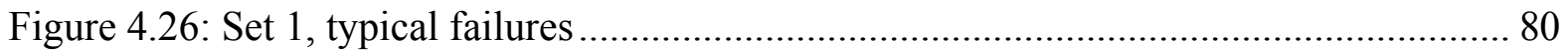

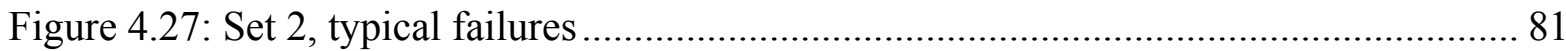

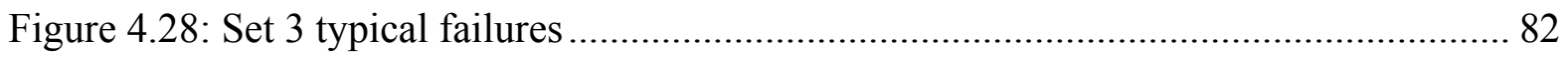

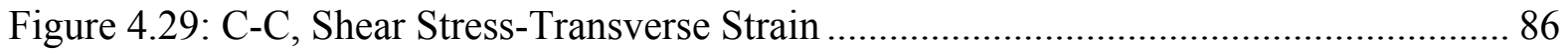

Figure 4.30: C-M, Shear Stress-Transverse Strain ....................................................... 87

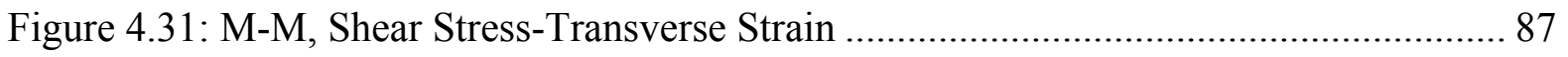

Figure 4.32: MMFX stress-strain relationship, measured vs. model................................. 93

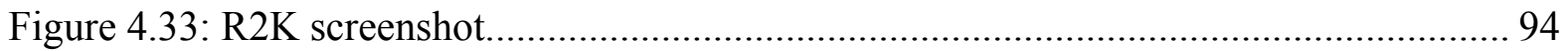

Figure 4.34: Location for sectional analysis ......................................................... 95

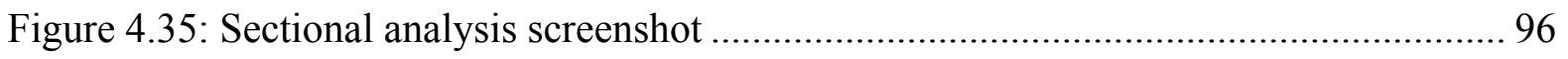

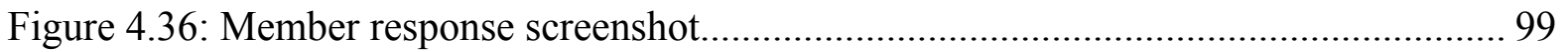

Figure 4.37: Flexural failure example, C-C-3 ........................................................ 102 
Figure 4.38: Shear failure example, M-M-4 ......................................................... 103

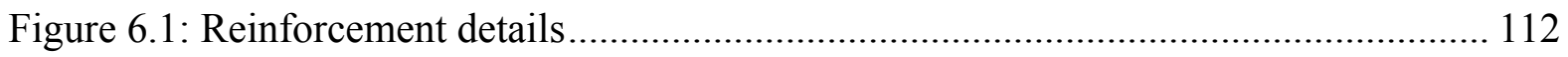

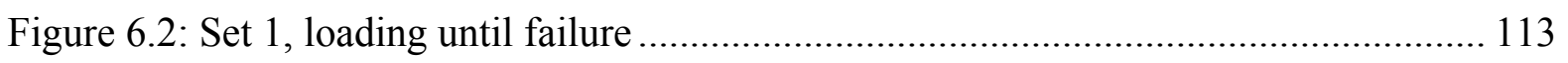

Figure 6.3: Set 2, loading until failure ..................................................................... 114

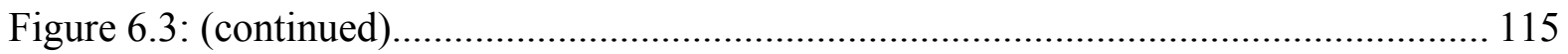

Figure 7.1: Set 1, Shear Load-Deflection, first tests .................................................... 118

Figure 7.2: Set 1, Shear Load-Deflection, repeat tests ................................................. 118

Figure 7.3: Set 2, Shear Load-Deflection, first tests...................................................... 119

Figure 7.4: Set 2, Shear Load-Deflection, repeat tests ................................................ 119

Figure 7.5: Set 3, Shear Load-Deflection, first tests.................................................. 120

Figure 7.6: Set 3, Shear Load-Deflection, repeat tests .................................................. 120

Figure 7.7: Set 1, Shear Load-Transverse Strain, first tests........................................... 121

Figure 7.8: Set 1, Shear Load-Transverse Strain, repeat firsts ...................................... 121

Figure 7.9: Set 2, Shear Load-Transverse Strain, first tests........................................... 122

Figure 7.10: Set 2, Shear Load-Transverse Strain, repeat tests ..................................... 122

Figure 7.11: Set 3, Shear Load-Transverse Strain, first tests.......................................... 123

Figure 7.12: Set 3, Shear Load-Transverse Strain, repeat tests ...................................... 123

Figure 7.13: C-M-6, Shear Load vs. Strain................................................................... 124

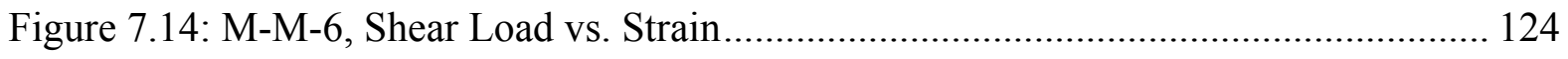

Figure 7.15: C-M-4, Shear Load vs. Strain............................................................... 125

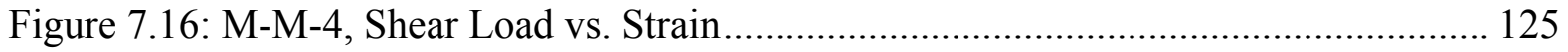

Figure 7.17: C-M-3, Shear Load vs. Strain.................................................................... 126

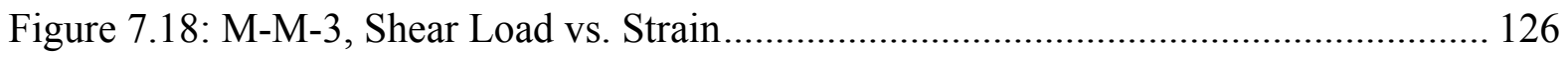

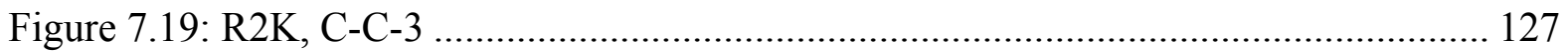

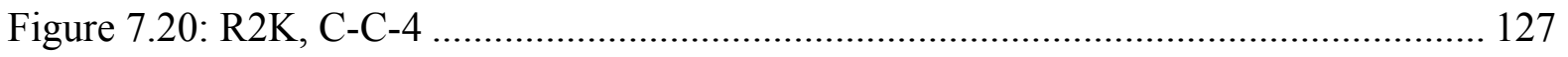

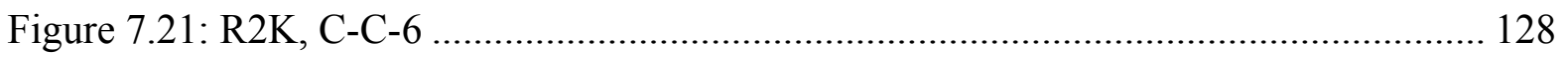

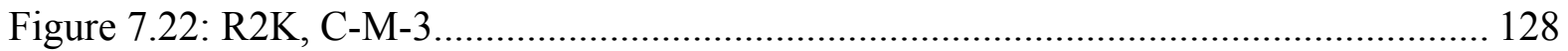

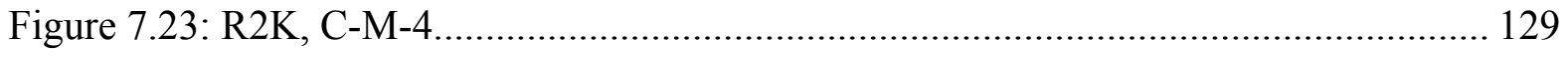

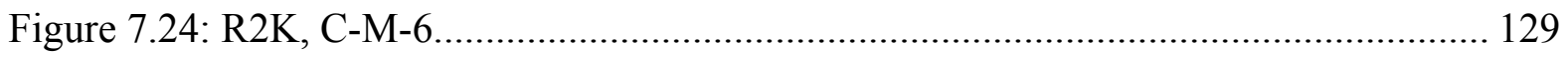

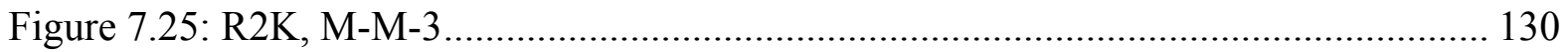

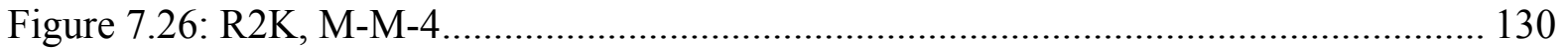




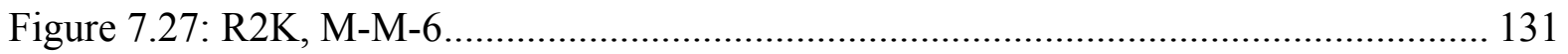

Figure 7.28: Steel material properties, Response 2000.............................................. 132

Figure 7.29: Concrete material properties, Response 2000 ............................................. 133 


\subsection{INTRODUCTION}

Typical steel reinforcing bars that are currently used for concrete structures have yield strengths ranging between $40-75 \mathrm{ksi}$, and concrete compressive strengths ranging between 4000-10,000 psi. More recently, there has been a growing interest in the use of high strength materials to reduce dead loads and consequently increase the span length. While significant research has already been performed on high strength concretes achieving compressive strength well beyond 10,000 psi, comparatively less research has been conducted on high performance steel.

In this thesis, high performance (HP) steel is classified as steel with a yield strength greater than $80 \mathrm{ksi}$. One major concern with using HP steel is the possibility to create cracks in the reinforced concrete larger than the acceptable limit. These cracks, besides being unsightly, could influence durability as well as the behavior of aggregate interlock and bond characteristics. However, since HP steel typically has higher corrosion resistance compared to conventional steel, there is less concern that the slight increase in crack width could affect the durability of structures. Further testing and research are needed to validate the use of high performance steel as a viable material for reinforced concrete structures. The type of high strength rebar used in this research program is commercially known as MMFX Steel (Microcomposite Multistructural Formable Steel). 


\subsection{Objective}

The primary objective of this research program is to determine the feasibility of using high performance reinforcing bars, specifically MMFX Steel (Microcomposite Multistructural Formable Steel), as shear reinforcement for concrete beams. The methodology for achieving the main objective consists of the following tasks:

1. Evaluate the behavior of beams reinforced with MMFX stirrups and longitudinal reinforcement.

2. Evaluate the capability of current design codes to predict the shear strength.

3. Evaluate the capability of available detailed analysis, such as the Modified Compression Field Theory, to predict the behavior.

4. Use the research findings to provide design guidelines for the use of high performance steel as shear reinforcement for concrete structures.

\subsection{Scope}

Currently, the ACI Code 318-05 specifies a maximum yield strength of $60 \mathrm{ksi}$ for conventional shear reinforcement and allows up to $80 \mathrm{ksi}$ for using welded wire shear reinforcement. However, El-Hacha (2002) has demonstrated that MMFX rebars achieve a yield strength of $120 \mathrm{ksi}$ using the $0.2 \%$ offset method. Therefore, with an increased design stress, there is a heightened concern that crack widths could be unacceptable during service load conditions. As a result, the main objective of this research is to determine the feasibility of using HP steel as shear reinforcement for concrete beams. The main variables considered in this program are the spacing of the MMFX shear reinforcement and the use of both conventional and MMFX longitudinal reinforcement. The behavior is compared to beams 
reinforced entirely with Grade 60 conventional steel, which were tested as the control specimens.

Chapter 2 presents most of the relevant information published about this subject including characteristics of high performance steel, shear resistance in concrete, available models typically used to examine shear behavior, and current design codes. The experimental program is described in Chapter 3, which details the fabrication of test specimens, test setup, instrumentation, and testing procedure. Chapter 4 presents the test results with an extensive discussion about the experimental program. Finally, a summary of the research findings along with recommendations for future research are given in Chapter 5. In addition to the main body of the thesis, two appendices have been included to provide further information regarding beam details, test results, and analysis. 


\subsection{LITERATURE REVIEW}

\subsection{High Performance Steel}

High performance steel typically displays higher strength, better corrosion resistance, or additional properties beyond that of conventional steel. For this research, the scope was focused on steel with yield strengths higher than $80 \mathrm{ksi}$. There are various types of high performance steel on the market today including SAS, stainless steel, and MMFX.

The high performance steel selected for this research is called Microcomposite Multistructural Formable Steel (MMFX Steel), which is produced by the MMFX Technologies Corporation. This high performance steel exhibits superior strength and corrosion properties in comparison to conventional Grade 60 steel (Rizkalla et al., 2005). The MMFX steel achieves its enhanced properties due to a patented and proprietary steel microstructure that is formed during the production process. The desired material composition was achieved by reducing the formation of galvanic cells, which is a substantial contributor to the initiation and acceleration of corrosion. As a result, corrosion activity can either be eliminated or minimized (MMFX, 2002).

\subsubsection{Mechanical characteristics}

It has been reported that MMFX steel is inherently stronger than conventional steel, while maintaining a good level of ductility (El-Hacha, 2002). Figure 2.1 shows the stressstrain relationship of the ASTM A1035 MMFX steel in comparison to A615 Grade 60 steel. 


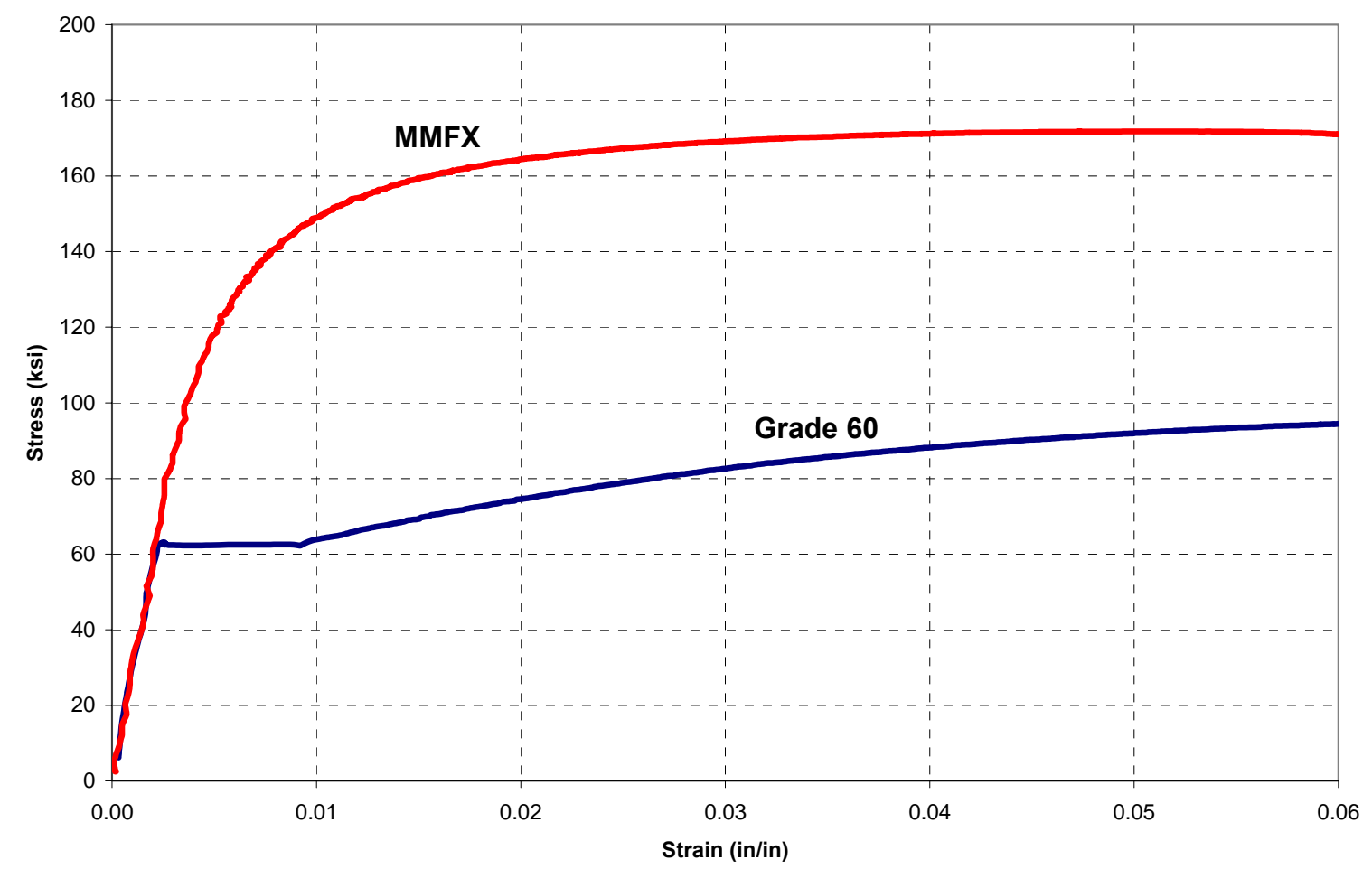

Figure 2.1 Typical stress-strain curve

Test results reported by El-Hacha (2002) indicate that MMFX steel has an average yield strength of $120 \mathrm{ksi}$ using the $0.2 \%$ offset method, and an average ultimate tensile strength of $177 \mathrm{ksi}$ with a minimum strain of 5\%. A greater yield strength is desirable since it allows the same sized section to carry larger loads without permanent deformation.

Ductility allows more plastic deformation before failure, and thus provides an additional margin of safety. While many types of high performance steels lose ductility, MMFX rebars maintain an acceptable ductile response. In addition, MMFX steel has been shown to have approximately $60 \%$ higher fatigue resistance than A615 steel, which allows more resistance to repetitive loading (MMFX, 2005). MMFX also has lower steel brittleness, allowing its strength to be maintained over a wider range of temperatures. Even though this 
type of high performance steel is slightly more expensive than traditional steel, it may provide a more economical solution due to reduced steel quantities and labor costs. In fact, the MMFX Technologies Corporation estimates that typically 20-40\% less steel will be needed with a labor cost savings of 20-50\% (MMFX, 2005).

\subsection{Shear Resistance of Reinforced Concrete Beams}

Shear failure in reinforced concrete, also known as diagonal tension failure, is difficult to accurately predict. This remains the case despite decades of experimental research, the development of new behavioral theories, and the use of sophisticated analytical tools. The difficulty lies in the fact that shear failure is really the sum of several internal mechanisms of resistance acting within the concrete. These include the uncracked compression zone, aggregate interlock, dowel action, and residual tensile stresses normal to cracks. The uncracked compression zone is the portion of uncracked concrete that is still able to fully resist shear forces. Aggregate interlock refers to the internal friction generated at a crack due to surface roughness, and can account for over one third of the total shear force. Dowel action results from the vertical forces across the longitudinal steel (Nilson et al., 2004). Collins et al. (1996) demonstrated that cracked concrete possesses tensile stresses that can considerably increase the ability of concrete to resist shear forces.

\subsection{Factors Affecting Shear Behavior}

Shear strength is controlled by the presence of web reinforcement, longitudinal reinforcement, coarse aggregate size, presence of axial loads, depth of the member, and concrete compressive strength. Web reinforcement is discussed in greater detail in Section 
2.3.1. The longitudinal reinforcement ratio $\rho_{\mathrm{x}}$ affects the crack size, and hence aggregate interlock, by reducing the size of cracks and helping to prevent their extension into the beam. Thus, a higher $\rho_{\mathrm{x}}$ increases the shear strength. A larger coarse aggregate size will increase the aggregate interlock and therefore increase resistance to shear. Researchers have concluded that axial compression serves to increase the shear capacity of a beam while axial tension greatly decreases the strength (NCHRP, 2005; MacGregor \& Wight, 2005). A phenomenon termed the "size effect" was researched by Kani (1967), who showed that the shear stress at failure decreases as the depth of the member increases. It is typical design practice is to take the contribution of concrete strength towards shear resistance proportionate to the square root of the maximum cylinder compressive strength $f_{c}^{\prime}$. However, more recent research has shown that high cylinder strengths do not necessarily result in high shear strength (Angelakos et al., 2001).

\subsubsection{Web reinforcement}

Web reinforcement, typically called stirrups, is used to increase the shear strength of concrete beams and to ensure a flexural failure. This is necessary due to the explosive and sudden nature of shear failures, compared with flexural failures which tend to show warnings of impending distress. Web reinforcement is normally provided as vertical stirrups and is spaced at varying intervals along a beam depending on the shear requirements. In general, small sized bars such as No. 3 to 5 are used in a U-shaped configuration that may be open or closed, or used as multiple legs. Alternatively, this reinforcement may be provided as inclined longitudinal bars. 
Shear reinforcement has very little effect prior to the formation of diagonal cracks. However after cracking, the web reinforcement enhances the beam in the following ways: (Nilson et al., 2004)

- The stirrups crossing the crack help in resisting the shear force.

- The stirrups restrict the growth of the cracks and reduce their penetration further into the compression zone.

- The stirrups oppose widening of the cracks, which helps to maintain aggregate interlock within the concrete.

- Since stirrups are tied to the longitudinal reinforcement, they provide extra restraint against the splitting of concrete along the longitudinal bars due to their confinement effect.

Figure 2.2 shows the fundamental shear resistance in a typical reinforced concrete beam.

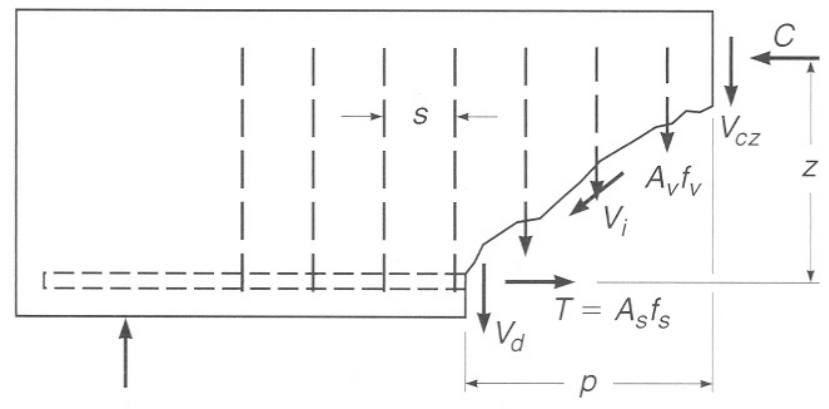

$\mathrm{V}_{\mathrm{cz}}=$ internal forces in the uncracked concrete

$\mathrm{V}_{\mathrm{i}}=$ aggregate interlock

$\mathrm{V}_{\mathrm{d}}=$ dowel action

$\mathrm{V}_{\mathrm{s}}=\mathrm{A}_{\mathrm{v}} \mathrm{f}_{\mathrm{v}}=$ force in stirrups

$\mathrm{T}=$ tension in longitudinal steel

$\mathrm{C}=$ compressive force in the uncracked concrete

$\mathrm{s}=$ spacing of stirrups

Figure 2.2: Forces at a crack (Nilson et al., 2004)

The amount of force resisted by the concrete and the stirrups vary, since it depends on the applied design procedure and codes of practice. This is further addressed in Section 2.4. 


\subsection{Mechanisms of Shear Resistance}

\subsubsection{Truss model}

The truss design model for reinforced concrete beams in shear was developed in 1899 and 1902 by the Swiss engineer Ritter, and the German engineer Mörsch. In the original truss model, Ritter used compression diagonals inclined at 45 degrees. Mörsch later suggested the possibility that angles other than 45 degrees exist (Ramirez \& Breen, 1991). Figure 2.3 below illustrates the simple truss model.

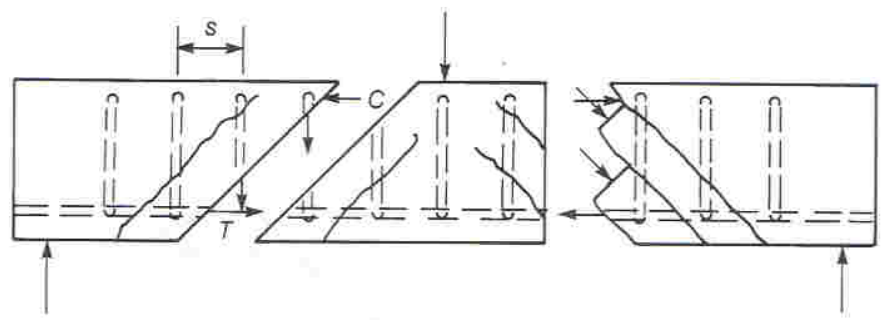

(a) Internal forces in a cracked beam.

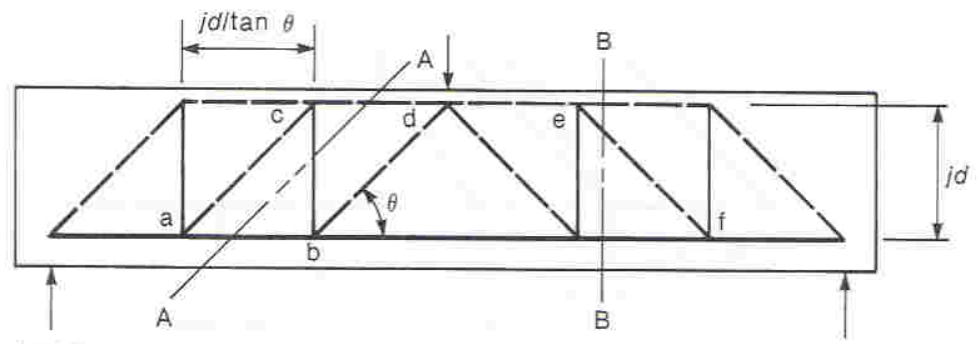

(b) Pin-jointed truss.

Figure 2.3: Simple truss model (MacGregor \& Wight, 2005)

Figure 2.3(a) depicts a beam with inclined cracks, which develops compressive and tensile forces in the top and bottom flanges, vertical forces in the stirrups, and compressive forces in the diagonals. This has been modeled as a simple truss depicted in Figure 2.3(b). All the vertical stirrups crossing section A-A are lumped together to form one member b-c. All the concrete compressive diagonals crossing section B-B are lumped together to form 
member e-f (MacGregor \& Wight, 2005). For typical cases, the truss model provides conservative results for members with small amounts of shear reinforcement. In the ACI Code (2005), this excess shear capacity is referred to as the concrete contribution $\mathrm{V}_{\mathrm{c}}$. In order to keep the truss a determinate system, all stirrups are assumed to yield. Therefore, each vertical force in the stirrup is equal to $A_{v} f_{y}$, where $A_{v}$ is the area of transverse reinforcement and $f_{y}$ is the yield strength.

More recently, the original truss method has been enhanced into the variable angle truss model. This model accounts for the fact that the concrete struts are generally not inclined at $45^{\circ}$, but may instead be in a range from about $25^{\circ}$ to $65^{\circ}$. Figure 2.4 depicts the newer proposed model for the truss mechanism.

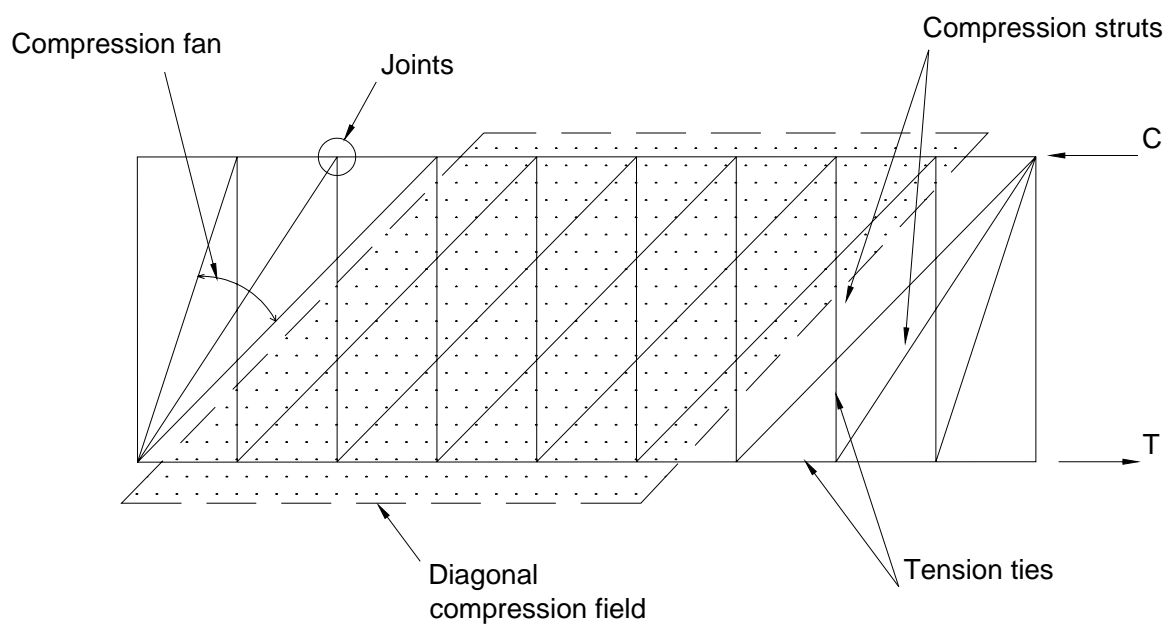

Figure 2.4: Variable angle truss model (Nilson et al., 2004)

The variable angle model involves compression fans and compression fields. The compression fans occur at supports or under direct loads, and involves a number of diagonal struts fanning out from the region. The number of struts should be enough such that the vertical load can fully be resisted. The compression field contains diagonal compression 
struts that run parallel between the compression fans. Like the original truss model, all stirrups are assumed to have yielded (Nilson et al., 2004).

\subsubsection{Modified Compression Field Theory}

The Modified Compression Field Theory (MCFT) was first presented by Collins and Vecchio (1986) as an extension to the Compression Field Theory (Mitchell \& Collins, 1974). The MCFT treats cracked concrete as a new material with its own stress-strain properties. In addition, formulations in terms of equilibrium, compatibility, and stress-strain relationships are made with regards to average stresses and average strains. The MCFT differs from the Compression Field Theory because it takes into account tensile stresses in the concrete between the cracks.

The compatibility conditions relate average strains in the concrete to average strains in the steel, although it is understood that local conditions may widely vary. Because any deformation in the concrete must be matched by an equal deformation in the steel, a change in concrete strain will show an identical change in steel strain. If the normal strains $\varepsilon_{\mathrm{x}}$ and $\varepsilon_{\mathrm{y}}$, and the shear strain $\gamma_{x y}$ are known, then the principal tensile strain $\varepsilon_{1}$ and the principal compressive strain $\varepsilon_{2}$ can be determined from Mohr's circle (Figure 2.5). Also, the angle of inclination $\theta$ of the principal compressive strain can be determined.

$$
\begin{array}{cc}
\gamma_{x y}=\frac{2\left(\varepsilon_{x}-\varepsilon_{2}\right)}{\tan \theta} & \text { Eqn. 2.1 } \\
\varepsilon_{x}+\varepsilon_{y}=\varepsilon_{1}+\varepsilon_{2} & \text { Eqn. 2.2 } \\
\tan ^{2} \theta=\frac{\varepsilon_{x}-\varepsilon_{2}}{\varepsilon_{y}-\varepsilon_{2}}=\frac{\varepsilon_{1}-\varepsilon_{y}}{\varepsilon_{1}-\varepsilon_{x}} & \text { Eqn. 2.3 }
\end{array}
$$



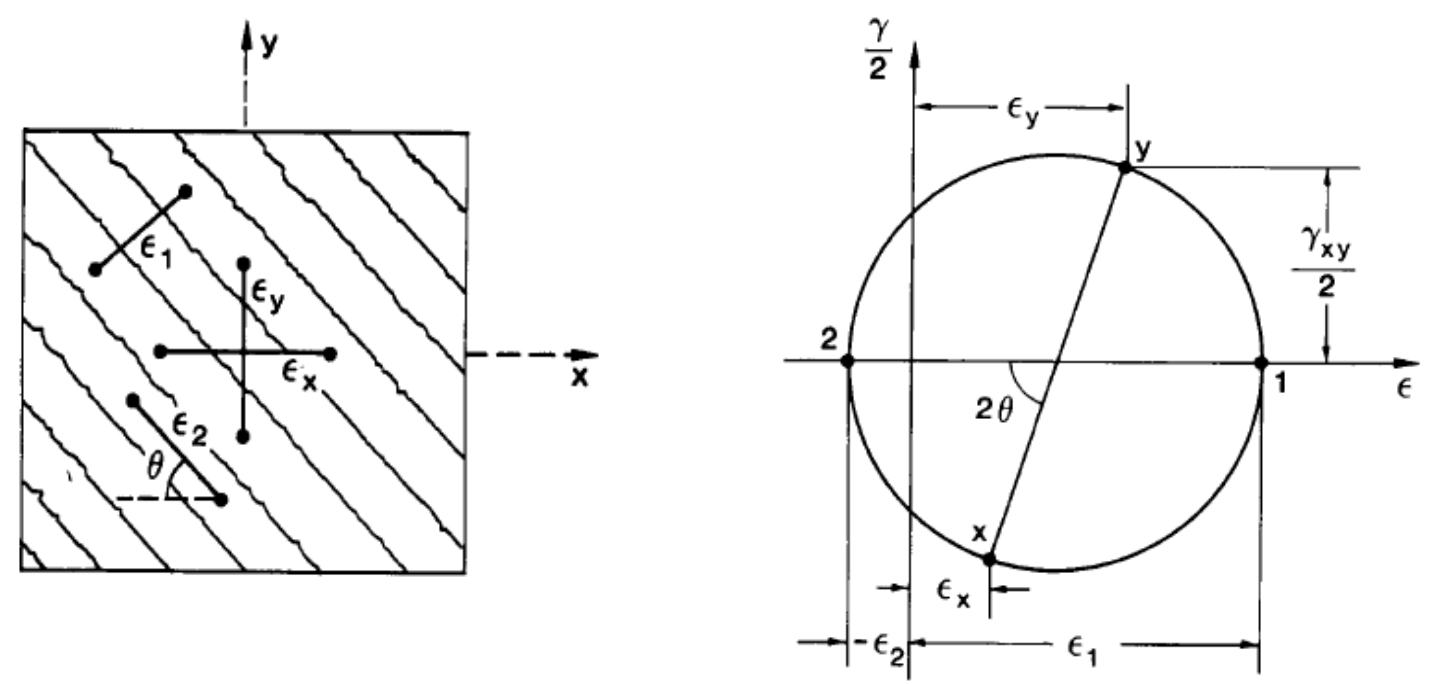

(a) Average strains in a cracked element

(b) Mohr's Circle for average strains

Figure 2.5 Average strains in a cracked element (Collins \& Vecchio, 1986)

The concrete element shown in Figure 2.6(a) will resist concrete shear forces $v_{c x}$, horizontal concrete stresses $f_{c x}$, and vertical concrete stresses $f_{c y}$. All three forces combine to form the principal tensile stress $f_{c 1}$ and the principal compressive stress $f_{c 2}$. By converting these stresses into a Mohr's circle of stress, as shown in Figure 2.6(c), the following equilibrium equations can be derived:

$$
\begin{array}{cc}
f_{c x}=f_{c 1}-\frac{v_{c x y}}{\tan \theta_{c}} & \text { Eqn. } 2.4 \\
f_{c y}=f_{c 1}-v_{c x y} \tan \theta_{c} & \text { Eqn. } 2.5 \\
f_{c 2}=f_{c 1}-v_{c x y}\left(\tan \theta_{c}+\frac{1}{\tan \theta_{c}}\right) & \text { Eqn. } 2.6
\end{array}
$$




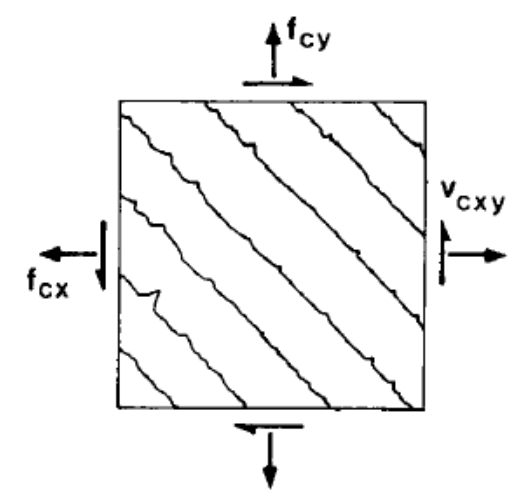

(a) Average concrete stresses

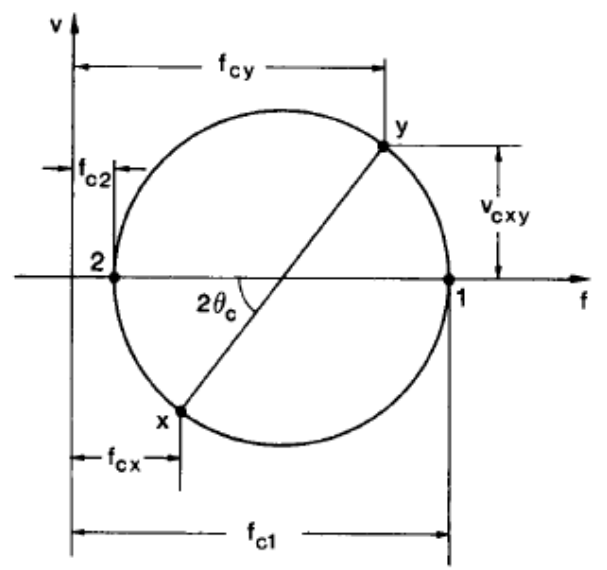

(c) Mohr's Circle for average concrete stresses

Figure 2.6 Average stresses in a cracked element (Collins \& Vecchio, 1986)

In order to simplify the stress-strain relationships, Collins and Vecchio (1986) assume that the principal stress axes coincide with the principal strain axes. Based on their experimental work, they determined that the principal compressive stress $f_{c 2}$ is both a function of the principal compressive strain $\varepsilon_{2}$ and of the principal tensile strain $\varepsilon_{1}$.

$$
f_{c 2}=f_{c 2 \max }\left[2\left(\frac{\varepsilon_{2}}{\varepsilon_{c}^{\prime}}\right)-\left(\frac{\varepsilon_{2}}{\varepsilon_{c}^{\prime}}\right)^{2}\right]
$$

Eqn. 2.7 


$$
\text { where } \frac{f_{c 2 \max }}{f_{c}^{\prime}}=\frac{1}{0.8-0.34 \frac{\varepsilon_{1}}{\varepsilon_{c}^{\prime}}} \leq 1.0
$$

Eqn. 2.8

In Eqn. $2.7, \varepsilon_{c}^{\prime}$ is the strain in a concrete cylinder at peak stress and is normally taken as -0.002. This causes $f_{c 2 \max }$ to decrease with increasing tensile strain. In order to relate the principal tensile stress in the concrete to the principal tensile strain, Eqn. 2.9 and Eqn. 2.10 were suggested:

$$
\begin{array}{lll}
f_{c 1}=E_{c} \varepsilon_{1} & \text { if } \varepsilon_{1} \leq \varepsilon_{c r} & \text { Eqn. } 2.9 \\
f_{c 1}=\frac{f_{c r}}{1+\sqrt{200 \varepsilon_{1}}} & \text { if } \varepsilon_{1}>\varepsilon_{c r} & \text { Eqn. 2.10 }
\end{array}
$$

where $E_{c}$ is the elastic modulus of the concrete, $f_{c r}$ is the stress in the concrete at cracking, and $\varepsilon_{c r}$ is the strain in the concrete at cracking. The formulas for average stress-strain in the reinforcement are based on a bilinear relationship.

For the majority of normal strength concretes, cracking occurs in the interface between the cement paste and aggregate particles. The shear is then carried by the aggregate interlock mechanism. The diagonal crack width can be computed by multiplying the principal tensile strain by the crack spacing $s_{\theta}$, as shown below.

$$
\begin{gathered}
w=\varepsilon_{1} S_{\theta} \\
S_{\theta}=\frac{1}{\frac{\sin \theta}{S_{m x}}+\frac{\cos \theta}{S_{m y}}}
\end{gathered}
$$

Eqn. 2.11

\section{Eqn. 2.12}

The term $s_{\theta}$ is the spacing of diagonally inclined cracks, $s_{m x}$ is the average spacing of cracks perpendicular to the longitudinal reinforcement, and $s_{m y}$ is the average spacing of cracks perpendicular to the transverse reinforcement. While not presented in the Modified 
Compression Field Theory paper, the formulas for average crack spacing are presented in a textbook written by Collins and Mitchell (1997).

$$
\begin{aligned}
& S_{m x}=2\left(c_{x}+\frac{s_{x}}{10}\right)+0.25 k_{1} \frac{d_{b x}}{\rho_{x}} \\
& S_{m y}=2\left(c_{y}+\frac{s}{10}\right)+0.25 k_{1} \frac{d_{b v}}{\rho_{v}}
\end{aligned}
$$

Eqn. 2.13

Eqn. 2.14

where $c_{x}$ and $c_{y}$ are the concrete covers for the longitudinal and transverse reinforcement, respectively; $s_{x}$ and $s_{y}$ are the spacing of the longitudinal and transverse reinforcement, respectively; $d_{b x}$ and $d_{b y}$ are the bar diameters of the longitudinal and transverse reinforcement, respectively; $\rho_{x}$ and $\rho_{y}$ are the ratios for the longitudinal and transverse reinforcement, respectively; and $k_{1}$ equals 0.4 for deformed bars.

The original MCFT paper suggests an iterative solution technique for determining the response of a biaxially stressed element, and is listed in that paper's Appendix A (Collins \& Vecchio, 1986). A subsequent article by Collins and Vecchio (1988) further describe three techniques, including one rigorous method and two other alternative methods. The rigorous procedure requires individual concrete layers and reinforcing bar elements to be analyzed separately along the entire cross section. Because this is very time consuming, the alternative methods were proposed. The first suggests using a uniform shear flow distribution between longitudinal steel centroids, while the second assumes that the shear strain distribution varies in a parabolic fashion.

Despite these different solution methods for the Modified Compression Field Theory, solving the equations by hand is very tedious. In 1996, Collins et al. created a simple procedure for the design of shear which utilizes the assumption that shear stress is to remain 
constant over the depth of the web. This procedure later formed the basis for the AASHTO LRFD Bridge Design Specifications, and will be described more fully in Section 2.5.2. In 2000, Bentz and Collins developed a computer software program called Response 2000 which allows full implementation of the MCFT in the analysis of beams and columns. This enables the user to quickly determine the load deformation response of reinforced concrete subjected to shear.

\subsubsection{Simplified Modified Compression Field Theory}

In 2006, Bentz et al. presented a more straightforward approach to the MCFT and entitled it the Simplified Modified Compression Field Theory (SMCFT). Their goal was to provide shear calculations nearly as accurate as the MCFT, while making an overall shear design method less complicated. The authors also drew on prior research (Collins et al., 1996) to complete many of the design equations. Today, the SMCFT forms much of the basis for the Canadian design code, which is discussed in Section 2.5.3.

\subsubsection{Strut and Tie Model}

Reinforced concrete theory hinges on various assumptions of simple beam theory such as plane sections remaining plane, and that strain various linearly throughout the section. However, regions near a discontinuity do not satisfy this assumption and are called D-regions. They approximately extend a distance $h$ away from the discontinuity which may include concentrated loads, openings, or changes in the cross section. Entire beams consisting of a D-region are labeled "deep beams." Regions in between these areas are subject to typical beam behavior, and are called B-regions (Nilson et al., 2004). 
In the early 1980s, the Strut and Tie Model (STM) was developed to account for these D-regions. They consist of struts, ties, and nodal zones. Figure 2.7 shows how each are combined within a beam.

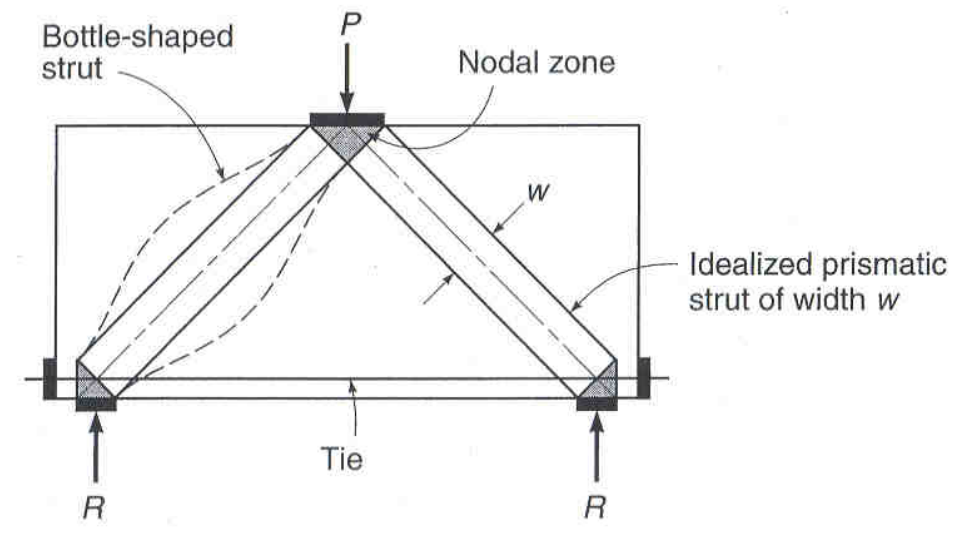

Figure 2.7: Strut and tie model (Nilson et al., 2004)

While the concrete beams and loading conditions in this experimental program were not technically deep beams, some of their behavior can be explained from the strut and tie methodology. Therefore, a brief discussion of STM will follow.

Struts are internal concrete compression members which may be rectangular or bottle-shaped. Bottle-shaped struts bulge throughout their depth, and are wider at the center than at the ends. The strut and tie model shown in Figure 2.7 features a rectangular strut, but the bottle-shaped strut is depicted from dashed lines.

Ties are tension members within the model and consist of steel reinforcement (prestressed and non-stressed), plus the portion of concrete surrounding the steel. However, the model assumes that the steel carries all of the tension force.

Nodal zones are regions where struts, ties, and concentrated loads intersect. Nodes are classified by the types of forces passing into them, which compose four types: C-C-C, 
C-C-T, C-T-T, and T-T-T, where "C" represents compression and " $\mathrm{T}$ " represents tension. A picture of each node type is featured below.

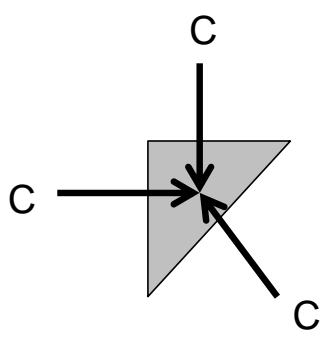

(a) $\mathrm{C}-\mathrm{C}-\mathrm{C}$

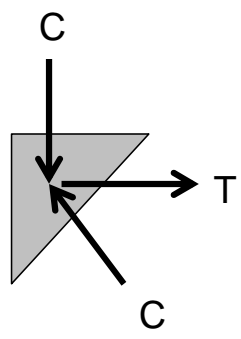

(b) C-C-T

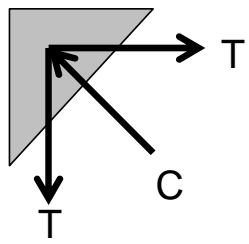

(c) $\mathrm{C}-\mathrm{T}-\mathrm{T}$

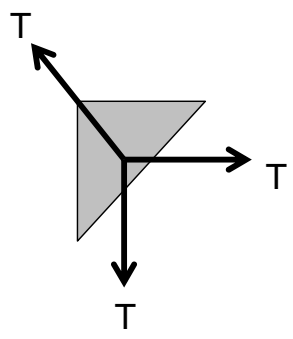

(d) T-T-T

Figure 2.8: Nodal zones (Nilson et al., 2004)

The creation of the strut and tie model offers no unique solution, and more than one admissible model may be valid for a given situation. The STM must be statically admissible, thus in equilibrium with the external loads, reactions, and nodes. Design occurs by selecting the amount of steel for the tension ties, effective width of the strut, and shape of the nodal zone such that the strength is sufficient (Kuchma \& Tjhin, 2005b). Selection of these components is based on recommendations by the ACI Code Appendix A. Many other papers and books are available to give examples and help in designing members. Such literature includes a journal paper by Wight and Parra-Montesinos (2003), the textbook by Nilson et al. (2004), and a computer program called CAST (Kuchma \& Tjhin 2005a). 


\subsection{Design Codes}

There is a multitude of design code philosophies that can be found across the world for shear design. Some of these rely on empirical formulas for estimating the shear strength, such as the ACI Code, while others like the AASHTO LRFD rely more heavily on concrete models such as the Modified Compression Field Theory. The forthcoming sections will detail three selected design codes. The reader should be aware that any notation defined within Section 2.5 will be the same for all subsections unless otherwise noted.

\subsubsection{American Concrete Institute, ACI 318-05}

The ACI Code (2005) is most commonly used for shear design in the United States, and is based on a $45^{\circ}$ truss model. The shear strength is based on an average shear stress distribution across the entire cross section, and is composed of a concrete component $V_{c}$ and a steel component $V_{s}$. The basic equations for normal-weight, non-prestressed reinforced concrete are listed below:

$$
\begin{gathered}
V_{u} \leq V_{n}=V_{c}+V_{s} \\
V_{c}=\left(1.9 \sqrt{f_{c}^{\prime}}+2500 \rho_{w} \frac{V_{u} d}{M_{u}}\right) b_{w} d \leq 3.5 \sqrt{f_{c}^{\prime}} b_{w} d \\
\text { Simplified version: } V_{c}=2 \sqrt{f_{c}^{\prime}} b_{w} d \\
A_{v, \text { min }}=0.75 \sqrt{f_{c}^{\prime}} \frac{b_{w} s}{f_{y t}} \geq \frac{50 b_{w} s}{f_{y t}} \\
V_{s}=\frac{A_{v} f_{y t} d}{s}
\end{gathered}
$$

Eqn. 2.15

Eqn. 2.16

Eqn. 2.17

Eqn. 2.18

Eqn. 2.19 
Where:

$$
\begin{aligned}
& V_{u}=\text { factored shear force on the section } \\
& \phi=\text { strength reduction factor }=0.75 \text { (not shown in Eqn. } 2.15 \text { ) } \\
& V_{n}=\text { nominal shear strength } \\
& \rho_{w}=\frac{A_{s}}{b_{w} d} \\
& A_{s}=\text { area of longitudinal reinforcement } \\
& b_{w}=\text { web width of section } \\
& d=\text { distance from the extreme compression fiber to the centroid of the longitudinal } \\
& \text { reinforcement } \\
& M_{u}=\text { factored moment at section } \\
& A_{v}=\text { area of shear reinforcement } \\
& f_{c}^{\prime}=\text { concrete compressive strength (psi) }
\end{aligned}
$$

\subsubsection{AASHTO LRFD Bridge Design Specifications (2004)}

The AASHTO LRFD method is known as the Sectional Design Model, and is based on the Modified Compression Field Theory. The nominal shear resistance $V_{n}$ can be computed by:

$$
V_{n}=V_{c}+V_{s}+V_{p}
$$




$$
\begin{array}{cc}
V_{n, \max }=0.25 f_{c}^{\prime} b_{v} d_{v}+V_{p} & \text { Eqn. 2.21 } \\
V_{c}=0.0316 \beta \sqrt{f_{c}^{\prime}} b_{v} d_{v} & \text { Eqn. 2.22 } \\
V_{s}=\frac{A_{v} f_{y} d_{v} \cot \theta}{s} & \text { Eqn. 2.23 } \\
A_{v, \text { min }} \geq 0.0316 \sqrt{f_{c}^{\prime}} \frac{b_{v} s}{f_{y}} & \text { Eqn. 2.24 }
\end{array}
$$

Where:

$$
\begin{aligned}
& V_{p}=\text { vertical component of the prestressing force } \\
& b_{v}=\text { effective web width, taken as the minimum web width within the depth } \\
& d_{v}=\text { effective shear depth }=\text { the greater of } 0.9 d \text { or } 0.72 \mathrm{~h} \\
& \beta=\text { factor indicating the ability of diagonally cracked concrete to transmit tension } \\
& \theta=\text { angle of inclination of the diagonal compressive struts } \\
& f_{c}^{\prime}=\text { concrete compressive strength (ksi) } \\
& f_{y}=\text { yield strength of the transverse reinforcement }(\mathrm{ksi})
\end{aligned}
$$

For sections containing at least the minimum amount of transverse reinforcement, the values $\beta$ and $\theta$ may be found using Table 2.1, which is shown at the end of Section 2.5.2. The designer should select the row corresponding to the shear design stress ratio $\frac{v}{f_{c}^{\prime}}=\frac{V_{u}}{b_{v} d_{v} f_{c}^{\prime}}$, and select the column corresponding to the longitudinal strain $\varepsilon_{x}$ at mid-depth. The longitudinal strain may be computed as: 


$$
\varepsilon_{x}=\frac{\frac{M_{u}}{d_{v}}+0.5 N_{u}+0.5\left(V_{u}-V_{p}\right) \cot \theta-A_{p s} f_{p o}}{2\left(E_{s} A_{s}+E_{p} A_{p}\right)}
$$

For sections containing less than the minimum amount of transverse reinforcement, the values of $\beta$ and $\theta$ may be found using Table 2.2, also found at the end of Section 2.5.2. The designer should select the row corresponding to an equivalent spacing parameter $s_{x e}$, and select the column corresponding to the longitudinal strain $\varepsilon_{x}$ at mid-depth. The longitudinal strain may be computed as:

$$
\begin{gathered}
\varepsilon_{x}=\frac{\frac{M_{u}}{d_{v}}+0.5 N_{u}+0.5\left(V_{u}-V_{p}\right) \cot \theta-A_{p s} f_{p o}}{E_{s} A_{s}+E_{p} A_{p}} \\
s_{x e}=\frac{1.38 s_{\chi}}{a_{g}+0.63}
\end{gathered}
$$

Eqn. 2.26

Eqn. 2.27

If either value for $\varepsilon_{x}$ is negative, one should use Eqn. 2.28 for the longitudinal steel strain instead:

$$
\varepsilon_{\chi}=\frac{\frac{M_{u}}{d_{v}}+0.5 N_{u}+0.5\left(V_{u}-V_{p}\right) \cot \theta-A_{p s} f_{p o}}{2\left(E_{c} A_{c}+E_{s} A_{s}+E_{p} A_{p}\right)}
$$

Eqn. 2.28

Where:

$A_{c}=$ area of concrete on the flexural tension side

$A_{p}=$ area of prestressing steel on the flexural tension side

$A_{s}=$ area of non-prestressed steel on the flexural tension side

$f_{p o}=\mathrm{E}_{\mathrm{p}}$ times locked in difference in strain at ultimate load between the prestressing tendons and the surrounding concrete 


$$
\begin{aligned}
& N_{u}=\text { factored axial force } \\
& s_{x}=\text { crack spacing parameter } \\
& a_{g}=\text { maximum aggregate size (in) (AASHTO, 2005). }
\end{aligned}
$$

Figure 2.9 shows a flowchart for the entire design procedure, as outlined by AASHTO (2005).

Table 2.1 Members with at least minimum shear reinforcement (NCHRP, 2005)

\begin{tabular}{|c|c|c|c|c|c|c|c|c|c|c|c|c|}
\hline \multicolumn{2}{|c|}{$v^{*}$} & \multicolumn{8}{|c|}{ Longitudinal Strain, $\varepsilon_{x} \times 1000$} \\
\cline { 2 - 12 }$f_{c}^{\prime}$ & & $\leq$ & $\leq$ & $\leq$ & $\leq$ & $\leq$ & $\leq$ & $\leq$ & $\leq$ & $\leq$ & $\leq$ & $\leq$ \\
$\leq 0.075$ & $\theta$ & $22.3^{\circ}$ & -0.10 & -0.05 & 0 & 0.125 & 0.25 & 0.50 & 0.75 & 1.00 & 1.50 & 2.00 \\
\hline \multirow{2}{*}{$\leq 0.4^{\circ}$} & $21.0^{\circ}$ & $21.8^{\circ}$ & $24.3^{\circ}$ & $26.6^{\circ}$ & $30.5^{\circ}$ & $33.7^{\circ}$ & $36.4^{\circ}$ & $40.8^{\circ}$ & $43.9^{\circ}$ \\
& $\beta$ & 6.32 & 4.75 & 4.10 & 3.75 & 3.24 & 2.94 & 2.59 & 2.38 & 2.23 & 1.95 & 1.67 \\
\hline \multirow{2}{*}{$\leq 0.100$} & $\theta$ & $18.1^{\circ}$ & $20.4^{\circ}$ & $21.4^{\circ}$ & $22.5^{\circ}$ & $24.9^{\circ}$ & $27.1^{\circ}$ & $30.8^{\circ}$ & $34.0^{\circ}$ & $36.7^{\circ}$ & $40.8^{\circ}$ & $43.1^{\circ}$ \\
& $\beta$ & 3.79 & 3.38 & 3.24 & 3.14 & 2.91 & 2.75 & 2.50 & 2.32 & 2.18 & 1.93 & 1.69 \\
\hline \multirow{2}{*}{$\leq 0.125$} & $\theta$ & $19.9^{\circ}$ & $21.9^{\circ}$ & $22.8^{\circ}$ & $23.7^{\circ}$ & $25.9^{\circ}$ & $27.9^{\circ}$ & $31.4^{\circ}$ & $34.4^{\circ}$ & $37.0^{\circ}$ & $41.0^{\circ}$ & $43.2^{\circ}$ \\
& $\beta$ & 3.18 & 2.99 & 2.94 & 2.87 & 2.74 & 2.62 & 2.42 & 2.26 & 2.13 & 1.90 & 1.67 \\
\hline \multirow{2}{*}{$\leq 0.150$} & $\theta$ & $21.6^{\circ}$ & $23.3^{\circ}$ & $24.2^{\circ}$ & $25.0^{\circ}$ & $26.9^{\circ}$ & $28.8^{\circ}$ & $32.1^{\circ}$ & $34.9^{\circ}$ & $37.3^{\circ}$ & $40.5^{\circ}$ & $42.8^{\circ}$ \\
& $\beta$ & 2.88 & 2.79 & 2.78 & 2.72 & 2.60 & 2.52 & 2.36 & 2.21 & 2.08 & 1.82 & 1.61 \\
\hline \multirow{2}{*}{$\leq 0.175$} & $\theta$ & $23.2^{\circ}$ & $24.7^{\circ}$ & $25.5^{\circ}$ & $26.2^{\circ}$ & $28.0^{\circ}$ & $29.7^{\circ}$ & $32.7^{\circ}$ & $35.2^{\circ}$ & $36.8^{\circ}$ & $39.7^{\circ}$ & $42.2^{\circ}$ \\
& $\beta$ & 2.73 & 2.66 & 2.65 & 2.60 & 2.52 & 2.44 & 2.28 & 2.14 & 1.96 & 1.71 & 1.54 \\
\hline \multirow{2}{*}{$\leq 0.200$} & $\theta$ & $24.7^{\circ}$ & $26.1^{\circ}$ & $26.7^{\circ}$ & $27.4^{\circ}$ & $29.0^{\circ}$ & $30.6^{\circ}$ & $32.8^{\circ}$ & $34.5^{\circ}$ & $36.1^{\circ}$ & $39.2^{\circ}$ & $41.7^{\circ}$ \\
& $\beta$ & 2.63 & 2.59 & 2.52 & 2.51 & 2.43 & 2.37 & 2.14 & 1.94 & 1.79 & 1.61 & 1.47 \\
\hline \multirow{2}{*}{$\leq 0.225$} & $\theta$ & $26.1^{\circ}$ & $27.3^{\circ}$ & $27.9^{\circ}$ & $28.5^{\circ}$ & $30.0^{\circ}$ & $30.8^{\circ}$ & $32.3^{\circ}$ & $34.0^{\circ}$ & $35.7^{\circ}$ & $38.8^{\circ}$ & $41.4^{\circ}$ \\
& $\beta$ & 2.53 & 2.45 & 2.42 & 2.40 & 2.34 & 2.14 & 1.86 & 1.73 & 1.64 & 1.51 & 1.39 \\
\hline \multirow{2}{*}{$\leq 0.250$} & $\theta$ & $27.5^{\circ}$ & $28.6^{\circ}$ & $29.1^{\circ}$ & $29.7^{\circ}$ & $30.6^{\circ}$ & $31.3^{\circ}$ & $32.8^{\circ}$ & $34.3^{\circ}$ & $35.8^{\circ}$ & $38.6^{\circ}$ & $41.2^{\circ}$ \\
& $\beta$ & 2.39 & 2.39 & 2.33 & 2.33 & 2.12 & 1.93 & 1.70 & 1.58 & 1.50 & 1.38 & 1.29 \\
\hline
\end{tabular}


Table 2.2: Members with less than minimum shear reinforcement (NCHRP, 2005)

\begin{tabular}{|c|c|c|c|c|c|c|c|c|c|c|c|c|}
\hline \multirow{2}{*}{\multicolumn{2}{|c|}{$\begin{array}{l}S_{x e}{ }^{*} \\
\text { (in) }\end{array}$}} & \multicolumn{11}{|c|}{ Longitudinal Strain, $\varepsilon_{x} \times 1000$} \\
\hline & & $\begin{array}{c}\leq \\
-0.20\end{array}$ & \multirow{2}{*}{$\begin{array}{c}\leq \\
-0.10 \\
25.5^{\circ}\end{array}$} & \multirow{2}{*}{$\begin{array}{c}\leq \\
-0.05 \\
25.9^{\circ}\end{array}$} & \multirow{2}{*}{$\begin{array}{c}\leq \\
0 \\
26.4^{\circ}\end{array}$} & \multirow{2}{*}{$\begin{array}{c}\leq \\
0.125 \\
27.7^{\circ}\end{array}$} & \multirow{2}{*}{$\begin{array}{c}\leq \\
0.25 \\
28.9^{\circ}\end{array}$} & \multirow{2}{*}{$\begin{array}{c}\leq \\
0.50 \\
30.9^{\circ}\end{array}$} & \multirow{2}{*}{$\begin{array}{c}\leq \\
0.75 \\
32.4^{\circ}\end{array}$} & \multirow{2}{*}{$\begin{array}{c}\leq \\
1.00 \\
33.7^{\circ}\end{array}$} & \multirow{2}{*}{$\begin{array}{c}\leq \\
1.50 \\
35.6^{\circ}\end{array}$} & \multirow{2}{*}{$\begin{array}{c}\leq \\
2.00 \\
37.2^{\circ}\end{array}$} \\
\hline & $\theta$ & $25.4^{\circ}$ & & & & & & & & & & \\
\hline & & 36 & 6.06 & 5.56 & 15 & 4.41 & 3.90 & 3.26 & 2.86 & 2.58 & 21 & 1.96 \\
\hline \multirow{2}{*}{$\leq 10$} & & & $.6^{\circ}$ & & & & & & & & & \\
\hline & & & & & & & & & & & & \\
\hline \multirow{2}{*}{$\leq 15$} & & & $.5^{\circ}$ & $.7^{\circ}$ & $\circ$ & & & $9.9^{\circ}$ & $2.4^{\circ}$ & & & \\
\hline & 1 & .34 & 4 & 7 & 3 & & & 4 & 2.27 & & & 16 \\
\hline \multirow{2}{*}{$\leq 20$} & & & $2^{\circ}$ & $2^{\circ}$ & & & & $7^{\circ}$ & $5.5^{\circ}$ & & & \\
\hline & & & 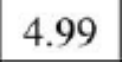 & 0 & & & & & 2.09 & & & 31 \\
\hline \multirow{2}{*}{$\leq 30$} & & $\circ$ & $1^{\circ}$ & $1^{\circ}$ & $2^{\circ}$ & & $3^{\circ}$ & $46.9^{\circ}$ & $50.1^{\circ}$ & $52.6^{\circ}$ & $2^{\circ}$ & $59.0^{\circ}$ \\
\hline & & & & & & & & & 84 & & & \\
\hline \multirow{2}{*}{$\leq 40$} & & $6^{\circ}$ & $36.6^{\circ}$ & $6.6^{\circ}$ & 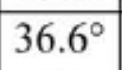 & $1^{\circ}$ & $45.0^{\circ}$ & $50.2^{\circ}$ & $53.7^{\circ}$ & $56.3^{\circ}$ & $60.2^{\circ}$ & $63.0^{\circ}$ \\
\hline & & & & & & & & & 1.66 & & & 0.95 \\
\hline & $\theta$ & $8^{\circ}$ & $.8^{\circ}$ & $40.8^{\circ}$ & $0.8^{\circ}$ & $7.5^{\circ}$ & $49.2^{\circ}$ & $55.1^{\circ}$ & $58.9^{\circ}$ & $61.8^{\circ}$ & $65.8^{\circ}$ & $68.6^{\circ}$ \\
\hline & $F$ & & & & & & & & 1.40 & & 2 & 0.75 \\
\hline \multirow{2}{*}{$\leq 80$} & & & & $44.3^{\circ}$ & & & $52.3^{\circ}$ & $58.7^{\circ}$ & $62.8^{\circ}$ & $65.7^{\circ}$ & $69.7^{\circ}$ & $72.4^{\circ}$ \\
\hline & & & & & & & & & 1.21 & 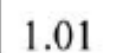 & 0.76 & 0.6 \\
\hline
\end{tabular}




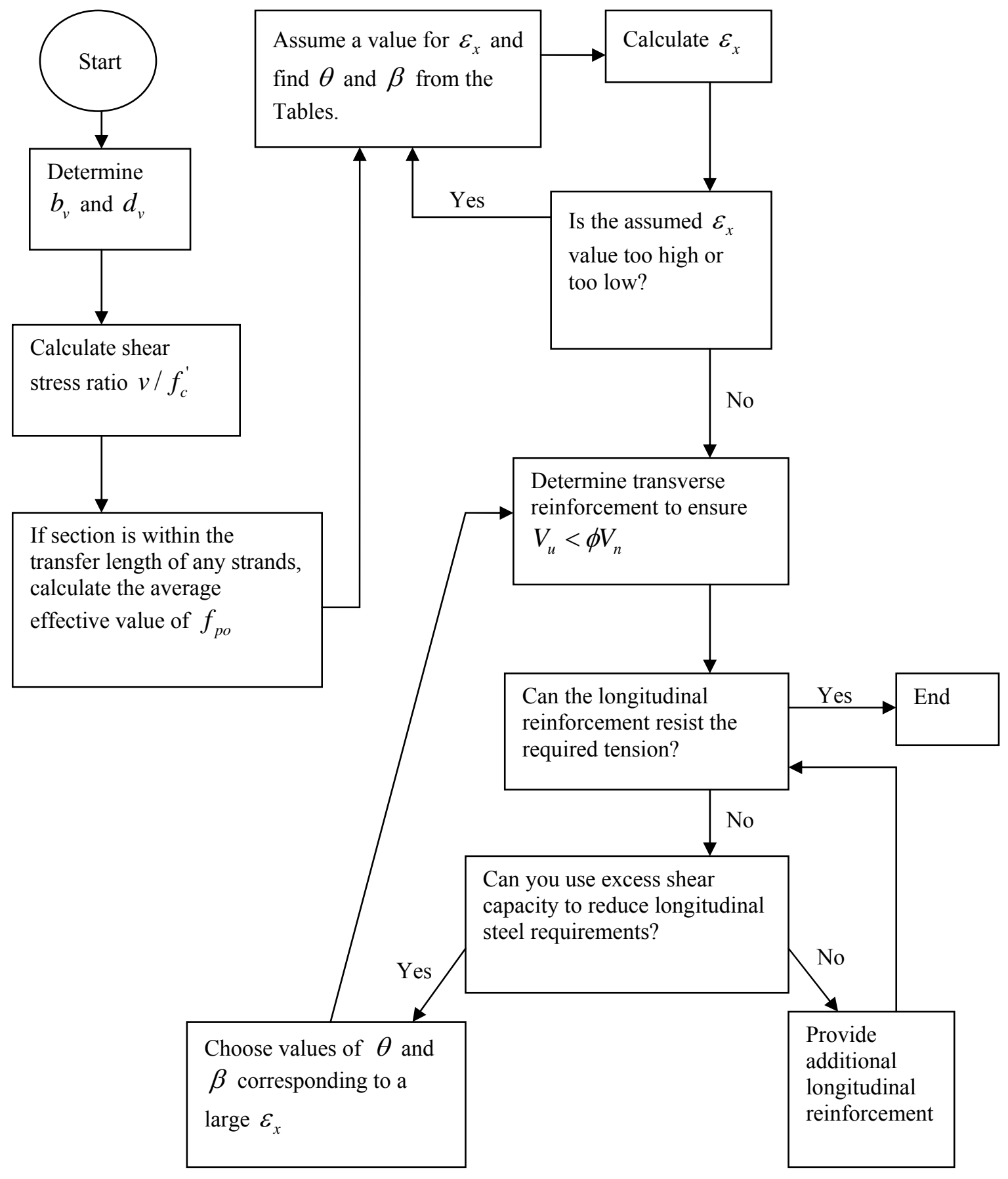

Figure 2.9 Flowchart for AASHTO design for shear reinforcement (NCHRP, 2005) 


\subsubsection{Canadian Standards Association, CSA A23.3-04}

The Canadian Standards Association gives the following formulas to calculate the shear strength of a section using their general method. Note that equations are in psi and inch units, with all notation defined in the previous sections.

$$
\begin{gathered}
V_{n}=V_{c}+V_{s}+V_{p} \\
V_{n, \max }=0.25 f_{c}^{\prime} b_{w} d_{v}+V_{p} \\
V_{c}=\beta \sqrt{f_{c}^{\prime}} b_{v} d_{v} \\
\beta=\frac{4.8}{1+1500 \varepsilon_{x}} * \frac{51}{39+s_{x e}} \\
\frac{s_{x e}=12 \text { inches for } A_{v} \geq A_{v, \text { min }}}{M_{u}}+0.5 N_{u}+V_{u}-V_{p}-A_{p} f_{p o} \\
2\left(E_{s} A_{s}+E_{p} A_{p}\right) \\
V_{s}=\frac{A_{v} f_{y} d_{v} \cot \theta}{s} \\
\theta=29+7000 \varepsilon_{x} \\
A_{v, \text { min }}=0.72 \sqrt{f_{c}^{\prime}} \frac{b_{v} s}{f_{y}}
\end{gathered}
$$

Eqn. 2.29

Eqn. 2.30

Eqn. 2.31

Eqn. 2.32

Eqn. 2.33

Eqn. 2.34

Eqn. 2.35

Eqn. 2.36 


\subsection{EXPERIMENTAL PROGRAM}

\subsection{Introduction}

This chapter describes the experimental program undertaken at the Constructed Facilities Laboratory on North Carolina State University's Centennial Campus, located in Raleigh, NC. The program was designed to investigate the behavior of high performance steel as shear reinforcement for flexural members. The research varied the shear strength resistance by adjusting the spacing of the transverse (shear) reinforcement and by changing the type of steel from conventional Grade 60 to high performance steel for both the transverse and longitudinal reinforcement. The type of high performance steel used in the experimental program is commercially known as MMFX Steel (Microcomposite Multistructural Formable Steel).

\subsection{Test Specimens}

The experimental program consisted of nine reinforced concrete beams divided into three main categories according to the type of reinforcement. Within each category, beams are varied based on the level of shear reinforcement by changing the stirrup spacing. All beams have nominal cross-sectional dimensions of 12 "x $16^{\prime \prime}$ with a total length of 16 feet, and were designed to have a nominal concrete compressive strength of 4000 psi. The total length was selected in order to have one test at each end of the beam, and thus double the test data. Detailed information about the test setup is described in Section 3.4. The stirrup spacing was varied to reflect a minimum, intermediate, and maximum level as allowed by the ACI Code. 
In addition, all stirrups were of $\# 3$ bar size. The complete test program matrix is given in Table 3.1.

Table 3.1: Test program matrix

\begin{tabular}{|c|c|c|c|c|}
\hline Beam ID & $\begin{array}{c}\text { Reinforcement } \\
\text { Level }\end{array}$ & $\begin{array}{l}\text { Longitudinal } \\
\text { Steel }\end{array}$ & $\begin{array}{c}\text { Stirrups } \\
(\# 3)\end{array}$ & $s$ (in) \\
\hline$C-C-6$ & Minimum & \multirow{3}{*}{ Conventional } & \multirow{3}{*}{ Conventional } & 6 \\
\hline C-C-4 & Intermediate & & & 4 \\
\hline $\mathrm{C}-\mathrm{C}-3$ & Maximum & & & 3 \\
\hline C-M-6 & Minimum & \multirow{3}{*}{ Conventional } & \multirow{3}{*}{ MMFX } & 6 \\
\hline C-M-4 & Intermediate & & & 4 \\
\hline $\mathrm{C}-\mathrm{M}-3$ & Maximum & & & 3 \\
\hline$M-M-6$ & Minimum & \multirow{3}{*}{ MMFX } & \multirow{3}{*}{ MMFX } & 6 \\
\hline M-M-4 & Intermediate & & & 4 \\
\hline M-M-3 & Maximum & & & 3 \\
\hline
\end{tabular}

Beams are labeled using three parameters: type of longitudinal steel, type of transverse steel, and the spacing of the transverse steel. The first letter indicates the type of longitudinal reinforcement, where " $\mathrm{C}$ " indicates conventional Grade 60 steel while "M" represents MMFX steel. The second letter indicates the type of shear reinforcement, where "C" indicates conventional Grade 60 steel while " $\mathrm{M}$ " represents MMFX steel. The third parameter indicates the spacing of the transverse reinforcement in inches. Because each beam was tested twice, the repeated test is labeled with the letter "R". For example, beam C-M-4 contains conventional longitudinal steel with MMFX stirrups spaced at four inches center to center.

The minimum reinforcement level is based on the maximum allowable spacing specified by the ACI Code 11.5.5.1, which is $\mathrm{d} / 2$. This value was also compared to $s_{\max }$ as calculated from Eqn. 2.18. The controlling size from these two calculations was 6.25 inches, 
but 6 inches was used in order to simplify the construction process. The maximum reinforcement level is based on the allowable spacing given in the ACI Code 11.5.5.3, which is $\mathrm{d} / 4$. This value is also subject to ACI 11.5.7.9 which restricts the steel contribution to $V_{s}=8 \sqrt{f_{c}^{\prime}} b_{w} d$. The maximum reinforcement level was controlled by $\mathrm{d} / 4$, which approximately equals 3 inches. The intermediate level was arbitrarily chosen in order to generate behavior somewhere in between the minimum and maximum levels. This spacing was selected to be 4 inches. The nominal capacity of the beam $V_{n}$ can then be determined by Eqn. 2.15, 2.17, and 2.19.

Flexural reinforcement was designed to allow the high performance stirrups to achieve a stress level of $80 \mathrm{ksi}$ or greater. This was accomplished by using a yield strength $f_{y}$ of $100 \mathrm{ksi}$ in Eqn. 2.19 to determine the nominal shear resistance $V_{n}$, and the corresponding moment capacity. The moment was determined using the ACI stress block parameters. Figure 3.1 shows the ACI stress block in comparison to using the actual nonlinear characteristics of the concrete in the compression zone. 


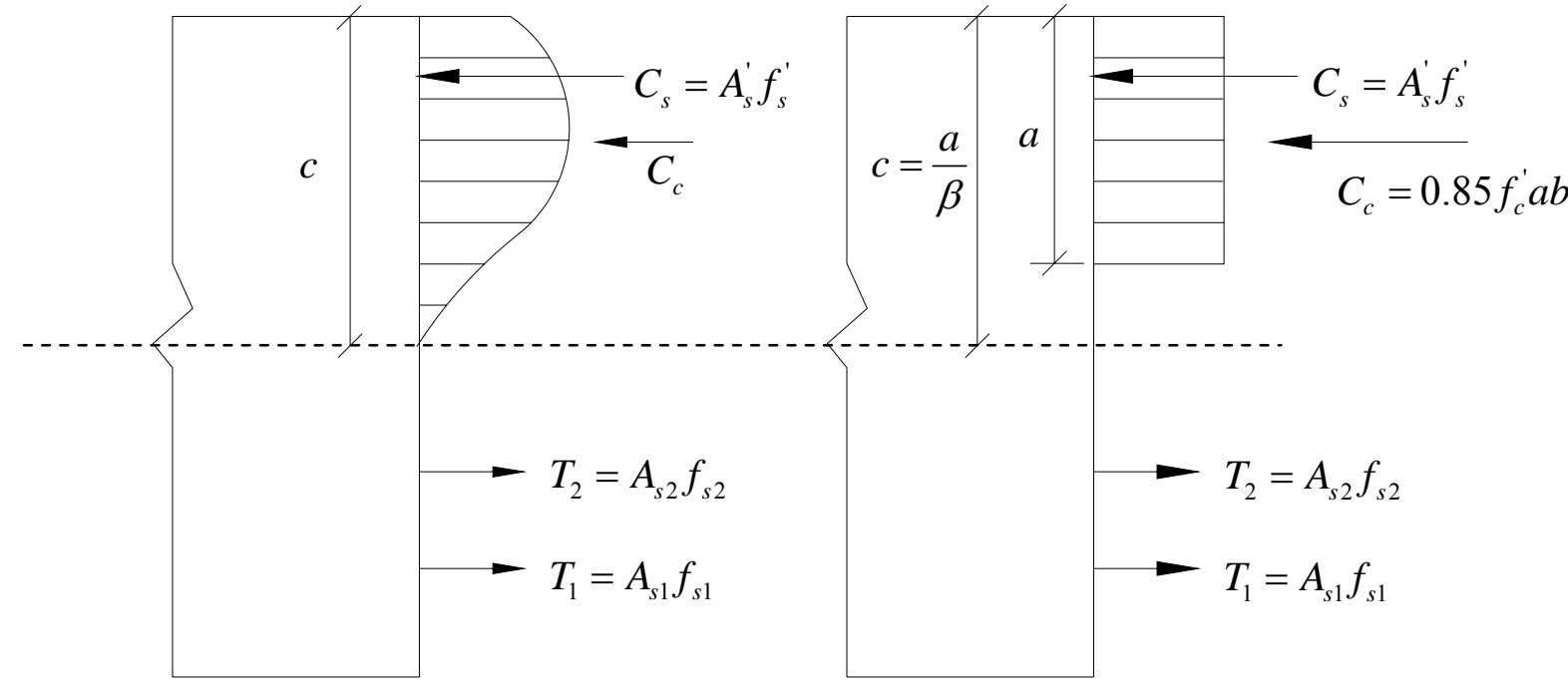

(a) Actual

(b) ACI equivalent

Figure 3.1: ACl stress block

A high longitudinal reinforcement ratio was selected to prevent premature flexural failure. All beams were provided with the same reinforcement ratio in order to keep the effect of dowel action constant. Two layers of three \#9 bars were used in the bottom and one layer of three \#9 bars was used in the top. The cover of concrete is defined to be the distance from the concrete surface to the bottom surface of the stirrups, and was selected to be 1.5 " as recommended by the ACI Code Section 7.7. Figure 3.2 illustrates a typical cross section of each beam.
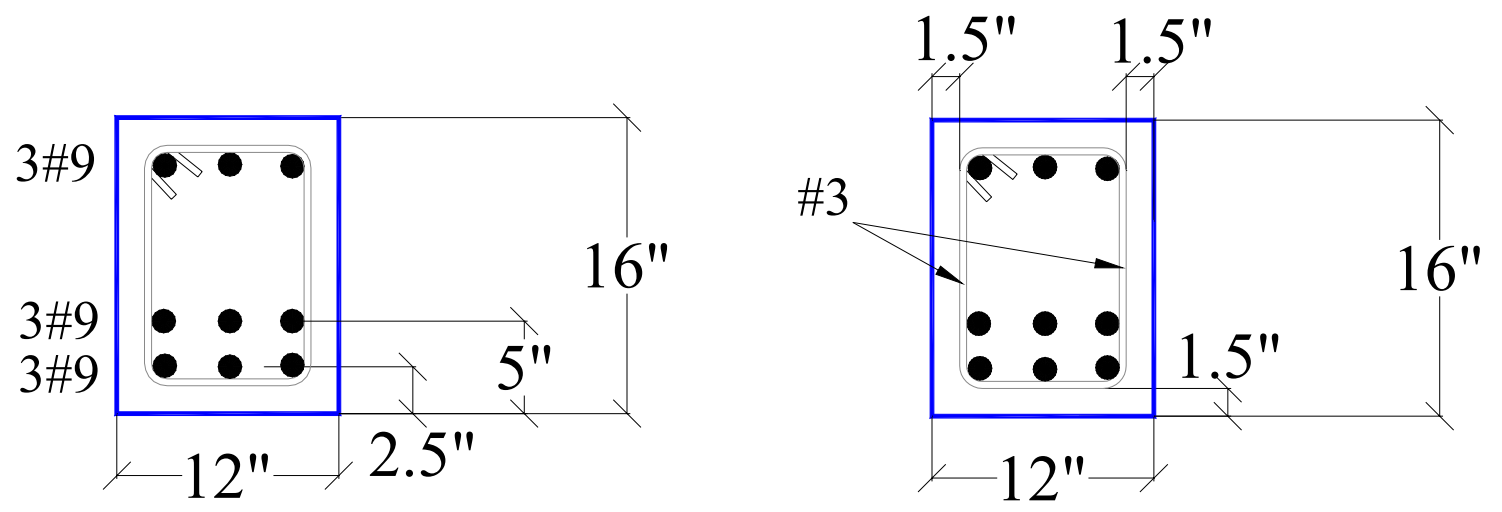

Figure 3.2: Beam cross-section 
All transverse reinforcement contained closed stirrups with hooks extending a distance of 6 bar diameters past the bend, as specified by the ACI Code Section 7.1. Longitudinal steel in the bottom layers were designed with a $90^{\circ}$ hook at the end of the bar in order to ensure proper anchorage. Combinations of Conventional-Conventional (C-C), Conventional-MMFX (C-M), and MMFX-MMFX (M-M) were used for the longitudinal and transverse reinforcement, respectively, and are given in Table 3.1. Since the longitudinal reinforcement ratios were kept constant, changes in the observed behavior are attributable to either the high performance steel or the stirrup spacing. Typical details of the reinforcement are shown in the Figure 3.3. 


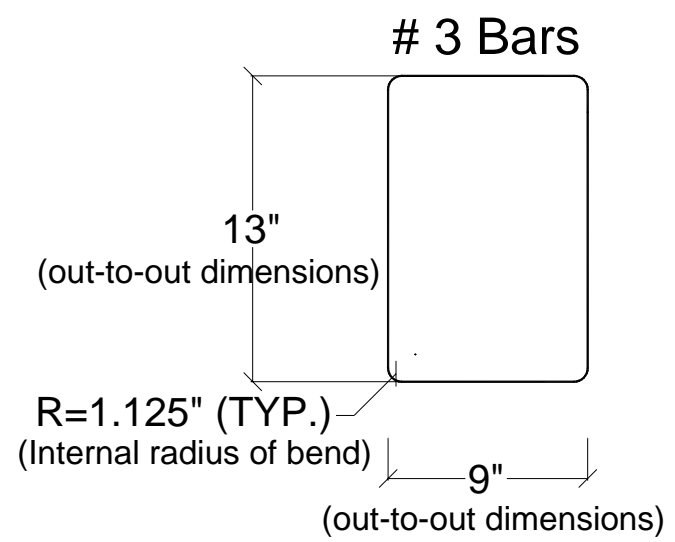

(a) Typical stirrup dimensions

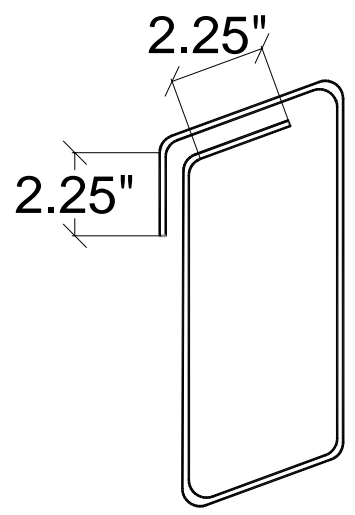

(b) Isometric view of stirrups

10" R=4.5" (internal radius of bend, TYP.) \# 9 Bars

15'-9" (out-to-out dimensions)

(c) Typical longitudinal bar with hook (bottom layer, bottom bar)

6" $\mathrm{R}=4.5^{\prime \prime}$ (internal radius of bend, TYP.) \# 9 Bars 15'-4" (out-to-out dimensions)

(d) Typical longitudinal bar with hook (bottom layer, top bar)

\# 9 Bars $15^{\prime}-9 "$

(e) Typical longitudinal bar without hook (top layer)

Figure 3.3: Typical reinforcement dimensions 


\subsection{Fabrication of the Specimens}

The test specimens were fabricated at the Constructed Facilities Laboratory. First, the steel beam cages were tied together before being placed into steel-ply forms, as shown in Figure 3.4.

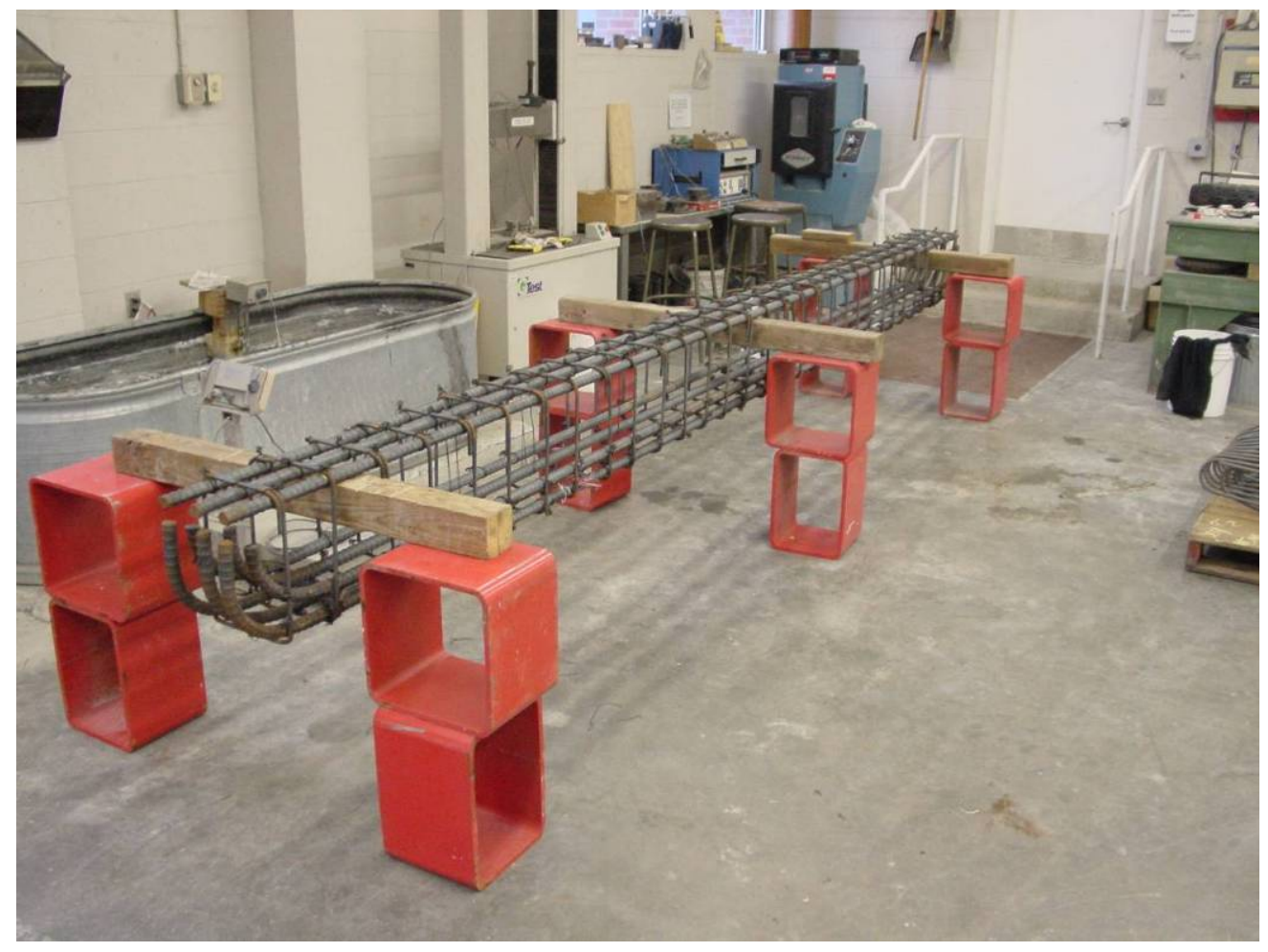

Figure 3.4: Finished beam cage

A specially designed casting bed located outside of the CFL was used for casting concrete inside U-shaped formwork, which was set on top of the bed. Instead of making forms out of plywood and dimension lumber, steel-ply formwork was rented through a local company. After formwork was erected, the inside surfaces were treated with a form release agent in order to facilitate stripping of the form. Each concrete cast consisted of three beams at a time, with a total of three casts. Figure 3.5 depicts the erected formwork with the steel cages placed inside, ready for casting. 


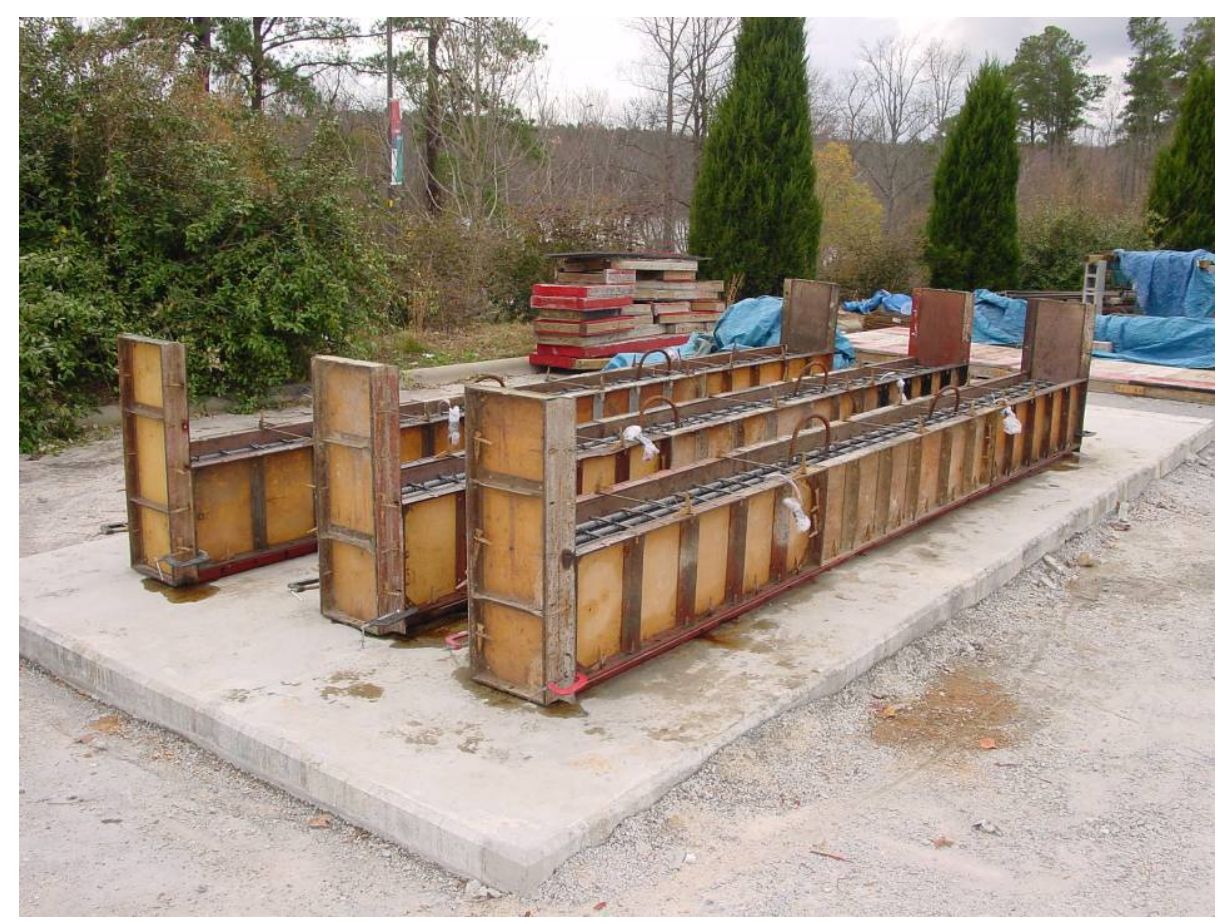

Figure 3.5: Casting bed with prepared formwork

The concrete was supplied by a ready mix concrete company and cast directly into the forms. An internal electric vibrator was used to consolidate the concrete during casting before the surface was leveled. The concrete beams were left on the casting bed and covered with wet burlap, plastic, and a tarp for approximately three days to allow for curing. Extra precaution was taken after casting to protect the fresh concrete from exposure to freezing overnight temperatures. Once the beams were removed from the forms, they were kept until reaching 28-day strength and ready for testing. Figure 3.6 shows two pictures depicting the beams just after casting and as they were covered during curing. 

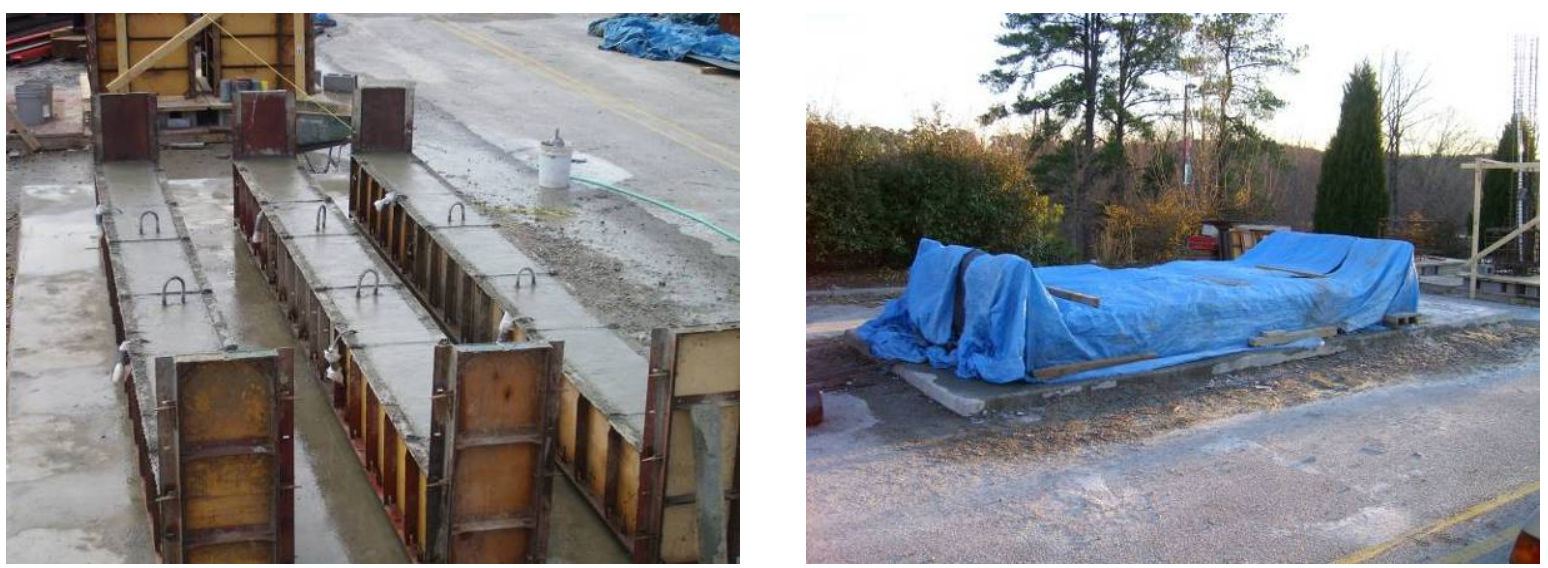

Figure 3.6: Casting pictures

Table 3.2 shows the casting and testing matrix represented by Set 1, Set 2, and Set 3, respectively, and the average concrete strength at the time of testing.

Table 3.2: Specimen casting matrix

\begin{tabular}{|c|c|c|c|c|}
\hline & $\begin{array}{l}\text { Beam } \\
\text { ID }\end{array}$ & $\begin{array}{l}\text { Spacing } \\
\text { (in) }\end{array}$ & $a / d$ & $\begin{array}{c}f_{c}{ }^{\prime} \\
\text { (psi) }\end{array}$ \\
\hline \multirow{3}{*}{ Set 1} & C-C-6 & \multirow{3}{*}{6} & \multirow{3}{*}{2.62} & 3904 \\
\hline & C-M-6 & & & 4282 \\
\hline & M-M-6 & & & 4660 \\
\hline \multirow{3}{*}{ Set 2} & C-C-4 & \multirow{3}{*}{4} & \multirow{3}{*}{3.08} & 4390 \\
\hline & C-M-4 & & & 4547 \\
\hline & M-M-4 & & & 4704 \\
\hline \multirow{3}{*}{ Set 3} & C-C-3 & \multirow{3}{*}{3} & \multirow{3}{*}{3.08} & 4730 \\
\hline & C-M-3 & & & 4730 \\
\hline & M-M-3 & & & 4730 \\
\hline
\end{tabular}




\subsection{Test Setup}

The test setup was designed so that each beam could be tested twice. The setup also had two configurations in order to observe the effect of the shear span to depth ratio $(\mathrm{a} / \mathrm{d})$ on the behavior, where $d=13$ inches. The first setup was used for beams in Set 1, where they were tested using a shear span to depth ratio $(\mathrm{a} / \mathrm{d})$ of 2.62 . It consisted of a single point load located at 34 inches from one end and 99 inches to the other end. The second setup was used for Set 2 and Set 3, and had an a/d ratio of 3.08. It consisted of a single point load located at 40 inches to one end and 81 inches to the other end. The remaining portion of the beam was cantilevered, and therefore, unstressed. After completion of the first test, the beam was rotated to test the remaining virgin portion. Pictures of the first and second test setup are shown in Figure 3.7 and Figure 3.8, respectively.

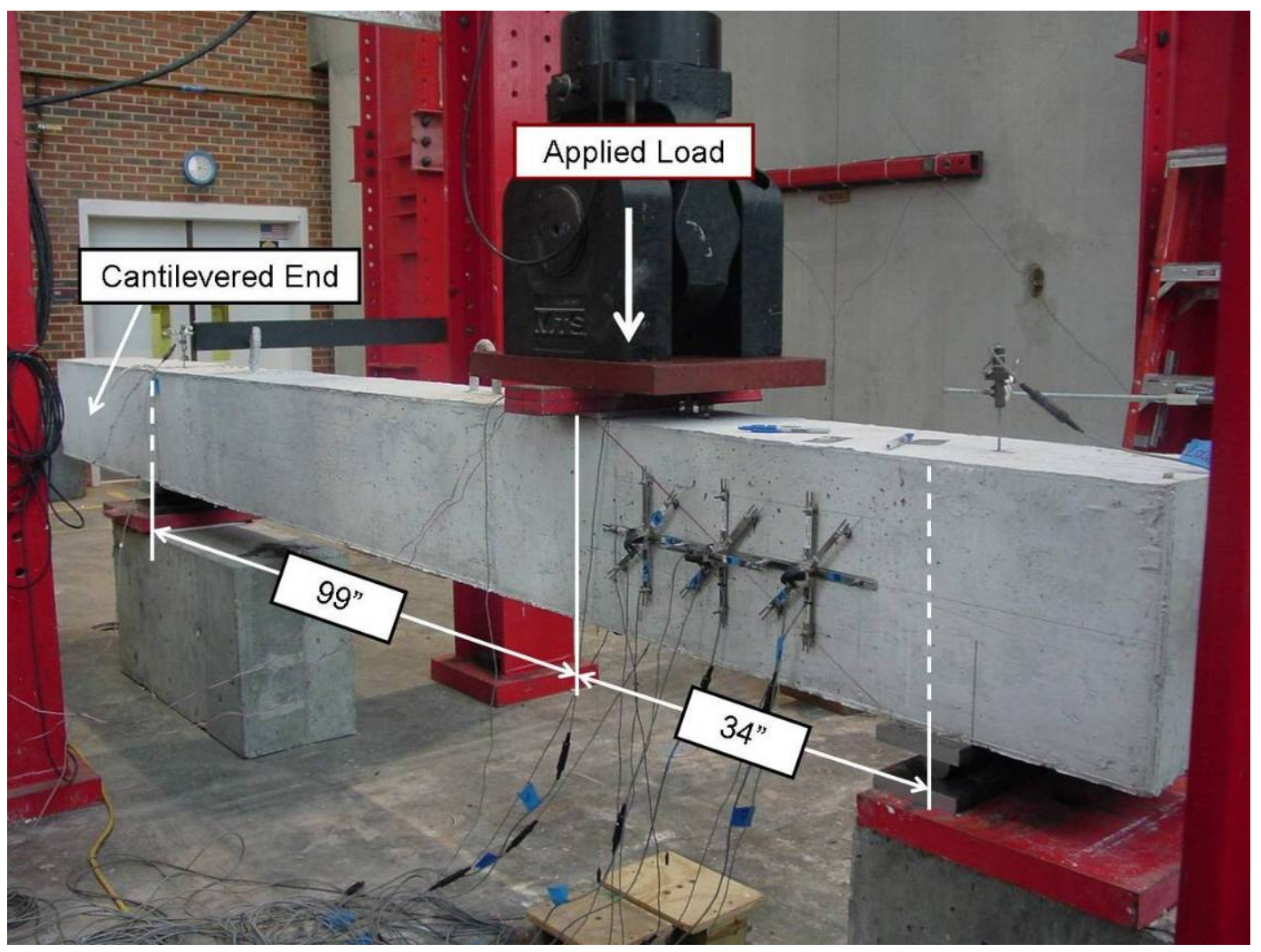

Figure 3.7: Test setup 1 


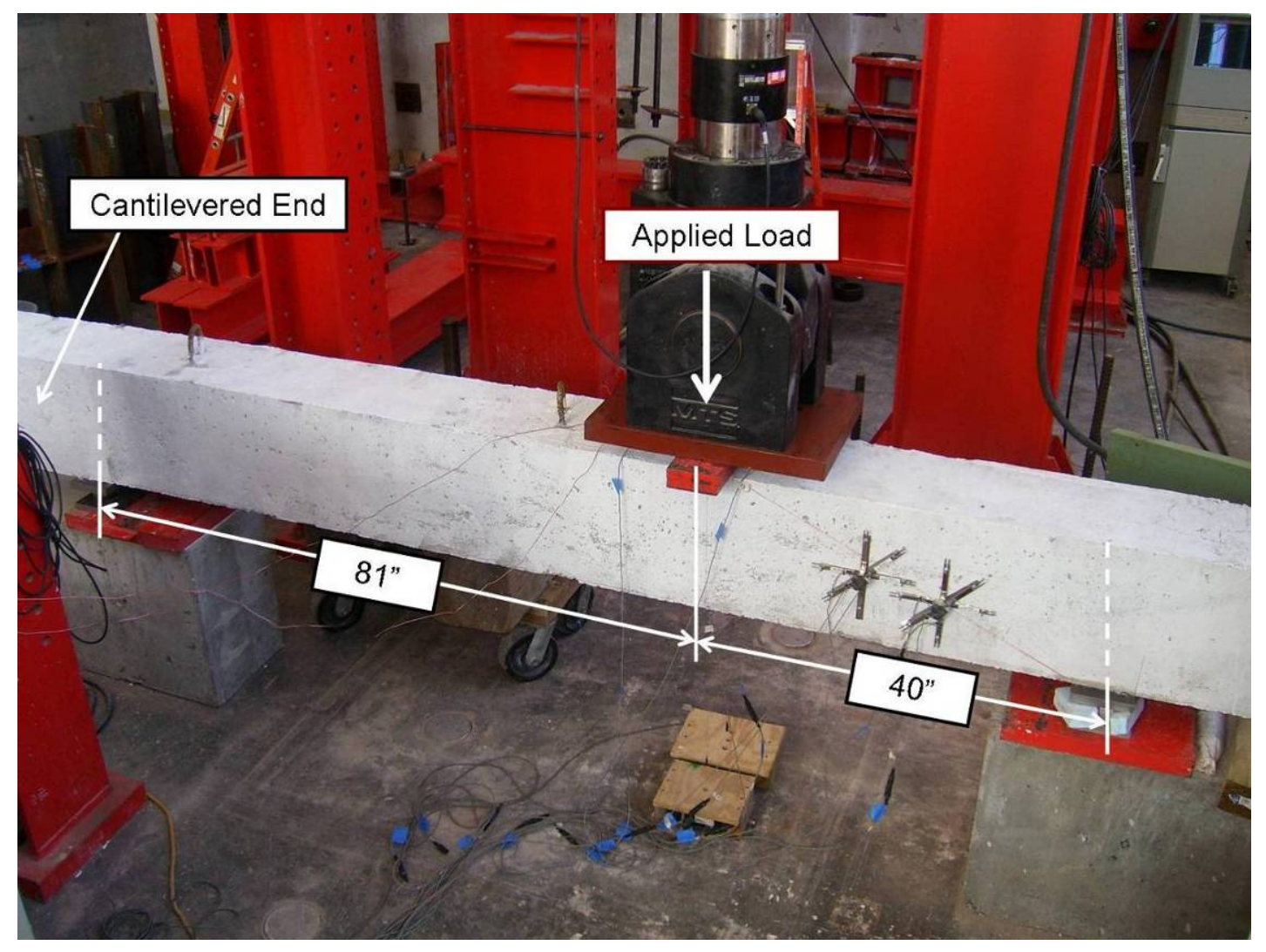

Figure 3.8: Test setup 2

The loads were applied using a 220-kip capacity hydraulic actuator supported by a steel testing frame, which was securely anchored to the strong floor. The load was then transferred through two steel loading plates which measured 1" thick and 5" wide. The beam was supported on steel plates measuring 1" thick and 6" wide, with one steel roller in between. This served to idealize a pin and roller condition. The support was located on the top of concrete blocks which were securely anchored to the strong floor. Figure 3.9 shows the upper portion of the test frame with the actuator attached. 


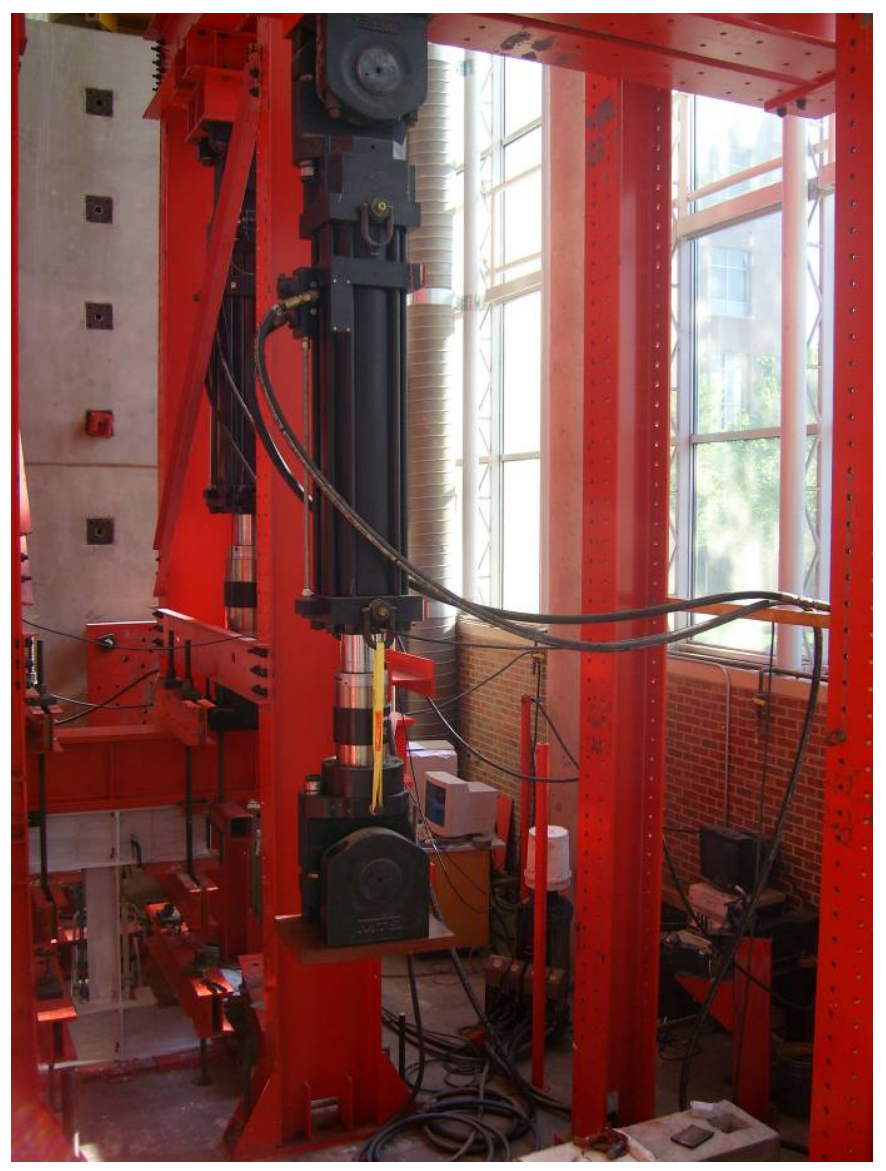

Figure 3.9: Test frame

\subsection{Instrumentation}

The applied load was measured by a load cell while the crack widths, steel strains, and deflection were measured using PI gages, electrical resistance strain gages, and string pots, respectively. For the first two tests, linear potentiometers were positioned over the supports in order to measure any support deflection. These instruments were later omitted from future tests since no deflection was detected.

The PI gages included two rosettes attached to the side of the beam to measure the crack widths and corresponding strains. Each rosette consisted of three 200-mm PI gages with one placed horizontal, one placed vertical, and one placed diagonally at a $45^{\circ}$ angle. 
Initial tests used three PI gage rosettes placed side by side to ensure that the diagonal crack was captured, as shown previously in Figure 3.7. After the experience of two tests, the location of the main diagonal crack was easily predicted and the number of rosettes was reduced to only two. Instead of placing them side by side, however, the rosettes were slightly staggered. This resulted in the reduction of test setup time while still capturing the main cracks. Two 100-mm PI gages were also placed on the top surface of the beam, at either side of the loading plate, to measure the top concrete strain. An additional two 100$\mathrm{mm}$ PI gages and two string pots were placed on the bottom surface of the beam, directly below the load point, to measure the bottom concrete strain and deflection, respectively. An overview of the instrumentation is shown in Figure 3.10.

Two electrical strain gages were placed on the bottom layer of the longitudinal rebars at approximately the location of the applied load, and were used to measure the longitudinal strain. They were covered by black mastic tape in order to protect and waterproof the gages after affixing them to the rebar. A picture of a finished strain gage attached to the cage is shown in Figure 3.11. No strain gages were attached to the transverse steel, and external PI gages were used instead to measure the corresponding strains. The reason for this is twofold:

1. Strain gages can only capture the local conditions, so if they are not perfectly located at where the diagonal crack develops then the measured strain could be much lower than the average.

2. Using a strain gage would require a significant amount of the stirrup to be de-bonded in order to protect the gage, and could therefore influence behavior. 


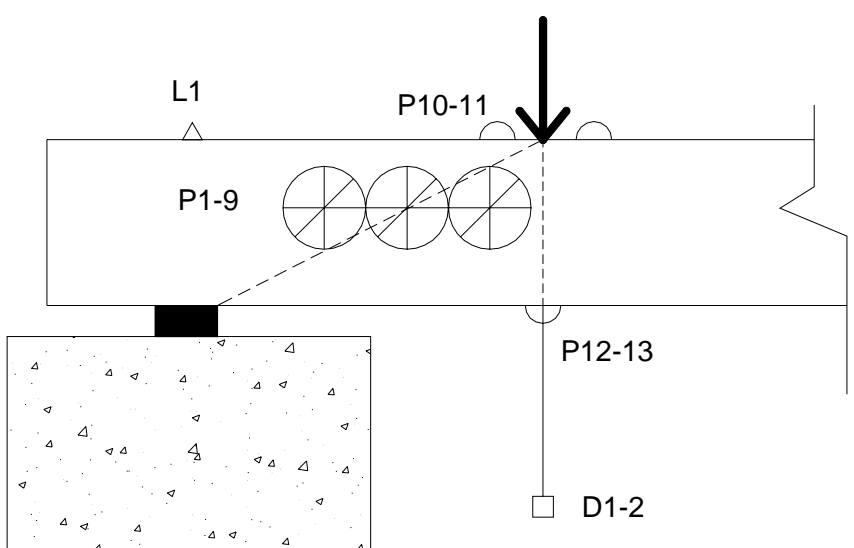

(a) Side view - 3 Rosettes

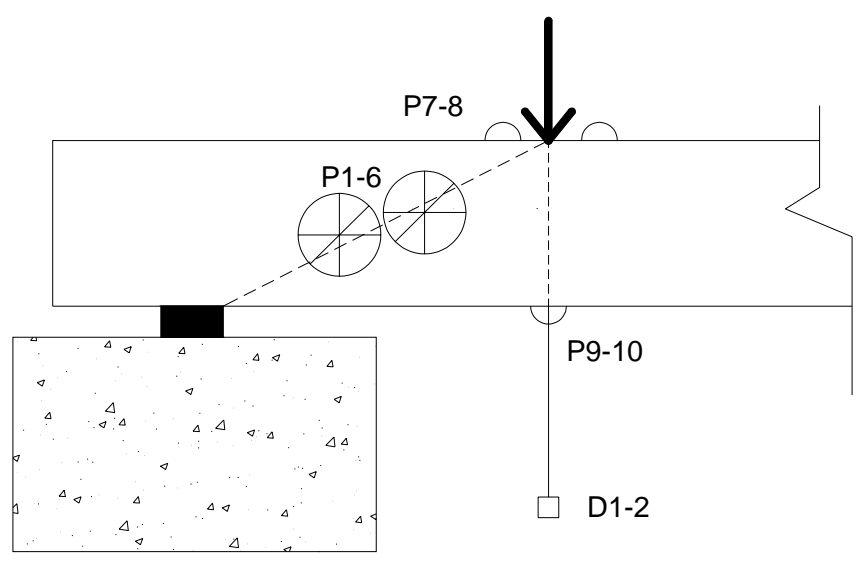

(b) Side view - 2 Rosettes

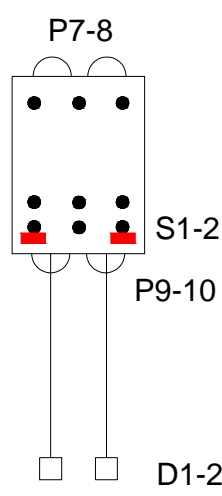

(c) Typical cross section
- Strain gages

Pi-gage

Pi-gage rosette

Linear potentiometer

String Pot

(d) Legend

Figure 3.10: Instrumentation 


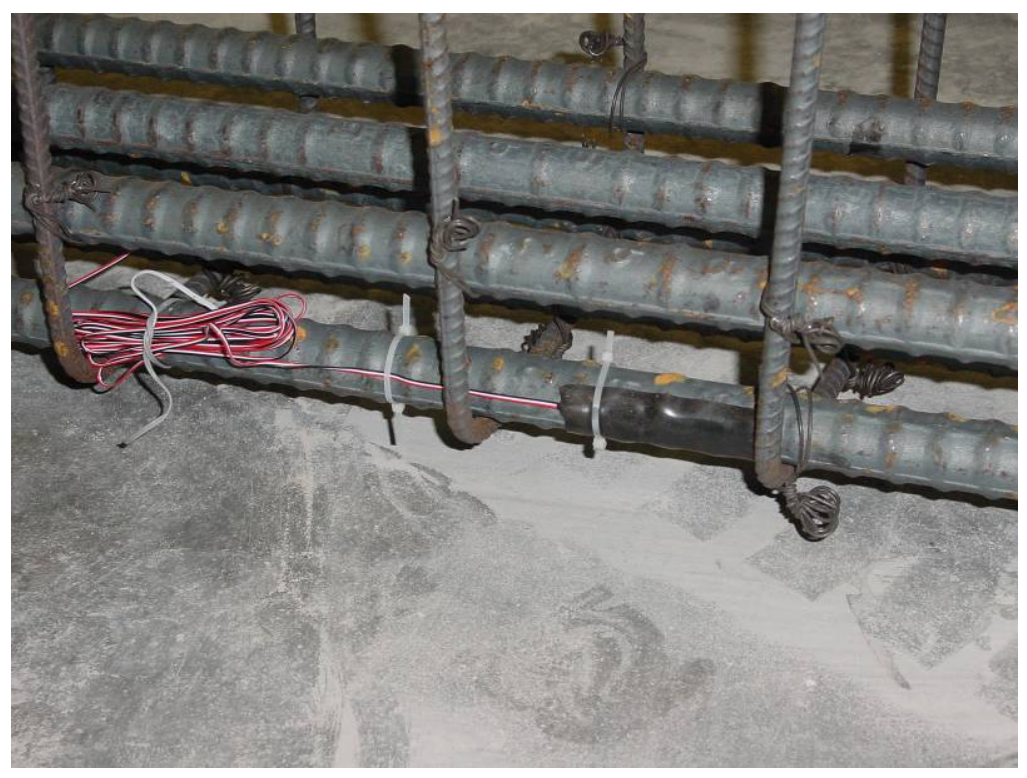

Figure 3.11: Strain gage

\subsection{Test Procedure}

Load was applied by a MTS actuator using an electronically controlled system. The loading was paused at increments of 15 kips to allow visual inspection of the beam, mark cracks, measure crack widths, and take photographs. In order to track the cracks, a red chalk grid was snapped on the side of the beam without instrumentation.

There were two methods of loading the beam: load-controlled or displacementcontrolled. The load-controlled method was used during most of the loading and is done by specifying a certain load over a given time increment. For this research, the rate was chosen to be 15 kips per 300 seconds. However, there is a potential for the actuator to rapidly increase stroke while it attempts to find the correct load if a beam suddenly fails. Therefore, the loading method was switched to displacement-controlled when it was observed that the beam was getting closer to failure. Displacement-controlled loading is done by specifying a certain displacement over a given time increment, which was measured as 0.05 inches per 
150 seconds for this research. The instrumentation readings were captured using a Vishay data acquisition system set to a rate of 1 scan per second. A typical test would last about 1.5 hours.

\subsection{Material Property Testing}

In order to accurately analyze the test data, it was necessary to determine the material properties of the concrete and reinforcing steel.

\subsubsection{Concrete}

For each concrete cast, fifteen 4" 8 " concrete cylinders were prepared in accordance with ASTM C31 and stored next to the beams to simulate actual curing conditions. The concrete used Type I Portland Cement with a specified aggregate size of $3 / 8$ ". This aggregate size was chosen due to the congestion of the steel rebar cage, and thus to ensure proper distribution and flow of aggregate particles. A slump test was also performed during casting to ensure that the concrete had adequate flow characteristics.

Three cylinders were tested after seven days, fourteen days, and twenty-eight days. Since nine cylinders were already used, only six cylinders remained to estimate the strengths of the experimental beams. Therefore, three cylinders were tested on the same day that the first beam in a set was tested, and three on the same day that the third beam was tested. The strength of concrete for the second beam was determined by considering the average of the first and the third beam. It should be noted that for Set 3 beams, which were tested within one week, the average concrete strength was used as the strength for all beams. 
Cylinder tests were performed using a 500-kip Forney compression testing machine at a rate of 35,000-50,000 lb/min, and in accordance with ASTM C39. Neoprene caps were placed on the ends of each cylinder in order to ensure an even distribution of force during testing. The maximum applied load was recorded, averaged between the three cylinders, and used to determine the concrete strength. Results of the material testing are given in Section 4.1, and pictures of the cylinder testing are shown in Figure 3.12.
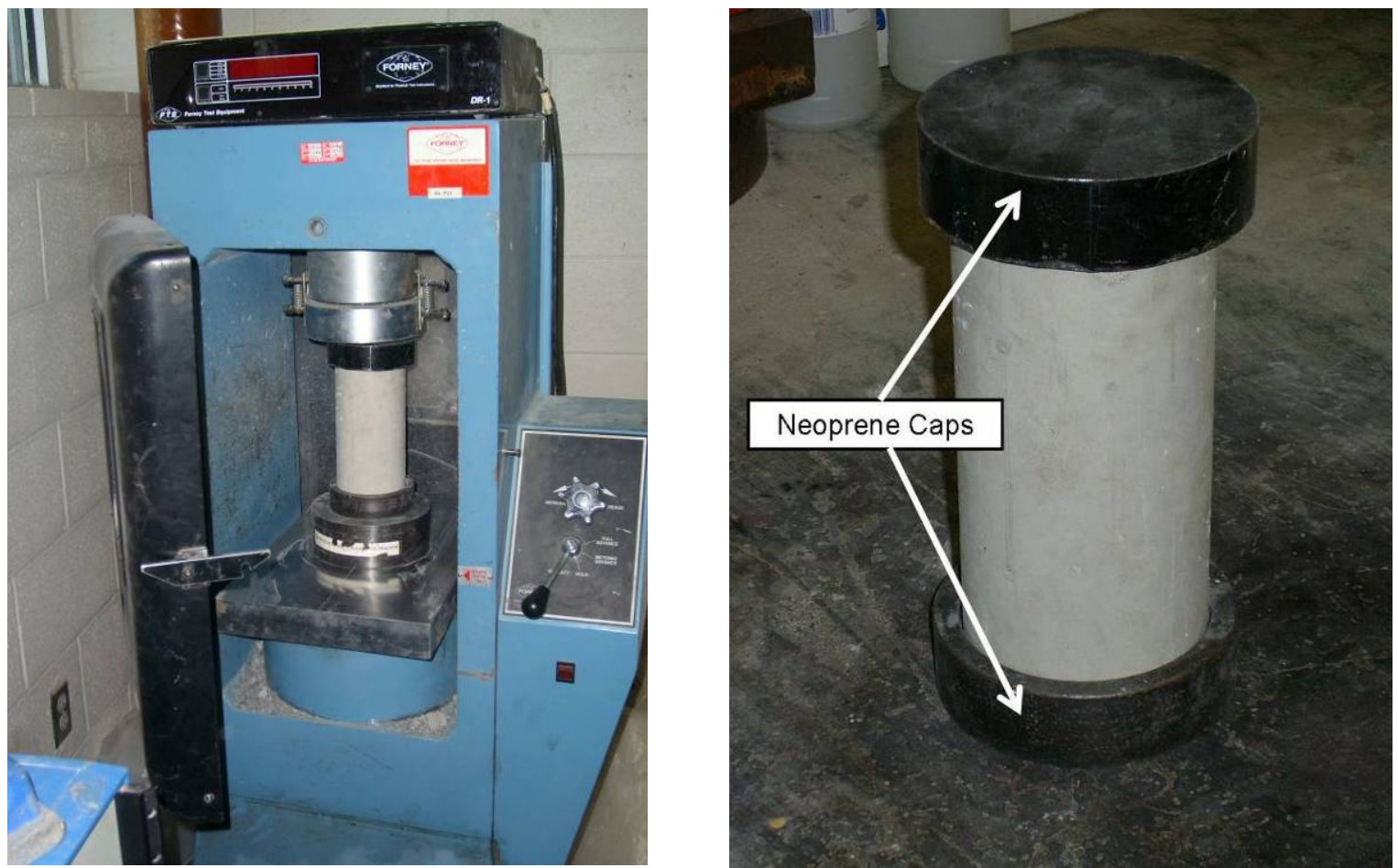

Figure 3.12: Concrete cylinder testing

\subsubsection{Steel}

In order to determine the stress-strain characteristics of reinforcing steel coupons, tension tests were performed in accordance with ASTM A370. Samples of the \#9 conventional Grade 60 steel and \#9 MMFX steel were taken from the same bars used to 
fabricate the beams. No. 3 bars, used for the stirrups, could not be tested since its length was inadequate to provide for an appropriate tension coupon. Three coupons were tested for the Grade 60 and the MMFX steel each, and an extensometer was attached to the tension coupon to measure elongation. The load and stroke were also measured, and all data was captured using an Optim data acquisition system.

Up to the yield strength, the rate used was 0.5 inches per minute of the distance between the grips $(0.5 \mathrm{in} / \mathrm{min} / \mathrm{in})$. After yielding, the rate was increased to 5 inches per minute of the distance between the grips ( $5 \mathrm{in} / \mathrm{min} / \mathrm{in})$. Because the MMFX bar does not have a well defined yield point, the loading was kept at a constant rate of 0.5 inches per minute of the distance between the grips. The bars were then loaded until failure, whereupon the specimen was removed from the machine, a new specimen was inserted, and the test repeated. Figure 3.13 shows a typical tension test.

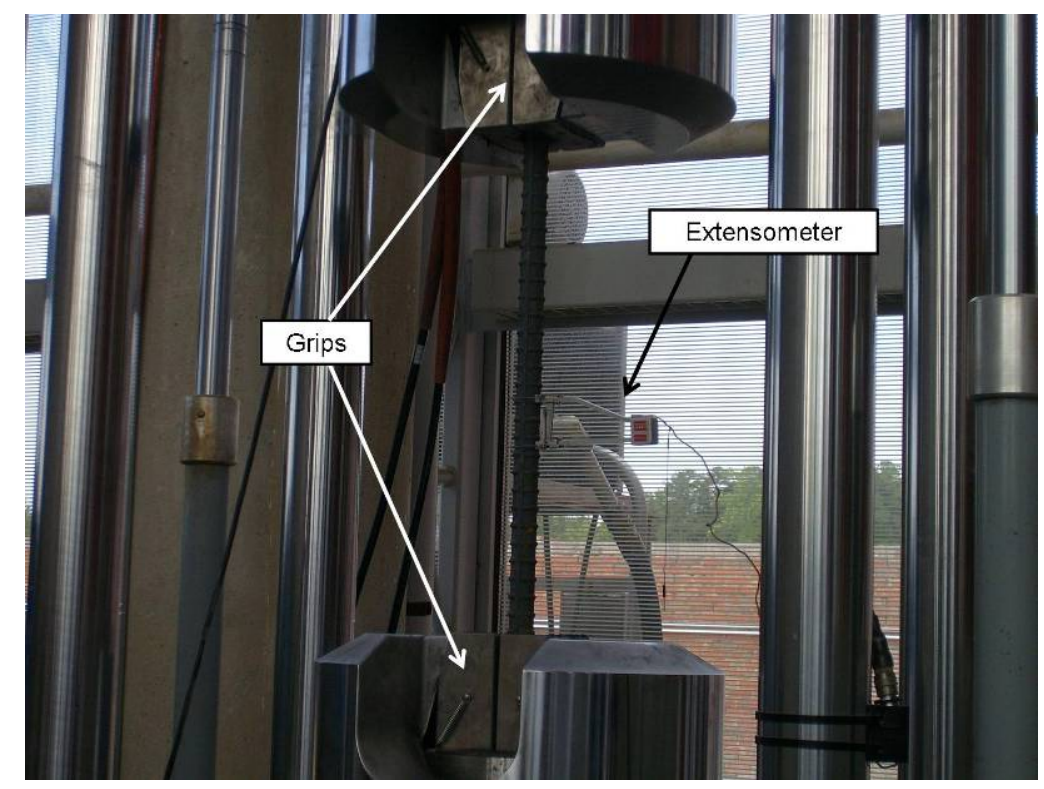

Figure 3.13: Tension tests of the \#9 bar 


\subsection{TEST RESULTS AND DISCUSSION}

This chapter summarizes the properties of materials used for fabricating the specimens, test results of the experimental program, and the overall behavior based on the measured data. The experimental program consisted of eighteen tests using nine reinforced concrete beams.

\subsection{Material Properties}

\subsubsection{Concrete}

A total of fifteen 4"x8" concrete cylinders were fabricated from each concrete patch. Cylinder testing was in accordance with ASTM C39 and occurred after seven days, fourteen days, and twenty-eight days. In order to evaluate each beam's concrete strength, three cylinders were tested on the same day that the first and third beams within a set were tested. The average concrete strengths of the first and third beams from each set were used as the concrete strength of the second beam. Table 4.1 provides test results of the measured concrete compressive strength of each beam. The actual recorded strength of each cylinder may be found in Appendix B. 
Table 4.1: Compressive strength of concrete (psi)

\begin{tabular}{|c|c|c|c|c|c|c|}
\cline { 2 - 6 } \multicolumn{1}{c|}{} & 7-day & 14-day & 28-day & Beam 1 & Beam 3 & $\begin{array}{c}\text { Beam 2 } \\
\text { (average) }\end{array}$ \\
\hline Set 1 & 2764 & 3428 & 3685 & 3904 & 4660 & 4282 \\
\hline Set 2 & 2824 & 3684 & 3593 & 4390 & 4704 & 4547 \\
\hline Set 3 & 2960 & 3138 & 4457 & 4768 & 4691 & 4730 \\
\hline
\end{tabular}

\subsubsection{Steel}

Tension coupon specimens were taken from the same steel reinforcement used to fabricate the beams, and tested in accordance with ASTM A370. The measured stress-strain relationships of the Grade 60 No. 9 bars are shown in Figure 4.1, and the measured stressstrain relationships of the MMFX steel No. 9 bars are shown in Figure 4.2.

Test results indicate that conventional Grade 60 bars have an average yield strength of $62 \mathrm{ksi}$ with an ultimate strength of $98 \mathrm{ksi}$. The initial stress-strain relationship is perfectly linear until the yield point, followed by a yielding plateau, and then non-linear strain hardening. The strain at peak stress typically occurred at 0.11 . The MMFX steel, on the other hand, experienced a linear behavior until a stress level of $80 \mathrm{ksi}$, followed by a small reduction in the elastic modulus. Non-linear behavior then occurred up to a maximum strength of $172 \mathrm{ksi}$, with a corresponding strain of 0.05 . The stress-strain relationship of the MMFX steel is modeled by the following equation:

$$
f_{s}=169\left(1-e^{-226 \varepsilon}\right) \quad \text { Eqn. } 4.1
$$


where $f_{s}$ is the stress in ksi units, and $\varepsilon$ is the strain in in/in units. Figure 4.2 shows Eqn. 4.1 along with the measured MMFX stress-strain relationship for No. 9 bars. For comparison purposes, the stress-strain curves of the Grade 60 and MMFX bars are combined in Figure 4.3.

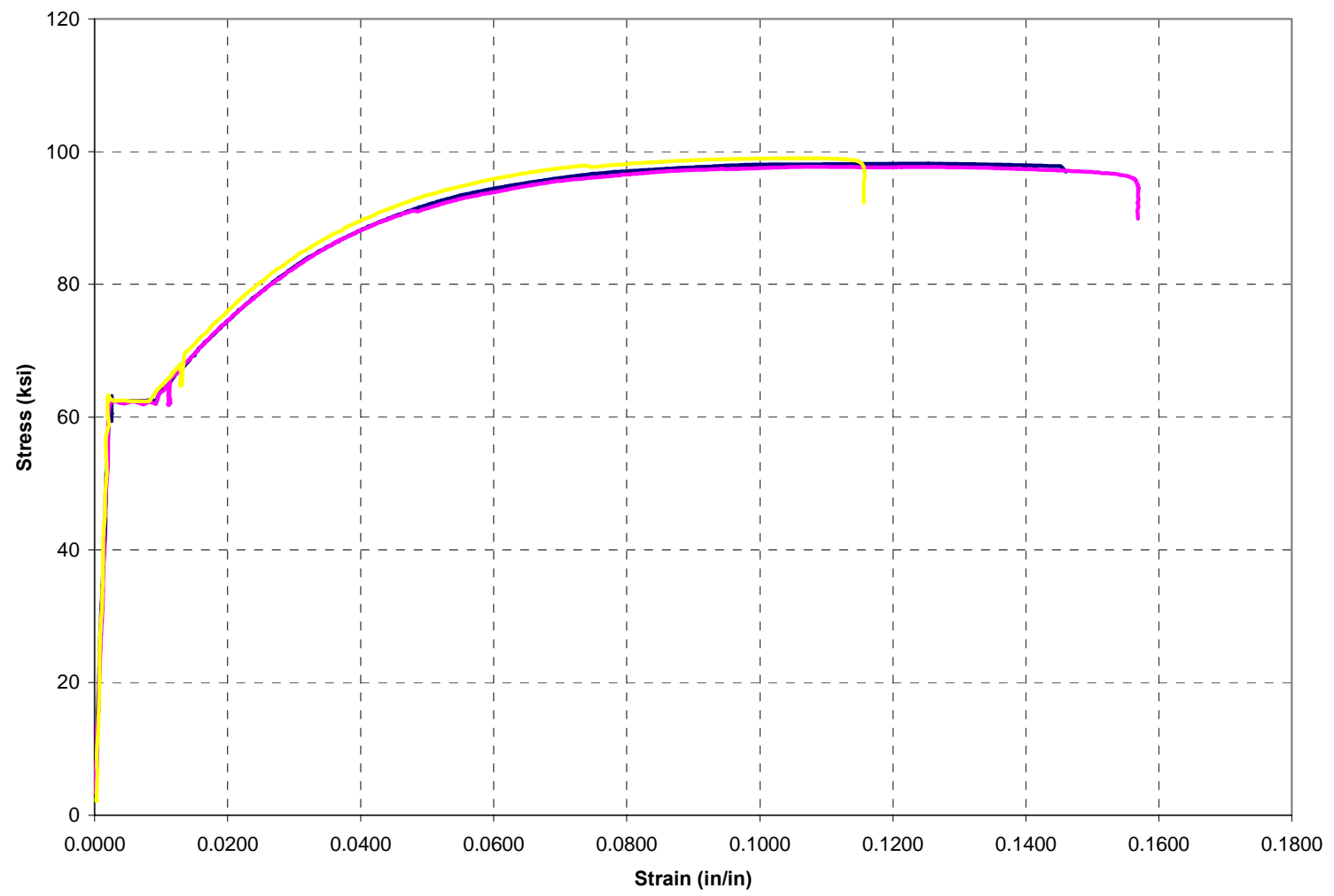

Figure 4.1: Conventional Grade 60 stress-strain relationship 


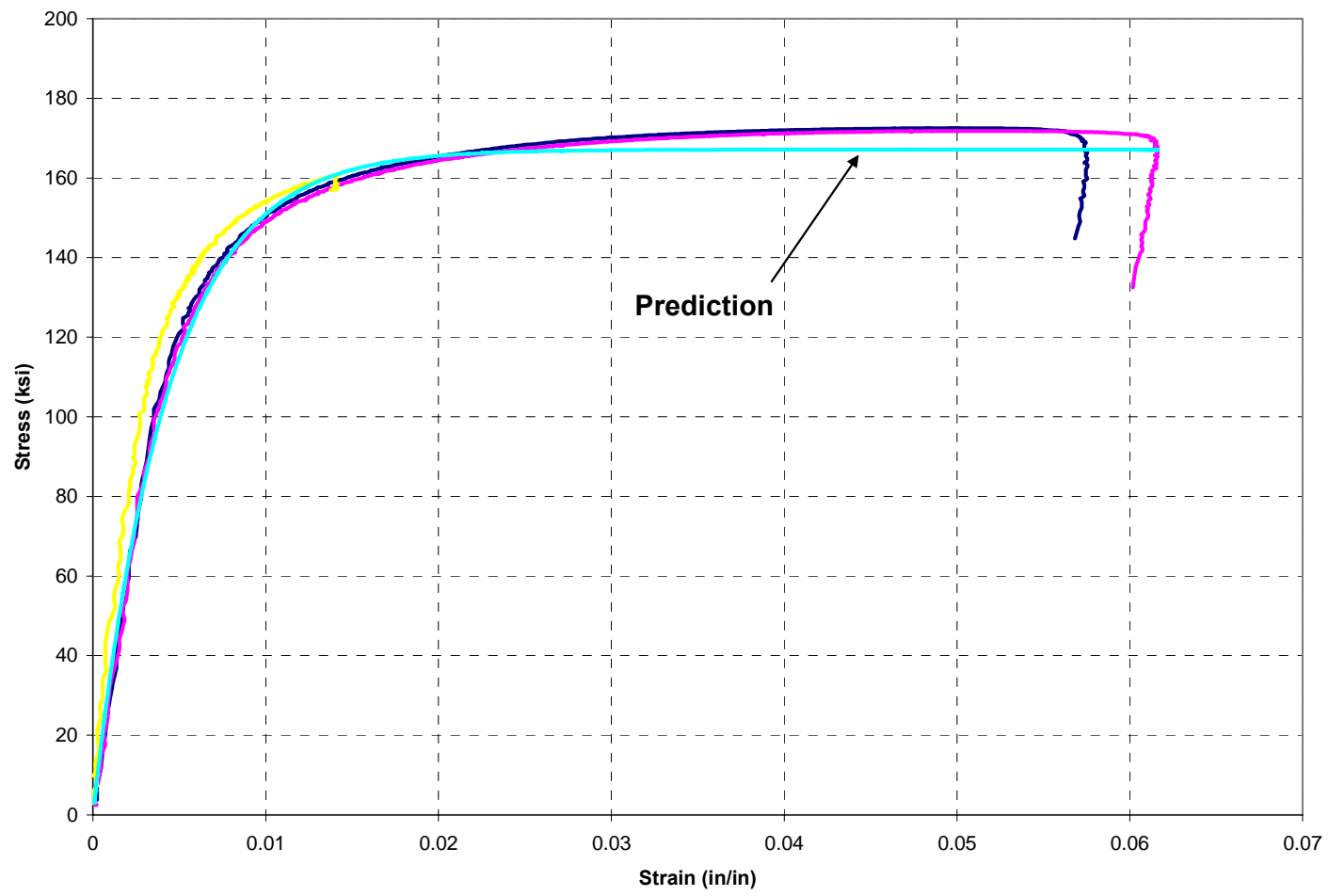

Figure 4.2: MMFX stress-strain relationship

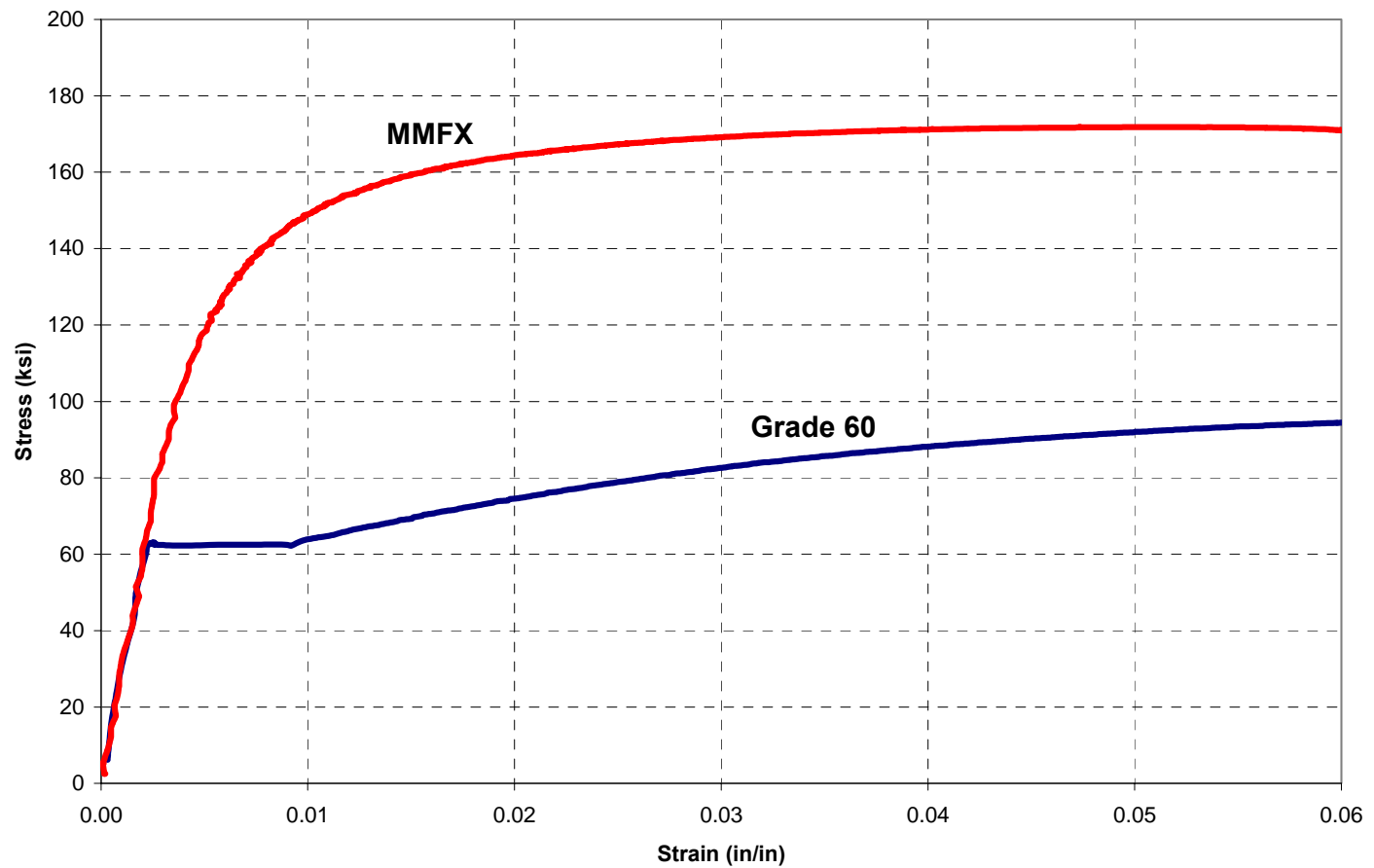

Figure 4.3: MMFX vs. G60 steel reinforcement 


\subsection{Test Beams}

As previously discussed in Section 3.4, two tests were performed on each beam specimen. Table 4.2 provides the average ultimate load for each beam, while results from each beam test are given in Appendix B.

Table 4.2: Average test results

\begin{tabular}{|c|c|c|c|c|c|c|}
\hline & $\begin{array}{l}\text { Spacing } \\
\text { (in) }\end{array}$ & $a / d$ & Beam ID & $\begin{array}{c}P_{\text {exp }} \\
\text { (kips) }\end{array}$ & $\begin{array}{c}V_{\text {exp }} \\
\text { (kips) }\end{array}$ & $\begin{array}{c}M_{\exp } \\
\text { (kip-in) }\end{array}$ \\
\hline \multirow{3}{*}{ Set 1} & \multirow{3}{*}{6} & \multirow{3}{*}{2.62} & C-C-6 & 110.0 & 81.88 & 1801 \\
\hline & & & C-M-6 & 115.6 & 86.05 & 1893 \\
\hline & & & M-M-6 & 128.8 & 95.87 & 2109 \\
\hline \multirow{3}{*}{ Set 2} & \multirow{3}{*}{4} & \multirow{3}{*}{3.08} & C-C-4 & 124.1 & 83.08 & 2326 \\
\hline & & & C-M-4 & 136.4 & 91.31 & 2557 \\
\hline & & & $M-M-4$ & 150.3 & 100.61 & 2817 \\
\hline \multirow{3}{*}{ Set 3} & \multirow{3}{*}{3} & \multirow{3}{*}{3.08} & C-C-3 & 143.5 & 96.06 & 2690 \\
\hline & & & C-M-3 & 148.5 & 99.41 & 2783 \\
\hline & & & $M-M-3$ & 160.0 & 107.11 & 2999 \\
\hline
\end{tabular}

\subsection{Shear Load-Deflection Behavior}

Typical graphs of shear load versus deflection behavior of the tested beams are given in Figure 4.4, Figure 4.5, and Figure 4.6 for beam Set 1, 2, and 3, respectively. As reported in Section 3.2, the letters " $\mathrm{C}$ " and "M" stand for conventional Grade 60 steel and MMFX steel, respectively. The first letter indicates longitudinal rebar type, the second letter indicates transverse reinforcement type, and the number indicates the spacing of transverse reinforcement in inches. For example, M-M-3 has MMFX longitudinal steel and MMFX 
stirrups spaced at three inches center to center. Failure was identified when the measured maximum load had dropped by more than $20 \%$.

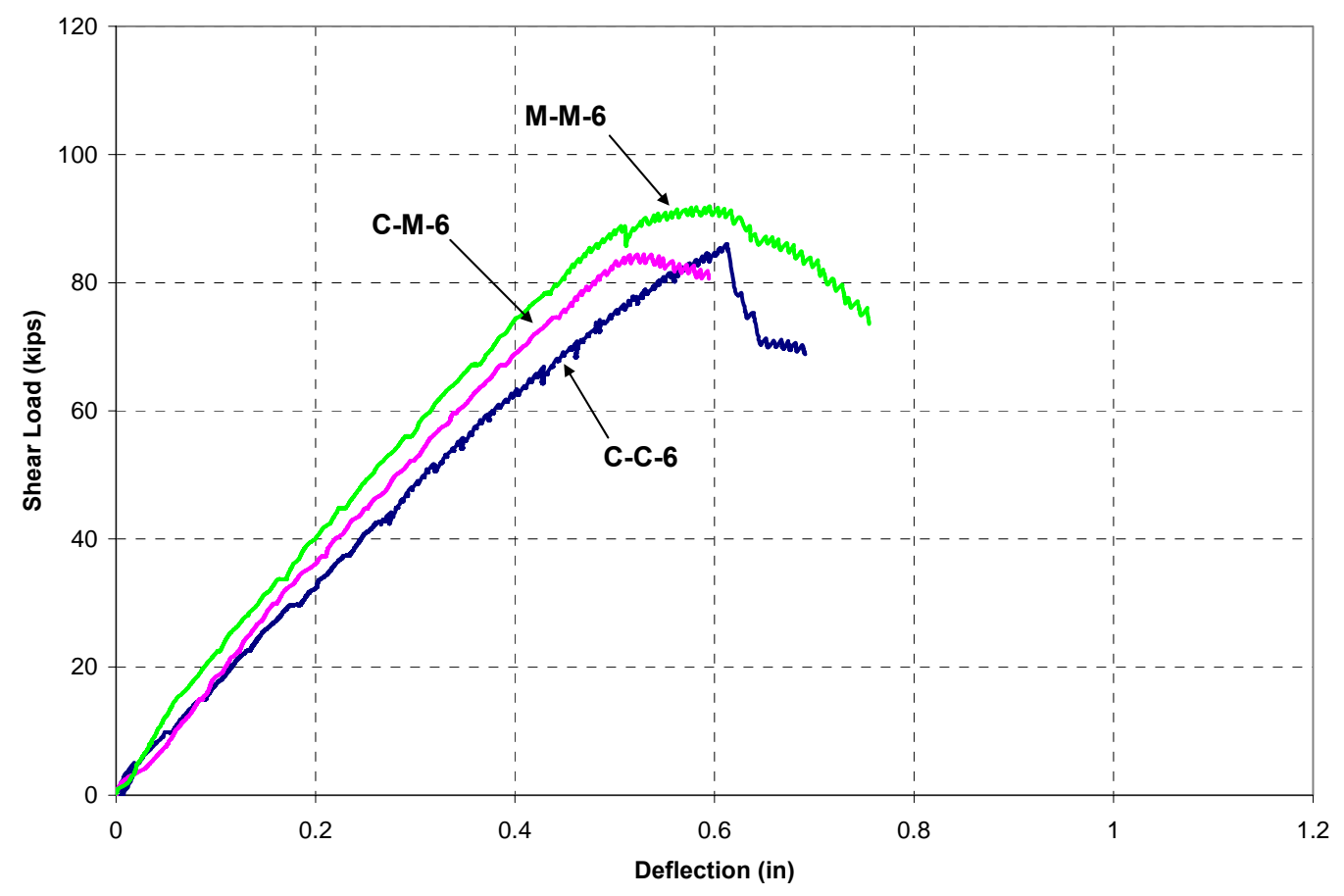

Figure 4.4: Typical Shear Load-Deflection behavior of Set 1, stirrup spacing = 6" 


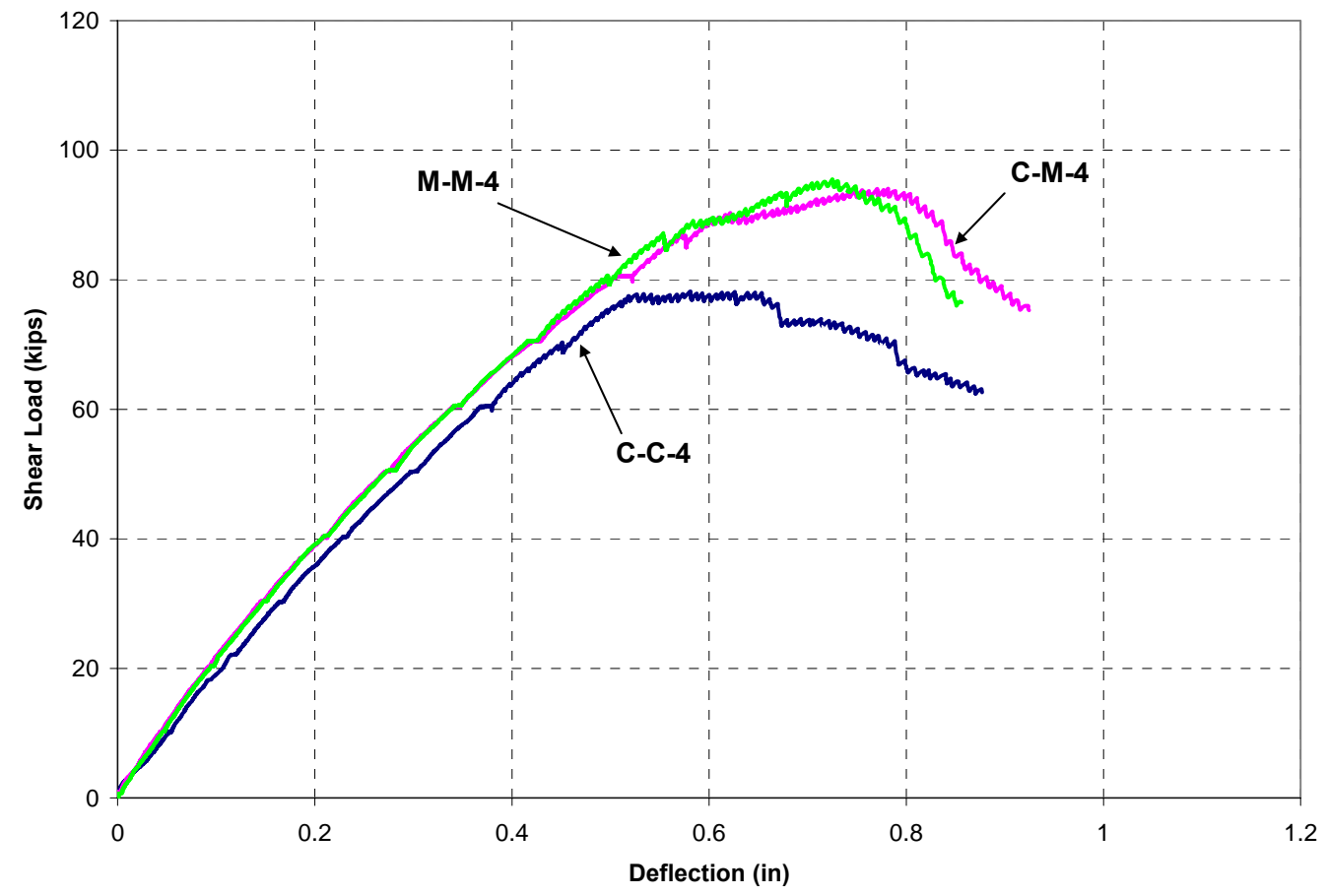

Figure 4.5: Typical Shear Load-Deflection behavior of Set 2, stirrup spacing = 4"

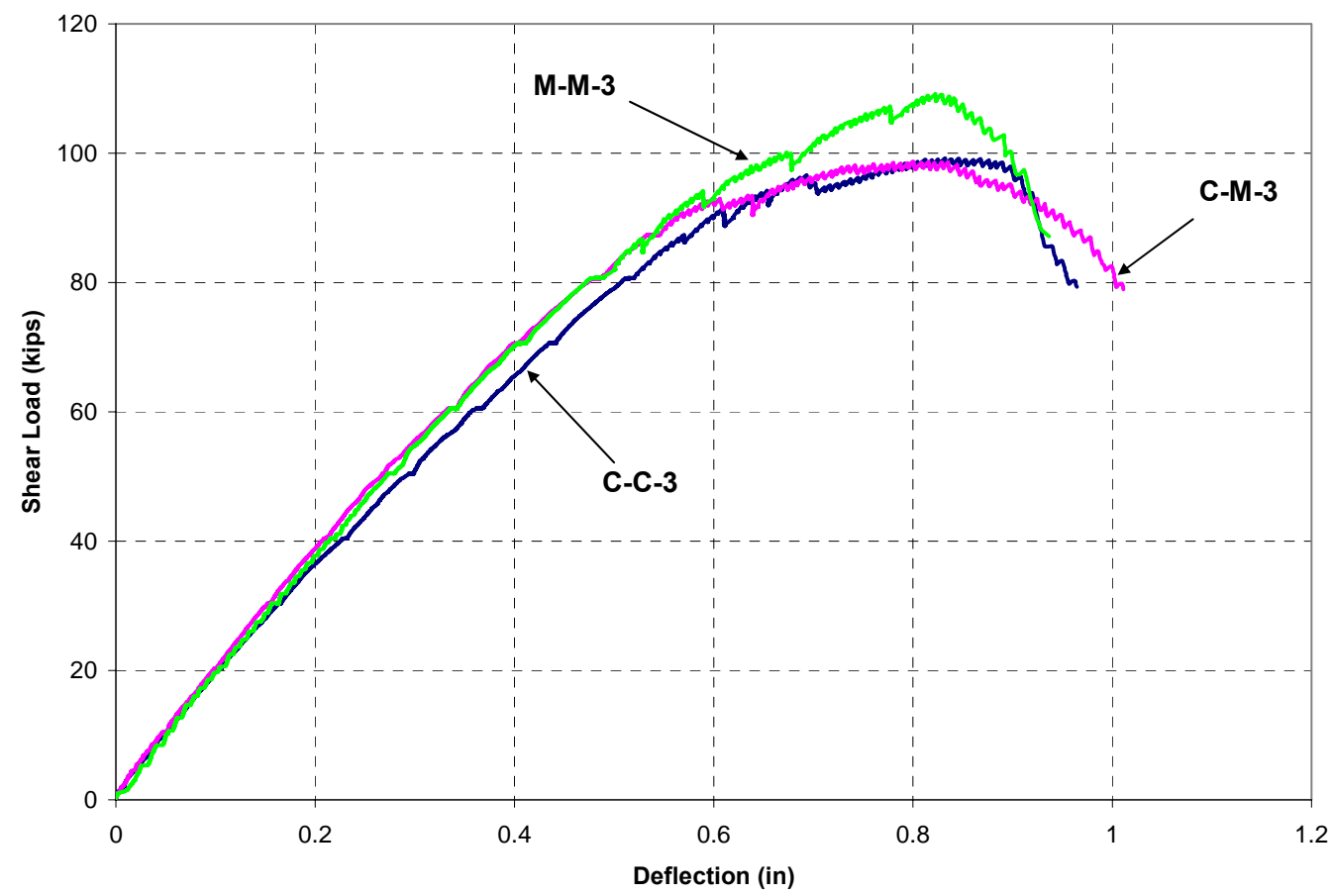

Figure 4.6: Typical Shear Load-Deflection behavior of Set 3, stirrup spacing = 3" 
In general, Figure 4.4, Figure 4.5, and Figure 4.6 indicate that increasing the shear reinforcement ratio, by reducing the stirrup spacing, increases both the load carrying capacity and deflection at failure. The maximum measured deflections of Set 1, 2, and 3 were approximately $0.7 ", 0.9 "$, and $1.0 "$, respectively. These relatively small deflections are due to the type of failure which was primarily in shear. The experimental results also indicate that the stiffness of a beam set was almost identical, regardless of the type of reinforcement. For example, the shear-deflection relationships for beams C-C-4, C-M-4, and M-M-4 remain coincident until separating at failure. Using different types of longitudinal and transverse steel only affects the ultimate load carrying capacity. Shear load-deflection relationships for each test can be found in Appendix B.

\subsection{Shear Load-Transverse Strain Behavior}

Strain in the transverse (vertical) direction was measured using vertical PI gages that were part of the strain gage rosette configuration discussed in Section 3.5. For each beam, two rosettes were used to capture the main diagonal shear crack. This allowed multiple sets of data to be obtained and verified for each beam test. The layout of the PI gage rosettes was shown in Figure 3.10.

The vertical PI gages selected for analysis were those that captured the main diagonal crack. If the readings of two PI gages were similar, then the data was averaged. In some cases a PI gage did not function properly so the data was therefore discarded. Since each beam contained two tests, only one of the tests was selected for analysis. This is based on a careful examination of the collected data after testing had concluded. A typical shear load vs. transverse strain relationship is shown in Figure 4.7. 


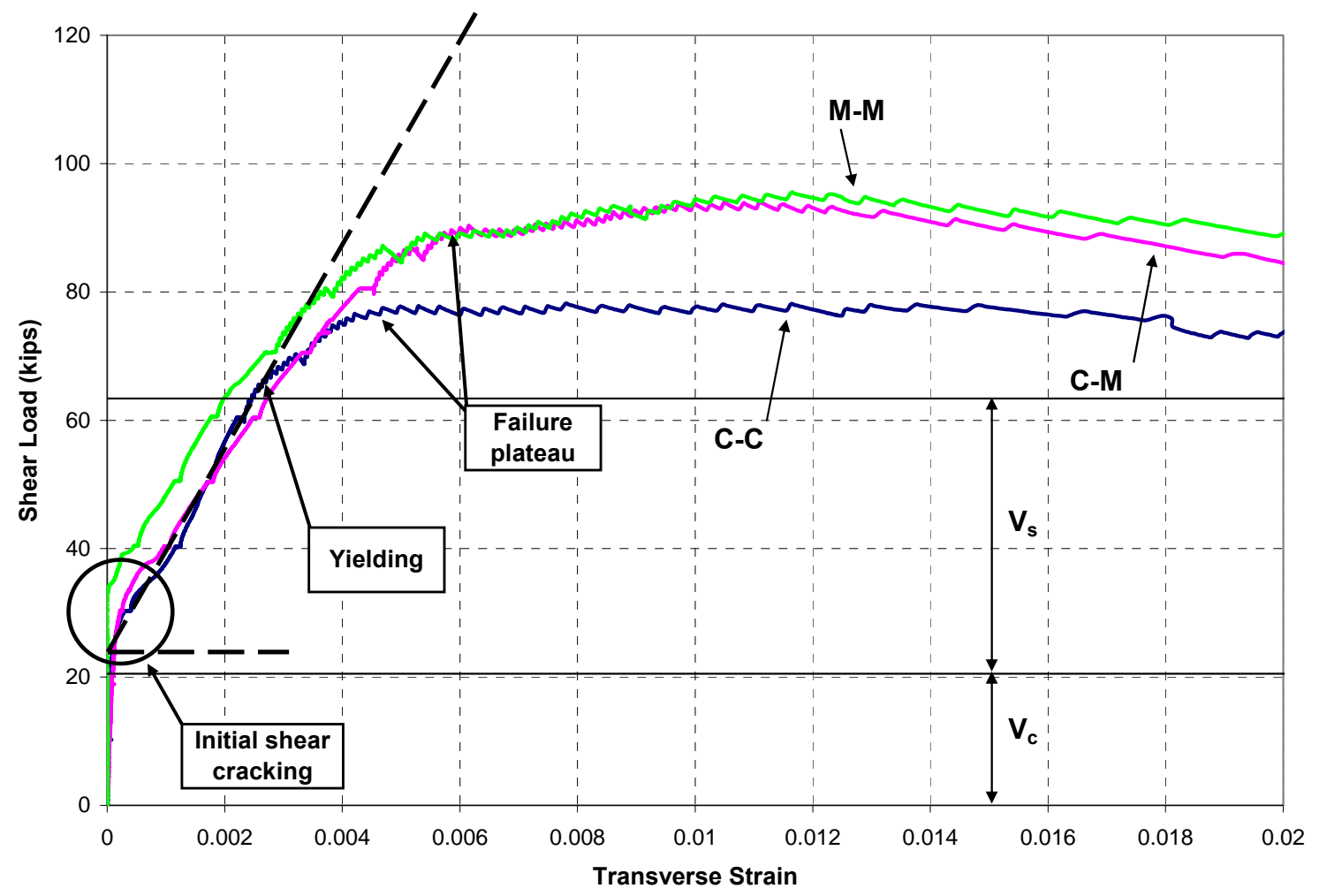

Figure 4.7: Typical Shear Load vs. Transverse Strain curve

Figure 4.7 can be used to determine the load corresponding to the initiation of the first shear crack by observing where the tangent of the curve intersects the vertical axis. This can be used to estimate the overall concrete contribution to the shear resistance $V_{c \text {,exp }}$. In general, the measured shear cracking load for all tested beams ranged from 25-30 kips, which is approximately $2.5 \sqrt{f_{c}^{\prime}} b d$ using the measured concrete compressive strength at the time of testing. The variation of the shear cracking load is also affected by the longitudinal and transverse reinforcement ratios. The figure also shows two lines representing the concrete and steel contributions based on the ACI Code, $V_{c}$ and $V_{s}$, in comparison to the measured strength. The terms $V_{c}$ and $V_{s}$ were calculated from Eqns. 2.17 and 2.19, respectively. 
These equations are based on an average concrete compressive strength for all tested beams and a yield strength of $60 \mathrm{ksi}$ for the steel stirrups. In general, the concrete contribution was 5-10 kips less than the measured shear cracking, while the nominal shear strength $V_{n}$ $\left(V_{c}+V_{s}\right)$ was much lower than the measured values. This highlights the conservatism built into the code equations for shear.

Figure 4.7 further indicates that the initial shear vs. transverse strain relationship is typically linear up to yielding of the stirrups, at which time a distinctive slope change occurs before the final failure. A dashed line shown in the figure for beam C-C demonstrates this deviation, and how it was used to determine the load corresponding to yielding of the stirrups. Measured data shows that this generally happens in a strain range of 0.002-0.003. As a result, the behavior indicates that yielding of the stirrups does not constitute failure since the beam exhibits more shear resistance up to failure. This increase is attributed to the resistance obtained from the two layers of longitudinal reinforcing steel. After yielding of the transverse reinforcement, the overall behavior of the beam becomes non-linear until the applied load begins to plateau and the beam fails. Failure of $\mathrm{C}-\mathrm{C}$ occurred after the stirrups and longitudinal reinforcement yielded, and is due to crushing of the concrete compression strut when the compressive strain reached its maximum strain value.

The two curves containing MMFX stirrups, C-M and M-M, exhibit a fairly linear slope up to failure. This is due to the characteristics of the MMFX steel, which does not exhibit a well defined yield point and stays linear to a much higher load as compared to Grade 60 steel. The non-linear behavior of the beams takes place immediately prior to the maximum load, with failure resulting from a combination of concrete crushing, yielding of the longitudinal bars, and/or the non-linear behavior of the MMFX stirrups. The upcoming 
three sections discuss the shear load vs. transverse strain relationships for each beam set, with relationships for each test given in Appendix B.

\subsubsection{Shear Load-Transverse Strain for Set 1}

Figure 4.8 shows the measured shear load vs. transverse strain relationship for the first set of beams.

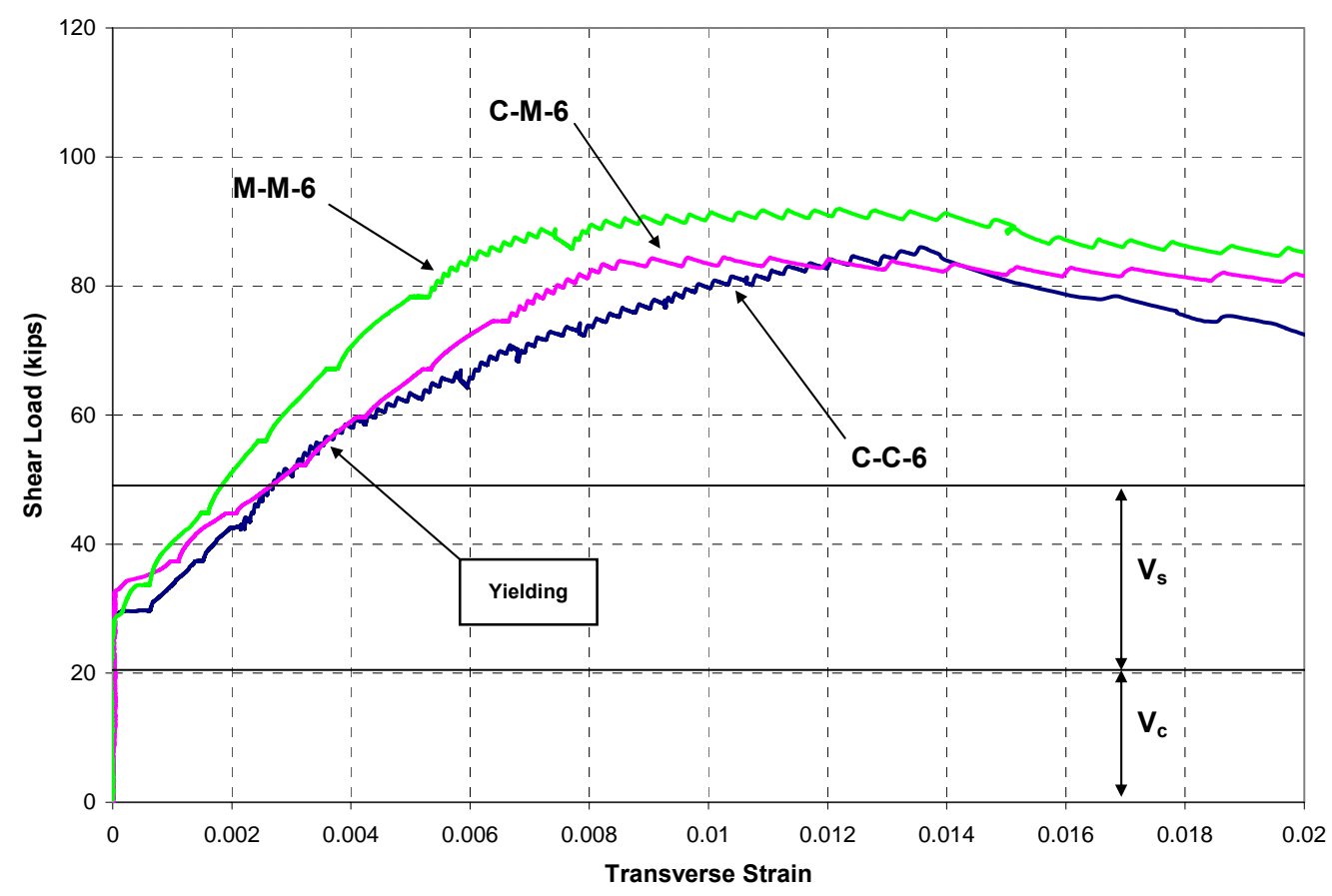

Figure 4.8: Shear Load vs. Transverse Strain, Set 1

From Figure 4.8, it is seen that the stirrups in C-C-6 yielded before failure. The estimated deviation from a linear relationship occurred at a shear load of 55 kips. Failure resulted when the bottom layer of longitudinal steel reached a strain of 0.002 and shear compression occurred. As expected, results indicate that the ACI is conservative when estimating the concrete contribution $V_{c}$ since initial cracking occurs much higher than the 
measured values $V_{c \text {,exp }}$. The total predicted nominal shear resistance $V_{n}$ is much lower than the measured capacity for Set 1 . This built-in conservatism is less for higher transverse reinforcement ratios, as will be shown in Set 2 and Set 3. Figure 4.9 shows the shear load versus the longitudinal strain (recorded by strain gages) and transverse strain (recorded by PI gages) for beam C-C-6.

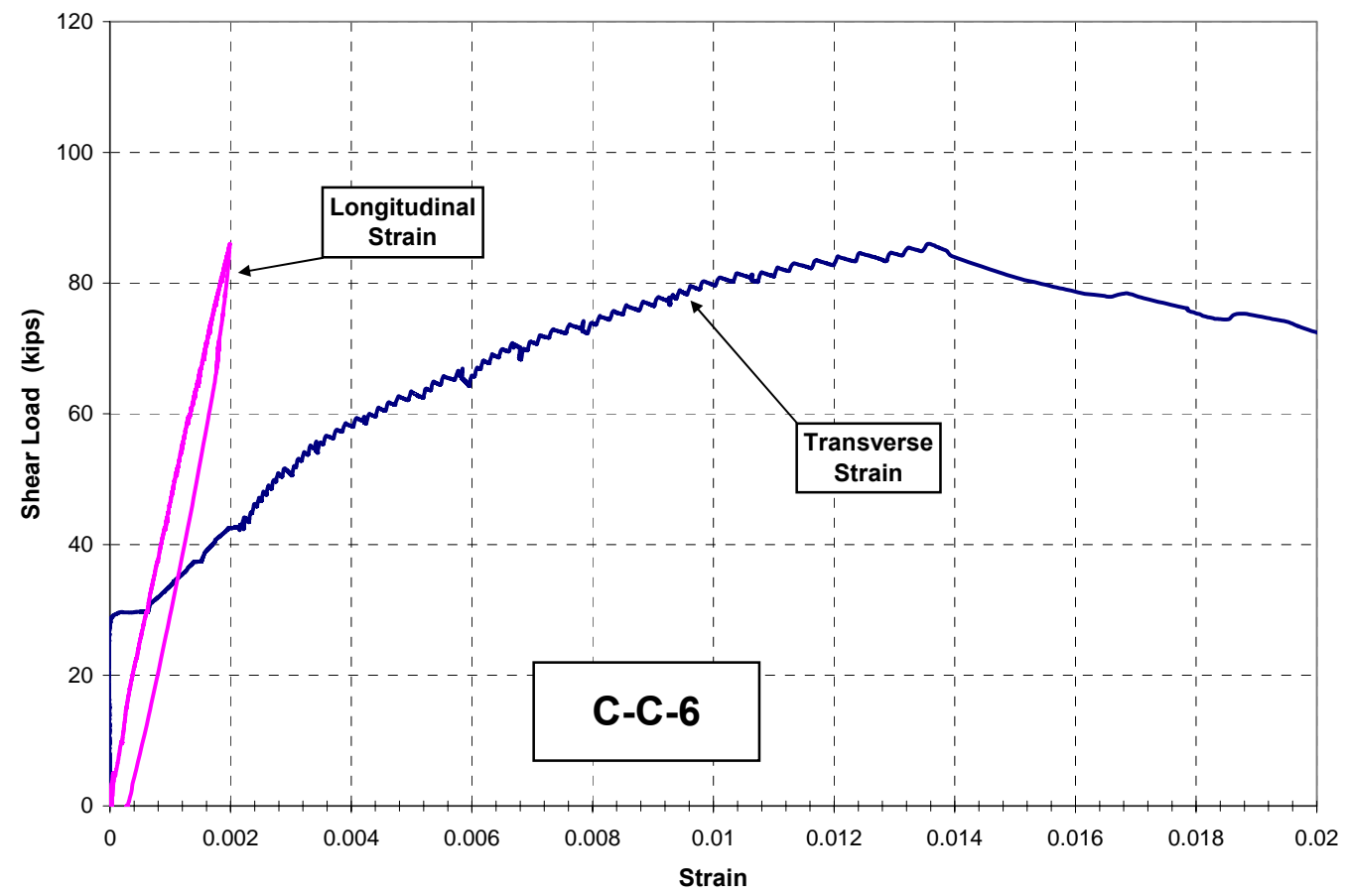

Figure 4.9: Shear Load vs. Strain, C-C-6

Beams C-M-6 and M-M-6 kept a fairly linear slope until failure occurred, as depicted in Figure 4.8. The non-linear behavior observed for beam C-M-6 before failure is due to the non-linear behavior of the MMFX stirrups and yielding of the longitudinal bars. The ultimate failure was due to crushing of the concrete in the strut. Beam M-M-6 experienced a similar behavior, except that the longitudinal MMFX rebars remained linear until the 
concrete strut crushed. The figures showing longitudinal strain for these beams can be found in Appendix B.

The behavior shown in Figure 4.8 suggests that the use of MMFX for stirrups and longitudinal reinforcement slightly increases the overall shear capacity. However, failure was mainly due to the capacity of the concrete strut as the truss mechanism developed within the beam. Yielding of the conventional reinforcement for beams C-C-6 and C-M-6 increased the overall strain, causing the concrete strut to reach its ultimate capacity at a lower strength than M-M-6. When comparing all three of the curves, M-M-6 clearly has the smallest strain for a given load level, resulting in smaller crack widths. This demonstrates the effectiveness of pairing MMFX for stirrups and longitudinal bars. However, the differences in strain between C-M-6 and C-C-6 are not significant enough to draw any definitive conclusions. Further discussion about the effect of steel can be found in Section 4.8. 


\subsubsection{Shear Load-Transverse Strain for Set 2}

Figure 4.10 shows the measured shear load vs. transverse strain relationship for the second set of tested beams.

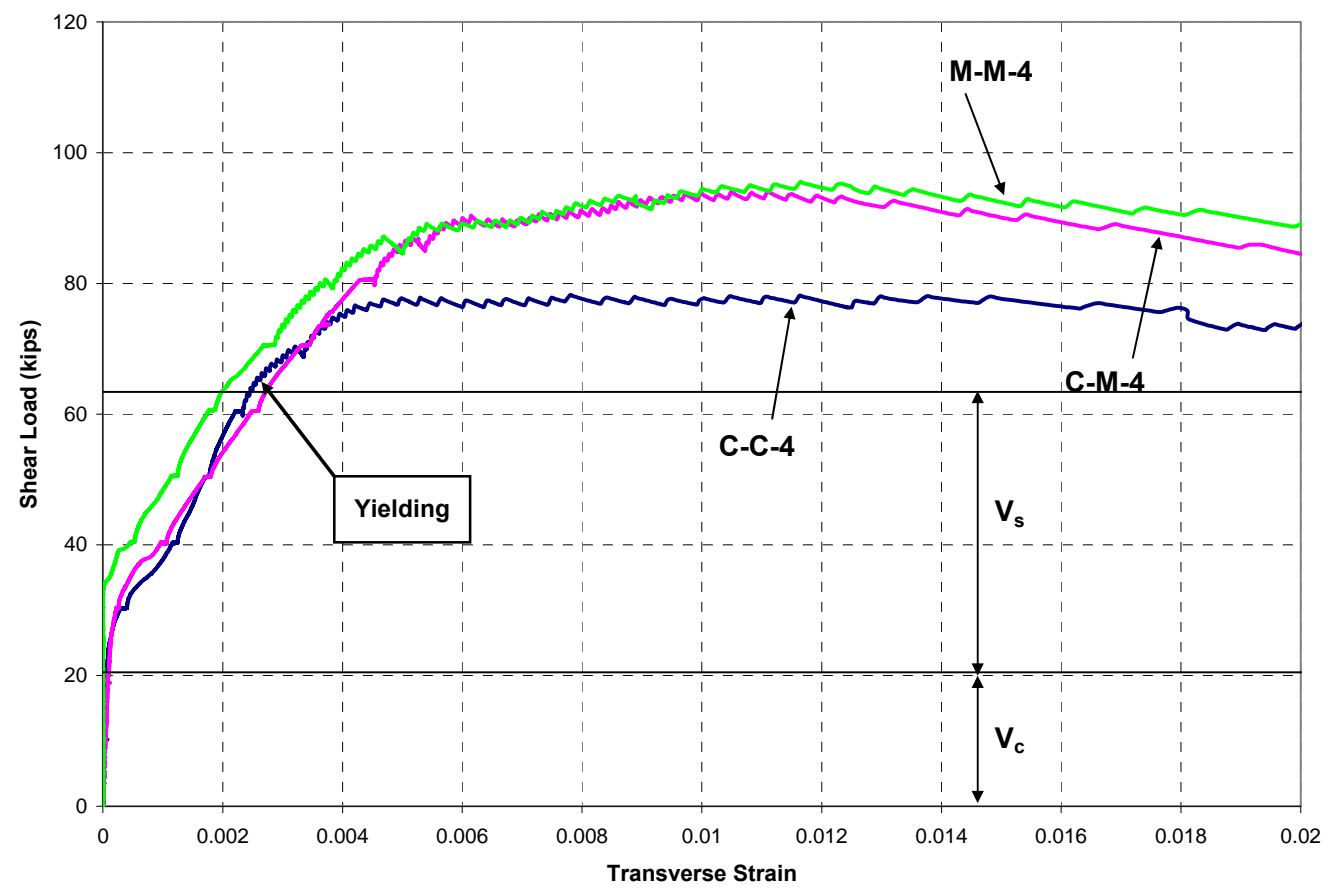

Figure 4.10: Shear Load vs. Transverse Strain, Set 2

C-C-4 shows a distinctive change of slope at a load level of 65 kips and a strain of 0.0027, due to yielding of the stirrups. The non-linear behavior extends to a load level of 76 kips, where the member was heavily cracked and failed. Similar to Set 1, the ACI Code underestimates the concrete contribution to shear since initial cracking occurs after the line marking $V_{c}$. The predicted nominal shear resistance is approximately 10 kips less than the actual capacity, which is less conservative than Set 1 due to the use of a high transverse reinforcement ratio. It should also be noted that the a/d ratio used for this test was higher, which caused the longitudinal bars to yield earlier than the first set. 
Yielding of both the transverse and longitudinal reinforcement increased the overall deformation and lead to an earlier failure in comparison to Set 1. This resulted in a less conservative prediction by the ACI Code equation. Figure 4.11 shows yielding of the longitudinal bar which occurred at the ultimate load level.

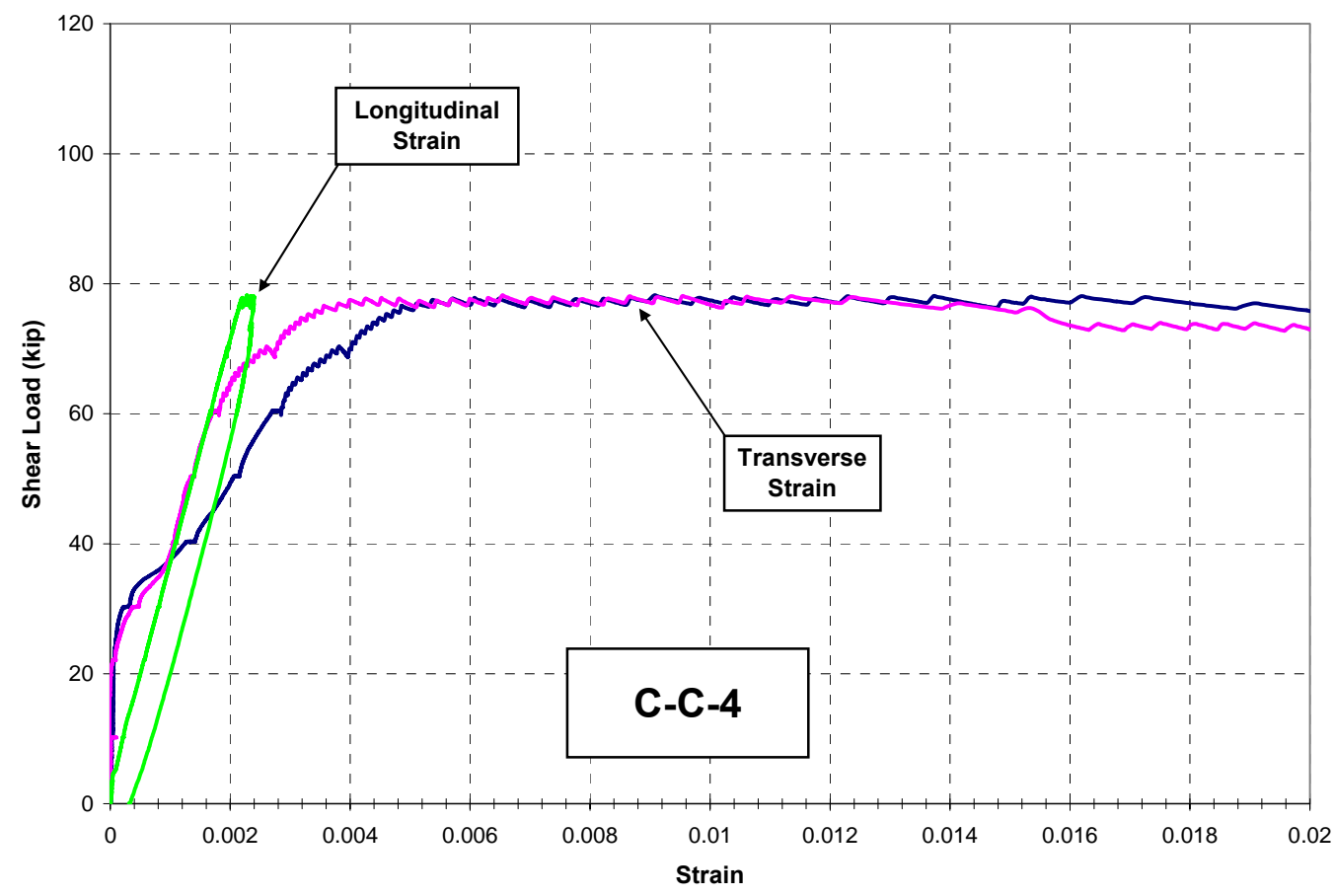

Figure 4.11: Shear Load vs. Strain, C-C-4

In Figure 4.10, beams C-M-4 and M-M-4 exhibit a linear slope up to a load level of 85 kips, where the capacity appears to plateau. The slight non-linear behavior observed in beam C-M-4 is likely due to yielding of the longitudinal bar. Due to the use of MMFX longitudinal reinforcement for beam M-M-4, the behavior is almost linear until failure due to concrete crushing in the compressive strut. For beams C-M-4 and M-M-4, a slight increase is observed in load carrying capacity after the initial load plateau. This is due to the absence 
of a yield plateau in MMFX steel, thus providing greater resistance at higher strain levels. Additional figures showing longitudinal strain for these beams can be found in Appendix B.

The behavior shown in Figure 4.10 suggests that the use of MMFX for stirrups and longitudinal reinforcement increases the overall shear capacity. However, failure was mainly due to the capacity of the concrete strut as the truss mechanism developed within the beam. Yielding of the conventional reinforcement for beam C-C-4 increased the overall strain, causing the concrete strut to reach its ultimate capacity at a lower level. While longitudinal reinforcement in C-M-4 likewise yielded, the presence of the MMFX stirrups allowed a greater load level to be achieved with higher strains. It is also evident that the use of MMFX longitudinal rebars helped to better control crack deformation by reducing strain at a given load level. Although not readily apparent in Figure 4.10, beam M-M-4 does increase shear capacity by a substantial amount over C-M-4 and will be discussed in Section 4.8. The differences in strain between C-M-4 and C-C-4 are not significant enough to draw any definitive conclusions. 


\subsubsection{Shear Load-Transverse Strain for Set 3}

Figure 4.12 shows the shear load vs. transverse strain relationship for the beams in Set 3 .

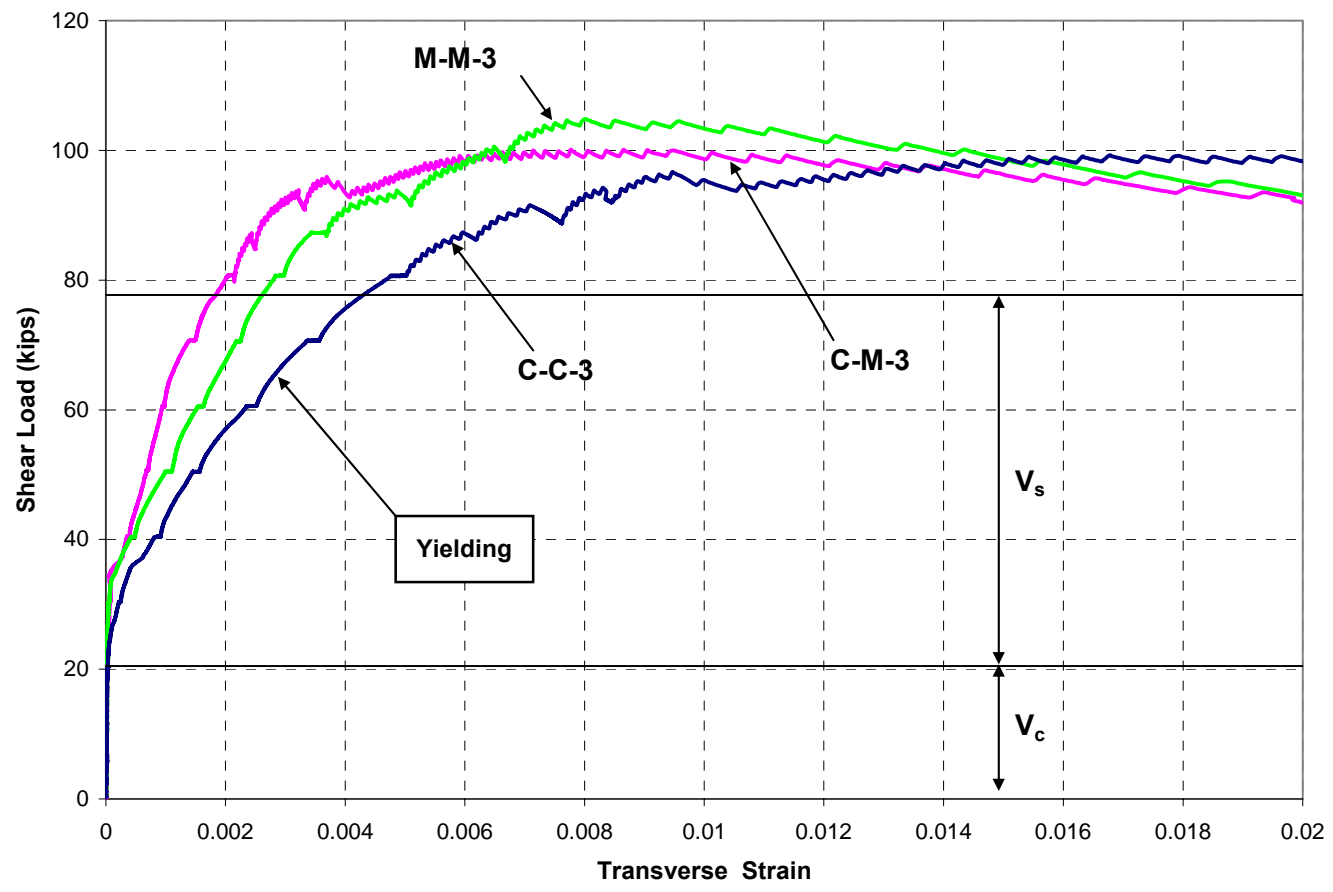

Figure 4.12: Shear Load vs. Transverse Strain, Set 3

The behavior of beam C-C-3 indicates that the stirrups yielded at a load level of 66 kips, which is a slightly higher load level than experienced in Set 1 and Set 2. The test results indicate that the ACI Code underestimates the concrete contribution to shear since initial cracking occurs at a higher load level than the predicted $V_{c}$. Also, the measured shear capacity is higher than the nominal value $V_{n}$ by $10 \mathrm{kips}$, which is less conservative than Set 1 due to the use of a higher transverse reinforcement ratio. 
Yielding of the Grade 60 longitudinal reinforcement subsequently increased the strain within the truss mechanism, and contributed to the failure of the concrete compressive strut. The shear load versus the longitudinal strain and transverse strain is shown in Figure 4.13.

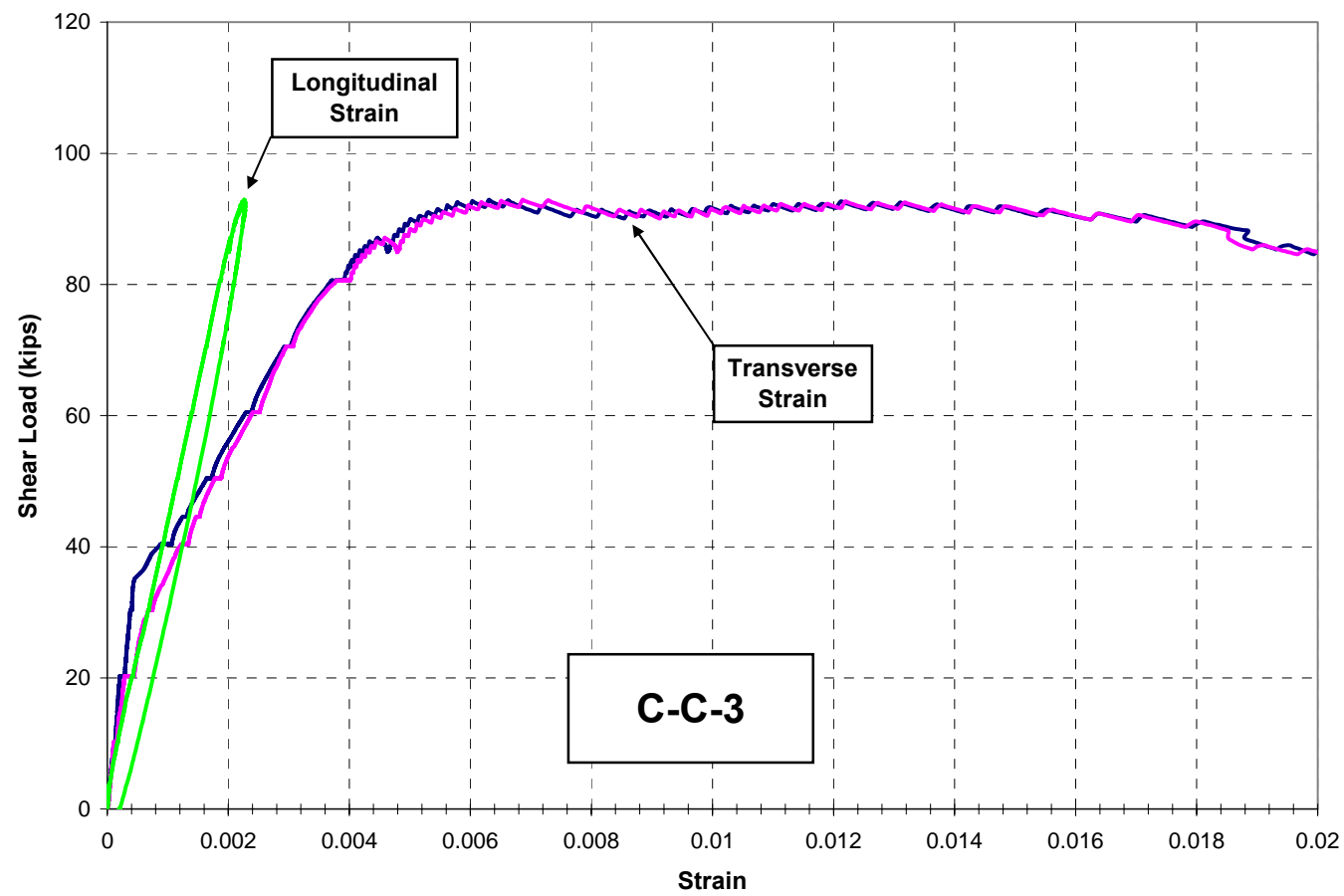

Figure 4.13: Shear Load vs. Strain, C-C-3

Behavior of beam C-M-3 shown in Figure 4.12 indicates a change in slope at the load level of 70 kips, which could be due to the first layer of longitudinal reinforcement yielding. M-M-3 follows the typical trend of being linear until failure begins, with failure due to crushing of concrete in the compressive strut. Both beams show a slight load increase after the initial non-linear region up to the ultimate, which is the same behavior described in Section 4.4.2. The figures showing longitudinal strain for beams C-M-3 and M-M-3 can be found in Appendix B. 
The relationships shown in Figure 4.12 suggest that the use of MMFX for stirrups and longitudinal reinforcement increases the overall shear capacity and improves crack deformation. This is evidenced by the fact that beams reinforced with MMFX stirrups show less strain at a given load level. Unlike Set 1 and Set 2, C-M-3 shows less crack deformation as compared to C-C-3 or M-M-3. Further discussion about the effect of steel can be found in Section 4.8.

\subsection{Crack Width}

Crack widths were examined to determine the effect of using high strength steel such as MMFX. Currently, the ACI Code neither limits the size of shear cracks nor provides a definitive guideline for the maximum flexural crack width. However, previous editions of the ACI Code provide some limitations about the acceptable crack widths as related to the condition of exposure. These values are included in the commentary of the current ACI Code 318-05 Section 10.6 which uses a value of 0.016 " for the maximum flexural crack, and is calculated from empirical equations. Therefore, this research will assume that an acceptable crack width at the service load level is equal to or less than this value.

In this study, service loads are assumed to be $60 \%$ of the nominal shear capacity as calculated from the ACI Code and using a yield strength of $60 \mathrm{ksi}$. As a result, this corresponds to a stress level of $36 \mathrm{ksi}$ in the stirrups. Other researchers (Rahal, 2006) have used similar values for calculating the service shear load, which is shown in the following equation.

$$
\text { Service load }=0.6\left(V_{c}+V_{s}\right) \quad \text { Eqn. } 4.2
$$


Two different methods were used to determine the width of the shear crack:

1. Measurements taken during testing using a crack comparator.

2. Total deformation within the gage length of three PI gages located in the rosette configuration shown in Figure 3.10.

The measurements using the crack comparator were comparable to those measured by the PI gages, but this discussion will only focus on the PI gage readings. The geometry of two PI gages was used in order to record the summation of the shear crack width. In the analysis, the vertical and diagonal gages were selected for this purpose. The amount of slide, or displacement along the crack, could also be computed using the following equations derived from Figure 4.14 (Shehata, 1999).
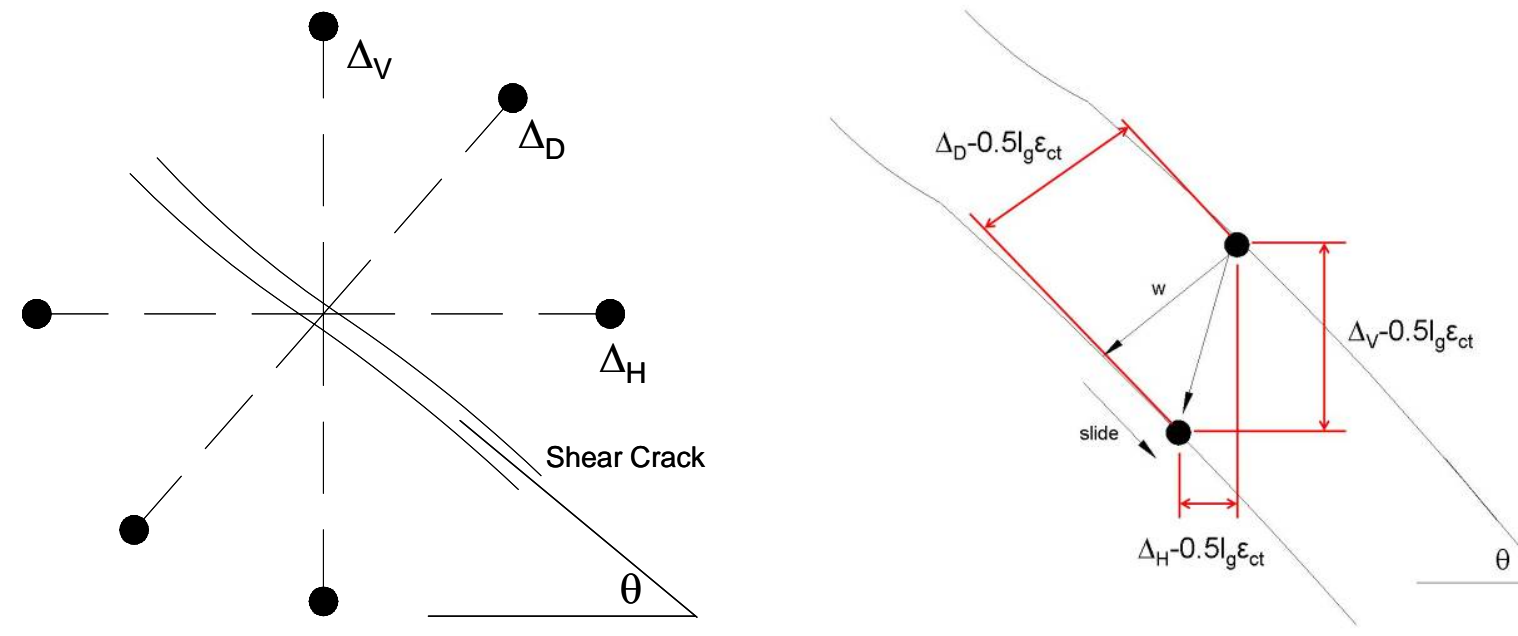

Figure 4.14: $\mathrm{PI}$ gages at a shear crack

$$
\begin{aligned}
& \sum w=\left(\sqrt{2} \Delta_{D}-\Delta_{V}-0.5 l_{g} \varepsilon_{c t}\right) \sin \theta+\left(\Delta_{V}-0.5 l_{g} \varepsilon_{c t}\right) \cos \theta \quad \text { Eqn. } 4.3 \\
& \text { slide }=\left(\sqrt{2} \Delta_{D}-\Delta_{V}-0.5 l_{g} \varepsilon_{c t}\right) \cos \theta-\left(\Delta_{V}-0.5 l_{g} \varepsilon_{c t}\right) \sin \theta \text { Eqn. } 4.4
\end{aligned}
$$


where $\Delta_{D}, \Delta_{V}, \Delta_{H}$ are the measured PI gage readings in the diagonal, vertical, and horizontal directions, respectively, $\theta$ is the measured crack angle to the horizontal beam axis, $l_{g}$ is the gage length of the PI gage $(200 \mathrm{~mm})$, and $\varepsilon_{c t}$ is the maximum tensile concrete strain $\left(0.1 \times 10^{-3}\right)$. The summation of the shear crack widths $\sum w$ calculates the width based on all cracks passing through the PI gage. The average width $w$ can then be calculated by dividing the summation by the number of cracks.

Measurement of the crack angle is difficult since it not only changes along the span, but also changes with the load level. As a result, the angle is estimated to be the distance from the edge of the support to the edge of the loading plate. This results in angles of $29.3^{\circ}$ and $24.9^{\circ}$ for the first and second test setups, respectively. Another variable is the number of cracks passing through the rosette, which changes based on the load level. Pictures of the crack pattern at service loads were used to identify the number of cracks used in the calculations.

Table 4.3 provides the service load levels for each set, and the number of cracks recorded for each beam. Because of the relative assumptions taken for the crack angle and the number of cracks at service levels, graphs of shear load versus crack width were only applicable around the service load level. Therefore, a limited range of values will be shown. 
Table 4.3: Service loads using a service stress of $36 \mathrm{ksi}$

\begin{tabular}{|c|c|c|c|c|}
\hline & $\begin{array}{l}\text { Crack } \\
\text { Angle }\end{array}$ & $\begin{array}{l}0.6 V_{n} \\
\text { (kips) }\end{array}$ & ID & $\begin{array}{c}\text { Number of } \\
\text { Cracks }\end{array}$ \\
\hline \multirow{6}{*}{ Set 1} & \multirow{6}{*}{$29.3^{\circ}$} & \multirow{6}{*}{28.9} & C-C-6 & 1 \\
\hline & & & C-C-6R & 1 \\
\hline & & & C-M-6 & 1 \\
\hline & & & C-M-6R & 1 \\
\hline & & & M-M-6 & 1 \\
\hline & & & M-M-6R & 1 \\
\hline \multirow{6}{*}{ Set 2} & \multirow{6}{*}{$24.9^{\circ}$} & \multirow{6}{*}{38.1} & C-C-4 & 1 \\
\hline & & & C-C-4R & 1 \\
\hline & & & C-M-4 & 1 \\
\hline & & & C-M-4R & 1 \\
\hline & & & M-M-4 & 2 \\
\hline & & & M-M-4R & 1 \\
\hline \multirow{6}{*}{ Set 3} & \multirow{6}{*}{$24.9^{\circ}$} & \multirow{6}{*}{47.2} & C-C-3 & 1 \\
\hline & & & C-C-3R & 1 \\
\hline & & & C-M-3 & 1 \\
\hline & & & \begin{tabular}{|l|}
$\mathrm{C}-\mathrm{M}-3 \mathrm{R}$ \\
\end{tabular} & 1 \\
\hline & & & M-M-3 & 1 \\
\hline & & & M-M-3R & 2 \\
\hline
\end{tabular}

The shear load versus crack width of beams tested in Set 1, Set 2, and Set 3 are shown in Figure 4.15, Figure 4.16, and Figure 4.17, respectively. All plots feature the shear load on the $y$-axis in kips, and the diagonal crack width on the x-axis in inches. The figures also show a line representing the service load level as $0.6 \mathrm{~V}_{\mathrm{n}, \mathrm{ACl}}$, which is based on a stress of 36 ksi in the stirrups. 


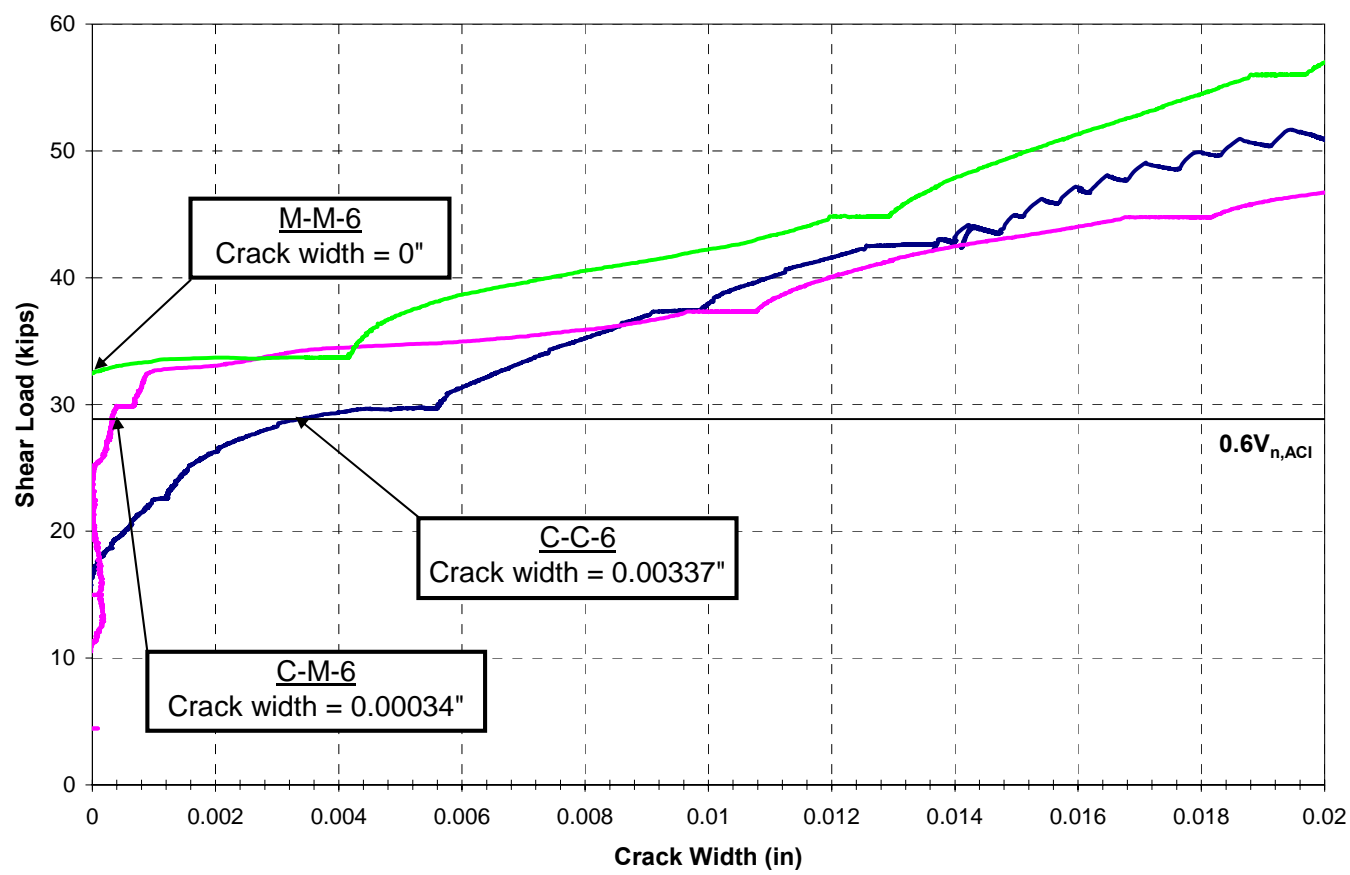

Figure 4.15: Set 1, Shear Load vs. Crack Width $\left(f_{s}=36\right.$ ksi)

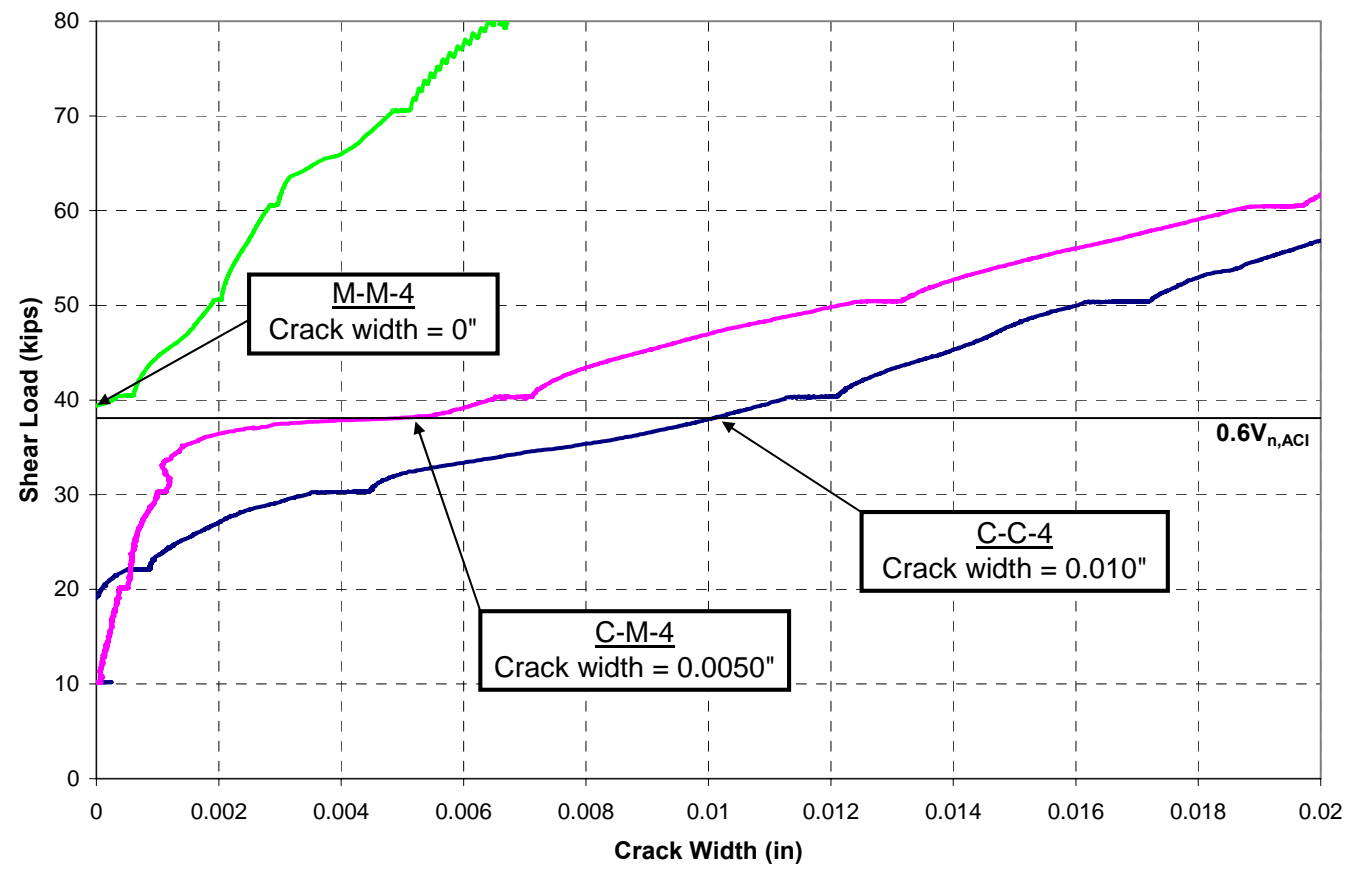

Figure 4.16: Set 2, Shear Load vs. Crack Width $\left(f_{s}=36\right.$ ksi) 


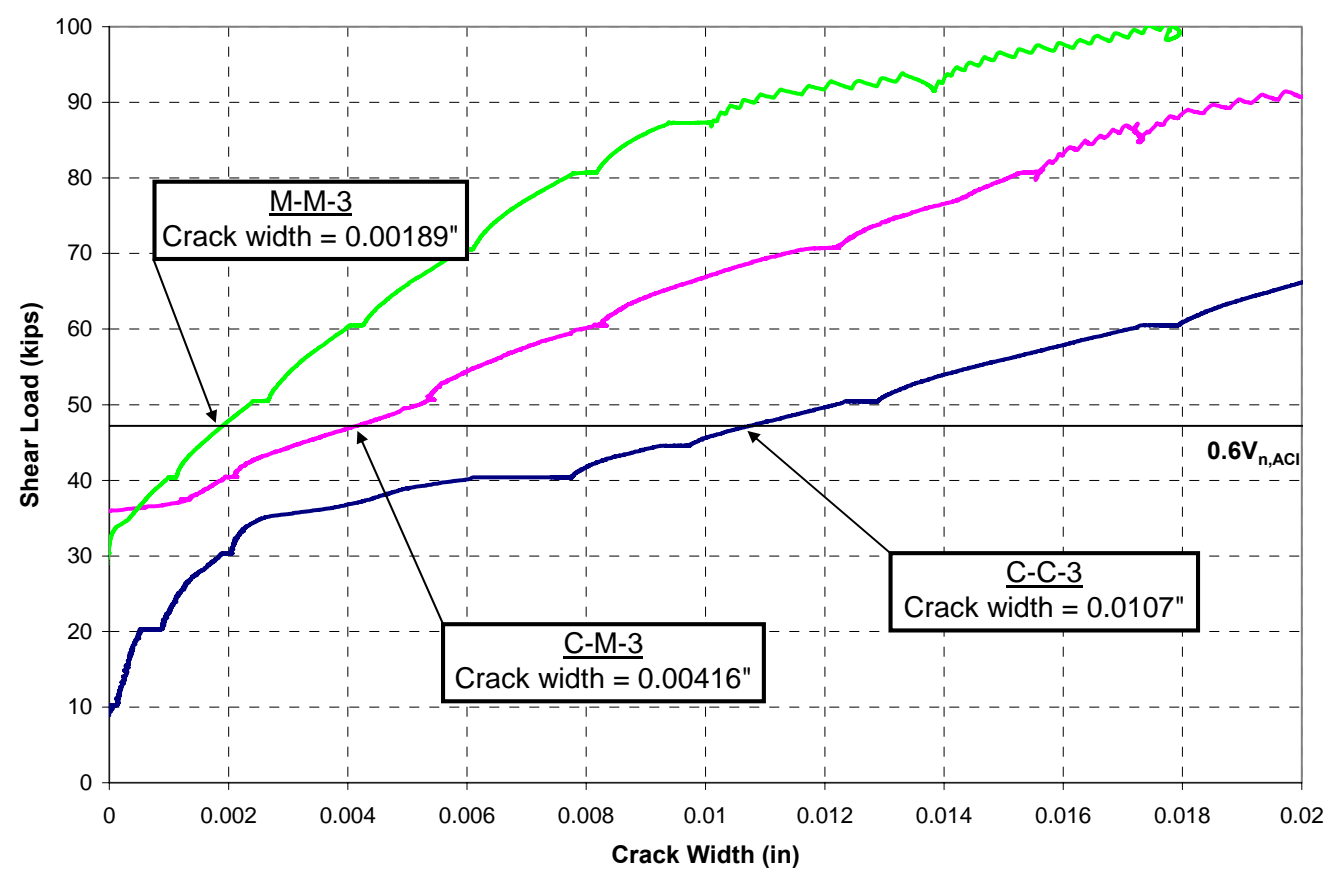

Figure 4.17: Set 3, Shear Load vs. Crack Width $\left(f_{s}=36\right.$ ksi)

One can see that all measured values are less than the ACI limit of 0.016 inches, regardless of the setup type or beam type. In Figure 4.15, the two beams containing MMFX stirrups showed very small crack widths at the service load level in comparison to C-C-6. In Figure 4.16, the beam M-M-4 still showed very small crack widths in comparison with the other two beams, with C-M-4 less than C-C-4. Set 3, shown in Figure 4.17, followed the same trend as just described for Set 2. Consequently, test results indicate that the direct replacement of conventional steel with MMFX steel significantly reduces the shear crack width at service load levels.

The various factors which notably affect the crack behavior of reinforced concrete beams include the bond characteristics of steel to concrete, concrete compressive strength, stress level in the reinforcement, and concrete cover. Since the crack width analysis 
considered service load levels, the stress in the MMFX and conventional steels are the same. The concrete cover can also be ignored since all beams were reinforced and built using the same dimensions. While different concrete strengths may have had some influence in Set 1 and Set 2, the beams in Set 3 had the same concrete compressive strengths while displaying the same shear load vs. crack width behavior. Therefore, the overall influence of the concrete strength is minor. As a result, the obvious enhancement of the crack width for beams reinforced with MMFX in comparison to conventional steel is mainly attributed to the better bond characteristics of MMFX steel.

Conventional steel bars tend to have ribs which are smoother and rounder in comparison to MMFX steel bar ribs. In general, smoother bars will reduce the surface bond with the concrete and cause a small number of wider cracks to develop (Nilson et al., 2004). One way to compare differences between bar ribs is to calculate the relative rib area $\left(\mathrm{R}_{\mathrm{r}}\right)$, which is the ratio of the projected rib area normal to the bar axis divided by the nominal bar perimeter. Seliem (2007) calculated MMFX to have a relative rib area equal to 0.092 , compared to conventional steel which has $\mathrm{R}_{\mathrm{r}}$ equal to 0.0727 for No. 8 bars. These values are expected to be close to the \#9 longitudinal bars used in this research, although may differ when considering the \#3 stirrups. Nevertheless, this clearly shows that MMFX bars have a greater amount of surface deformation compared to conventional steel.

Since test results indicate that MMFX stirrups reduce the shear crack width at a service stress of $36 \mathrm{ksi}$, using high strength steel could allow for an increased service load level. However, increased design strength also creates larger crack deformations. Table 4.4 provides the revised service load levels for each set using a service stress of $48 \mathrm{ksi}$, where the number of cracks and crack angles remain the same as presented in Table 4.3. 
Table 4.4: Service loads using a service stress of $\mathbf{4 8} \mathrm{ksi}$

\begin{tabular}{|c|c|}
\hline & $\begin{array}{c}0.6 V_{n} \\
(k i p s)\end{array}$ \\
\hline Set 1 & 35.4 \\
\hline Set 2 & 47.0 \\
\hline Set 3 & 58.6 \\
\hline
\end{tabular}

Figure 4.18, Figure 4.19, and Figure 4.20 show the shear load vs. crack width for Set 1,2 , and 3, respectively, using a service stress of $48 \mathrm{ksi}$.

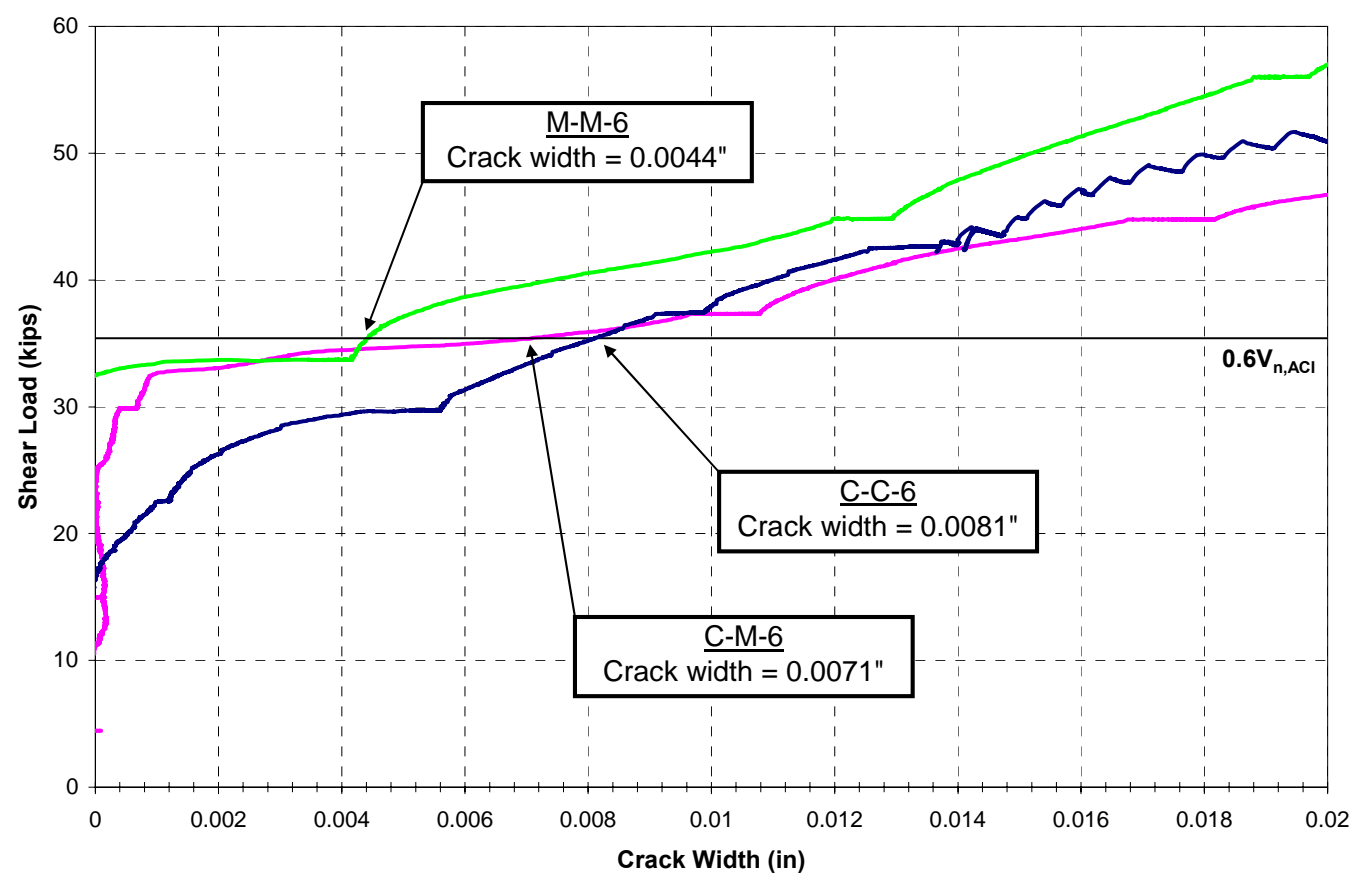

Figure 4.18: Set 1, Shear Load vs. Crack Width $\left(f_{s}=48\right.$ ksi) 


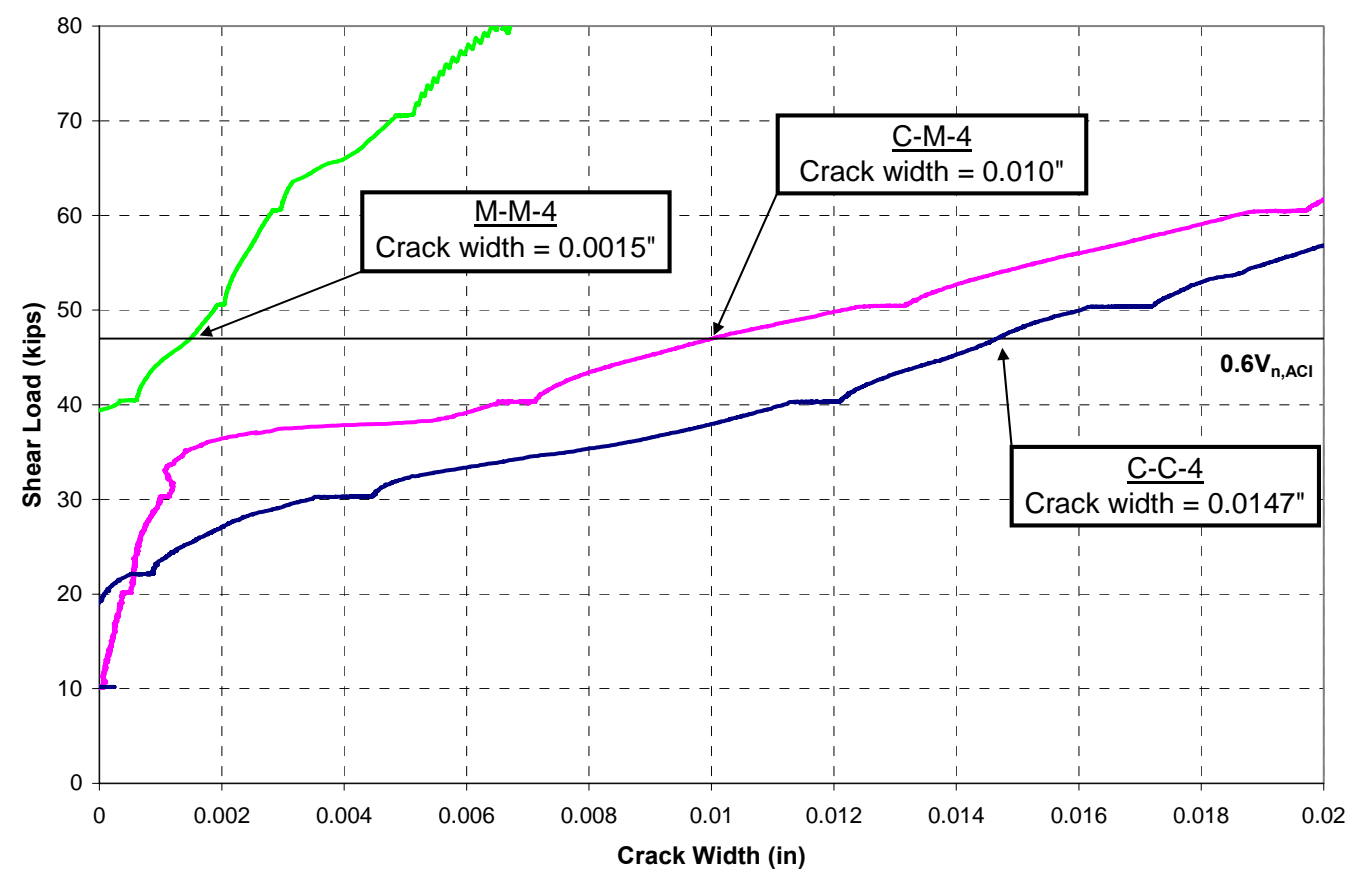

Figure 4.19: Set 2, Shear Load vs. Crack Width $\left(f_{s}=48\right.$ ksi)

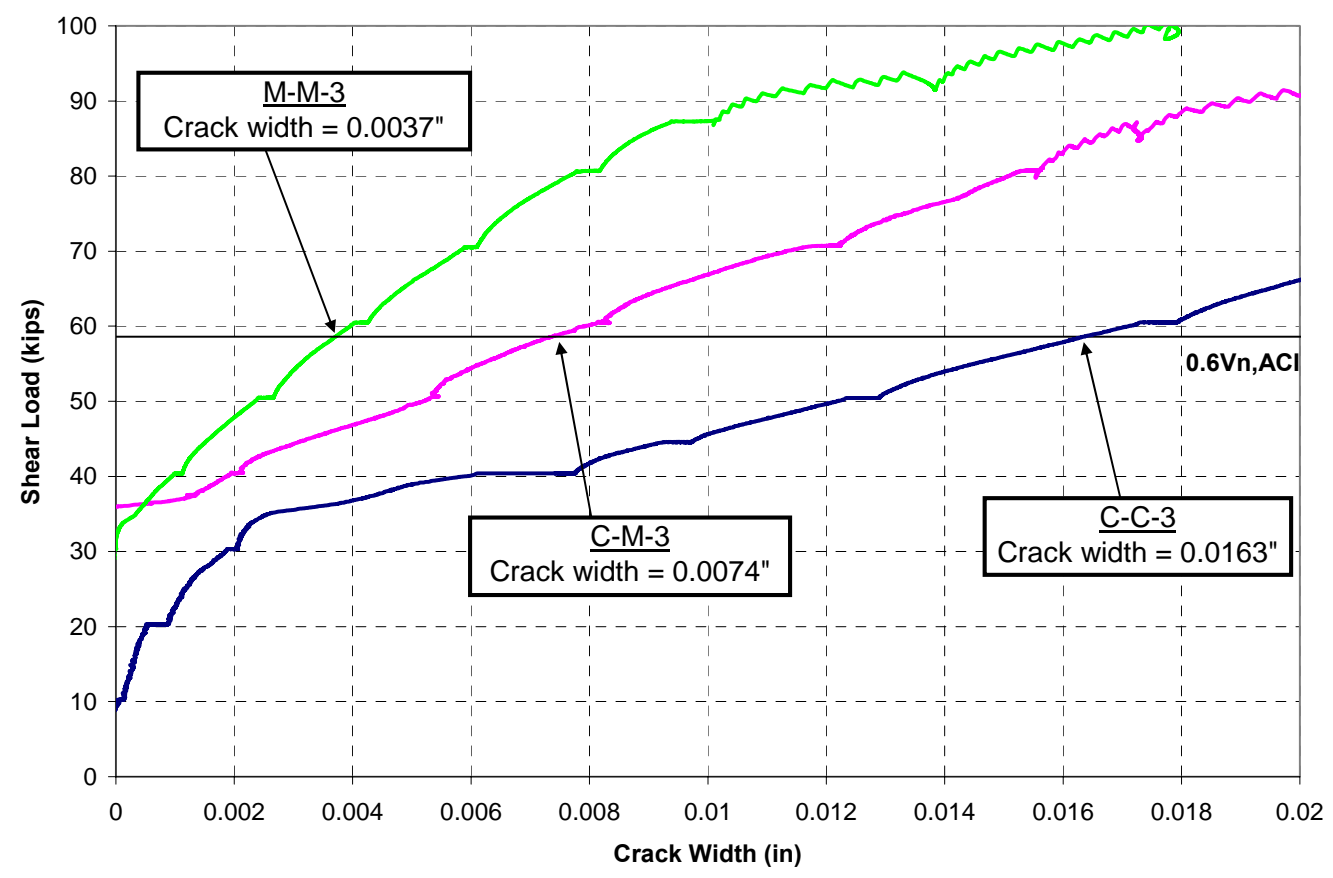

Figure 4.20: Set 3, Shear Load vs. Crack Width $\left(f_{s}=48\right.$ ksi) 
Results indicate that using a service load corresponding to a service stress of $48 \mathrm{ksi}$ is acceptable for beams reinforced with MMFX stirrups. In general, M-M beams had smaller crack widths at the higher service load level than C-M beams, although both types were within the 0.016 inch limit. All beams reinforced with MMFX steel had smaller crack widths than beams reinforced entirely with conventional steel. As previously indicated, this is attributed to the increased bond that MMFX steel has with the concrete. While beams C-C-6 and C-C-4 were within the prescribed shear crack width limit, beam C-C-3 had measured crack widths exceeding 0.016 inches. Therefore, a higher service stress level is conservative for beams reinforced with MMFX steel, but not for beams entirely reinforced with conventional steel.

\subsection{Cracking Behavior}

Initiation of the first flexural cracks typically occurred at an applied load level of 15 kips. Increasing the applied load caused propagation of the cracks and initiation of new flexural cracks along the span. Further load increase extended the existing flexural cracks into flexure-shear cracks, as shown in Figure 4.21. 


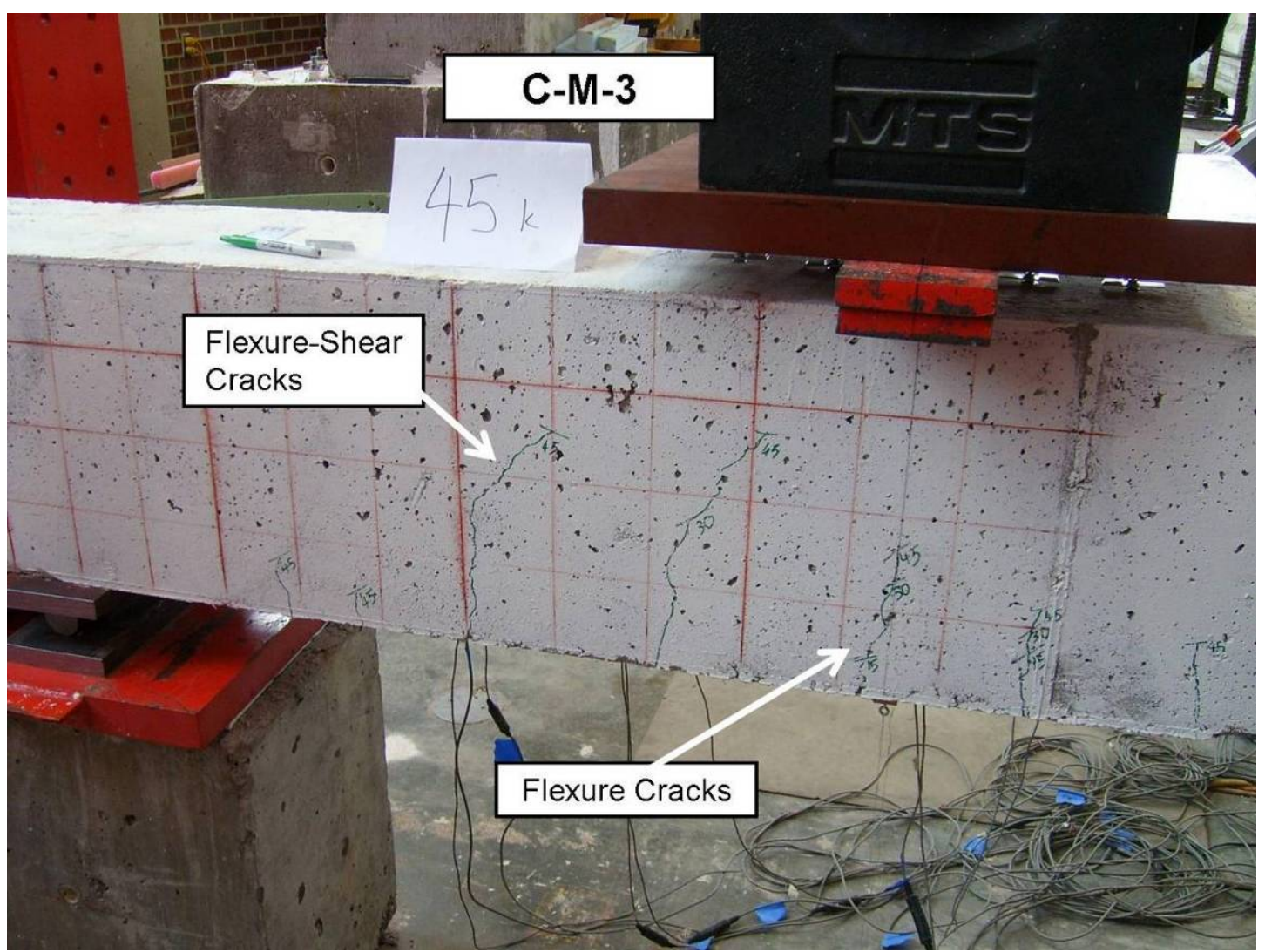

Figure 4.21: Flexure-shear cracking

After formation of the flexure-shear cracks, increasing the applied load caused an extension of the shear cracks and an increase of crack width within the span. While all cracks grew wider over the course of continued loading, the shear cracks propagated at a faster rate than the flexural cracks. In all cases, failure occurred due to local crushing of the concrete at the edge of the loading plate. This nodal zone region was also at the extension of the major diagonal shear crack as shown in Figure 4.22 and Figure 4.23. 


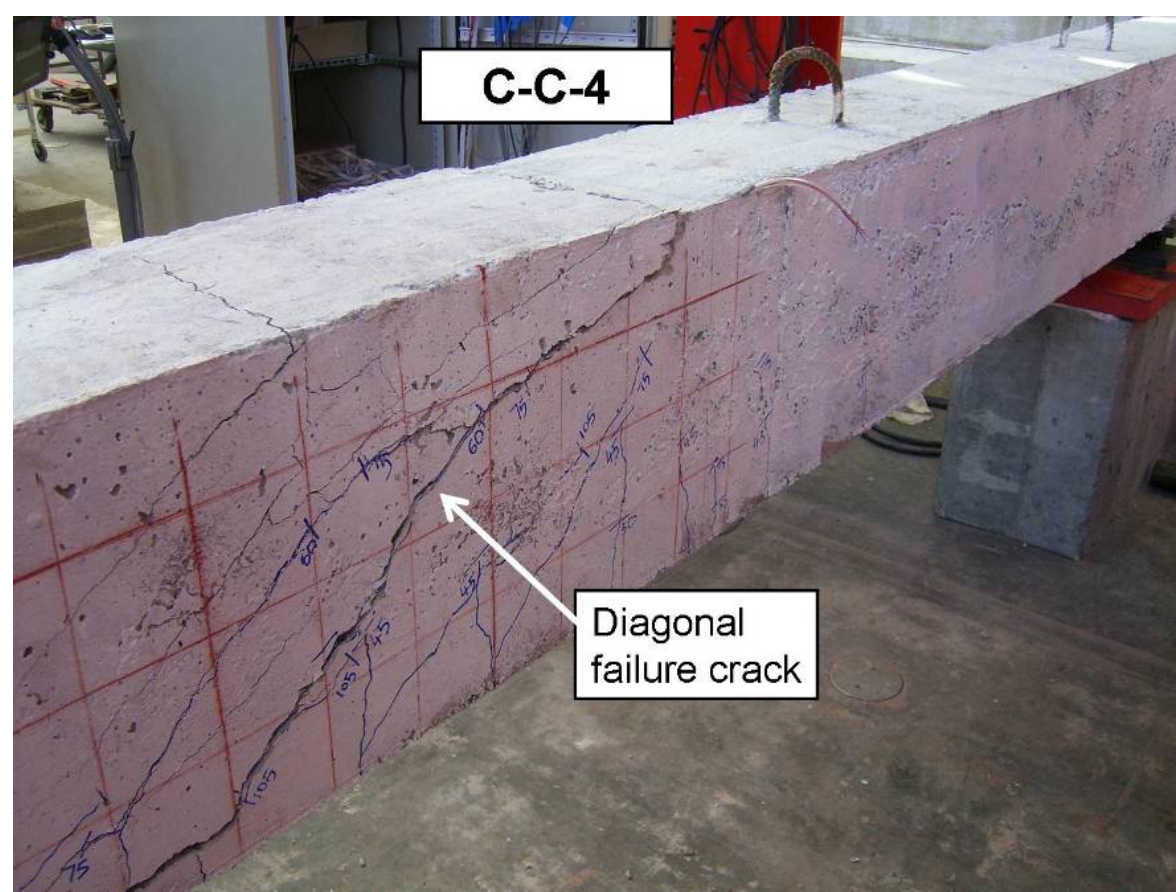

Figure 4.22: Typical diagonal crack

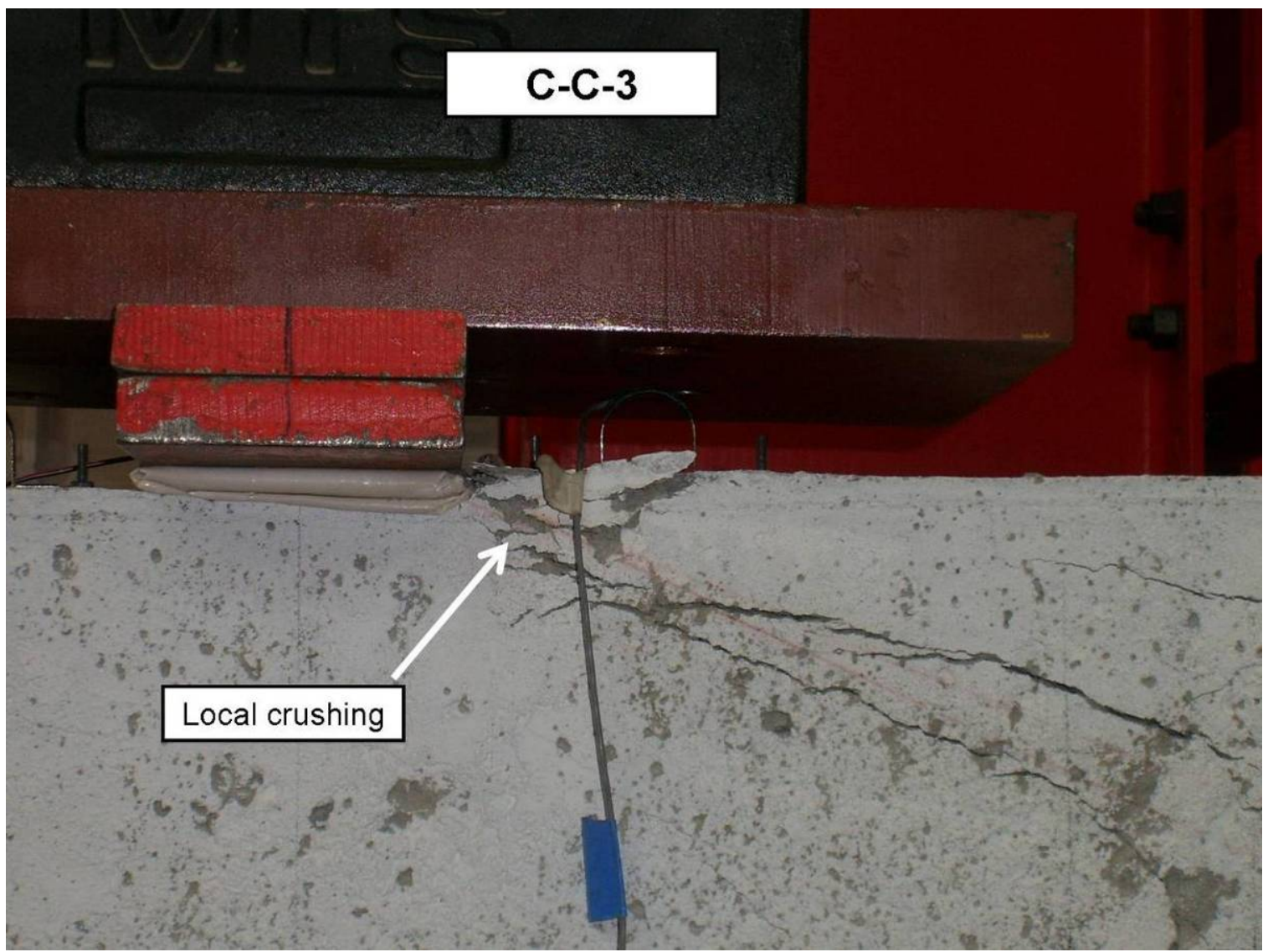

Figure 4.23: Local crushing at nodal zone 
In general, failures of the tested beams were not explosive in nature. The applied load was maintained for significant deformation until failure, as evidenced by the measured strain plateau for all beams. After removal of the top loading plate, it was observed that concrete had crushed beneath the plate. It was also observed that splitting cracks occasionally formed along the top surface of the beam towards the final loading stages, as shown in Figure 4.24. The longitudinal splitting cracks are due to the Poisson's effect of high compressive stresses developed at the top surface of the beam during loading.

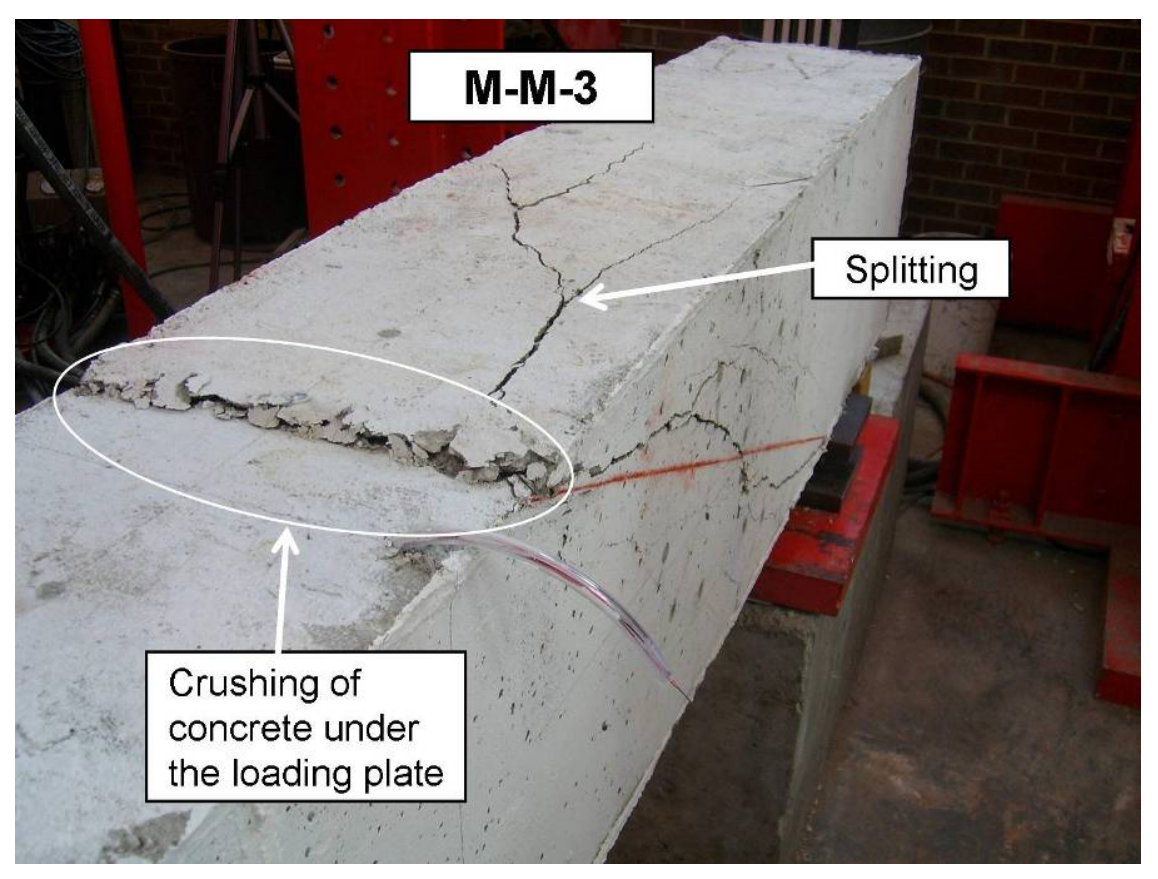

Figure 4.24: Localized failure zone of beam M-M-3

For a given set, the cracking pattern at each load level was almost the same for all three beams. In order to illustrate this behavior, the cracking pattern of each beam tested in Set 3 is shown in Figure 4.25 for the 130 kip, 140 kip, and 150 kip load levels. The figure indicates a similar crack pattern for all tested beams at the same load level with the exception 
of beam M-M-3, which displays slightly more distributed cracking. This suggests that the use of MMFX has the capability to distribute cracks and control crack width in comparison to conventional Grade 60 reinforcement.

Beam C-C-3 failed before reaching the 140 kip load level, therefore no picture is shown in Figure 4.25b. The two remaining beams show almost the same crack pattern at the increased load. At a load level of 150 kips, only beam M-M-3 is shown due to the failure of the other two beams. Appendix A provides similar figures for Set 1 and Set 2. 


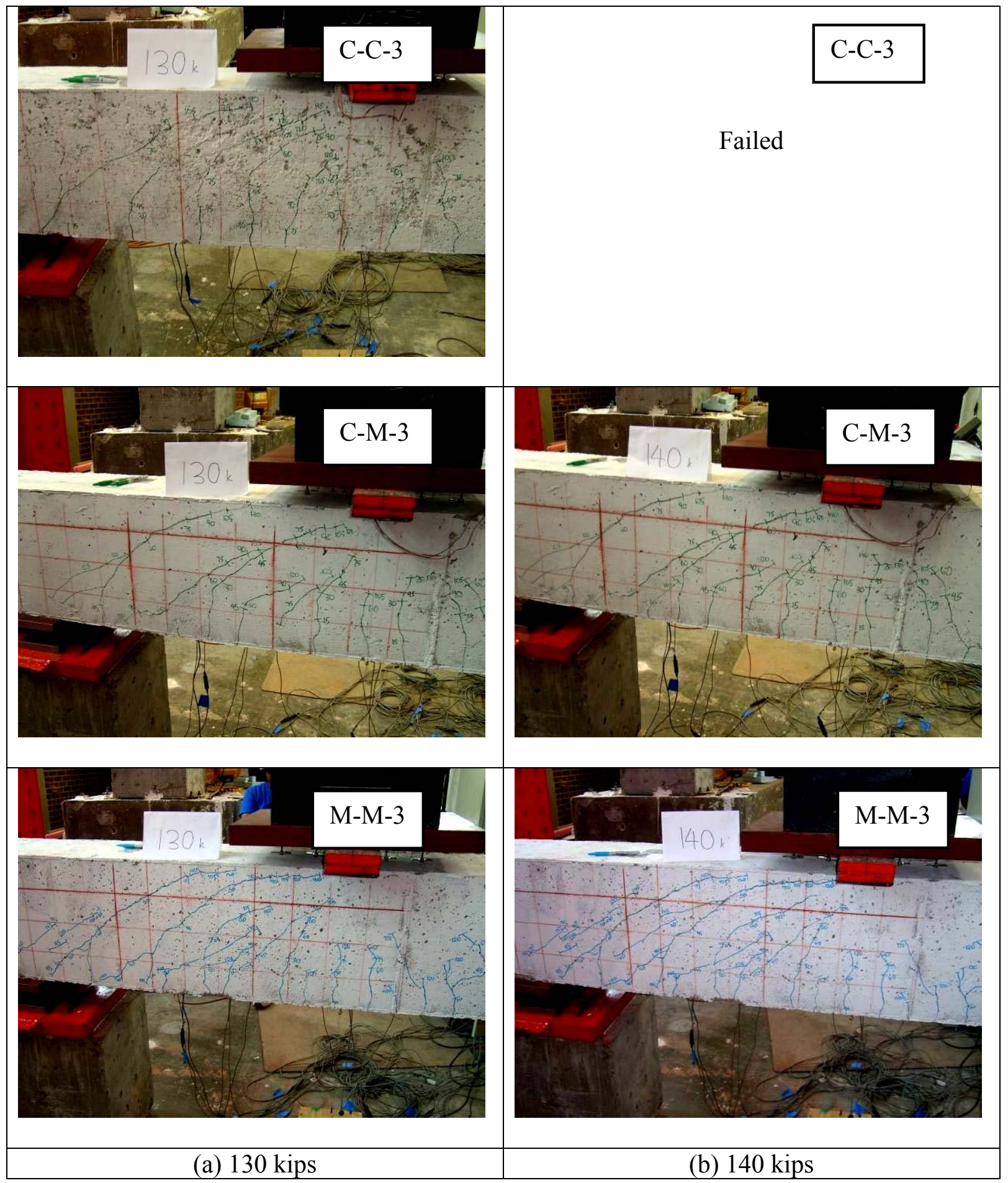

Figure 4.25: Set 3, loading until failure 


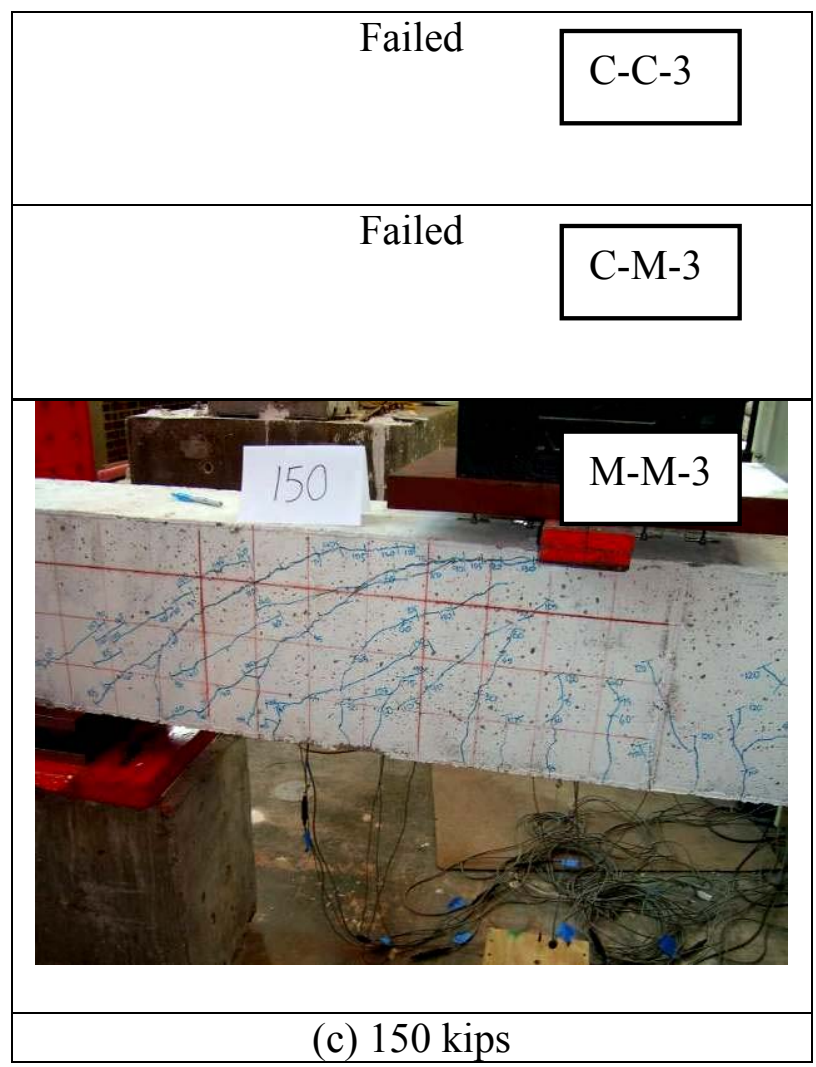

Figure 4.25: (continued)

\subsection{Mode of Failure}

The mode of failure observed during the experimental program was shear compression, regardless of the transverse reinforcement level. Since failure was controlled by the crushing of concrete in the nodal zone of the strut, the research could not fully utilize the strength of the MMFX stirrups beyond $80 \mathrm{ksi}$. However, pairing high strength concrete with high performance steel would take better advantage of the high strength characteristics of the MMFX steel.

Despite of the different shear span to depth ratios, every beam exhibited almost the same behavior during testing and up to failure. As expected, decreasing the amount of stirrup spacing increased the overall shear capacity of the member. Similarly, reinforcing the 
member with longitudinal MMFX rebars provided additional flexural strength and increased the shear compression capacity. The type of transverse steel had less influence compared to the type of longitudinal steel, although did create a slight increase in shear capacity.

\subsubsection{Failure mode of Set 1}

Failure of the three beams tested in Set 1, with a transverse spacing of six inches, was due to the crushing of concrete in the compressive strut. All beams were overly-reinforced with longitudinal rebars, so that yielding of the stirrups in beam C-C-6 did not cause an immediate failure in shear compression mode. While beam C-M-6 failed in the same manner, the stirrups did not yield due to the high strength characteristics of MMFX steel. Beam M-M-6 also failed due to crushing of concrete in the strut, although was at a slightly higher shear load carrying capacity. The longitudinal reinforcement serves an important function by preventing the extension of cracks into the beam depth as well as reducing the overall crack width. Therefore, the greater capacity of M-M-6 was due to the high strength characteristics of the MMFX longitudinal steel which did not yield, and thus helped to limit crack deformation.

One or possibly two main diagonal shear cracks occurred before failure. It was also not unusual for one side of the beam to develop one main crack, while the other side to develop two. This is due to a multitude of factors, such as not having the steel cage perfectly symmetric within the concrete or simply due to the nature of cracking in concrete structures. Figure 4.26 illustrates the typical diagonal shear cracks experienced near failure. 


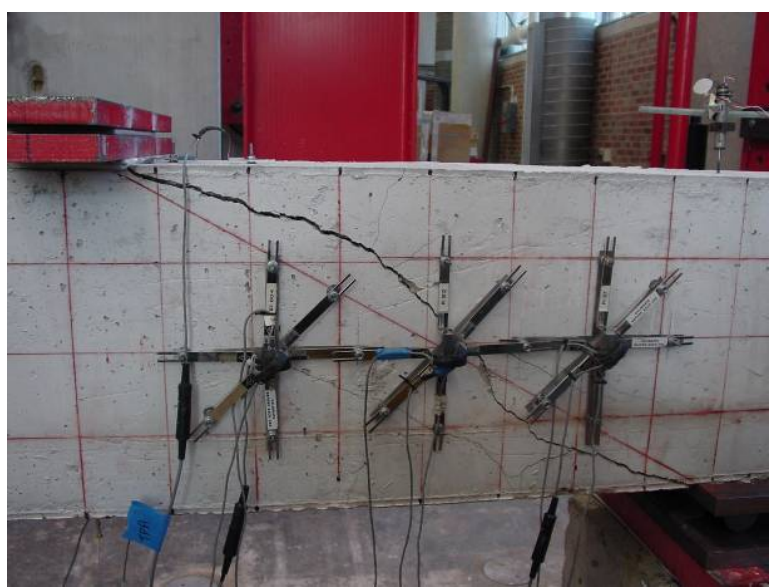

(a) C-C-6

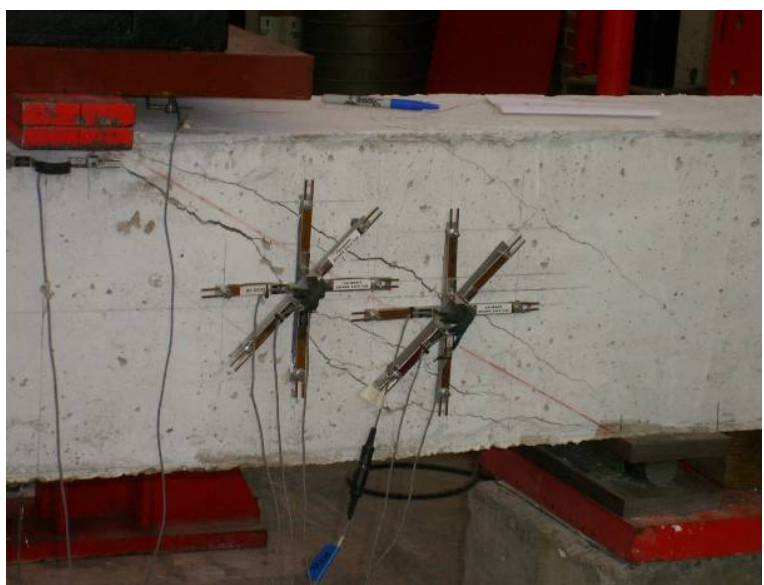

(b) M-M-6

Figure 4.26: Set 1, typical failures

\subsubsection{Failure mode of Set 2}

The beams of Set 2 were different from Set 1 in two aspects: the spacing of the transverse reinforcement was four inches, and the tested shear span to depth ratio was 3.08. The combined effect of these two factors increased the shear strength resistance of the beam and increased the applied moment to shear ratio relative to the first set. Failure of beam C-C-4 was due to shear compression after yielding of both the stirrups and the longitudinal reinforcement. Subsequent to yielding of the stirrups, the beam continued to resist the applied load until yielding of the bottom longitudinal bar layer. The beam then failed due to crushing of the concrete in the compression strut.

Beam C-M-4 likewise experienced yielding of the bottom longitudinal layer, but did not immediately fail. This is due to the ability of MMFX to withstand higher strain levels in comparison to conventional steel until shear failure occurred. Beam M-M-4 failed in the same manner as M-M-6, where the MMFX longitudinal reinforcement increased the flexural 
capacity. Similar to Set 1, one or more major diagonal shear cracks developed before failure, as shown in Figure 4.27.

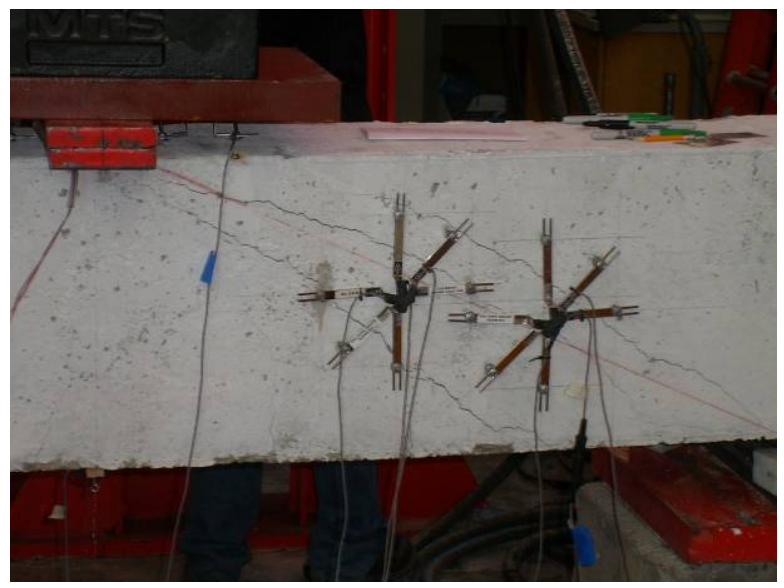

(a) C-C-4

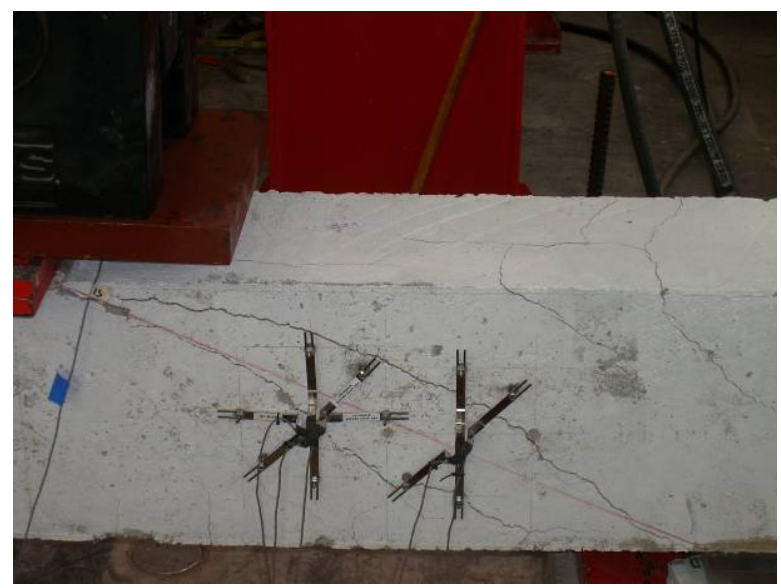

(b) C-M-4

Figure 4.27: Set 2, typical failures

\subsubsection{Failure mode of Set 3}

Beams in Set 3 were reinforced with stirrups spaced at three inches center to center, and tested with a shear span to depth ratio of 3.08. Beam C-C-3 failed due to yielding in both the stirrups and longitudinal steel. While the analysis discussed in Section 4.11 predicts the failure mode as flexural, the overall behavior is still indicative of a shear failure. Beam C-M-3 experienced yielding of the longitudinal bars with the MMFX stirrups nearing the non-linear region, and a failure mode in shear. Beam M-M-3 had the same shear compression mode as previously mentioned for M-M-6 and M-M-4. This is characterized by an increased flexural capacity produced by the MMFX longitudinal rebars. All beams tested in Set 3 typically developed two more main diagonal shear cracks as shown in Figure 4.28. 


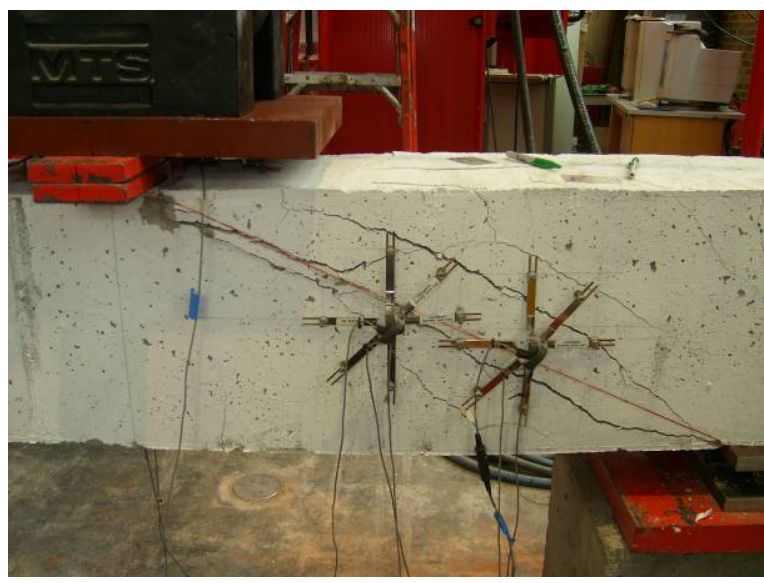

(a) C-M-3

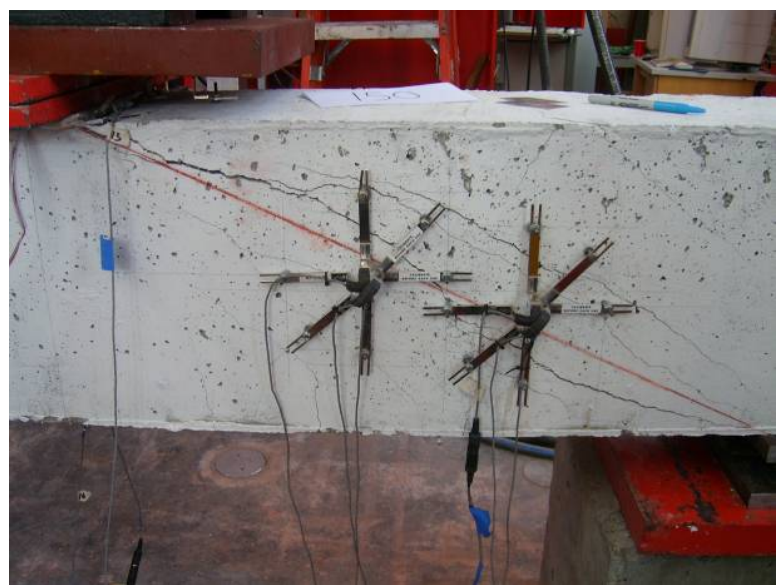

(b) M-M-3

Figure 4.28: Set 3 typical failures

\subsubsection{Analysis of the tested beams}

To verify the mode of failure, the applied moment at failure $M_{\text {exp }}$ was evaluated against the predicted moments $M_{n}$ based on cracked section analysis and moment-curvature analysis. The measured moment is taken at a distance $d_{v}$ away from the center of the applied load, which corresponds to the analytical procedure described in Section 4.11. The length $d_{v}$ is calculated from the AASHTO LRFD design code, which assumes that $d_{v}=0.9 d$. For the beams in this research, $d_{v}=11.7$ inches and is approximated to 12 inches for analysis.

Cracked section analysis is based on the ACI stress block and assumes that the maximum concrete strain is 0.003 at the top of the section, as previously shown in Figure 3.1. The moment-curvature analysis was developed using Hognestad stress-strain characteristics of concrete, and varying the strain in the concrete from 0 to 0.0038 . Table 4.5 provides the 
ratio of the applied moment $M_{\exp }$ at failure to the predicted nominal moment resistance of the section.

Table 4.5: Analysis of the tested beams

\begin{tabular}{|c|c|c|c|c|c|c|c|c|}
\cline { 4 - 9 } \multicolumn{2}{c|}{} & \multicolumn{3}{c|}{ Cracked Section } & \multicolumn{3}{c|}{ Moment-Curvature } \\
\hline $\begin{array}{c}\text { Beam } \\
\text { ID }\end{array}$ & $\begin{array}{c}\mathbf{V}_{\text {exp }} \\
\text { (kips) }\end{array}$ & $\begin{array}{c}\mathbf{M}_{\text {exp }} \\
\text { (kip-in) }\end{array}$ & $\begin{array}{c}\mathbf{M}_{\mathbf{n}} \\
\text { (kip-in) }\end{array}$ & $\mathbf{M}_{\text {exp }} / \mathbf{M}_{\mathbf{n}}$ & Failure & $\begin{array}{c}\mathbf{M}_{\mathbf{n}} \\
\text { (kip-in) }\end{array}$ & $\mathbf{M}_{\text {exp }} / \mathbf{M}_{\mathbf{n}}$ & Failure \\
\hline C-C-6 & 81.88 & 1801 & 3587 & 0.50 & $\mathrm{~S}$ & 3463 & 0.52 & $\mathrm{~S}$ \\
\hline C-M-6 & 86.05 & 1893 & 3624 & 0.52 & $\mathrm{~S}$ & 3501 & 0.54 & $\mathrm{~S}$ \\
\hline M-M-6 & 95.87 & 2109 & 4267 & 0.49 & $\mathrm{~S}$ & 4376 & 0.48 & $\mathrm{~S}$ \\
\hline C-C-4 & 83.08 & 2326 & 3634 & 0.64 & $\mathrm{~S}$ & 3507 & 0.66 & $\mathrm{~S}$ \\
\hline C-M-4 & 91.31 & 2557 & 3649 & 0.70 & $\mathrm{~S}$ & 3517 & 0.73 & $\mathrm{~S}$ \\
\hline M-M-4 & 100.61 & 2817 & 4281 & 0.66 & $\mathrm{~S}$ & 4392 & 0.64 & $\mathrm{~S}$ \\
\hline C-C-3 & 96.06 & 2690 & 3665 & 0.73 & $\mathrm{~S}$ & 3527 & 0.76 & $\mathrm{~S}$ \\
\hline C-M-3 & 99.41 & 2783 & 3665 & 0.76 & $\mathrm{~S}$ & 3527 & 0.79 & $\mathrm{~S}$ \\
\hline M-M-3 & 107.11 & 2999 & 4289 & 0.70 & $\mathrm{~S}$ & 4401 & 0.68 & $\mathrm{~S}$ \\
\hline
\end{tabular}

The failure mode is defined as " $\mathrm{S}$ " for shear or " $\mathrm{F}$ " for flexure. When the ratio of $\mathrm{M}_{\mathrm{exp}} / \mathrm{M}_{\mathrm{n}}$ is greater than one then failure was classified as flexural, but when the ratio is less than one then failure was classified as shear. Both the ACI moment analysis and momentcurvature agree very well with the observed failure mode, which predict all beams to fail in shear. Also, as the transverse reinforcement ratio increases, the applied to predicted moment ratio increases. 


\subsection{Effect of the Steel Type}

Within each beam set, the effect of the steel type can be observed by isolating the effect of the concrete compressive strength. The nominal shear stress for each beam $v$ was approximately calculated using the following equation:

$$
v=\frac{V}{b d}
$$

Eqn. 4.5

where $V$ is the maximum shear load, $b$ is the width of the beam taken as 12 inches, and $d$ is the depth from the top compression fiber to the centroid of the steel and taken as 13 inches. The shear stress is normalized by the square root of the concrete compressive strength $f_{c}^{\prime}$ and given in Table 4.6. The same table also lists the ultimate shear capacity for each beam, as well as the shear stress.

Table 4.6: Increase in strength due to material type

\begin{tabular}{|c|c|c|c|c|c|c|c|}
\cline { 2 - 8 } \multicolumn{1}{c|}{} & Beam ID & $\begin{array}{c}\mathbf{f}_{\mathbf{c}}{ }^{\prime} \\
\text { (psi) }\end{array}$ & $\begin{array}{c}\mathbf{V}_{\text {exp }} \\
\text { (kip) }\end{array}$ & $\begin{array}{c}v \\
\text { (psi) }\end{array}$ & $v / \sqrt{ } \mathbf{f}^{\prime c}$ & $\begin{array}{c}\text { \% Relative } \\
\text { Increase }\end{array}$ & $\begin{array}{c}\text { \% Total } \\
\text { Increase }\end{array}$ \\
\hline \multirow{3}{*}{ Set 1 } & C-C-6 & 3904 & 81.88 & 525 & 8.40 & - & - \\
\cline { 2 - 8 } & C-M-6 & 4282 & 86.05 & 552 & 8.43 & $0.35 \%$ & $0.35 \%$ \\
\cline { 2 - 8 } & M-M-6 & 4660 & 95.87 & 615 & 9.00 & $6.80 \%$ & $7.17 \%$ \\
\hline \multirow{3}{*}{ Set 2 } & C-C-4 & 4390 & 83.08 & 533 & 8.04 & - & - \\
\cline { 2 - 8 } & C-M-4 & 4547 & 91.31 & 585 & 8.68 & $8.00 \%$ & $8.00 \%$ \\
\cline { 2 - 8 } & M-M-4 & 4704 & 100.61 & 645 & 9.40 & $8.34 \%$ & $17.00 \%$ \\
\hline \multirow{3}{*}{ Set 3 } & C-C-3 & 4730 & 96.06 & 616 & 8.95 & - & - \\
\cline { 2 - 8 } & C-M-3 & 4730 & 99.41 & 637 & 9.27 & $3.48 \%$ & $3.48 \%$ \\
\cline { 2 - 8 } & M-M-3 & 4730 & 107.11 & 687 & 9.98 & $7.74 \%$ & $11.50 \%$ \\
\hline
\end{tabular}

The relative shear strength to $\sqrt{f_{c}^{\prime}}$ for each beam ranges from $8 \sqrt{f_{c}^{\prime}}$ to $10 \sqrt{f_{c}^{\prime}}$, which is close to the maximum shear capacity allowed by the ACI Code for a reinforced 
concrete section. Therefore, the current limit of $10 \sqrt{f_{c}^{\prime}}$ suggested by the ACI Code should be maintained for high performance steel since failure was controlled by the concrete compressive strength rather than yielding of the stirrups. The "\% Relative Increase" column shown in Table 4.6 relates the percentage increase in shear strength of a beam to the previous beam in the same set. For example, beam M-M-3 had an increase of $7.74 \%$ in measured shear strength in comparison to beam C-M-3. The "\% Total Increase" column relates the percentage increase in shear strength of beams $\mathrm{C}-\mathrm{M}$ and $\mathrm{M}-\mathrm{M}$, respectively, to beam $\mathrm{C}-\mathrm{C}$ within the same set. For example, beam C-M-4 had an $8 \%$ strength increase in comparison to beam C-C-4.

Test results in Set 1 indicate that there is no significant increase in the shear carrying capacity due to the use of high strength stirrups. This behavior is due to the nature of the shear failure which is controlled by crushing of the concrete strut and not yielding of the stirrups. The $7.17 \%$ increase in shear load capacity measured for beam M-M-6 is due to the additional flexural resistance provided by the MMFX longitudinal steel.

Beams in Set 2 provided relatively large differences in strength carrying capacity due to the longer shear span to depth ratio $(\mathrm{a} / \mathrm{d})$ used for testing. The use of a larger $\mathrm{a} / \mathrm{d}$ ratio increases the ratio of the applied moment to shear, therefore making shear less critical. This load configuration allows more utilization of the shear reinforcement and causes an increase of shear resistance within the beam. While failure of beam C-C-4 occurred after yielding of the longitudinal bar, the high strength MMFX stirrups in beam C-M-4 continued to provide resistance even after the longitudinal reinforcement yielded. The use of MMFX longitudinal reinforcement for beam M-M-4 provided additional flexural resistance, and therefore increased the overall capacity before failure. 
The additional strength measured for beams in Set 3 is similar to the mechanism described for Set 2. The higher overall measured shear strengths are due to the increased transverse reinforcement ratio.

\subsection{Effect of Stirrup Spacing}

This section compares beams reinforced with the same type of steel at the three stirrup spacing levels. To identify the effect of the stirrup spacing, the shear stress $v$ is normalized with respect to $\sqrt{f_{c}^{\prime}}$ in order to compensate for the effect of different concrete strengths in the tested beams. The normalized shear stress versus the measured transverse strain for beams reinforced with C-C, C-M, and M-M are shown in Figure 4.29, Figure 4.30, and Figure 4.31, respectively. The only difference within each graph is the stirrup spacing.

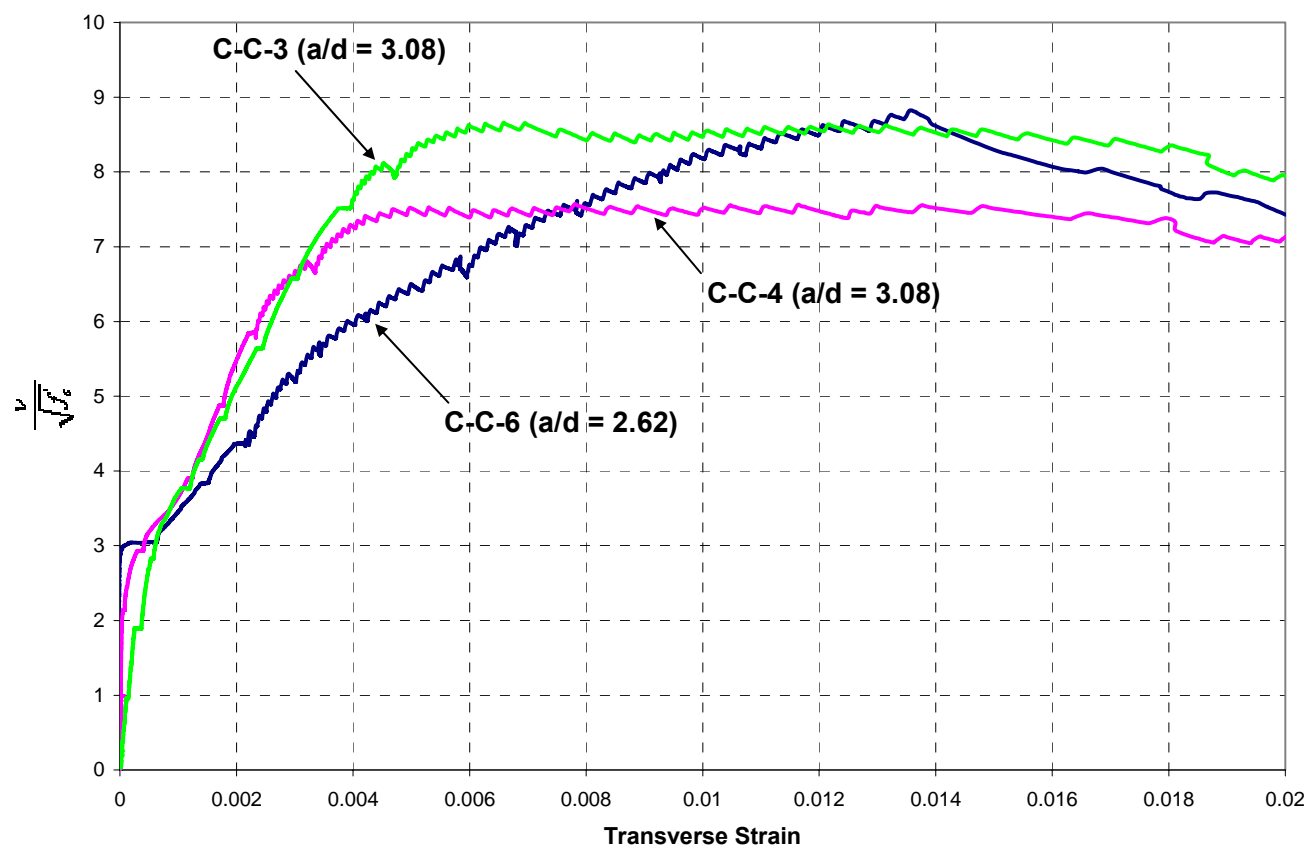

Figure 4.29: C-C, Shear Stress-Transverse Strain 


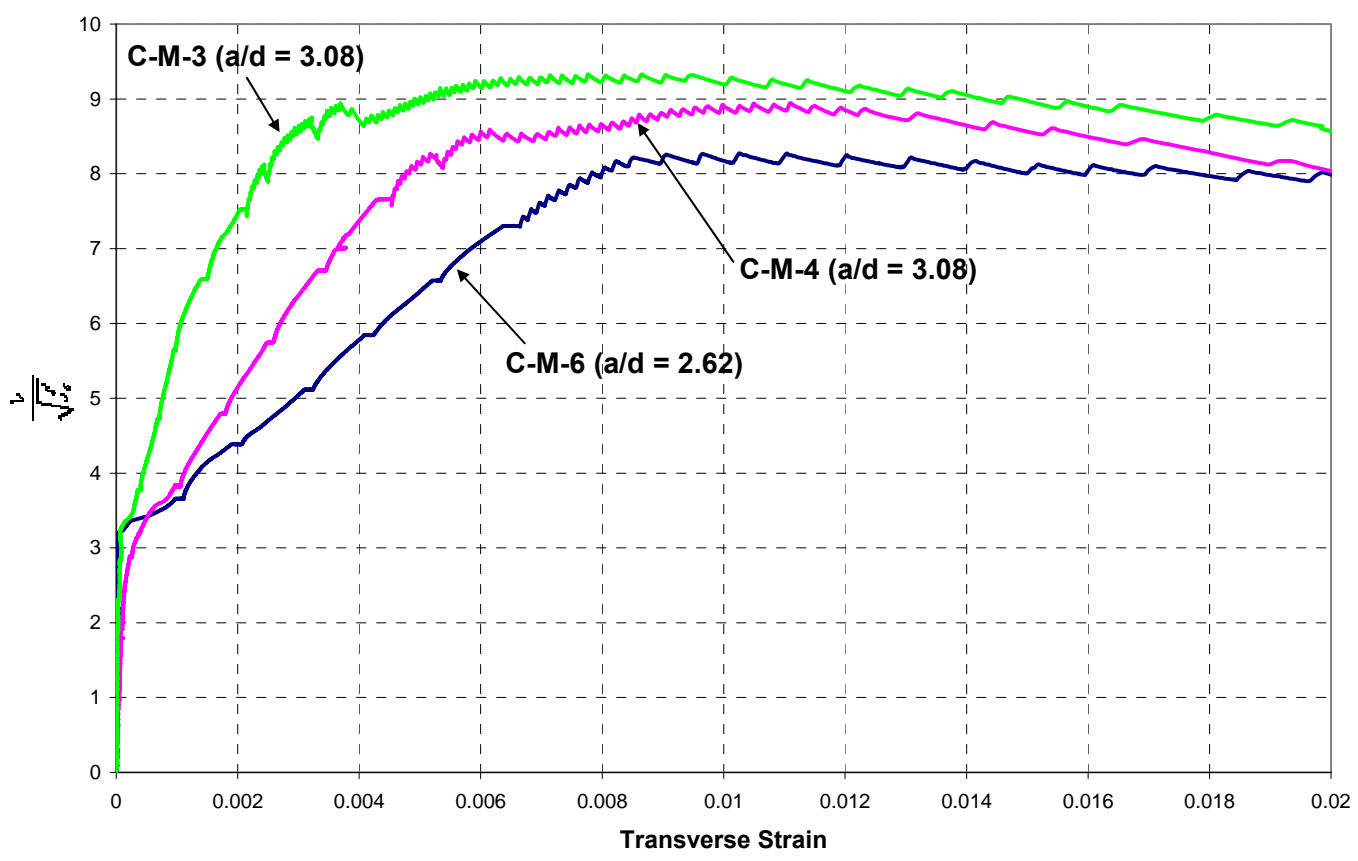

Figure 4.30: C-M, Shear Stress-Transverse Strain

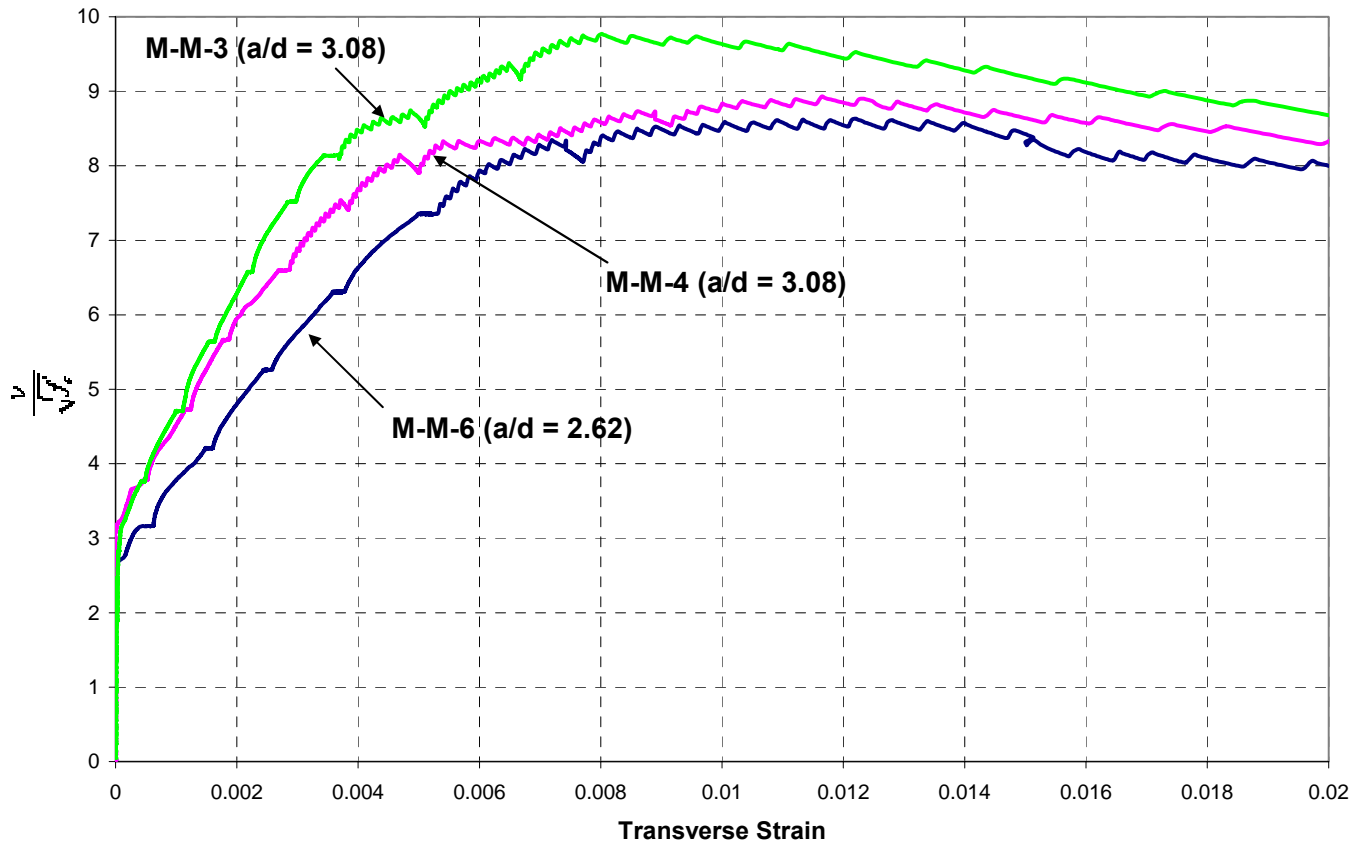

Figure 4.31: M-M, Shear Stress-Transverse Strain 
In general, the behavior indicates that using a closer stirrup spacing increases the overall shear capacity of the beam. Furthermore, using a smaller spacing reduces the transverse strain at any given load level. This is particularly clear for the C-M and M-M cases, however is not as defined for the $\mathrm{C}-\mathrm{C}$ case. While beam $\mathrm{C}-\mathrm{C}-6$ yields at a much lower load level, resulting in significantly higher transverse strains than the other two beams, it has the same shear capacity as C-C-3. This could partially be attributed to the higher a/d ratio present in testing beam C-C-6 It is important to note that these comparisons do not account for the changing shear span to depth ratio between beams with six inch stirrup spacing, and those with three and four inch spacing.

\subsection{Code Predictions}

The maximum measured shear load obtained from testing $V_{\exp }$ was compared to the predictions using the ACI 318-05 Code, the Canadian Standards Association (CSA) Code, and AASHTO LRFD Bridge Design Specifications. Equations used to calculate the code predictions can be found in Section 2.5. Table 4.7 lists the predicted nominal shear strength $V_{n}$ from each design code as well as the ratio of the measured to predicted values. 
Table 4.7: Code comparisons

\begin{tabular}{|c|c|c|c|c|c|c|c|c|}
\hline & \multirow[b]{2}{*}{ ID } & \multirow{2}{*}{$\begin{array}{l}V_{\text {exp }} \\
\text { (kips) }\end{array}$} & \multicolumn{2}{|c|}{$\mathrm{ACl}-318$} & \multicolumn{2}{|c|}{ CSA } & \multicolumn{2}{|c|}{ AASHTO } \\
\hline & & & $\begin{array}{c}V_{n} \\
\text { (kips) }\end{array}$ & $\mathbf{V}_{\exp } / \mathbf{V}_{\mathrm{n}}$ & $\begin{array}{c}V_{n} \\
\text { (kips) }\end{array}$ & $V_{\exp } / V_{n}$ & $\begin{array}{c}V_{n} \\
\text { (kips) }\end{array}$ & $V_{\exp } / V_{n}$ \\
\hline \multirow{3}{*}{ Set 1} & C-C-6 & 81.88 & 48.09 & 1.70 & 53.88 & 1.52 & 52.01 & 1.57 \\
\hline & C-M-6 & 86.05 & 58.55 & 1.47 & 65.66 & 1.31 & 64.14 & 1.34 \\
\hline & M-M-6 & 95.87 & 59.43 & 1.61 & 63.92 & 1.50 & 54.39 & 1.76 \\
\hline \multirow{3}{*}{ Set 2} & C-C-4 & 83.08 & 63.57 & 1.31 & 69.69 & 1.19 & 58.54 & 1.42 \\
\hline & C-M-4 & 91.31 & 78.24 & 1.17 & 84.62 & 1.08 & 73.68 & 1.24 \\
\hline & M-M-4 & 100.61 & 78.60 & 1.28 & 81.88 & 1.23 & 73.93 & 1.36 \\
\hline \multirow{6}{*}{ Set 3} & C-C-3 & 96.06 & 78.66 & 1.22 & 83.38 & 1.15 & 73.98 & 1.30 \\
\hline & C-M-3 & 99.41 & 97.72 & 1.02 & 104.39 & 0.95 & 93.46 & 1.06 \\
\hline & $M-M-3$ & 107.11 & 97.72 & 1.10 & 101.48 & 1.06 & 93.46 & 1.15 \\
\hline & \multicolumn{2}{|c|}{ Average } & \multicolumn{2}{|c|}{1.32} & \multicolumn{2}{|c|}{1.22} & \multicolumn{2}{|c|}{1.36} \\
\hline & \multicolumn{2}{|c|}{$\begin{array}{l}\text { Standard } \\
\text { Deviation }\end{array}$} & \multicolumn{2}{|c|}{0.23} & \multicolumn{2}{|c|}{0.19} & \multicolumn{2}{|c|}{0.21} \\
\hline & \multicolumn{2}{|c|}{$\begin{array}{l}\text { Coefficient of } \\
\text { Variation }\end{array}$} & \multicolumn{2}{|c|}{0.18} & \multicolumn{2}{|c|}{0.16} & \multicolumn{2}{|c|}{0.16} \\
\hline
\end{tabular}

Statistical analysis was performed to determine the average, standard deviation, and coefficient of variation of the measured-predicted ratio. The standard deviation indicates the spread of data relative to the mean, or average. The coefficient of variation is a statistical measure of the dispersion of data points about the mean, and is helpful for comparing data sets with different means. It is desirable to have the standard deviation and coefficient of variation as small as possible.

Based on the results presented in Table 4.7, it can be seen that the CSA code gives the closest predictions to the actual shear capacity. The average ratio for the CSA is 1.22 , compared to 1.32 for the ACI-318 and 1.36 for the AASHTO. It should be noted that analysis for the ACI code is based on $V_{c}=2 \sqrt{f_{c}^{\prime}} b d$, with all codes using a yield strength of 80 ksi for the MMFX stirrups. Test results indicate that all codes are capable to conservatively predict the shear capacity of beams reinforced with conventional and MMFX 
stirrups up to $80 \mathrm{ksi}$, with the standard deviation and coefficient of variation in the same order of magnitude. The predictions are quite conservative for beams reinforced with and without longitudinal MMFX steel for Set 1 and Set 2, which correspond to a typical shear design range for flexural members.

Table 4.8 shows predictions using the ACI equation 11-5 for the concrete contribution, which provides very similar results to the CSA. The ratio average is 1.24 and 1.22 for the ACI and CSA, respectively, with matching values for the standard deviation and coefficient of variation.

Table 4.8: $\mathrm{ACl}$ predictions using the detailed equation for $\mathrm{V}_{\mathrm{c}}$

\begin{tabular}{|c|c|c|c|c|}
\hline & \multirow[b]{2}{*}{ ID } & \multirow[b]{2}{*}{$\begin{array}{l}V_{\text {exp }} \\
\text { (kips) }\end{array}$} & \multicolumn{2}{|c|}{$\mathrm{ACl}-318$} \\
\hline & & & $\begin{array}{c}V_{n} \\
\text { (kips) }\end{array}$ & $V_{\exp } / V_{n}$ \\
\hline \multirow{3}{*}{ Set 1} & $\mathrm{C}-\mathrm{C}-6$ & 81.88 & 52.85 & 1.55 \\
\hline & C-M-6 & 86.05 & 63.26 & 1.36 \\
\hline & M-M-6 & 95.87 & 64.10 & 1.50 \\
\hline \multirow{3}{*}{ Set 2} & C-C-4 & 83.08 & 67.41 & 1.23 \\
\hline & C-M-4 & 91.31 & 82.06 & 1.11 \\
\hline & M-M-4 & 100.61 & 82.40 & 1.22 \\
\hline \multirow{6}{*}{ Set 3} & $\mathrm{C}-\mathrm{C}-3$ & 96.06 & 82.46 & 1.16 \\
\hline & C-M-3 & 99.41 & 101.53 & 0.98 \\
\hline & M-M-3 & 107.11 & 101.53 & 1.05 \\
\hline & \multicolumn{2}{|c|}{ Average } & \multicolumn{2}{|c|}{1.24} \\
\hline & \multicolumn{2}{|c|}{$\begin{array}{l}\text { Standard } \\
\text { Deviation }\end{array}$} & \multicolumn{2}{|c|}{0.19} \\
\hline & \multicolumn{2}{|c|}{$\begin{array}{l}\text { Coefficient of } \\
\text { Variation }\end{array}$} & \multicolumn{2}{|c|}{0.16} \\
\hline
\end{tabular}

In general, all codes provide conservative estimates for the shear strength of flexural members, except beam C-M-3. The CSA slightly overestimates the strength as given by the measured to predicted ratio of 0.95 . The codes are the least conservative for the C-M cases, 
which is due to the fact that a yield strength of $80 \mathrm{ksi}$ was not originally included in the design. The conservatism shown for the M-M cases is due to the unaccounted contribution of the MMFX longitudinal steel towards the shear capacity of the beams. The built-in conservatism of the code equations is due to the complex nature of shear failure.

Most of the current codes do not adequately account for the strength of the longitudinal reinforcement. This is evidenced by predictions of the M-M shear strengths, which are predicted to be equal to, or less than, C-M. Beams reinforced with three inch stirrup spacing, for example, show an ACI prediction of 97.72 kips and 97.72 kips for beams C-M-3 and M-M-3, respectively. The codes can only discern differences between the two beams based on the concrete compressive strength. However, measured values show that beams with MMFX longitudinal rebars have higher strengths than beams reinforced with conventional rebars by $6.80-8.34 \%$ (Table 4.6 ).

Test results indicate that the ACI-318, CSA, and AASHTO codes can adequately predict the behavior for concrete beams reinforced with MMFX rebars using a design yield strength of $80 \mathrm{ksi}$. In order to validate higher stress levels such as $100 \mathrm{ksi}$, further testing should be performed by specifically designing the shear reinforcement up to this level.

\subsection{Response 2000}

Response $2000(\mathrm{R} 2 \mathrm{~K})$ is a program that allows users to analyze beams and columns subjected to moment, shear, and axial loads. It was created as part of the $\mathrm{PhD}$ thesis by $\mathrm{Dr}$. Evan Bentz (2000) at the University of Toronto. Dr. Bentz also created a helpful online manual that can be downloaded as a PDF file, or viewed in html format (2000). Virtually any type of beam geometry, material types, and material properties can be input and used in 
analysis. The fundamental theory supporting the program is the Modified Compression Field Theory. Two main assumptions implicit within R2K are that plane sections remain plane, and that there is no transverse clamping over the beam depth. Transverse clamping stresses occur close to concentrated loads or supports, and serve to locally increase the strength (Bentz, 2000).

There are three main types of analysis that Response 2000 can perform: flexural, sectional, and member response. The flexural analysis assumes no shear or axial load, and solves for the maximum moment of the beam. The sectional analysis predicts the sectional behavior at any location along the member due to the combined effects of moment and shear. Finally, member response predicts the full member behavior for a given span. In this research, sectional and member response analysis were used to verify the strength and the behavior at ultimate conditions.

\subsubsection{Cross section inputs}

The cross section is created through a graphical interface. The user first defines material properties such as concrete strength, longitudinal bar yield strength, and transverse bar yield strength. These values can later be modified to specifically fit the material. Geometry of the cross section, the number and type of longitudinal bars, and the type and spacing of transverse steel can be selected. This creates the entire input data for the cross section and can be graphically viewed on the screen. Finally, the distances to the center of each steel bar and the concrete cover are checked and, if necessary, corrected.

In order to properly model the behavior, it was necessary to accurately input the material properties of the steel and concrete. For concrete, the program automatically 
assumes a sophisticated stress-strain relationship including compression softening and tension stiffening, so the only value modified was the compressive strength. The rebar, however, was changed in order to match the actual properties observed during material testing. R2K allows the user to input the elastic modulus, yield strength, strain hardening, rupture strain, and ultimate strength. While these values can easily be extrapolated from the conventional Grade 60 stress-strain curve, it is slightly more complicated for the MMFX. Because of this, an iterative approach was used to determine a best-fit curve for the stressstrain relationship of the MMFX steel. Figure 4.32 shows a comparison of the measured stress-strain curve of the MMFX and the model curve used for R2K analysis.

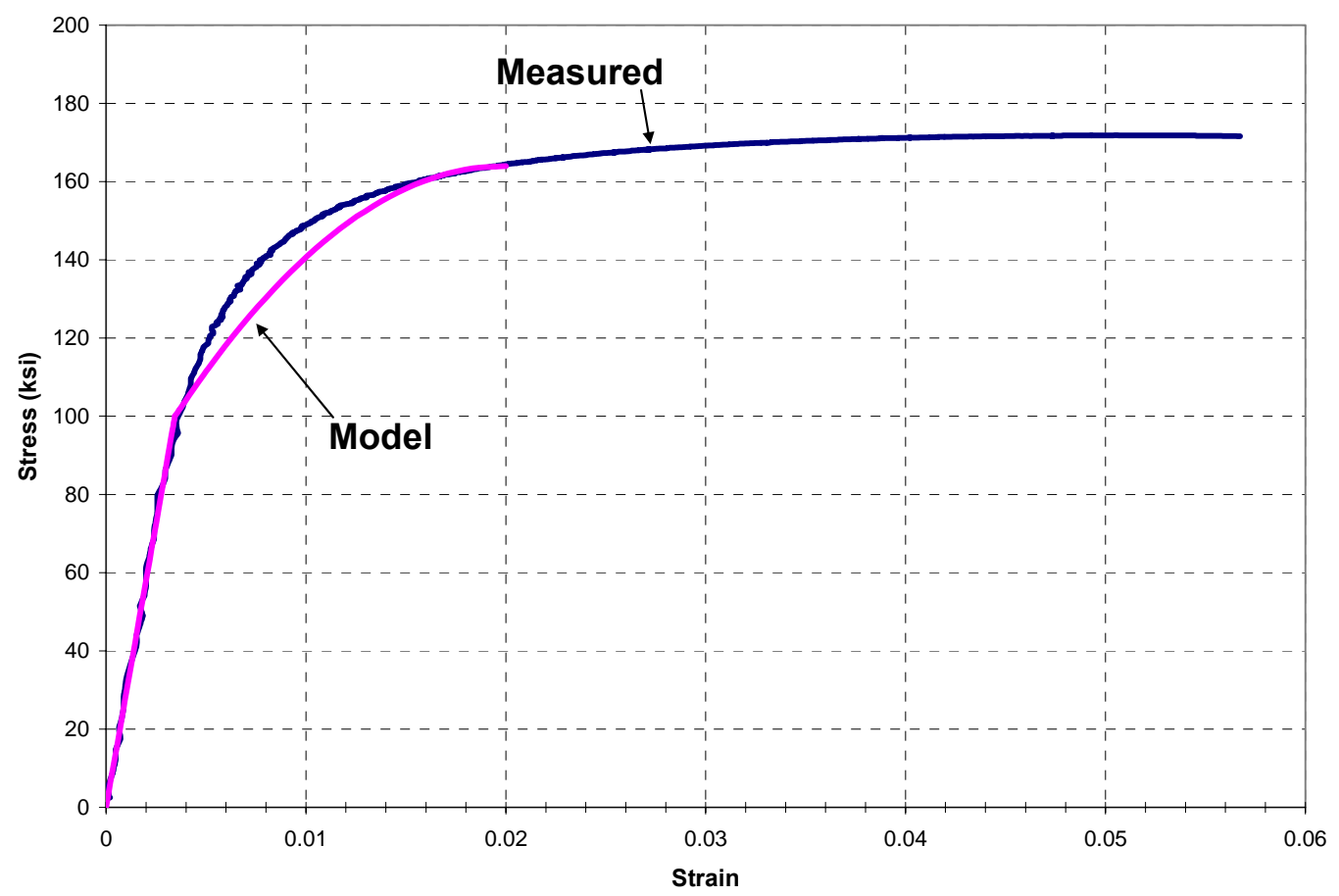

Figure 4.32: MMFX stress-strain relationship, measured vs. model

Figure 4.32 shows a very close correlation between the measured MMFX stress-strain curve and the model used in Response 2000 analysis. This fit was created by modifying the 
parameters mentioned previously. In order to increase the slope of the non-linear region, the ultimate strain was reduced to 0.02 . In reality this value is much less than the actual, but proved to be an acceptable model since strains were less than this level. Figure 4.33 shows a screenshot of the R2K program after inputting a beam's cross section and material properties.

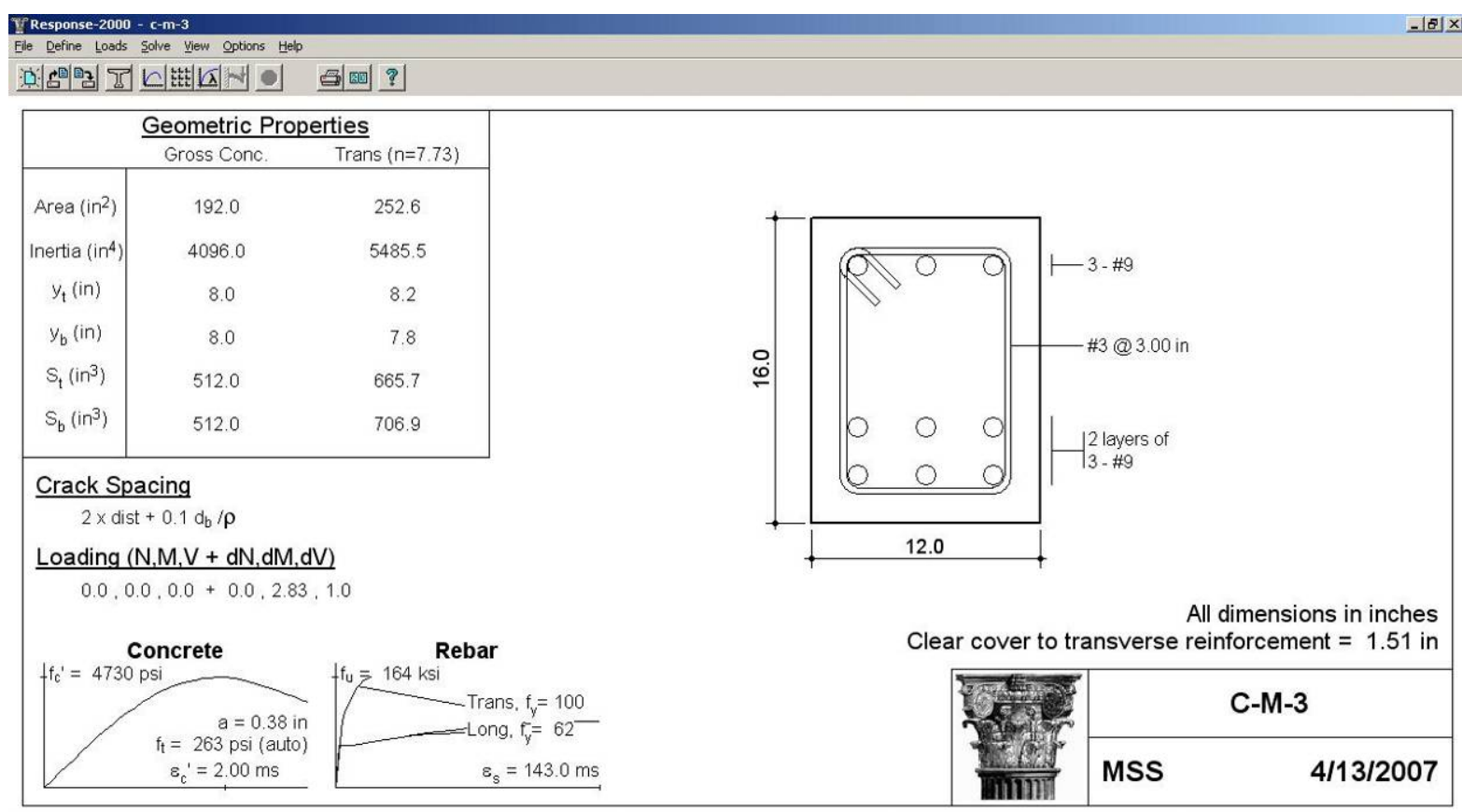

Figure 4.33: R2K screenshot

\subsubsection{Sectional analysis}

The key parameter in sectional analysis when predicting the strength of a beam is selecting the location of the section. Although it may seem obvious to look at a section underneath the applied load, which corresponds to the maximum moment and shear, experience indicates that this may not be the best location. Instead, it is recommended to use a section at a distance $d_{v}$ from the support or applied concentrated load, which can be taken 
as $0.9 d$. The regions within a length $d_{v}$ to a discontinuity (D-region) do not follow the strain compatibility assumption. The Modified Compression Field theory, and consequently Response 2000, assumes that a linear strain relation within the section is applicable. As a result, analysis on sections taken within the D-region will result in very conservative predictions. A corollary to this statement is that R2K cannot be used for deep beams. From this discussion, sectional analysis was taken at a distance of 12 " from the center of the applied load and is shown in Figure 4.34.

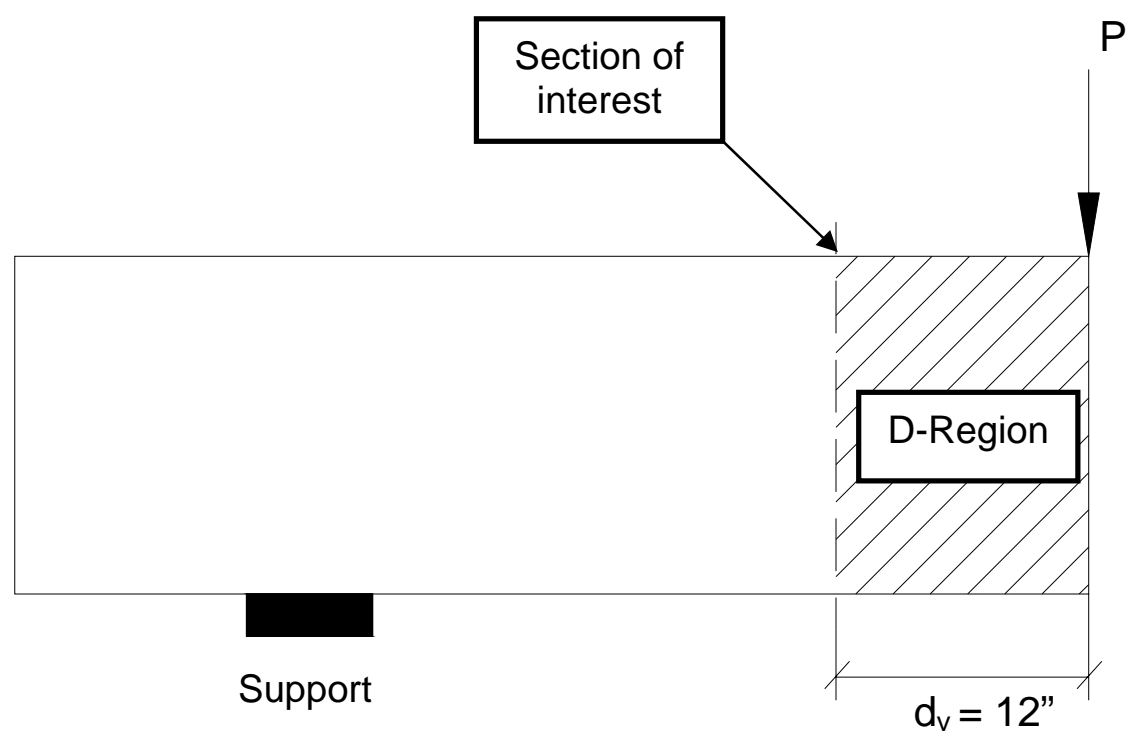

Figure 4.34: Location for sectional analysis

After choosing the correct section of interest, the ratio of moment versus shear at that point is input as data into the program.

The advantage to using sectional analysis is the wealth of information provided by Response 2000, as well as the speed of running the program. A normal test takes only seconds to run. After analysis, a series of nine graphs are provided for the cross section under consideration. These include: longitudinal strain, transverse strain, crack diagram, 
shear strain, shear stress, principal compressive stress, shear on crack, and the principal tensile stress at the state of failure. In addition, two control plots are also given for the maximum shear and moment at this section. A typical screen shot of this information is featured in Figure 4.35 .

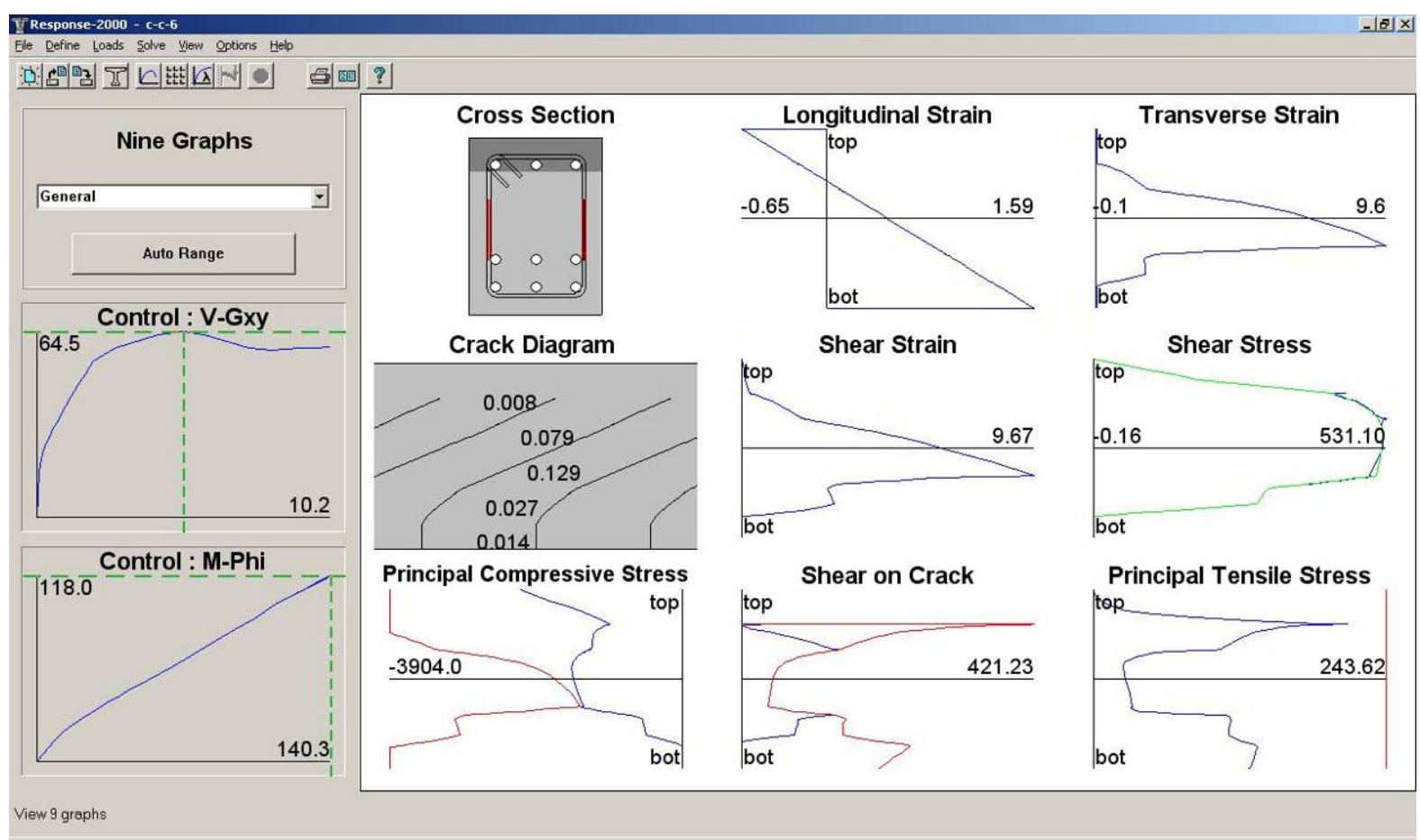

Figure 4.35: Sectional analysis screenshot

In order to better understand the information in each plot, a brief description of them is provided below. The main plots used during analysis were the Shear-Shear Strain control plot, the Cross Section, and the Principal Compressive Stress. Note that each of the nine plots has the y-axis as the section depth. 
- Cross section: Darker regions of the cross section indicate uncracked concrete. Reinforcement drawn in dark red have yielded, while drawn in bright red is within the strain hardening region.

- Longitudinal strain: The longitudinal strain shows the assumption that plane sections remain plane. Maximum and minimum strain values are listed.

- Transverse strain: The transverse strain is not linearly distributed due to local stressstrain conditions. Maximum and minimum strain values are listed.

- Crack diagram: This shows the estimated crack pattern and the crack widths (inch units). Sections will be drawn pink where the concrete is crushing, or drawn in purple where cracks are slipping.

- Shear strain: This plots the section shear strain and gives the maximum and minimum strain values.

- Shear stress: This gives the calculated shear stress profile in green and the stress from strain in blue (psi units). These lines will usually be coincident, but extra caution should be taken if they are not.

- $\quad$ Principal compressive stress: The maximum allowable stress is shown in red, and the applied stress along the section is shown in blue (psi units). When the red and blue lines touch, failure is due to concrete crushing.

- Shear on the crack: The shear stress limit on the crack is shown in red, with the applied stress shown in blue (psi units).

- Principal tensile stress: The maximum allowable stress is shown in red, and the applied stress along the section is shown in blue (psi units). If the red line extends diagonally and intersects the blue line, then the section is close to flexural failure. 
- Shear-Shear Strain control plots: The plot shows the maximum predicted shear and shear strain on the section.

- Moment-Curvature control plot: The plot shows the maximum predicted moment and curvature at the section.

Other graphs and charts can be created through various program menus, however these were not examined.

\subsubsection{Member response analysis}

Member response calculates the full member behavior including the deflection and curvature along the member length, as well as predicted failure modes. Although it is not in the scope of this research, further information on how member response is performed can be found in the literature (Bentz, 2000). Analysis is performed by specifying the "length subjected to shear" and any constant moment region. For this research, the constant moment region was zero while the shear span was 34", 40", and 40" for Set 1, Set 2, and Set 3, respectively. Running the program is very fast, and typically takes less than ten seconds to perform. Similar to the sectional analysis, member response should not be performed for deep beams.

Once analysis is complete, five plots are shown in the main window with two plots in the left window. These include the member crack diagram, curvature distribution, shear strain distribution, deflection, load-max deflection, moment-shear interaction diagram, and the shear-deflection diagram. A screenshot is shown in Figure 4.36. 


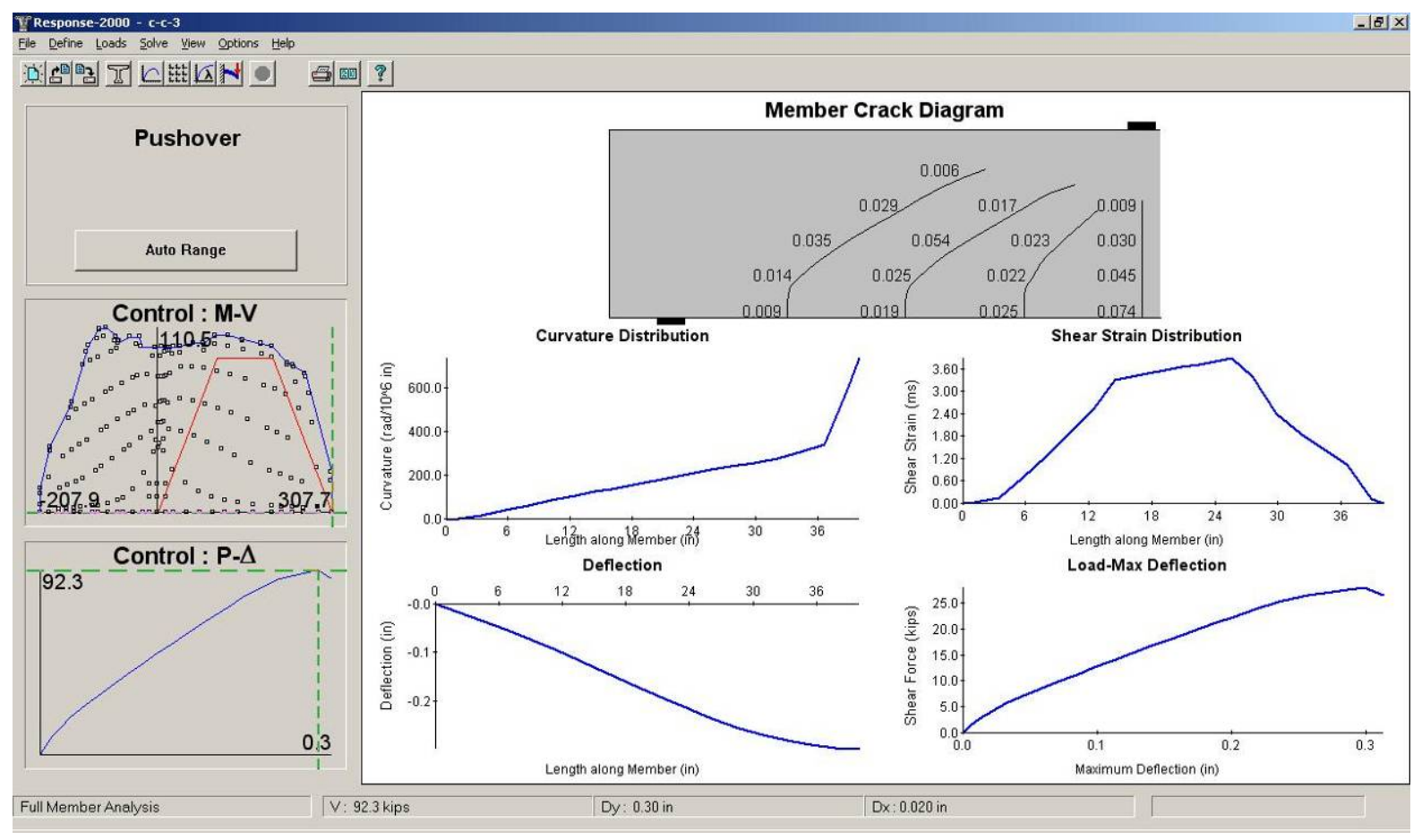

Figure 4.36: Member response screenshot

Each graph in the main window plots values along the length of the member. However, the information used for research analysis was from the interaction plots in the left window. A description of the various diagrams is given below:

- Moment-Shear Interaction diagram (M-V): The vertical axis is the shear in kips and the horizontal axis is the moment in kip-ft. The outer blue line represents the failure envelope, while the inner red line represents the loading envelope.

- Shear-Deflection diagram (P- $\Delta$ ): The vertical axis is the shear in kips and the horizontal axis is the deflection in inches. The corresponding load and deflection is based on the maximum values achieved by the loading envelope in the moment-shear interaction diagram. 


\subsubsection{Results of the analysis}

Both sectional analysis and member response analysis were performed to study the behavior. The member response was used to identify the failure mode. In the case of a flexural failure, the maximum shear load was determined based on member response. The sectional analysis was used to validate the behavior from member response, and to view the stresses and strains. In the case of shear failure, the sectional response was used to evaluate the maximum shear, stresses, and strains. Table 4.9 shows the Response 2000 results with the same type of statistical analysis given in Section 4.10.

Table 4.9: Response 2000 analysis results

\begin{tabular}{|c|c|c|c|c|c|}
\hline & $\begin{array}{l}\text { Beam } \\
\text { ID }\end{array}$ & $\begin{array}{c}V_{\exp } \\
(\text { kips) }\end{array}$ & $\begin{array}{c}V_{n} \\
(k i p s)\end{array}$ & $\mathbf{V}_{\exp } / \mathbf{V}_{\mathrm{n}}$ & $\begin{array}{c}\text { Predicted } \\
\text { Failure }\end{array}$ \\
\hline \multirow{3}{*}{ Set 1} & C-C-6 & 81.88 & 64.5 & 1.27 & $\mathrm{~S}$ \\
\hline & C-M-6 & 86.05 & 94.8 & 0.91 & $\mathrm{~S}$ \\
\hline & M-M-6 & 95.87 & 103.9 & 0.92 & $S$ \\
\hline \multirow{3}{*}{ Set 2} & C-C-4 & 83.08 & 81.2 & 1.02 & $\mathrm{~S}$ \\
\hline & C-M-4 & 91.31 & 92.0 & 0.99 & $\mathrm{~F}$ \\
\hline & M-M-4 & 100.61 & 112.8 & 0.89 & $\mathrm{~S}$ \\
\hline \multirow{3}{*}{ Set 3} & C-C-3 & 96.06 & 92.3 & 1.04 & $\mathrm{~F}$ \\
\hline & C-M-3 & 99.41 & 92.3 & 1.08 & $\mathrm{~F}$ \\
\hline & M-M-3 & 107.11 & 112.3 & 0.95 & $\mathrm{~S}$ \\
\hline & \multicolumn{2}{|c|}{ Average } & \multicolumn{2}{|r|}{1.01} & \\
\hline & \multicolumn{2}{|c|}{$\begin{array}{l}\text { Standard } \\
\text { Deviation }\end{array}$} & \multicolumn{2}{|r|}{0.12} & \\
\hline & \multicolumn{2}{|c|}{$\begin{array}{l}\text { Coefficient of } \\
\text { Variation }\end{array}$} & \multicolumn{2}{|r|}{0.12} & \\
\hline
\end{tabular}

Results in Table 4.9 show a close correlation of the measured data to the analysis by Response 2000 in comparison with the predictions using the ACI-318, CSA, and AASHTO design codes. The ratio average is 1.01 with a standard deviation and coefficient of variation 
equal to 0.12 . One reason Response 2000 is more accurate is because it takes into account the additional resistance provided by the MMFX longitudinal reinforcement. Predictions for Set 2 and Set 3 tend to be better than that of Set 1. This is likely due to the fact that Set 1 beams have a smaller a/d ratio and are close to being considered a deep beam, which could result in conservative or inaccurate predictions by Response 2000. The predictions for beams with MMFX stirrups were also as accurate as those using conventional stirrups, which validates the use of the stress-strain model shown in Figure 4.32.

The last column gives the predicted failure for each beam, where "S" represents shear failure and "F" represents flexural failure. All beams in Set 1 and Set 2 were predicted to fail in shear, with the exception of C-M-4 which failed in flexure. The beams in Set 3 failed in flexure, except M-M-3 which failed in shear. This mode of failure coincides closely with the failure described in Sections 4.4 and 4.7, and calculated from analysis (Table 4.5). There were three ways to determine the mode of failure in $\mathrm{R} 2 \mathrm{~K}$ : moment-shear diagram from member response, shear-shear strain diagram from sectional analysis, and the principal compressive stress from sectional analysis. The methods of determining failure are listed below:

- Moment-Shear interaction diagram: If the red line touches the blue line towards the top, then a shear failure is predicted. Conversely, if it touches on the far right hand side then a positive flexural failure is predicted.

- Shear-Shear strain control plots: If the plot begins descending with increasing strain, then a shear failure is predicted.

- Principal compressive stress: Shear failures generally showed both lines touching, or about to touch, which indicates concrete strut crushing in the section. 
Beams C-C-3 and M-M-4 are shown in Figure 4.37 and Figure 4.38, respectively, to demonstrate how flexural and shear failures were identified. Diagrams of analysis for each beam will be shown in Appendix B.

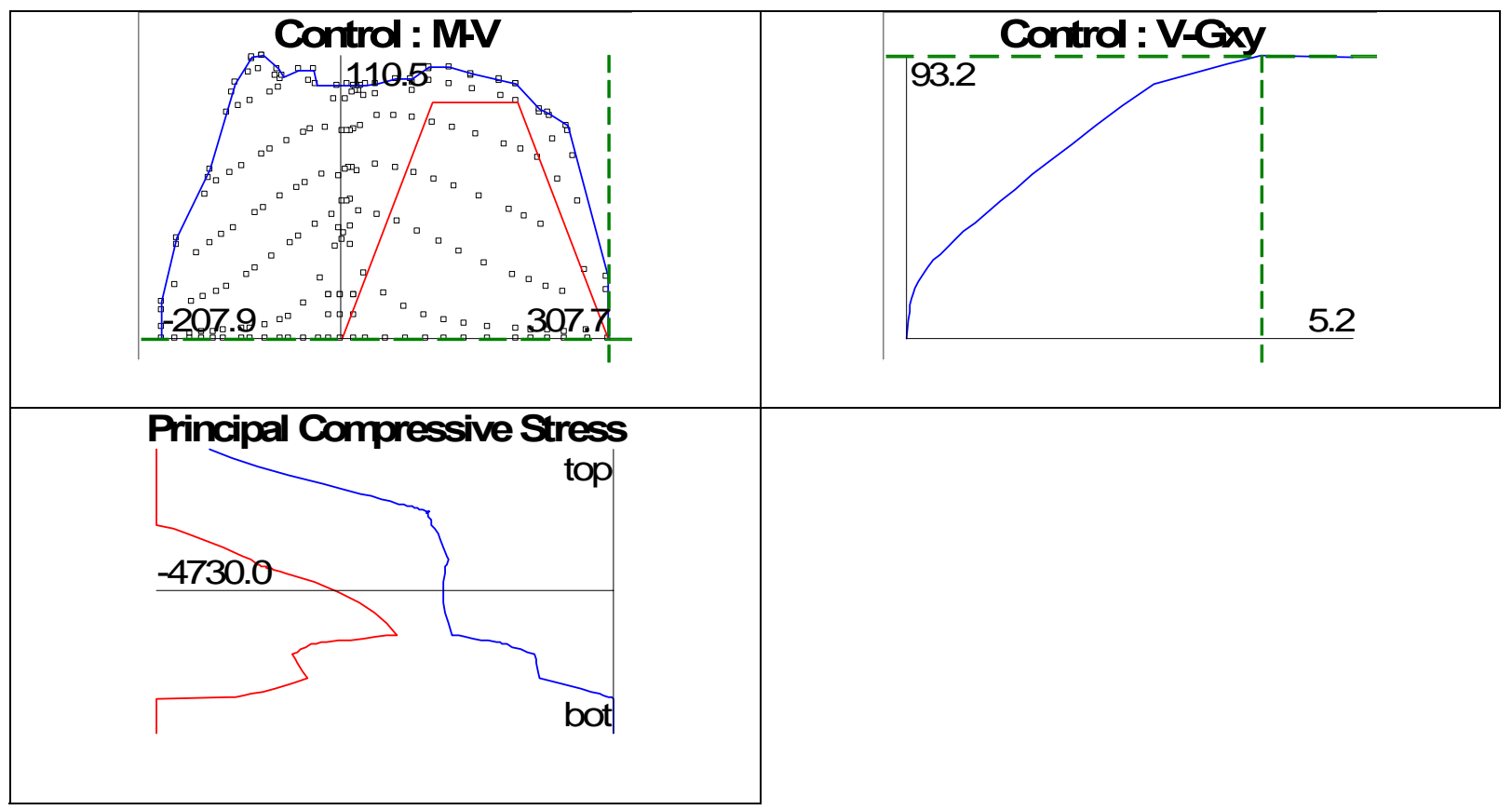

Figure 4.37: Flexural failure example, C-C-3

The three plots in Figure 4.37 indicate a flexural failure. In the M-V plot, the red loading envelope is touching the blue line at the bottom right. The $V-G_{x y}$ plot reaches a maximum value, but then stops. Finally, the allowable and applied principal stresses do not intersect so the concrete did not crush in the strut. 


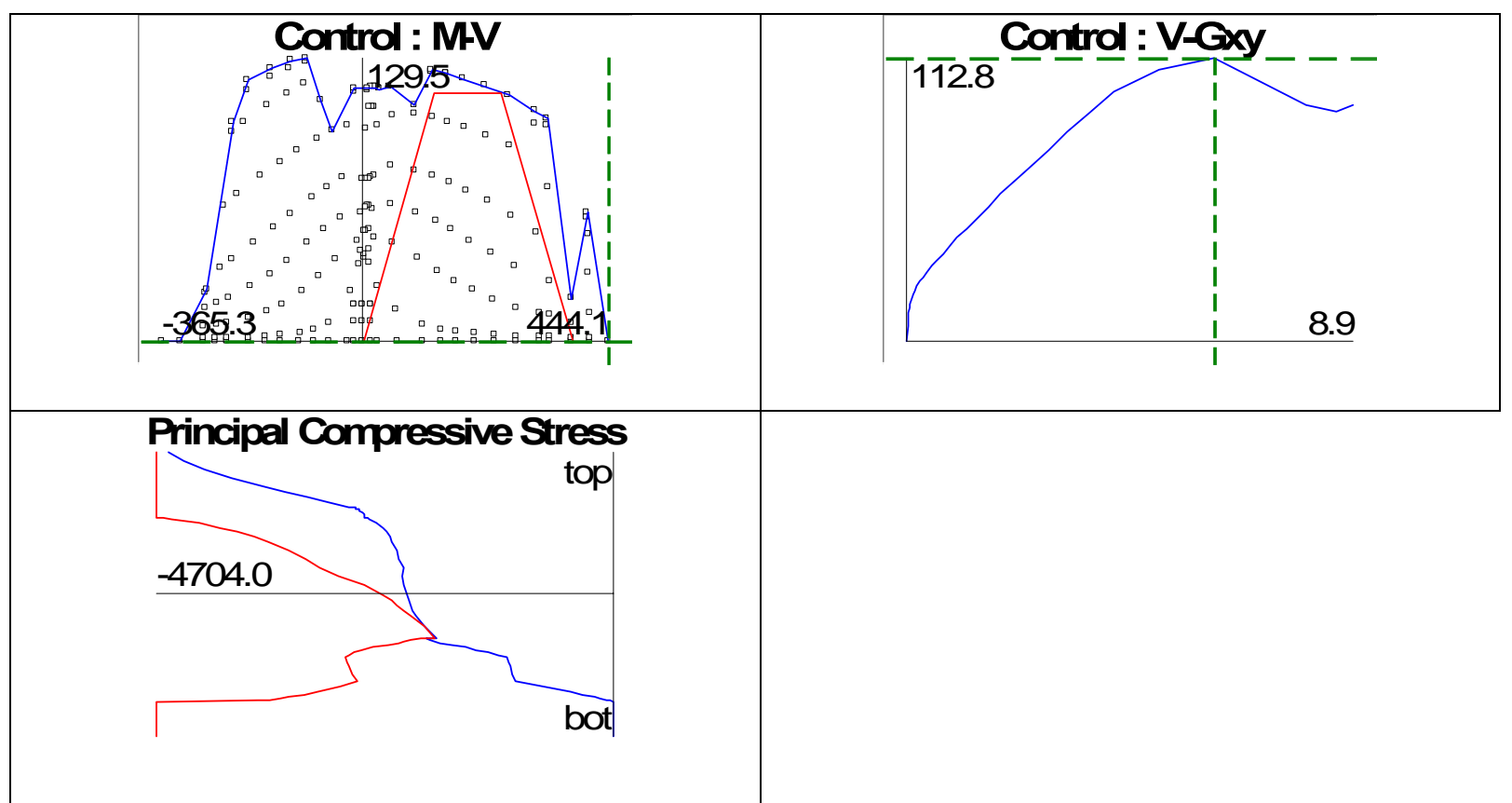

Figure 4.38: Shear failure example, M-M-4

The three plots in Figure 4.38 indicate a shear failure. In the $\mathrm{M}-\mathrm{V}$ plot, the red loading envelope is touching the blue line at the top. The $\mathrm{V}-\mathrm{G}_{\mathrm{xy}}$ plot reaches a maximum point, but then begins descending. Finally, the allowable and applied principal stresses intersect near the bottom of the beam indicating the concrete strut has crushed. 


\subsection{CONCLUSIONS AND RECOMMENDATIONS}

\subsection{Overview}

This research investigated the shear behavior of reinforced concrete using high performance (HP) steel reinforcement commercially known as MMFX Steel (Microcomposite Multistructural Formable Steel). MMFX steel has an enhanced corrosion resistance coupled with significantly higher strength in comparison to conventional Grade 60 steel. Advantages of using higher strength steel include the ability to design longer span lengths and/or reducing the amount of material typically needed for design. Consequently, this could greatly reduce the overall costs of construction for future structures. Researchers at NC State University are currently investigating the bond behavior of reinforced concrete using MMFX steel. This research focused on the behavior of MMFX steel as shear reinforcement, which complements the ongoing efforts at NC State and elsewhere.

The research consisted of an experimental program where nine reinforced concrete beams were fabricated and tested at the Constructed Facilities Laboratory, North Carolina State University. Testing was performed using a single point load positioned closer to one end of the beam, which allowed two tests per beam. This enabled results of the research program to be duplicated. The main parameters considered in the study included the spacing of stirrups along the beam and the replacement of conventional stirrups and longitudinal steel by MMFX.

Concrete cylinders and steel coupons were tested to determine the material properties. An exponential equation used to fit the stress-strain relationship of the MMFX steel was determined to be: $\sigma=169\left(1-e^{-226 \varepsilon}\right)$. Measured data was analyzed to evaluate the effect of 
the steel type on the shear strength. Test results were compared to predicted values using three design codes, and by using a comprehensive detailed analysis which satisfies equilibrium and compatibility.

\subsection{Conclusions}

Based on the experimental program, analysis of the data, and analytical modeling, the following conclusions have been reached:

1. Direct replacement of conventional Grade 60 stirrups with MMFX stirrups increased the shear load capacity of flexural members and enhanced the serviceability in terms of distributing cracks and reducing crack width. This behavior suggests better bond characteristics of the MMFX steel due to the rib configuration in comparison with Grade 60 steel.

2. Direct replacement of conventional Grade 60 longitudinal reinforcement with MMFX longitudinal reinforcement showed an optimum design by further increasing the shear strength and enhancing serviceability.

3. The use of MMFX steel, with a yield strength of $80 \mathrm{ksi}$, increases the allowable service stress level to $48 \mathrm{ksi}$. Shear crack widths measured for all tested beams reinforced with MMFX steel were within the allowable limit specified by the ACI Code.

4. The ACI, CSA, and AASHTO LRFD design codes can conservatively predict the shear behavior of concrete beams reinforced with high performance steel using a yield strength of $80 \mathrm{ksi}$. 
5. The maximum shear resistance of a concrete section recommended by the ACI Code, $10 \sqrt{f_{c}^{\prime}} b_{w} d$, should be maintained for high performance steel reinforcement.

6. Most of the design codes do not consider the effect of the yield strength of longitudinal reinforcement on the shear strength of the member, therefore providing conservative predictions in most cases. This factor is most apparent for the beams reinforced entirely with MMFX steel due to their high tensile capacity.

7. Current research could not fully utilize the strength of MMFX stirrups beyond $80 \mathrm{ksi}$ since the failure was controlled by crushing of the concrete in the strut. Pairing high strength concrete with MMFX steel could provide a better utilization for the high performance steel.

8. Detailed analysis using the Modified Compression Field Theory, included in Response 2000, provides accurate predictions of the overall shear strength of concrete members reinforced with HP steel.

\subsection{Recommendations for Future Research}

Based on the results and conclusions of this research program, several recommendations are given for future work. Subsequent research will serve to develop the effective use of high performance steel.

- Reinforced concrete beams should be specifically designed to utilize the high strength of MMFX steel in order to validate their behavior and current code predictions. While this research has shown that an $80 \mathrm{ksi}$ design level is acceptable, yield strengths up to $100 \mathrm{ksi}$ could be utilized. Therefore, future work should strive to achieve these higher levels and provide further guidance for the design. 
- Future research should continue to use a rectangular section, since this type of section is more representative of shear critical locations. Use of a rectangular section will also allow utilization of the data presented in this thesis.

- Beams should have larger dimensions in order to simulate typical reinforced concrete structures. Future specimens should be approximately 1.5 times the size used in this thesis.

- The test setup should be continued in the same manner described in this study. One point loading provides a convenient method to allow each specimen to be tested twice in order to duplicate the collected data. 


\section{REFERENCES}

1. AASHTO LRFD (2004). Bridge Design Specifications and Commentary ( $3^{\text {rd }}$ Ed.). Washington, DC: American Association of State and Highway Transportation Officials.

2. ACI Committee 318 (2005). Building Code Requirements for Structural Concrete (ACI 318-05) and Commentary (318R-05). Farmington Hills: American Concrete Institute.

3. Angelakos, D., Bentz, E.C., \& Collins, M.P. (2001). "Effect of Concrete Strength and Minimum Stirrups on Shear Strength of Large Members.” ACI Structural Journal, v.98, n.3, pp.290-300.

4. ASTM A 370 (2003). Standard Test Methods and Definitions for Mechanical Testing of Steel Products. West Conshohocken, PA: American Society for Testing and Materials.

5. ASTM C31-03a (2003). Making and Curing Concrete Test Specimens in the Field. West Conshohocken, PA: American Society for Testing and Materials.

6. ASTM C39-05 (2005). Standard Test Method for Compressive Strength of Cylindrical Concrete Specimens. West Conshohocken, PA: American Society for Testing and Materials.

7. Bentz, E.C. (2000). "Sectional Analysis of Reinforced Concrete Members." PhD thesis. University of Toronto: Toronto, Canada.

8. Bentz, E.C. (2000). "Response 2000.” Retrieved August 30, 2006, from: http://www.ecf.utoronto.ca/ bentz/r2k.htm.

9. Bentz, E.C. (2000). “Response 2000 Manual.” Retrieved April 10, 2007, from: http://www.ecf.utoronto.ca/ bentz/manual.shtml.

10. Bentz, E.C., Vecchio, F.J., \& Collins, M.P. (2006). "Simplified Modified Compression Field Theory for Calculating Shear Strength of Reinforced Concrete Elements." ACI Structural Journal, v.103, n.4, pp.614-624. 
11. Collins, M.P., \& Mitchell, D., Adebar, P., \& Vecchio, F.J. (1996). “A General Shear Design Method.” ACI Structural Journal, v.93, n.1, pp.36-45.

12. Collins, M.P., \& Mitchell, D. (1997). Prestressed Concrete Structures ( $1^{\text {st }}$ Ed.). Canada: Response Publications.

13. Collins, M.P., \& Vecchio, F.J. (1986). "The Modified Compression Field Theory for Reinforced Concrete Elements Subjected to Shear.” ACI Journal, v.83, n.2, pp.219-231.

14. Collins, M.P., \& Vecchio, F.J. (1988). "Predicting the Response of Reinforced Concrete Beams Subjected to Shear Using Modified Compression Field Theory." ACI Structural Journal, v.85, n.3, pp.258-268.

15. CSA Committee A23.3 (2004). Design of Concrete Structures, CSA A23.3-04. Rexdale, Ontario, Canada: Canadian Standards Association.

16. El-Hacha, R. (2002). "Fundamental Steel Properties of MMFX Steel Rebars." NC State University, CFL Report No.02-04.

17. Kani, G.N.J. (1967). “How Safe are our Large Reinforced Concrete Beams?” ACI Journal, v.64, n.3, pp.128-141.

18. Kuchma, D., \& Tjhin, T. (2005a). “CAST Design Tool.” Retrieved May 10, 2007, from: http://cee.uiuc.edu/kuchma/strut $\% 5$ Fand $\% 5$ Ftie/CAST/.

19. Kuchma, D., \& Tjhin, T. (2005b). "Strut and Tie Method." Retrieved May 10, 2007, from: http://cee.uiuc.edu/kuchma/strut\%5Fand\%5Ftie/STM/Models.htm.

20. MacGregor, J.G., \& Wight, J.K. (2005). Reinforced Concrete Mechanics and Design ( $4^{\text {th }}$ Ed.). New Jersey: Prentice Hall.

21. Mitchell, D., \& Collins, M.P. (1974). "Diagonal Compression Field Theory - A Rational Model for Structural Concrete in Pure Torsion.” ACI Journal, v.71, n.8, pp. $396-408$.

22. MMFX Technologies Corporation (2002). MMFX Steel Product Bulletin. Irvine, CA. 
23. MMFX Technologies Corporation (2005). MMFX Steel Technologies. Retrieved September 8, 2006, from: http://www.mmfxsteel.com/.

24. National Cooperative Highway Research Program (2005). NCHRP Report 549: Simplified Shear Design of Structural Concrete Members. Washington, D.C.

25. Nilson, A.H., Darwin, D., \& Dolan, C.W. (2004). Design of Concrete Structures $\left(13^{\text {th }}\right.$ ed.). New York: McGraw Hill.

26. Rahal, K.N. (2006). "Shear Behavior of Reinforced Concrete Beams with Variable Thickness of Concrete Side Cover.” ACI Structural Journal, v.103, n.2, pp.171-177.

27. Ramirez, J.A., \& Breen, J.E. (1991). "Evaluation of a Modified Truss-Model Approach for Beams in Shear." ACI Structural Journal, v.88, n.5, pp.562-571.

28. Rizkalla, S., Zia, P., Seliem, H., \& Lucier, G. (2005). "Evaluation of MMFX Steel for NCDOT Concrete Bridges.” NCDOT Research Project 2004-27.

29. Seliem, H.M.A. (2007). "Behavior of Concrete Bridges Reinforced with HighPerformance Steel Reinforcing Bars." Ph.D thesis. North Carolina State University: Raleigh, NC.

30. Shehata, E.F.G. (1999). "Fibre-Reinforced Polymer (FRP) for Shear Reinforcement in Concrete Structures.” $\mathrm{PhD}$ thesis. University of Manitoba: Winnipeg, Manitoba, Canada.

31. Wight, J.K., \& Parra-Montesinos, G.J. (2003). "Strut-and-Tie Model for Deep Beam Design.” Concrete International, May 2003, pp.63-70. 
APPENDICES 


\subsection{APPENDIX A: TESTING DETAILS}

\subsection{Beam Details}

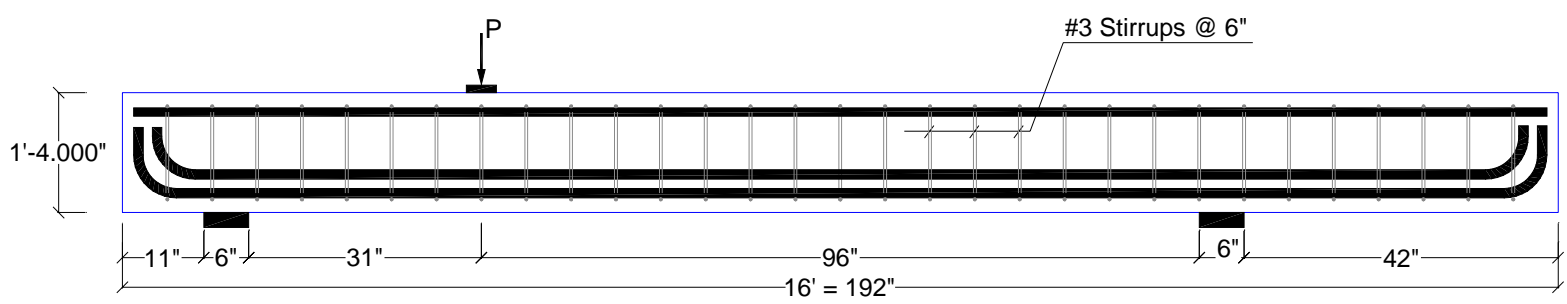

C-C-6, C-M-6, M-M-6

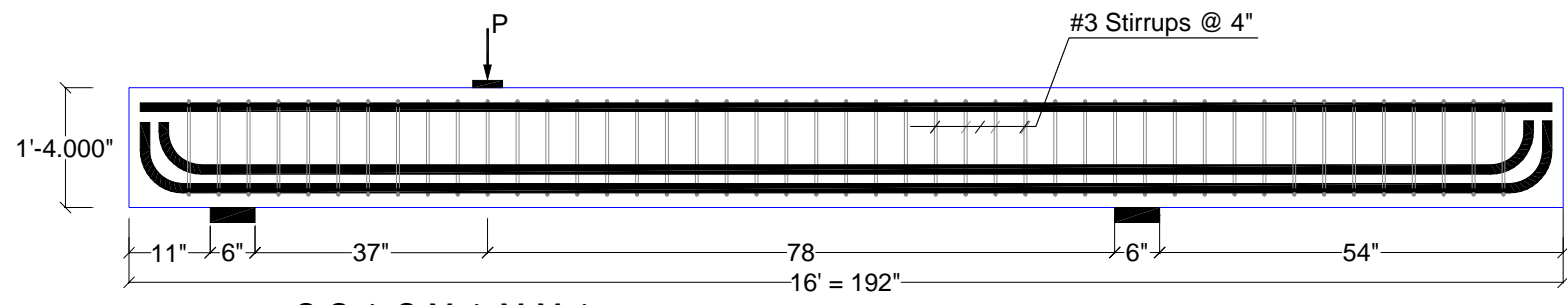

C-C-4, C-M-4, M-M-4

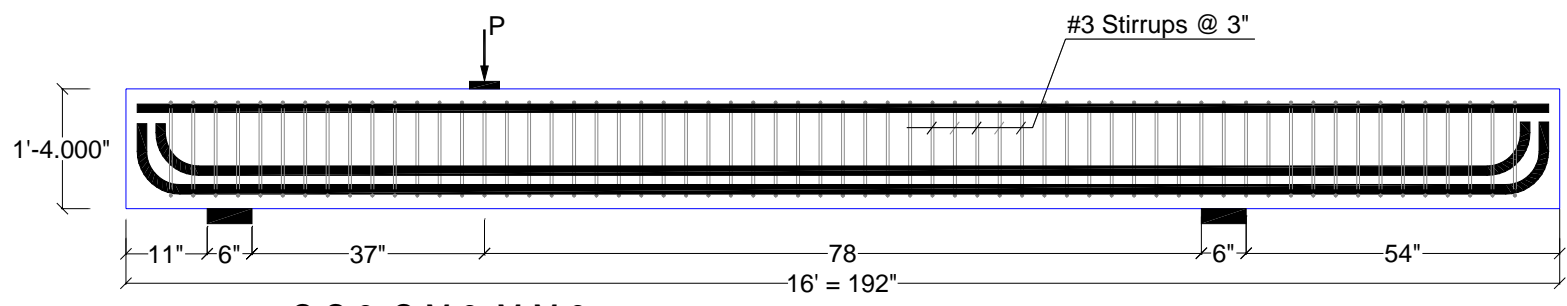

C-C-3, C-M-3, M-M-3

Figure 6.1: Reinforcement details 


\subsection{Failure Comparisons}
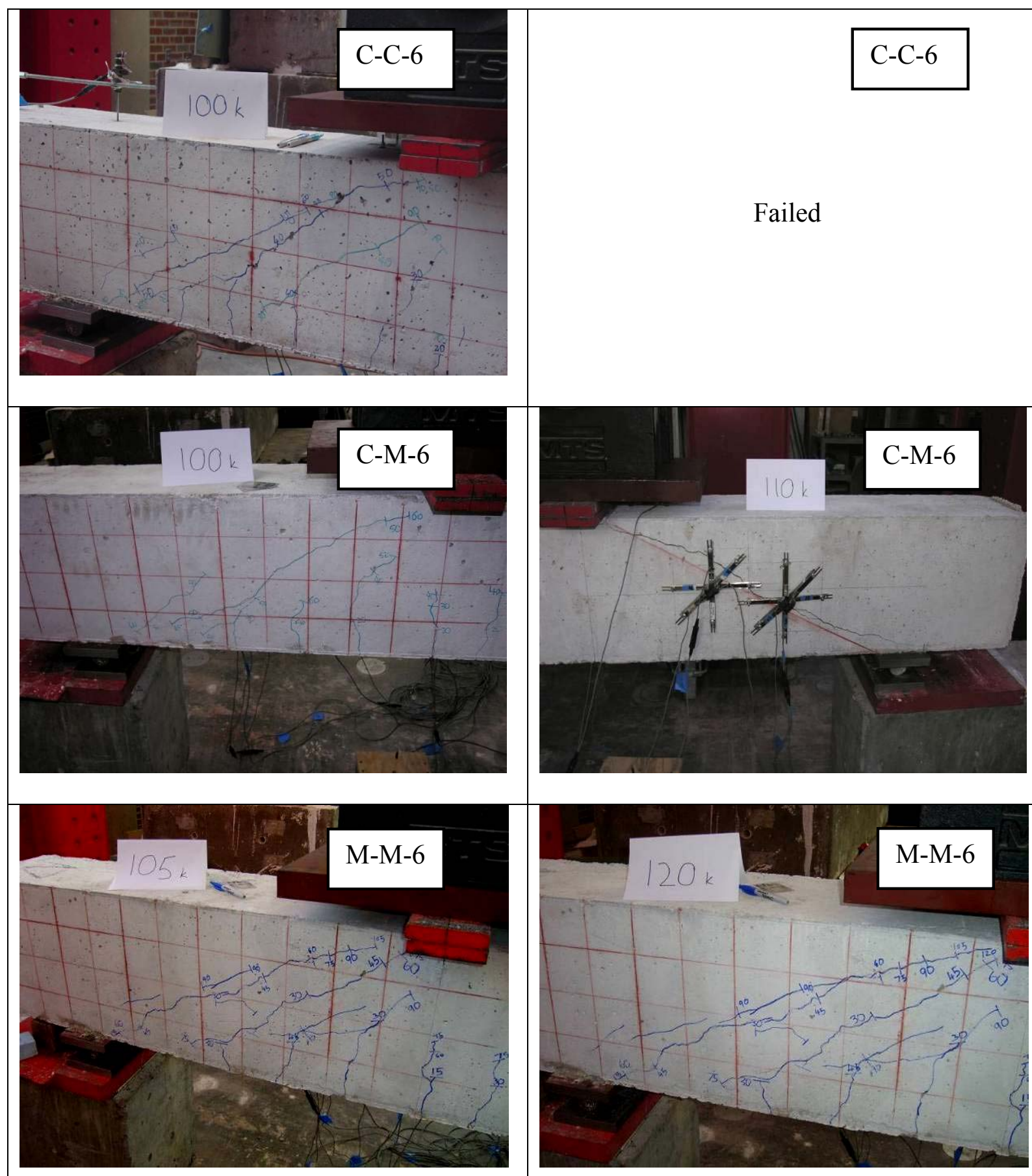

Figure 6.2: Set 1, loading until failure 


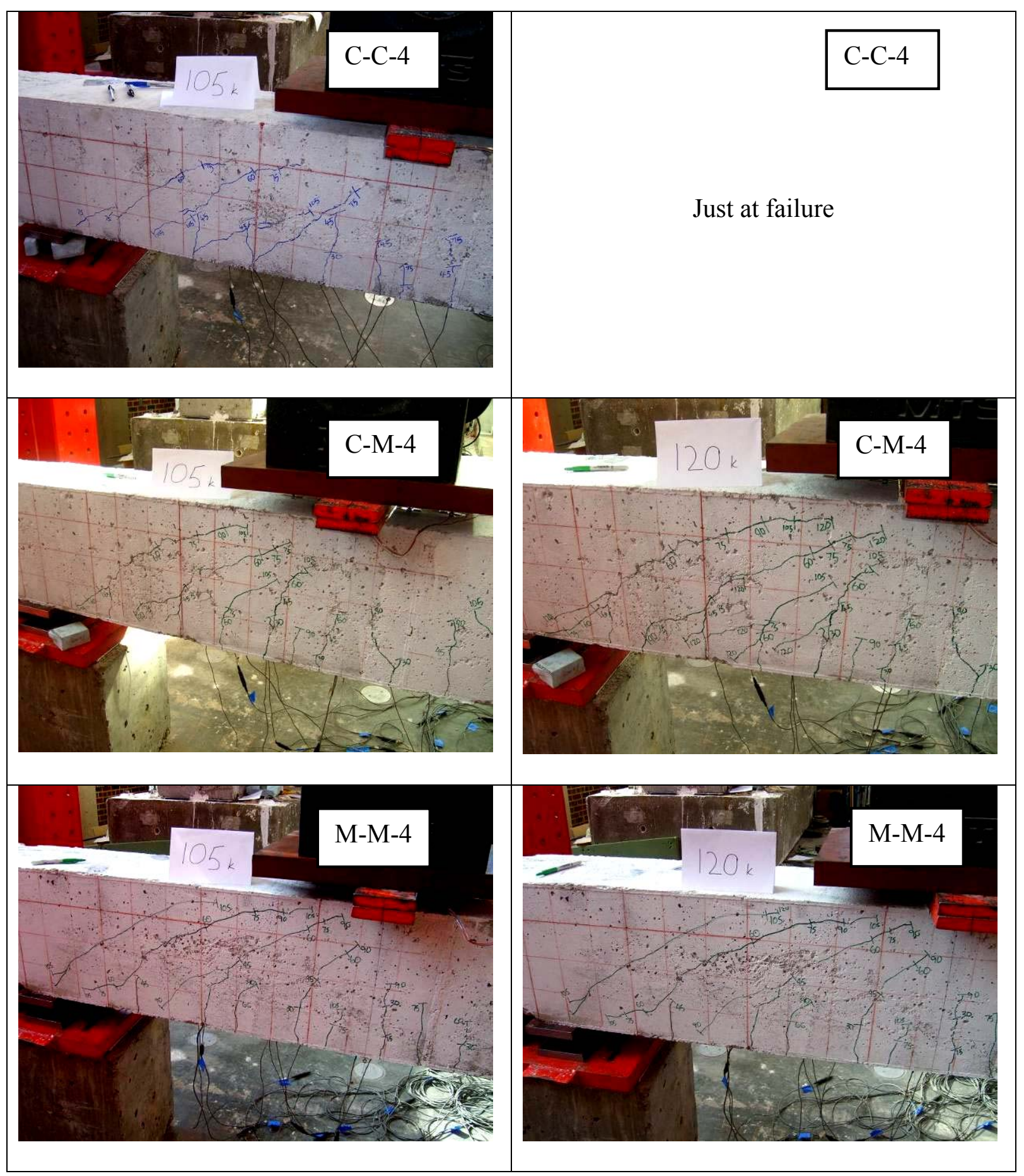

Figure 6.3: Set 2, loading until failure 


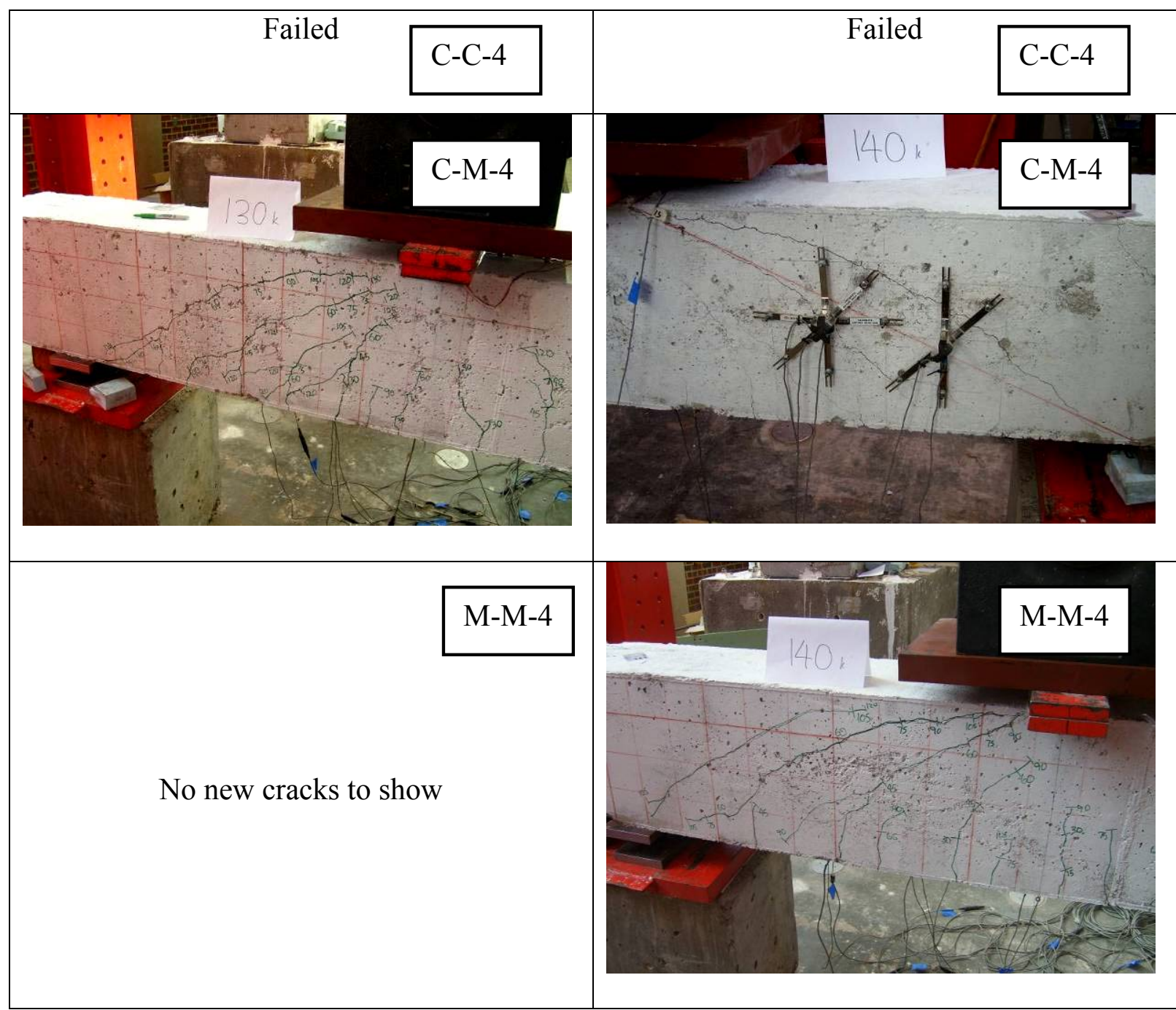

Figure 6.3: (continued) 


\subsection{APPENDIX B: DATA AND ANALYSIS}

\subsection{Concrete Compressive Cylinder Strengths}

Table 7.1: Compressive strength of cylinders (Ib)

\begin{tabular}{|c|c|c|c|c|c|c|}
\hline & 7-day & 14-day & 28-day & Beam 1 & Beam 3 & $\begin{array}{c}\text { Beam } 2 \\
\text { (average) }\end{array}$ \\
\hline \multirow{3}{*}{ Set 1} & 35,766 & 43,203 & 47,783 & 49,395 & 62,033 & \\
\hline & 35,597 & 43,881 & 45,465 & 48,462 & 55,078 & \\
\hline & 32,826 & 42,156 & 45,662 & 49,310 & - & \\
\hline Average & 34,730 & 43,080 & 46,303 & 49,056 & 58,556 & 53,806 \\
\hline \multirow{3}{*}{ Set 2} & 33,589 & 48,405 & 47,613 & 54,201 & 59,347 & \\
\hline & 37,463 & 46,313 & 44,164 & 57,651 & 59,149 & \\
\hline & 35,399 & 44,164 & 43,655 & 53,636 & 58,838 & \\
\hline Average & 35,484 & 46,294 & 45,144 & 55,163 & 59,111 & 57,137 \\
\hline \multirow{3}{*}{ Set 3} & 37,548 & 37,519 & 55,361 & 58,527 & 58,753 & \\
\hline & 38,198 & 41,450 & 56,492 & 61,581 & 58,725 & \\
\hline & 35,823 & 39,329 & 56,152 & 59,630 & 59,376 & \\
\hline Average & 37,190 & 39,433 & 56,002 & 59,913 & 58,951 & 59,432 \\
\hline
\end{tabular}




\subsection{Measured Test Results}

Table 7.2: Measured ultimate load for each test

\begin{tabular}{|c|c|c|c|c|c|c|c|}
\hline & $\begin{array}{l}\text { Spacing } \\
\text { (in) }\end{array}$ & $a / d$ & $\begin{array}{c}\mathbf{f}_{\mathrm{c}}{ }^{\prime} \\
(\mathbf{p s i})\end{array}$ & Beam ID & $\begin{array}{l}P_{\text {exp }} \\
\text { (Ib) }\end{array}$ & $\begin{array}{c}V_{\text {exp }} \\
\text { (kips) }\end{array}$ & $\begin{array}{c}M_{\exp } \\
\text { (kip-in) }\end{array}$ \\
\hline \multirow{6}{*}{ Set 1} & \multirow{6}{*}{6} & \multirow{6}{*}{2.62} & \multirow{2}{*}{3904} & $C-C-6$ & 115,553 & 86.0 & 2924 \\
\hline & & & & C-C-6R & 104,360 & 77.7 & 2641 \\
\hline & & & \multirow{2}{*}{4282} & C-M-6 & 113,451 & 84.4 & 2871 \\
\hline & & & & C-M-6R & 117,823 & 87.7 & 2982 \\
\hline & & & \multirow{2}{*}{4660} & M-M-6 & 123,523 & 91.9 & 3126 \\
\hline & & & & M-M-6R & 133,998 & 99.7 & 3391 \\
\hline \multirow{6}{*}{ Set 2} & \multirow{6}{*}{4} & \multirow{6}{*}{3.08} & \multirow{2}{*}{4390} & C-C-4 & 116,842 & 78.2 & 3129 \\
\hline & & & & C-C-4R & 131,272 & 87.9 & 3515 \\
\hline & & & \multirow{2}{*}{4547} & C-M-4 & 140,525 & 94.1 & 3763 \\
\hline & & & & C-M-4R & 132,360 & 88.6 & 3544 \\
\hline & & & \multirow{2}{*}{4704} & M-M-4 & 142,680 & 95.5 & 3821 \\
\hline & & & & $\mathrm{M}-\mathrm{M}-4 \mathrm{R}$ & 157,923 & 105.7 & 4229 \\
\hline \multirow{6}{*}{ Set 3} & \multirow{6}{*}{3} & \multirow{6}{*}{3.08} & \multirow{2}{*}{4730} & C-C-3 & 148,186 & 99.2 & 3968 \\
\hline & & & & C-C-3R & 138,759 & 92.9 & 3716 \\
\hline & & & \multirow{2}{*}{4730} & C-M-3 & 147,475 & 98.7 & 3949 \\
\hline & & & & C-M-3R & 149,482 & 100.1 & 4003 \\
\hline & & & \multirow{2}{*}{4730} & M-M-3 & 163,086 & 109.2 & 4367 \\
\hline & & & & $M-M-3 R$ & 156,600 & 104.8 & 4193 \\
\hline
\end{tabular}




\subsection{Shear Load vs. Deflection}

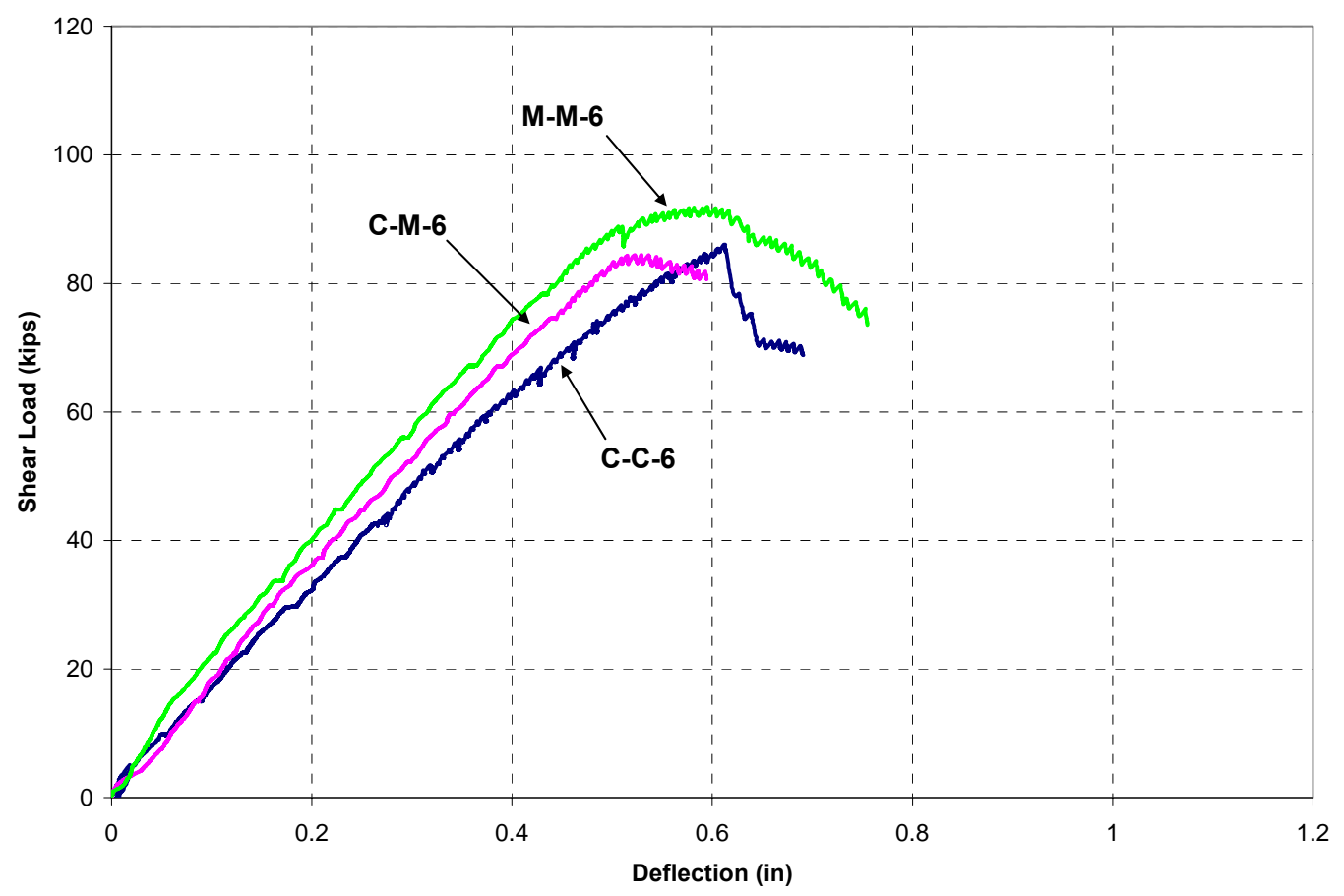

Figure 7.1: Set 1, Shear Load-Deflection, first tests

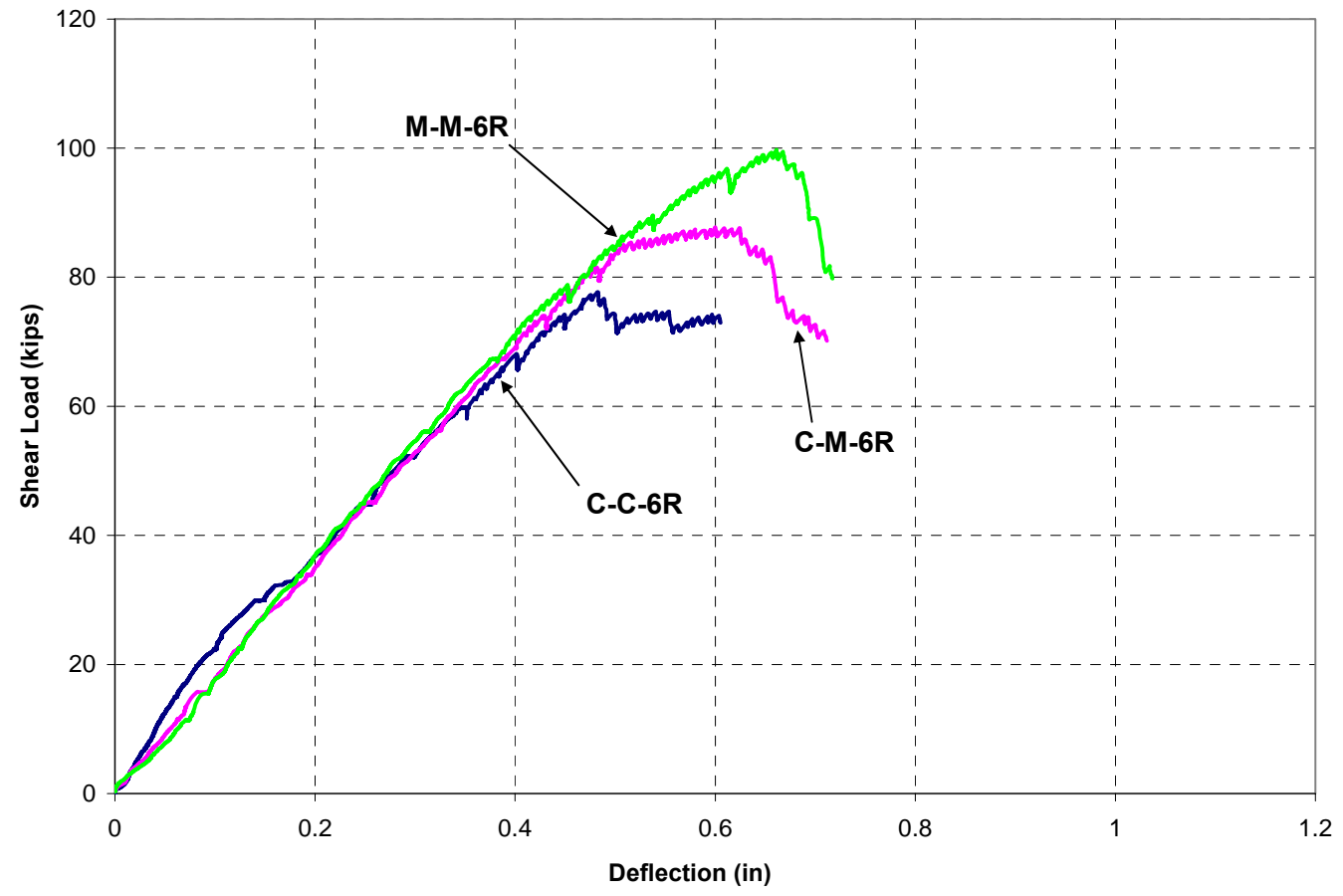

Figure 7.2: Set 1, Shear Load-Deflection, repeat tests 


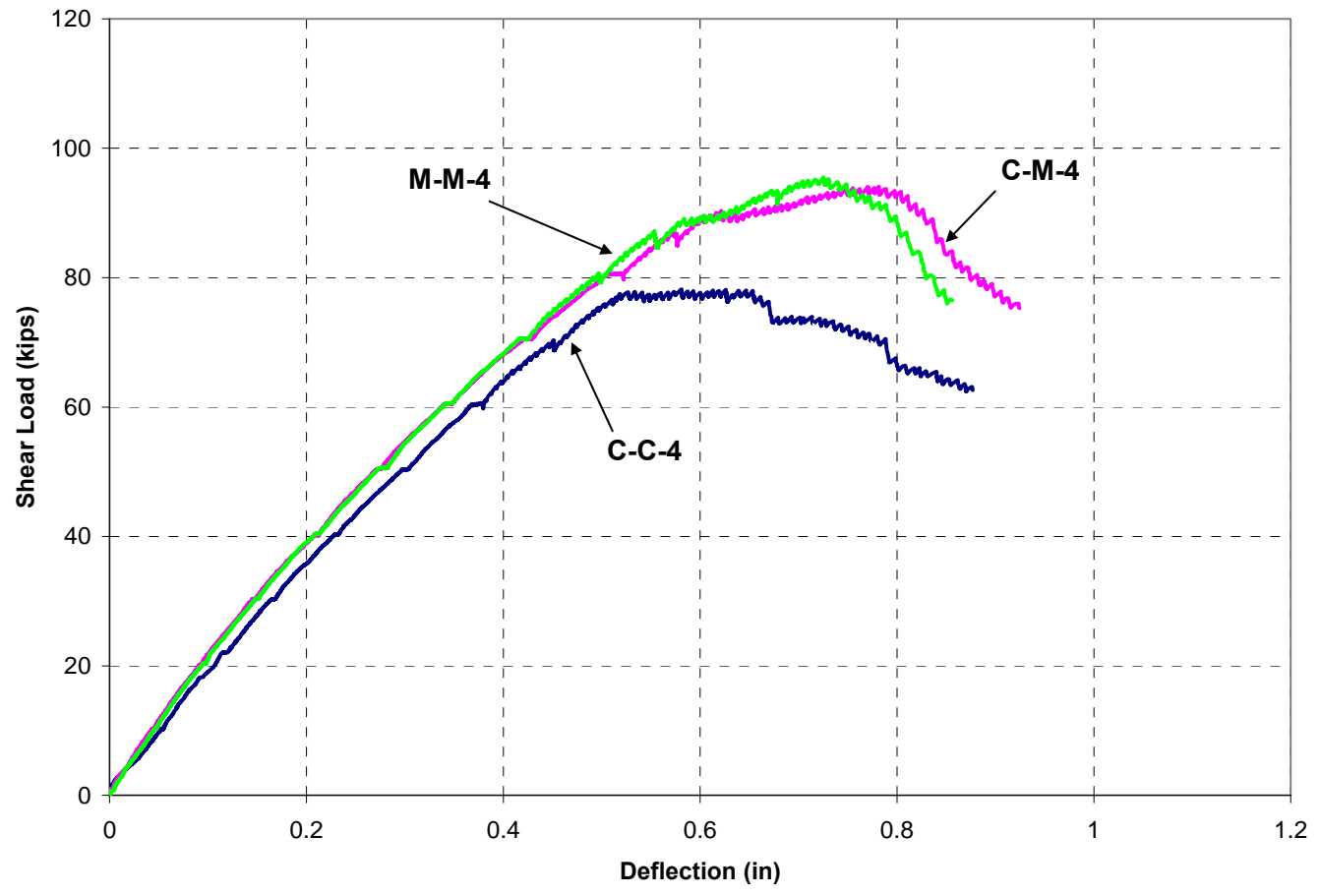

Figure 7.3: Set 2, Shear Load-Deflection, first tests

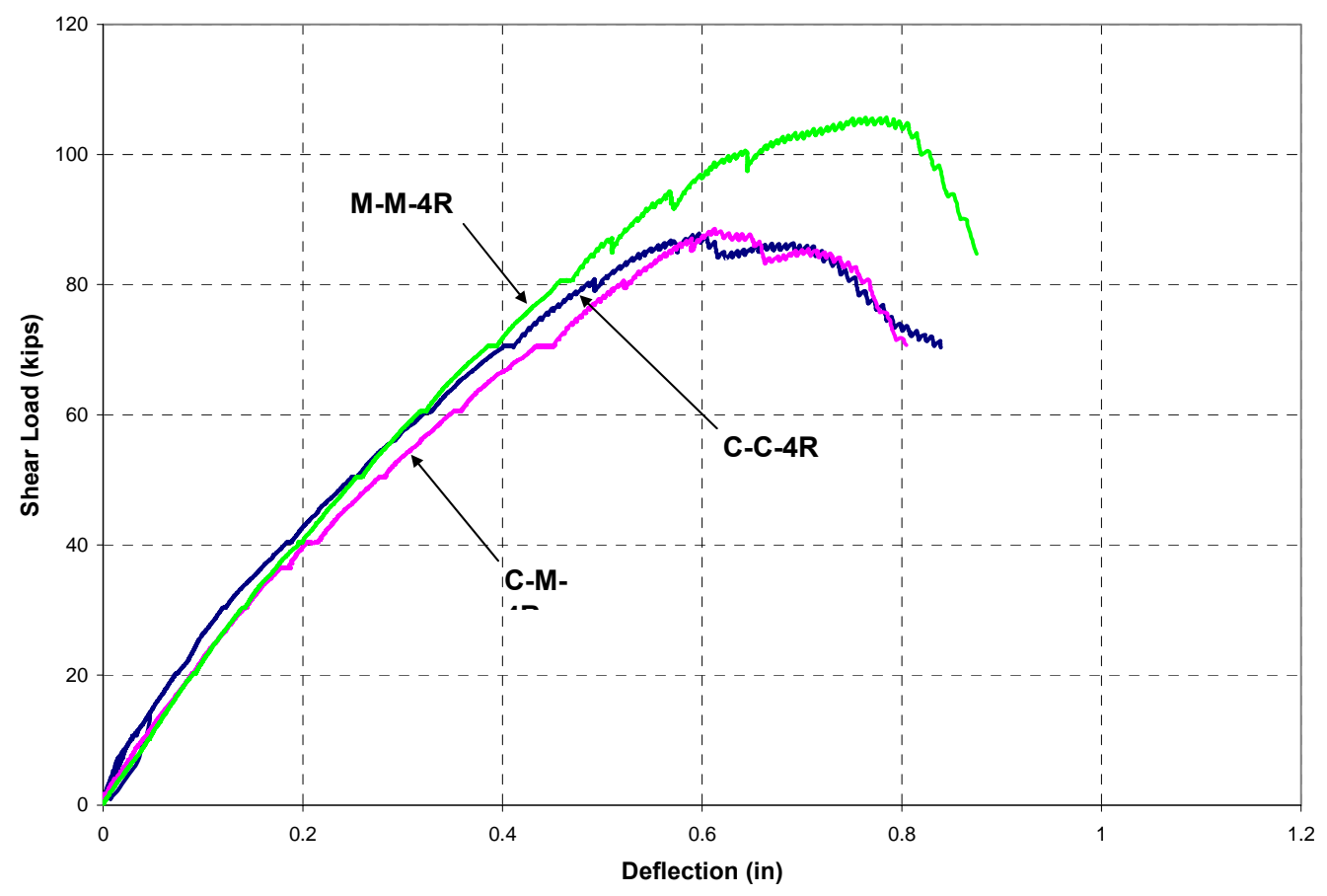

Figure 7.4: Set 2, Shear Load-Deflection, repeat tests 


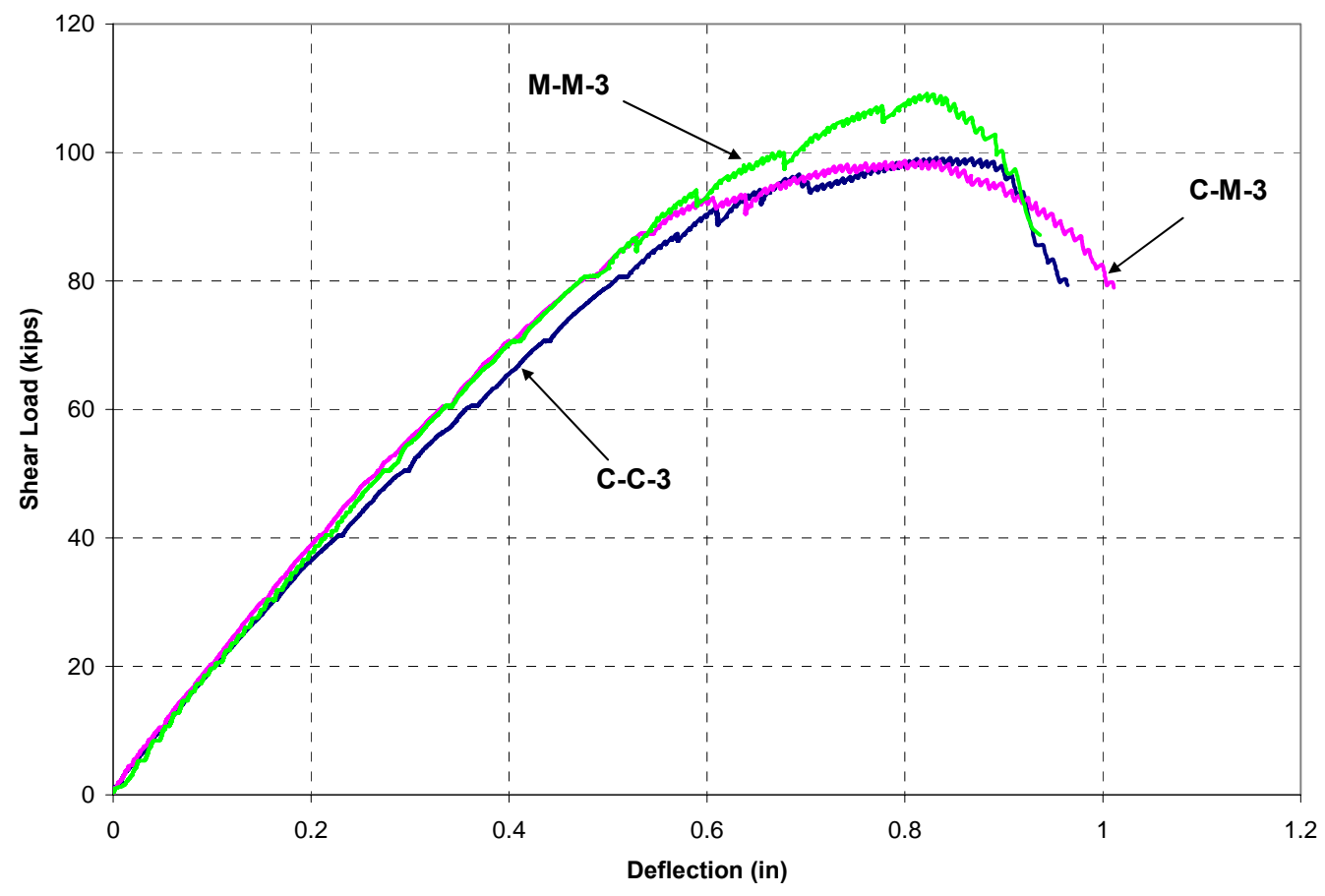

Figure 7.5: Set 3, Shear Load-Deflection, first tests

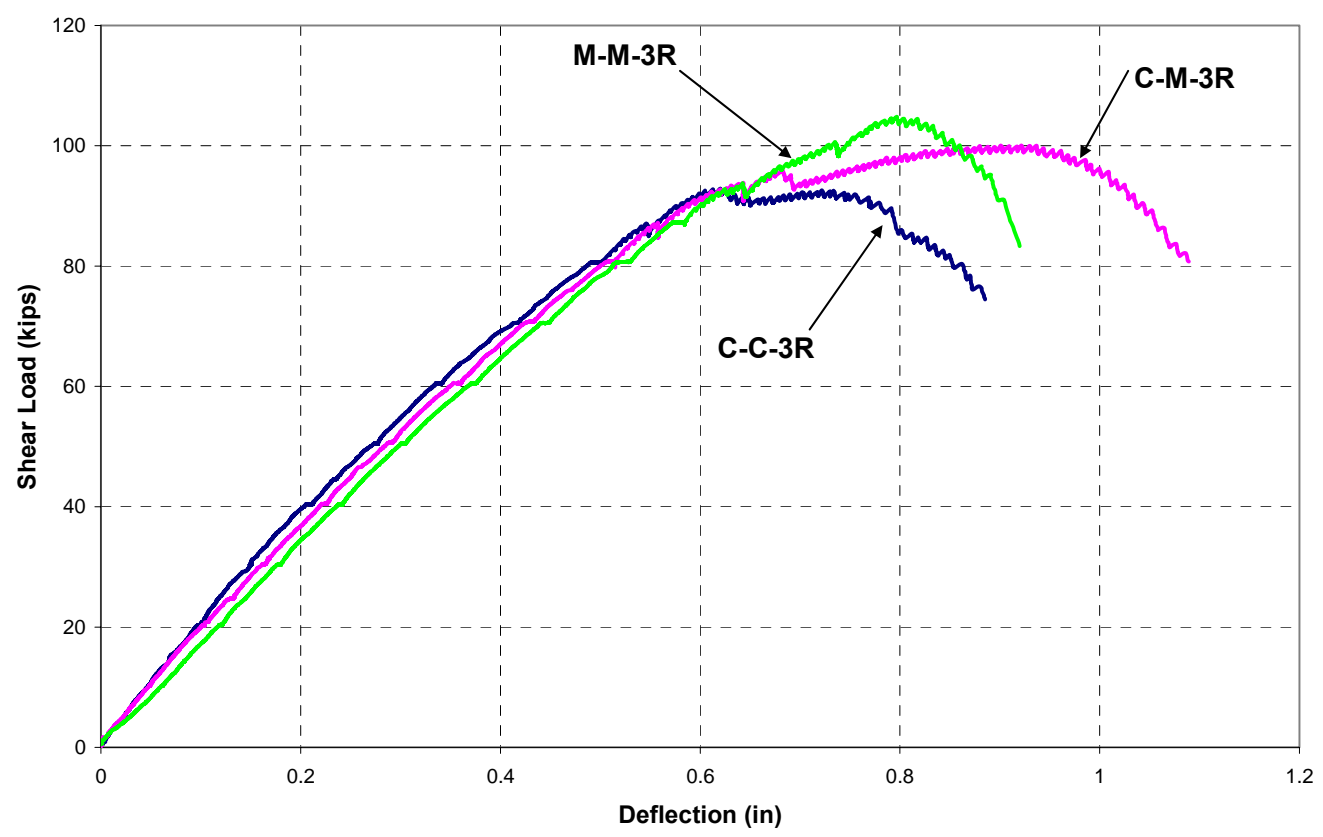

Figure 7.6: Set 3, Shear Load-Deflection, repeat tests 


\subsection{Shear Load vs. Transverse Strain}

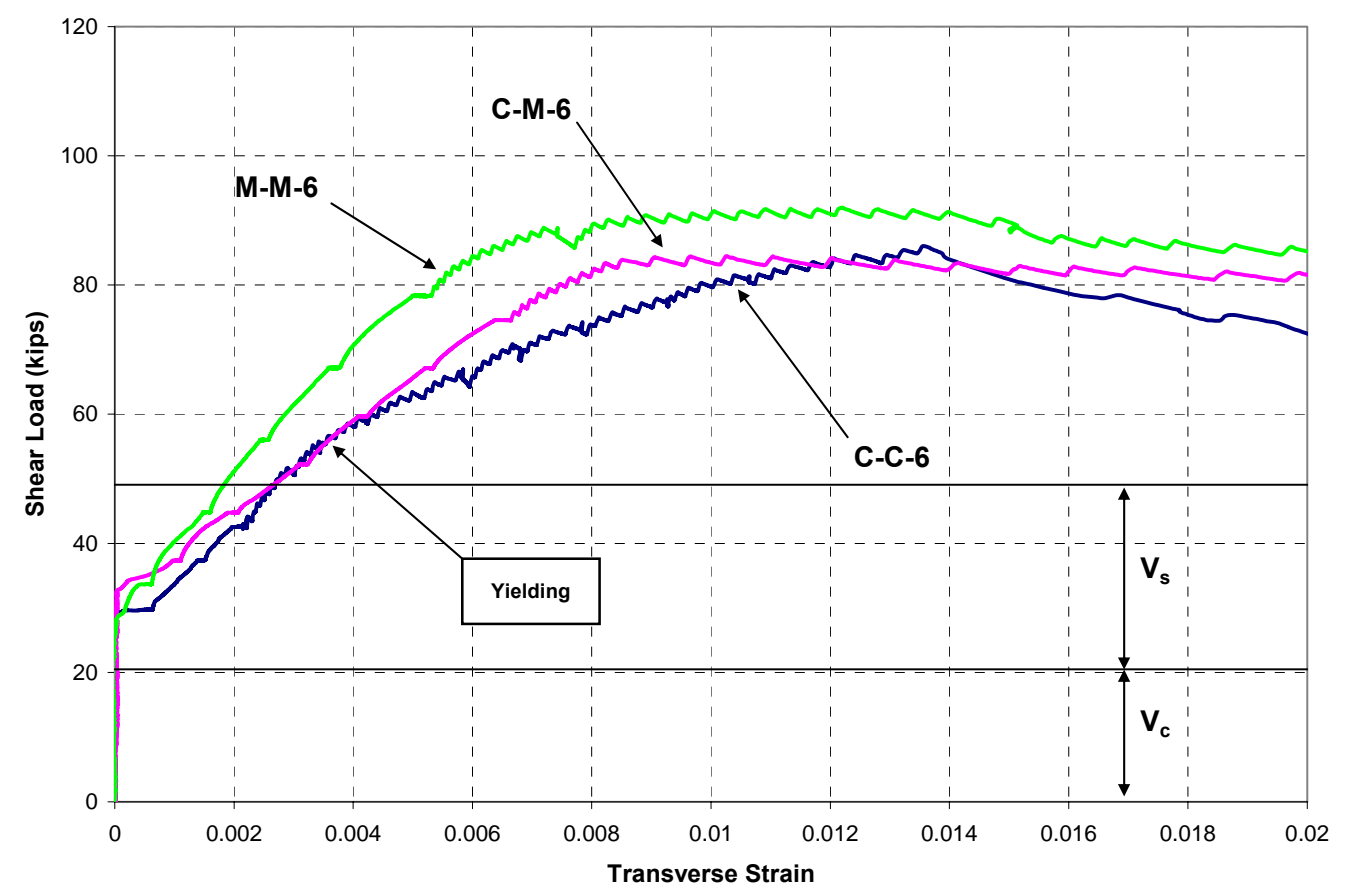

Figure 7.7: Set 1, Shear Load-Transverse Strain, first tests

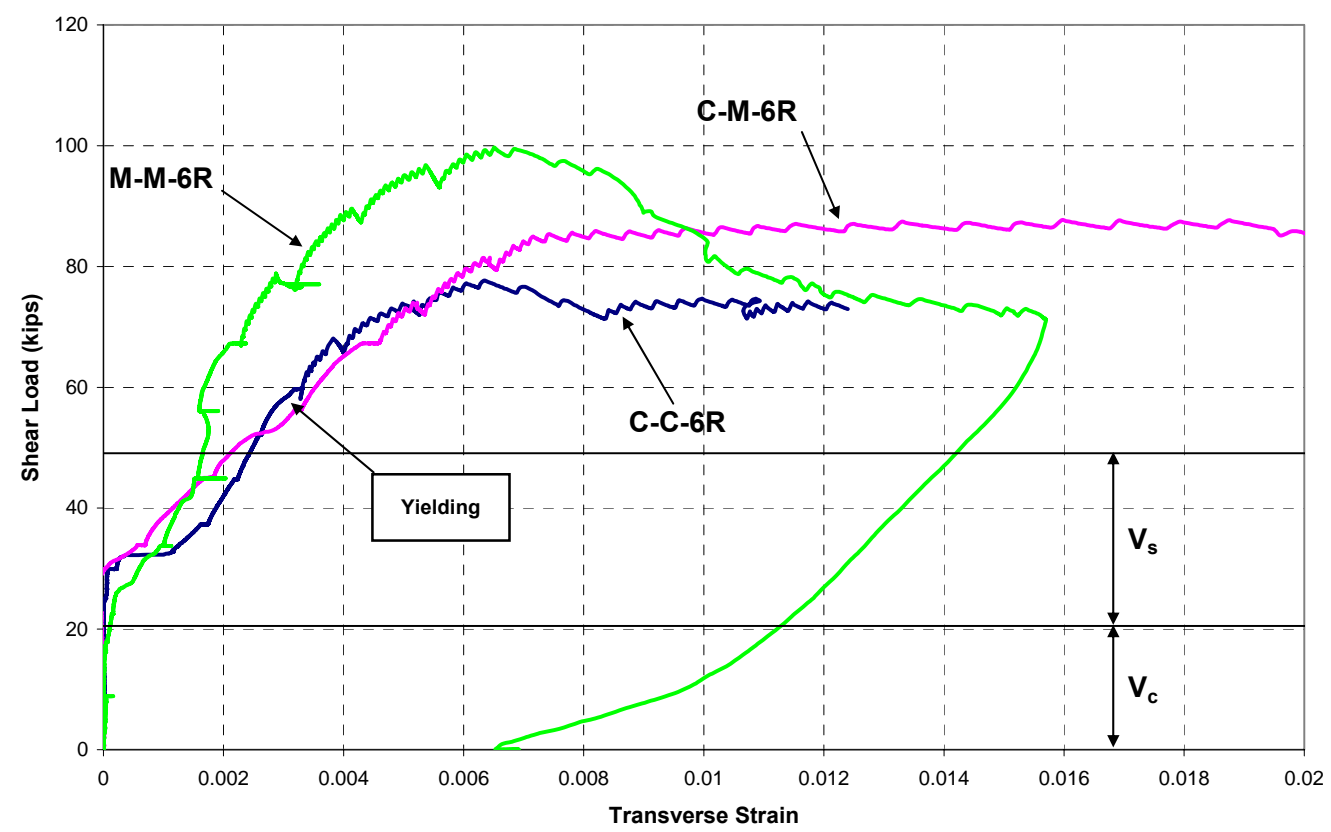

Figure 7.8: Set 1, Shear Load-Transverse Strain, repeat firsts 


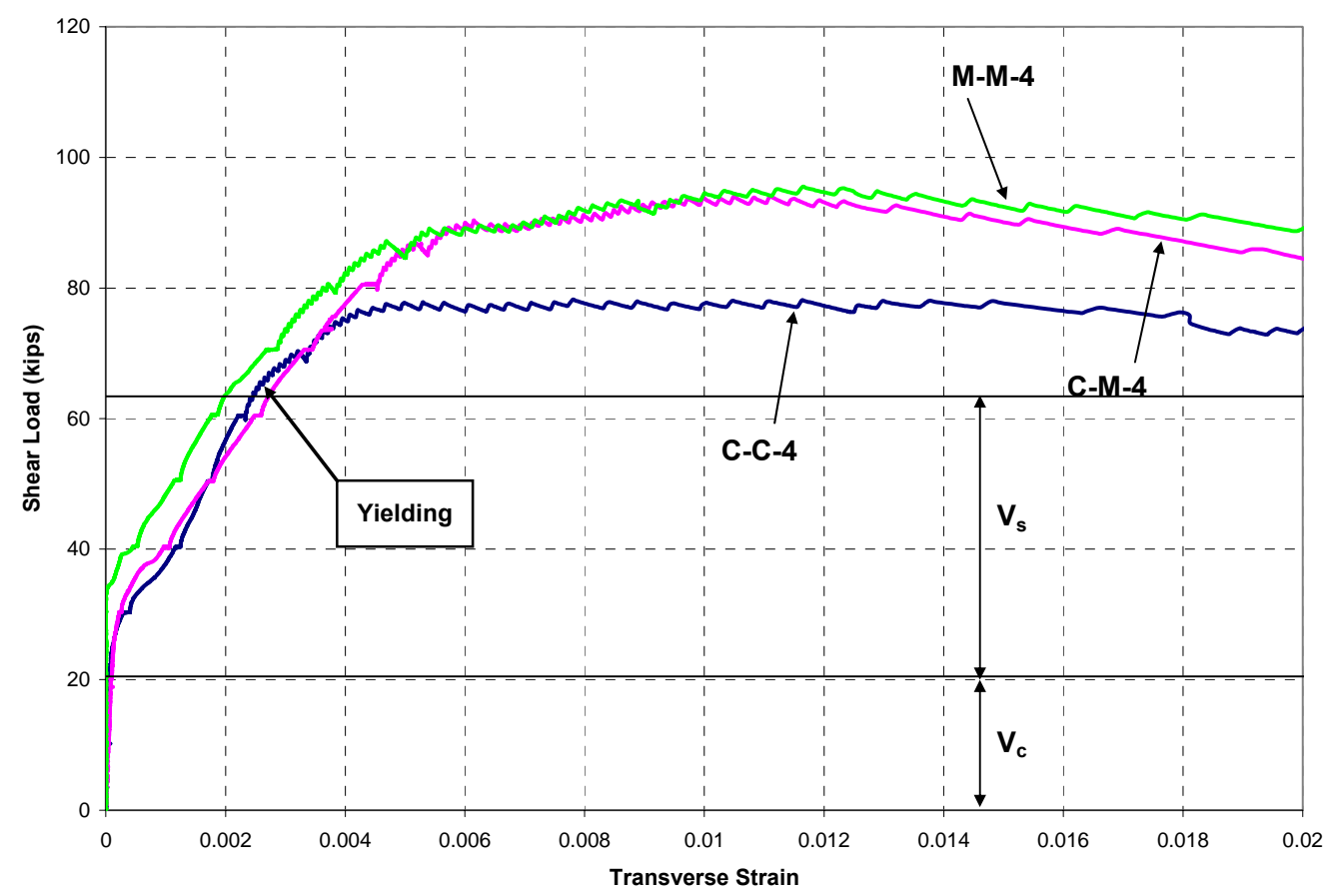

Figure 7.9: Set 2, Shear Load-Transverse Strain, first tests

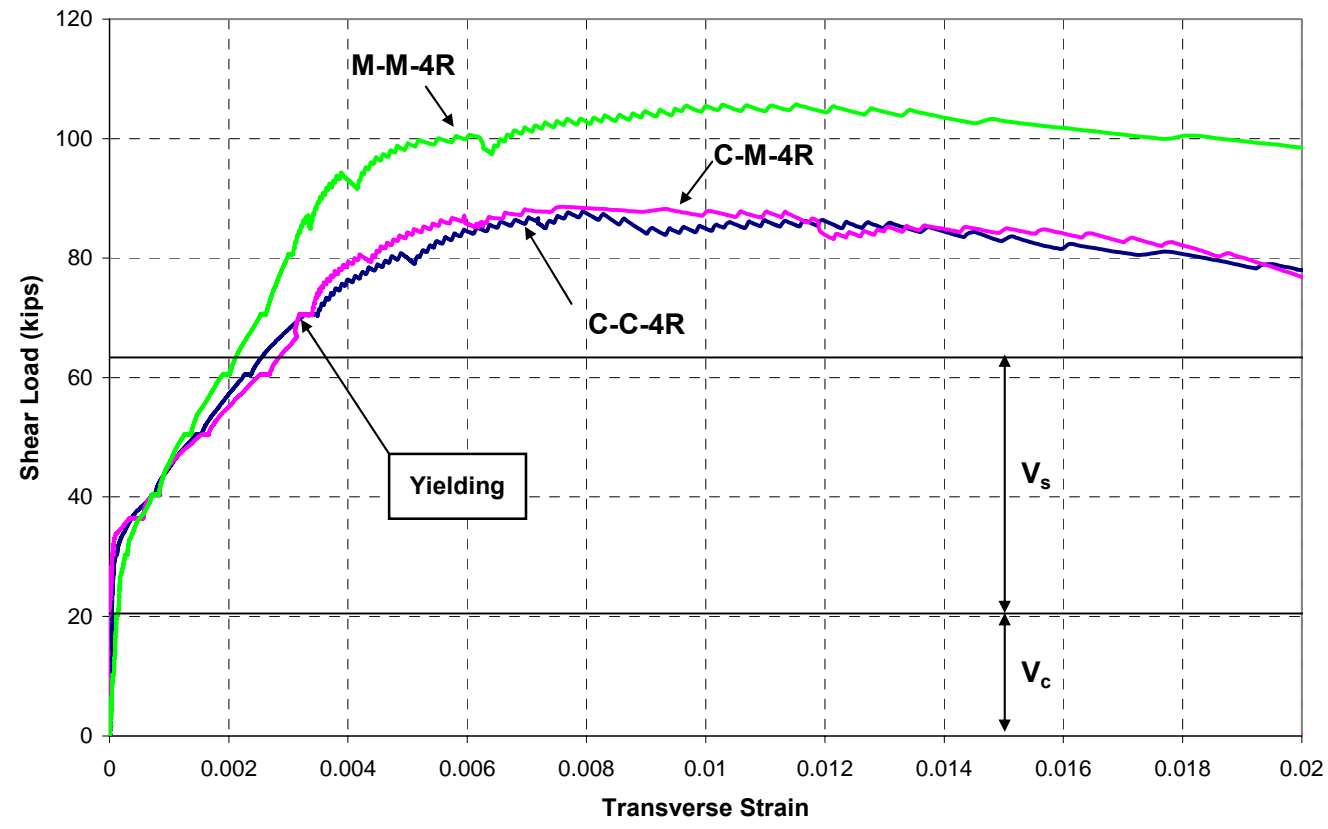

Figure 7.10: Set 2, Shear Load-Transverse Strain, repeat tests 


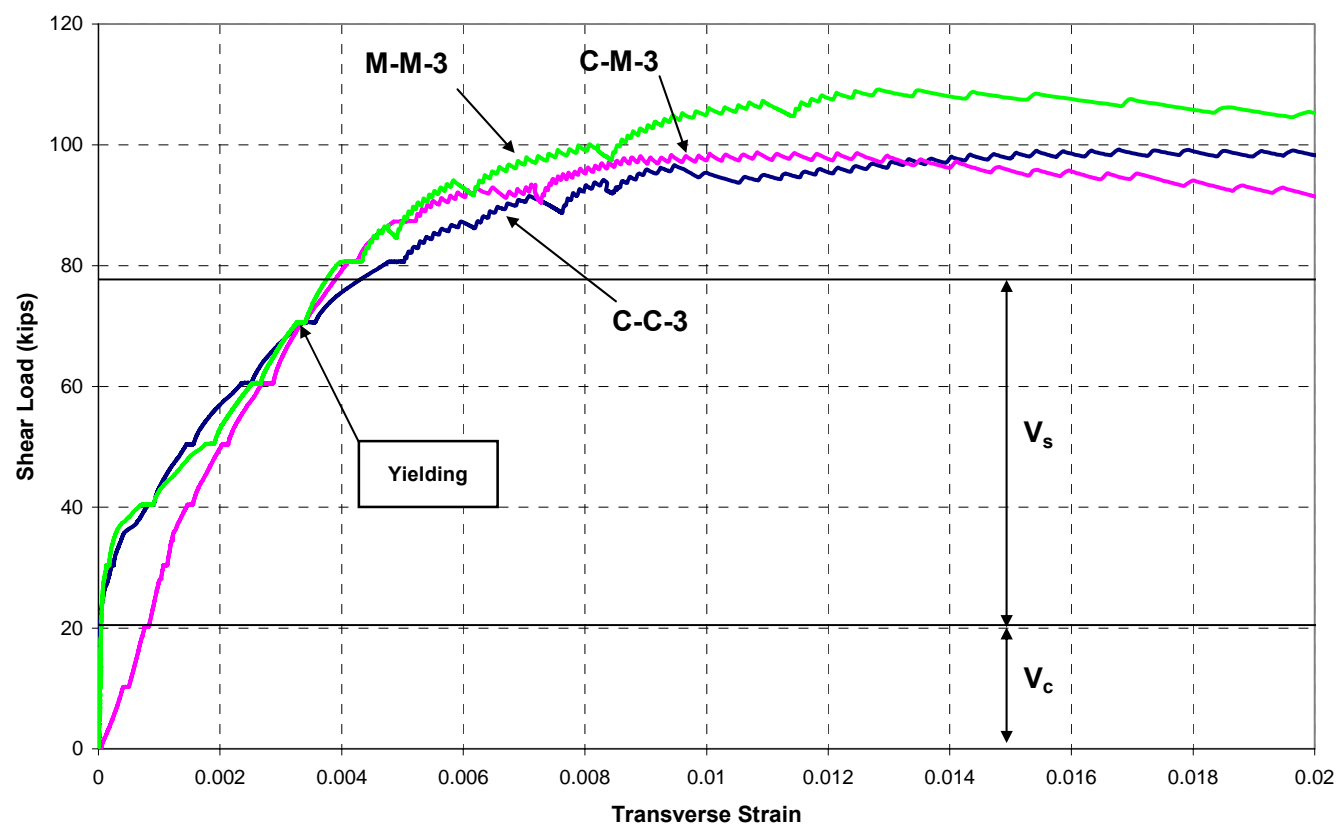

Figure 7.11: Set 3, Shear Load-Transverse Strain, first tests

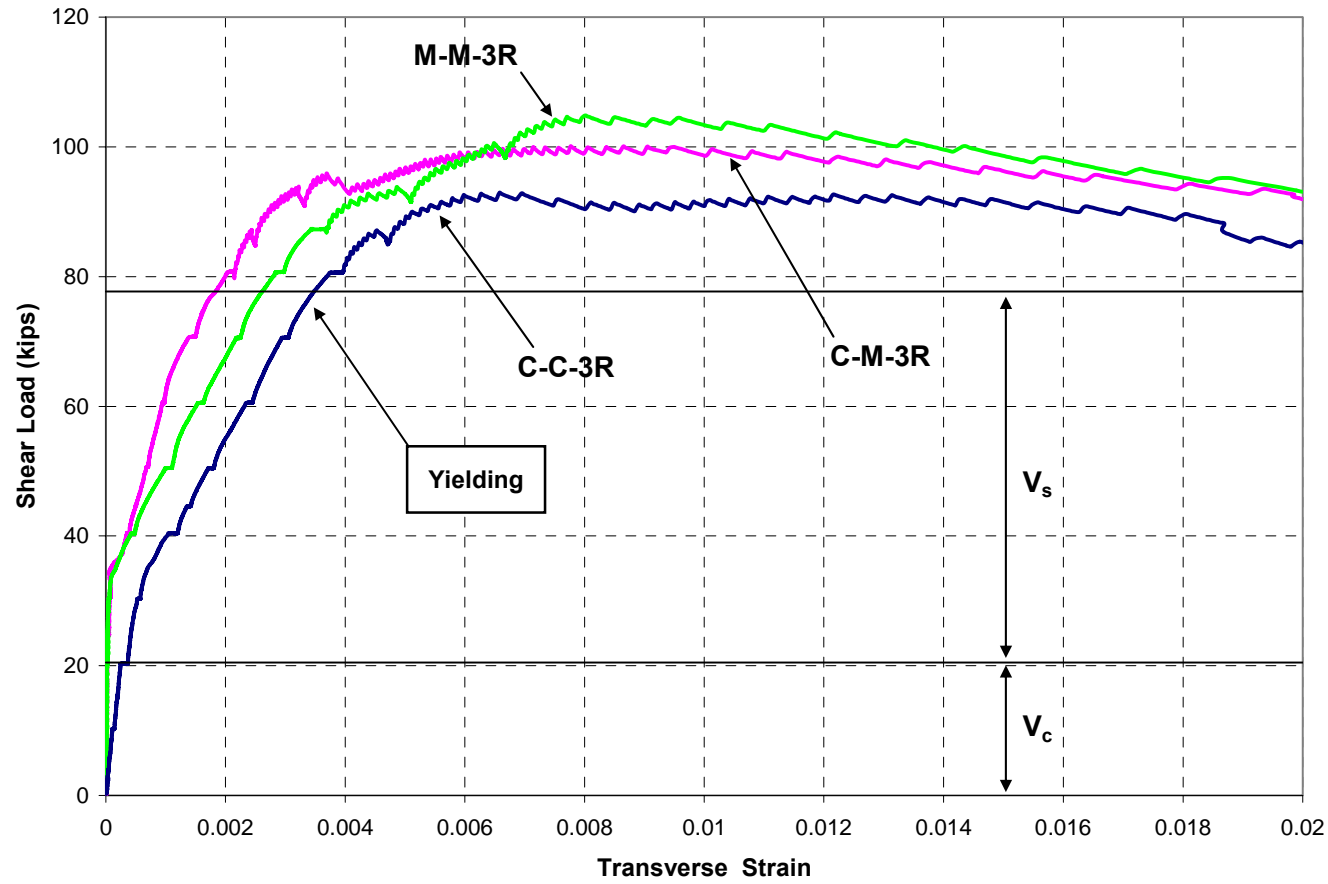

Figure 7.12: Set 3, Shear Load-Transverse Strain, repeat tests 


\subsection{Shear Load vs. Strain}

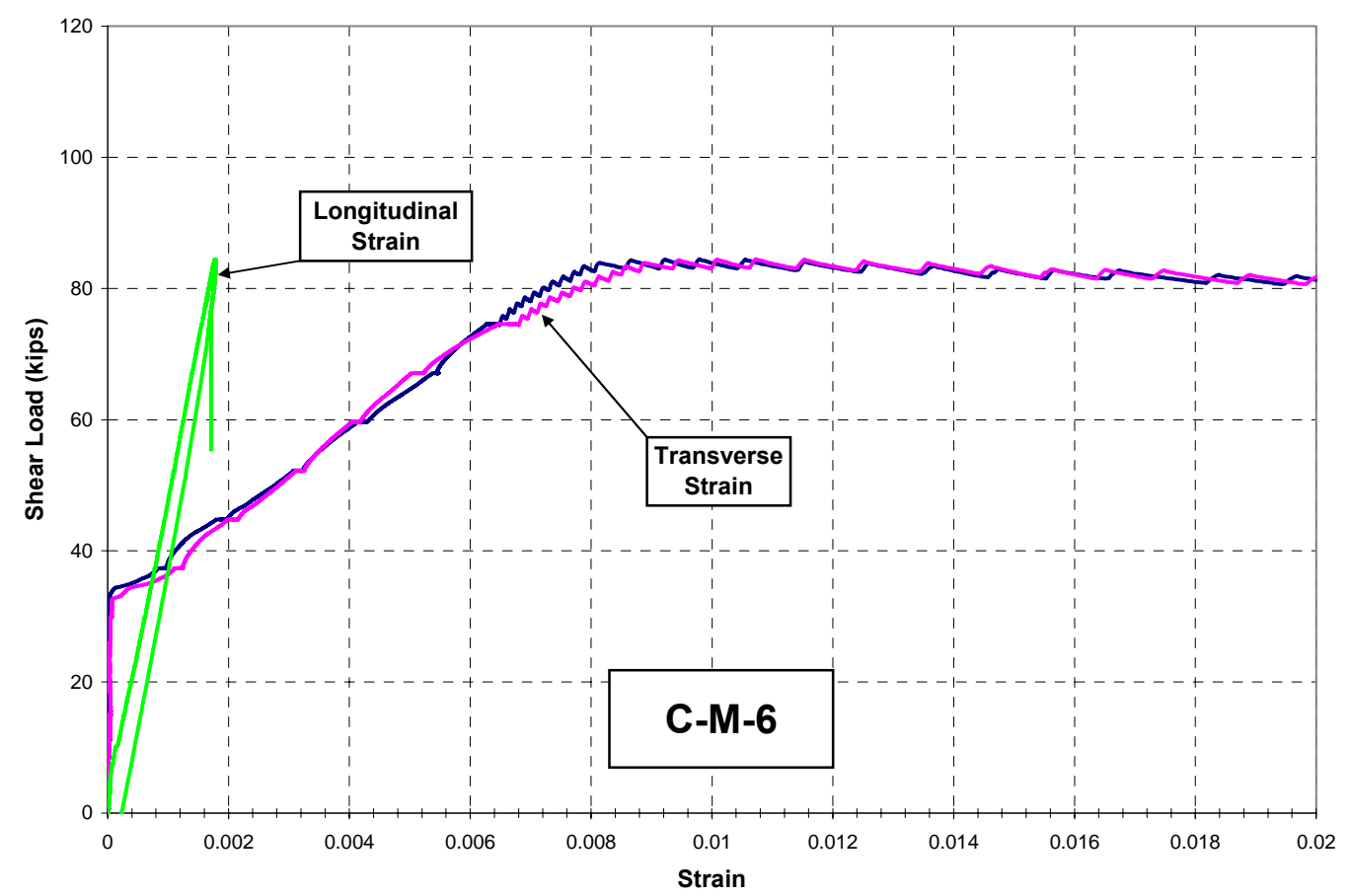

Figure 7.13: C-M-6, Shear Load vs. Strain

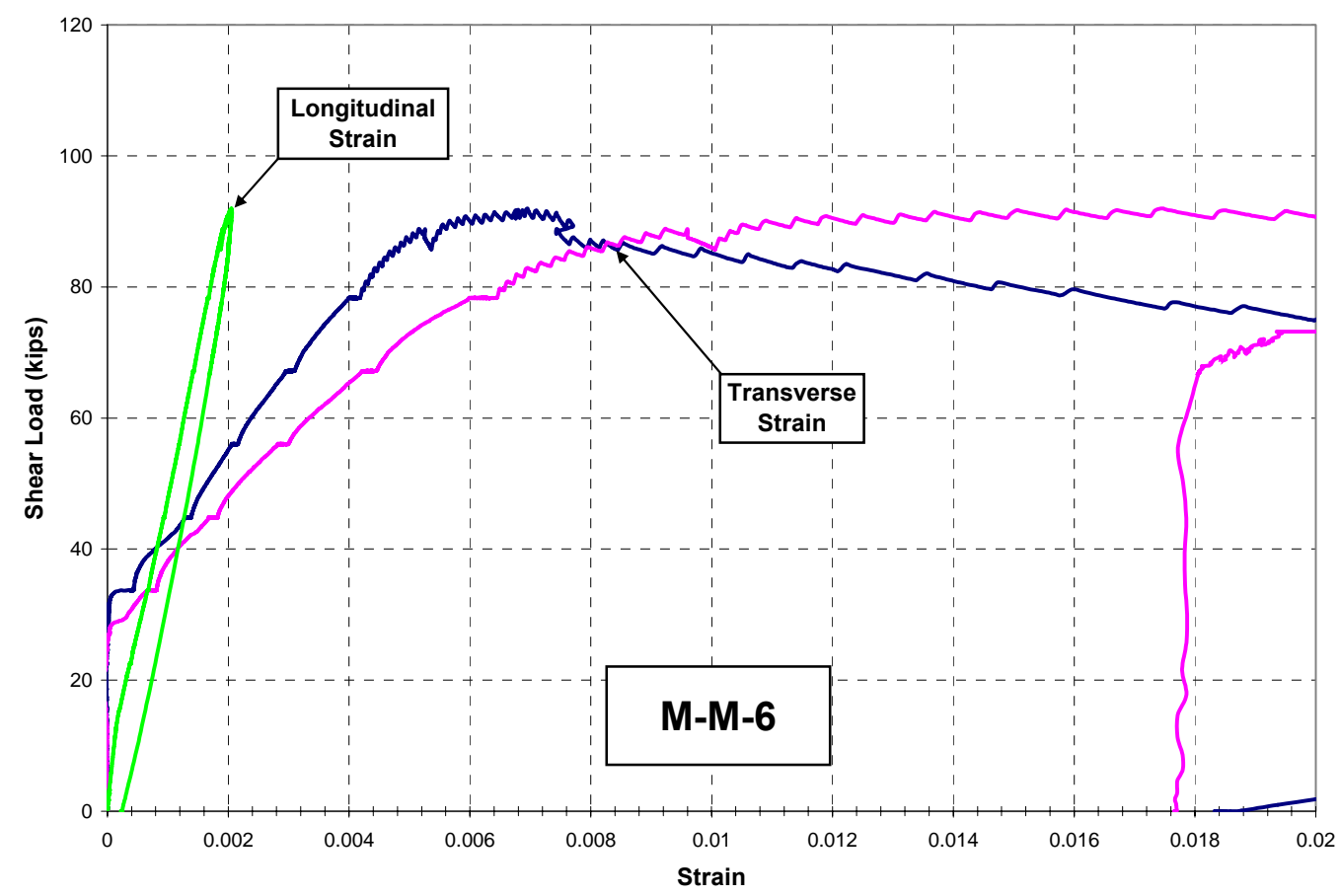

Figure 7.14: M-M-6, Shear Load vs. Strain 


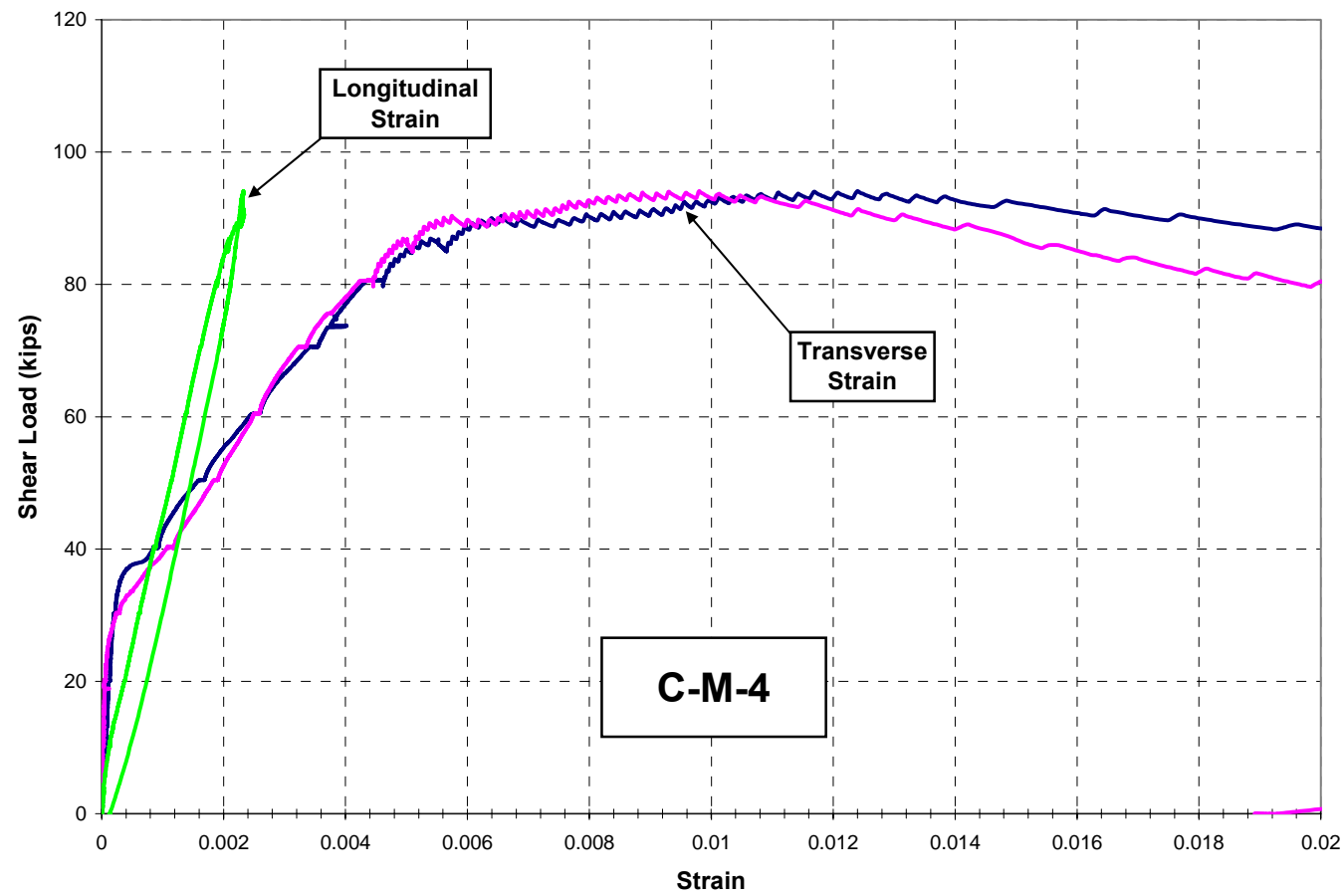

Figure 7.15: C-M-4, Shear Load vs. Strain

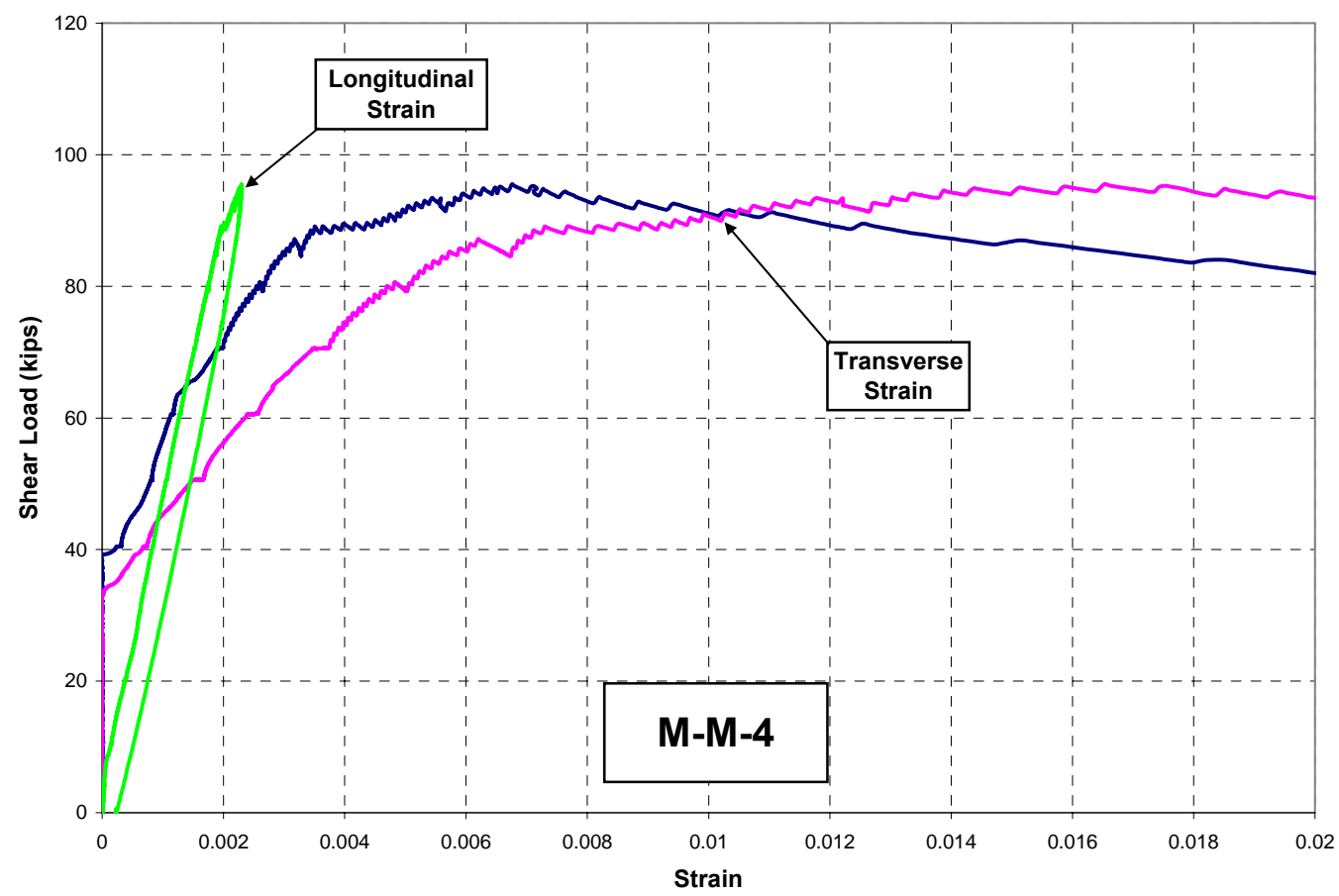

Figure 7.16: M-M-4, Shear Load vs. Strain 


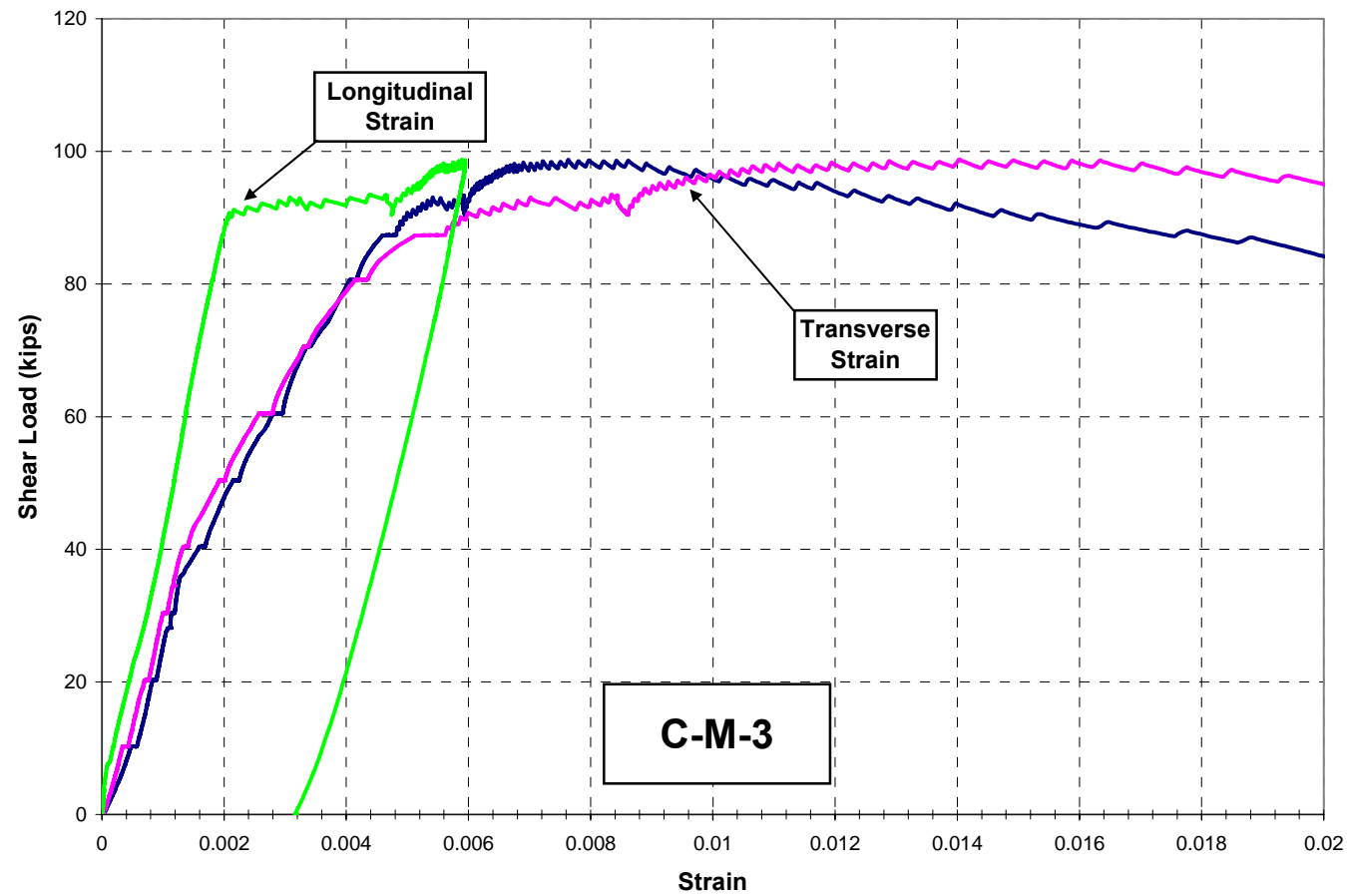

Figure 7.17: C-M-3, Shear Load vs. Strain

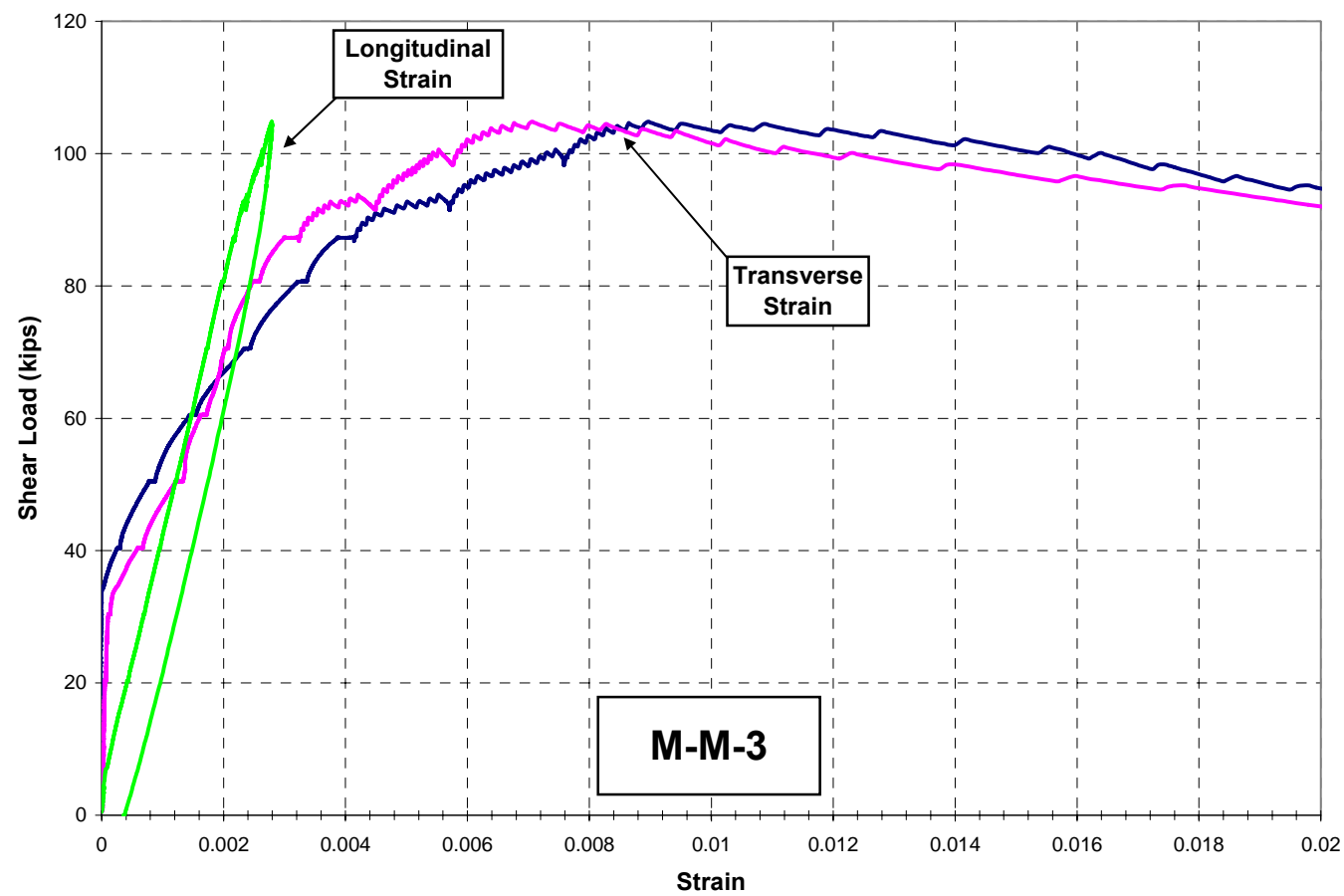

Figure 7.18: M-M-3, Shear Load vs. Strain 


\subsection{Response 2000 Results}
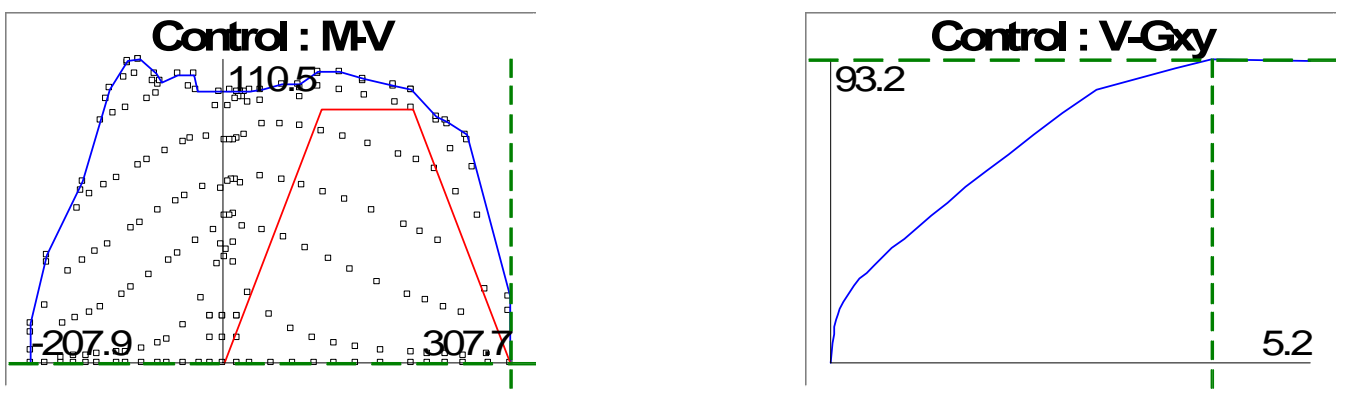

Principal Compressive Stress

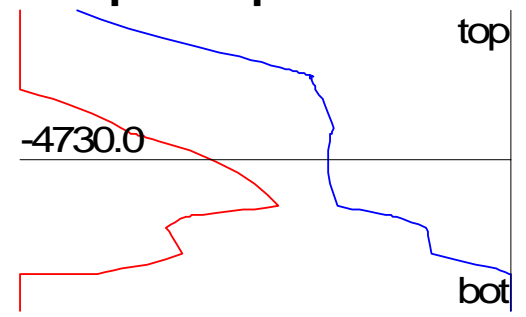

Figure 7.19: R2K, C-C-3
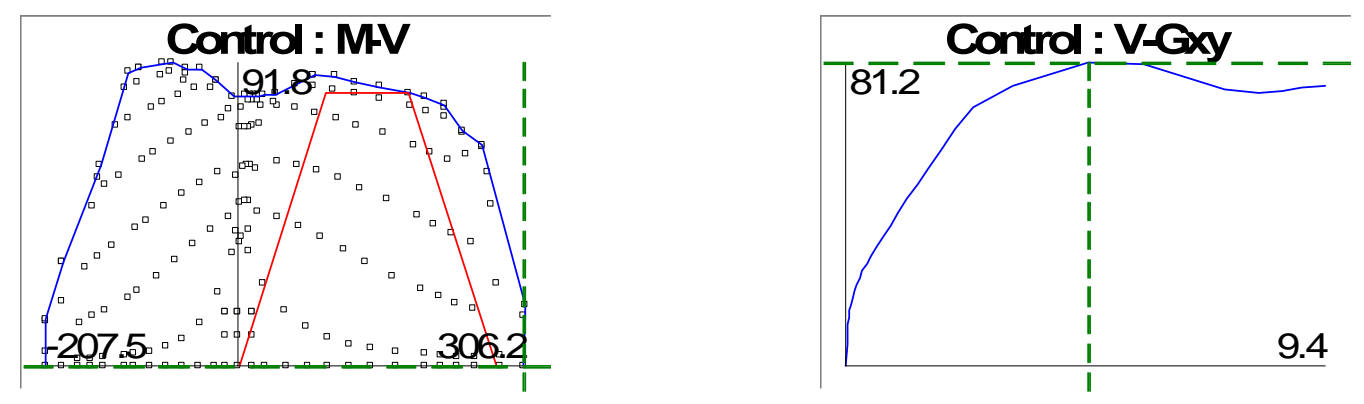

Principal Compressive Stress

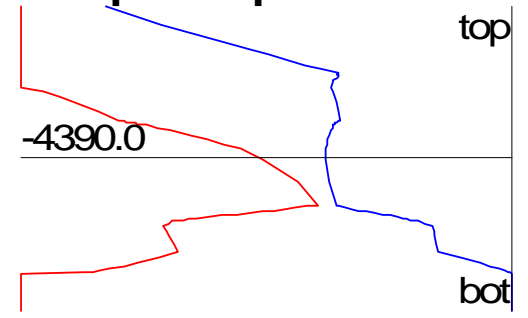

Figure 7.20: R2K, C-C-4 

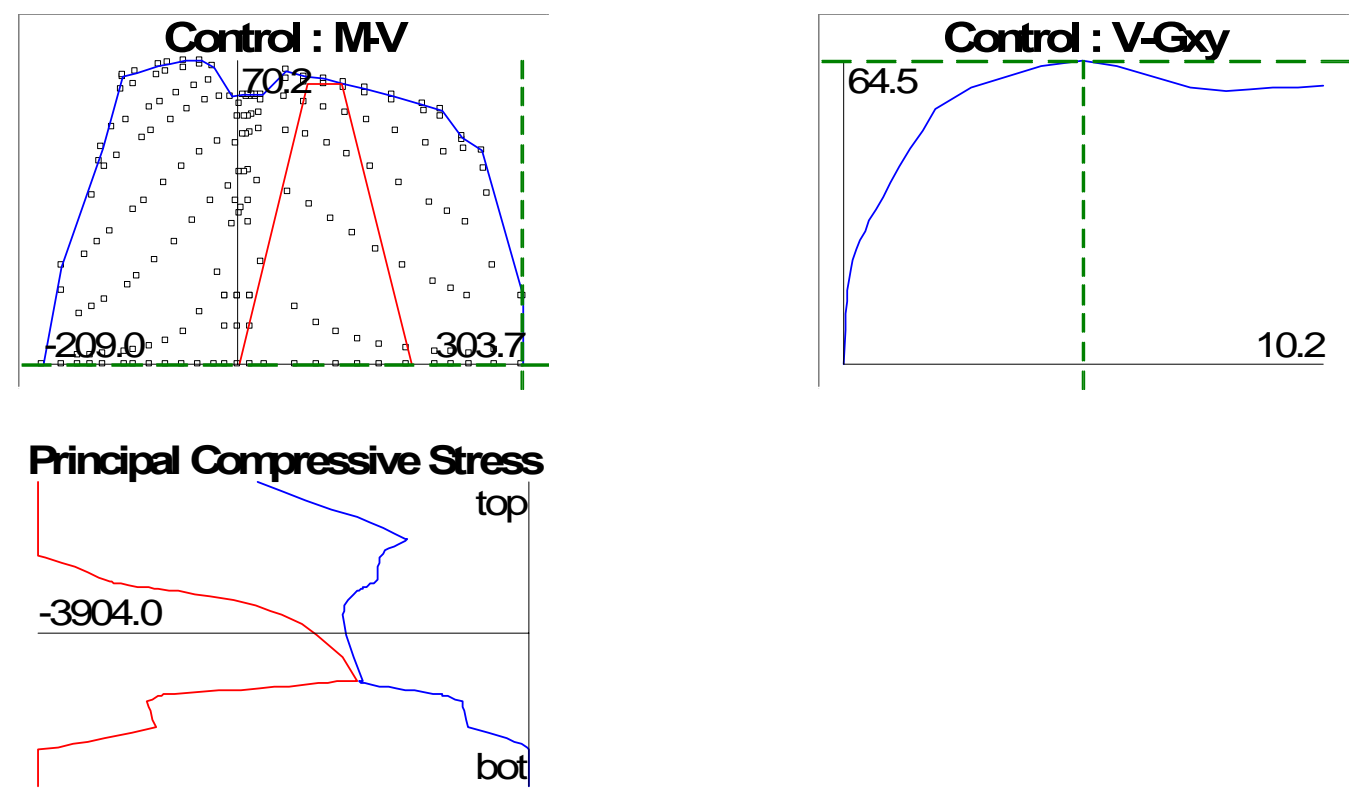

Figure 7.21: R2K, C-C-6
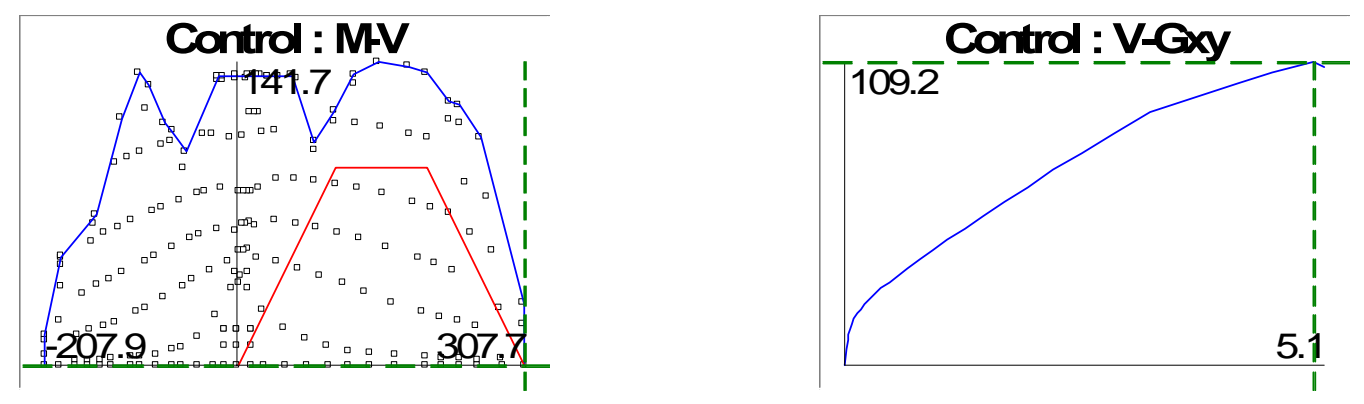

Principal Compressive Stress

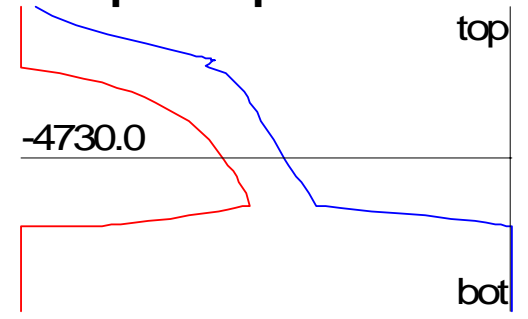

Figure 7.22: R2K, C-M-3 

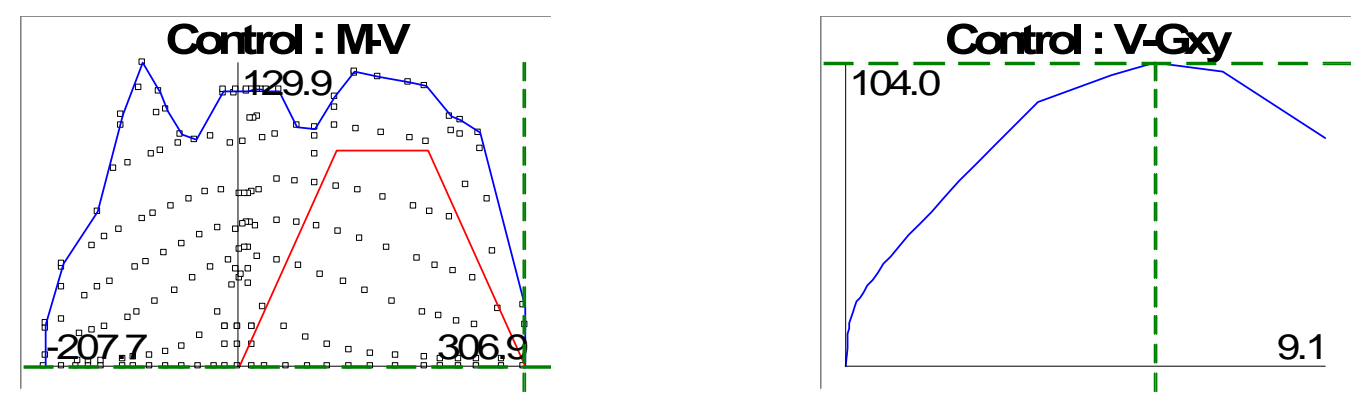

\section{Principal Compressive Stress}

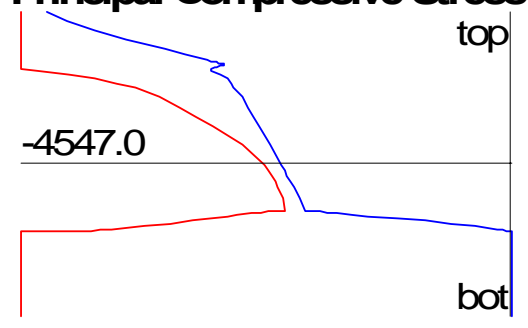

Figure 7.23: R2K, C-M-4
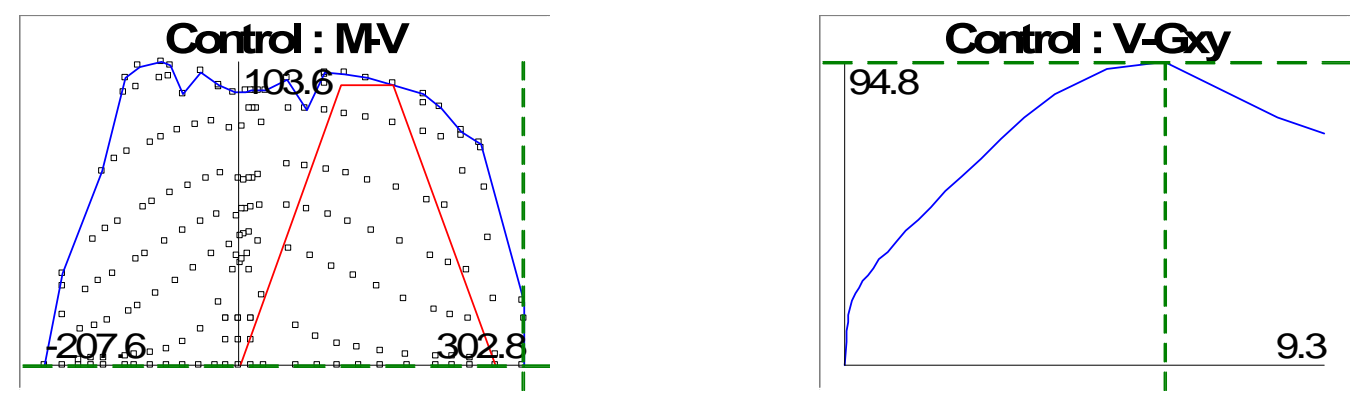

\section{Principal Compressive Stress}

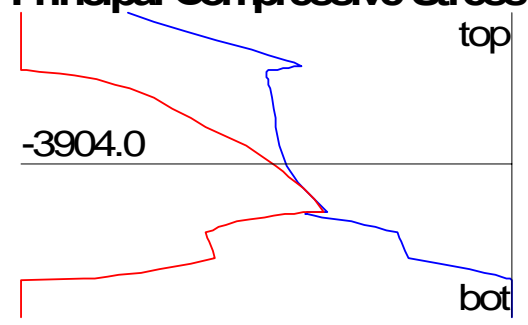

Figure 7.24: R2K, C-M-6 

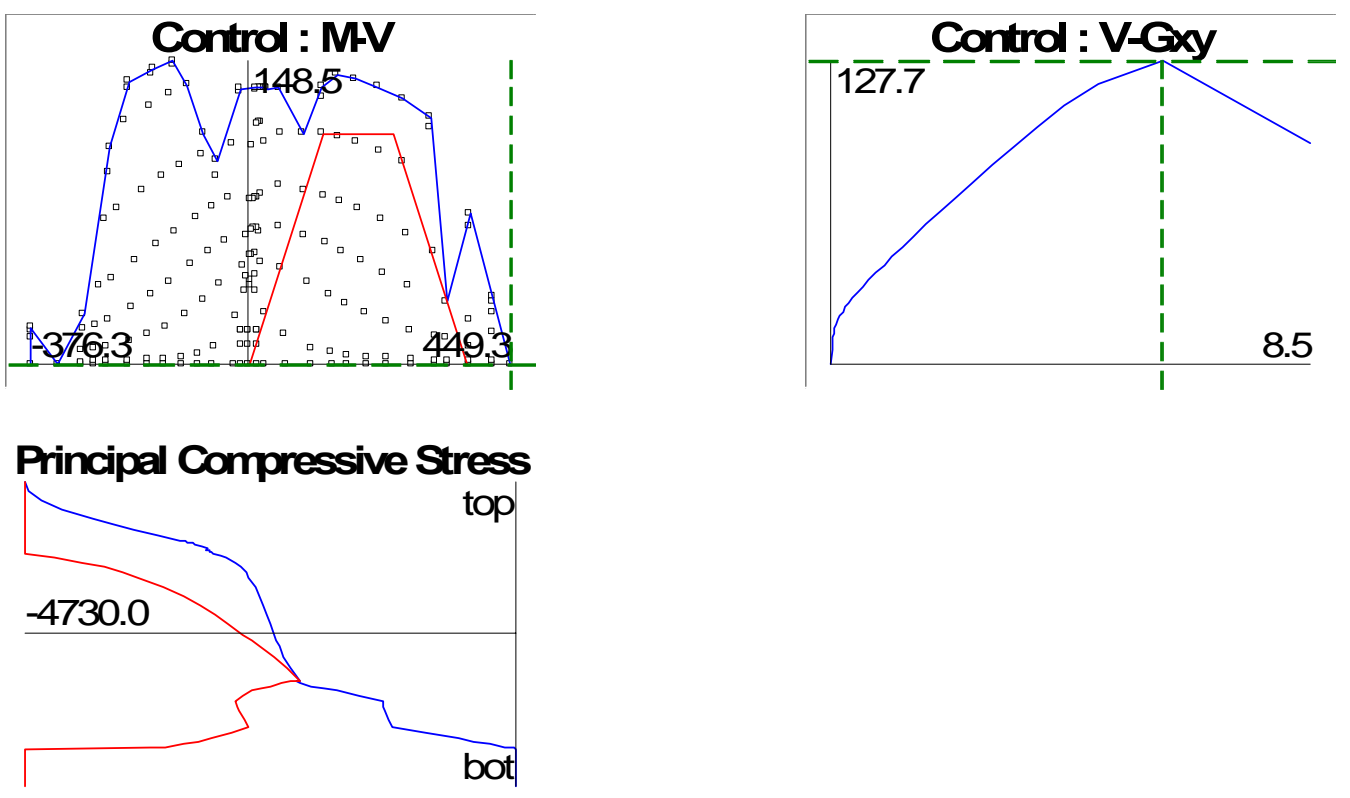

Figure 7.25: R2K, M-M-3
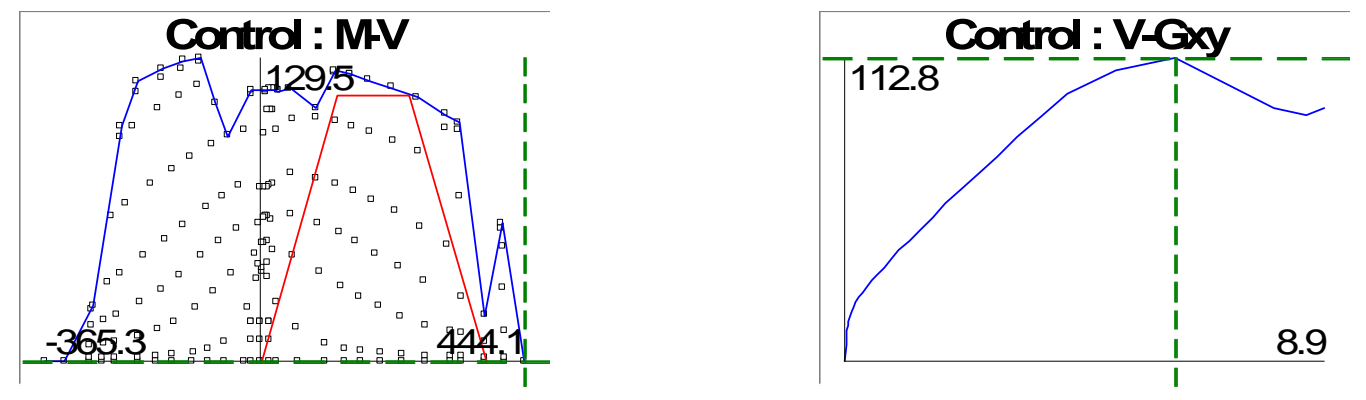

Principal Compressive Stress

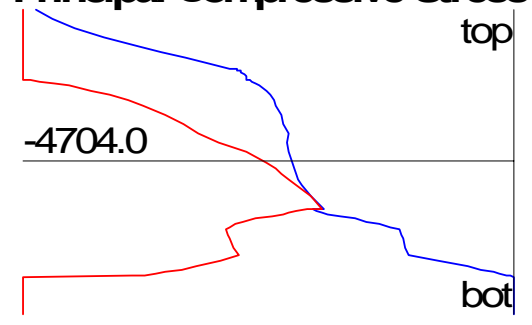

Figure 7.26: R2K, M-M-4 

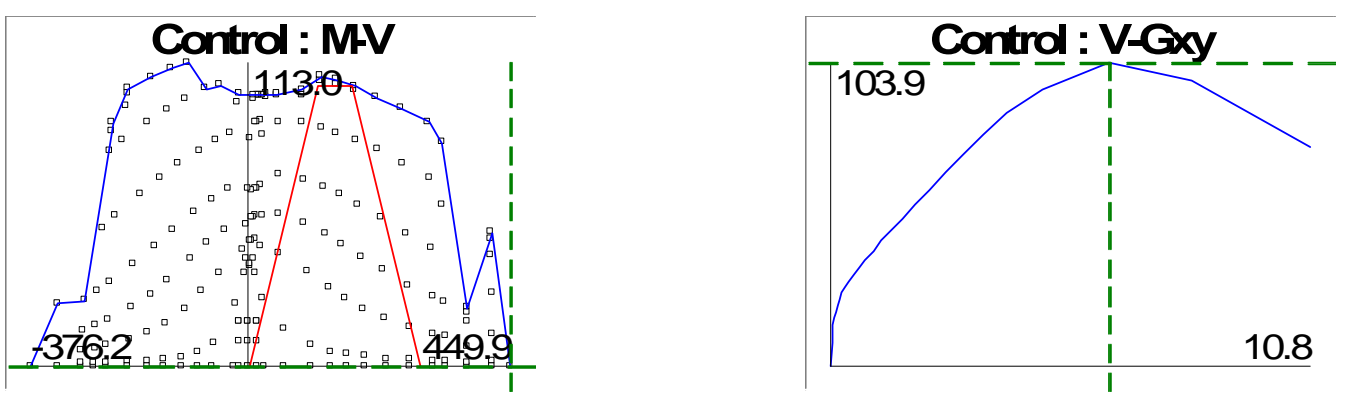

Principal Compressive Stress

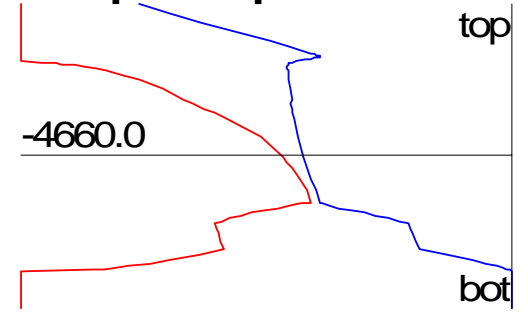

Figure 7.27: R2K, M-M-6 


\subsection{Response 2000 Material Inputs}

\begin{tabular}{|c|c|}
\hline Reinforcement Material Type Information & Reinforcement Material Type Information \\
\hline Reinforcement Type: G60 & Reinforcement Type: MMFX \\
\hline Yield Stress: $62.0 \mathrm{ksi}$ & Yield Stress: $100.0 \mathrm{ksi}$ \\
\hline Initial Elastic Modulus: 29008 ksi & Initial Elastic Modulus: 29008 ksi \\
\hline Strain at strain hardening: $9.2 \mathrm{~ms}$ & Strain at strain hardening: $3.4 \mathrm{~ms}$ \\
\hline Strain at maximum stress: $143.0 \mathrm{~ms}$ & Strain at maximum stress: $20.0 \mathrm{~ms}$ \\
\hline Ultimate Stress: 98.0 ksi & Ultimate Stress: 164.0 ksi \\
\hline $\begin{array}{l}\text { Stress Strain curves of each type in order } \\
\text { below }\end{array}$ & $\begin{array}{l}\text { Stress Strain curves of each type in order } \\
\text { below }\end{array}$ \\
\hline Strain (ms) Stress (ksi) & Strain (ms) Stress (ksi) \\
\hline $0.0000,0.000$ & $0.0000,0.000$ \\
\hline $2.1373,62.000$ & $3.4473,100.000$ \\
\hline $9.2000,62.000$ & $3.4473,100.000$ \\
\hline $9.2000,62.000$ & $5.1026,112.160$ \\
\hline $22.5800,68.840$ & $6.7579,123.040$ \\
\hline $35.9600,74.960$ & $8.4131,132.640$ \\
\hline $49.3400,80.360$ & $10.0684,140.960$ \\
\hline $62.7200,85.040$ & $11.7237,148.000$ \\
\hline $76.1000,89.000$ & $13.3789,153.760$ \\
\hline $89.4800,92.240$ & $15.0342,158.240$ \\
\hline $102.8600,94.760$ & $16.6895,161.440$ \\
\hline $116.2400,96.560$ & $18.3447,163.360$ \\
\hline $129.6200,97.640$ & $20.0000,164.000$ \\
\hline $143.0000,98.000$ & \\
\hline (a) Grade 60 steel & (b) MMFX steel \\
\hline
\end{tabular}

Figure 7.28: Steel material properties, Response 2000 
Concrete Material Type Information

$================$

Concrete Type: Concrete 1

Cylinder Strength: 4730 psi*

Tensile Strength (auto): 261 psi

Cracking Strain: $0.070 \mathrm{~ms}$

Strain at peak stress (auto): $1.99 \mathrm{~ms}$

Initial tangent Stiffness: $3730.2 \mathrm{ksi}$

Tension stiffening factor: 1.00

Maximum aggregate size: 0.38 in

Concrete Base Curve: Popovics/Thorenfeldt/Collins

Concrete Compression Softening: Vecchio-Collins 1986

Concrete Tension Stiffening: Bentz-1999

(stress-strain curve values not listed due to length)

*Cylinder strength varies for each beam

Figure 7.29: Concrete material properties, Response 2000 